\title{
Untersuchungen zur Inhibierung der Expression der Poly(ADP-Ribose) Polymerase (PARP) nach Infektion mit Toxoplasma gondii
}

\author{
Dissertation \\ zur Erlangung des Doktorgrades \\ der Mathematisch-Naturwissenschaftlichen Fakultäten \\ der Georg-August-Universität zu Göttingen
}

vorgelegt von

Andrea Nadja Gais

aus Langen

Göttingen 2008 
D 7

Referent: Prof. Dr. U. Groß

Korreferent: Prof. Dr. J. Stülke

Tag der mündlichen Prüfung: 


\section{Danksagung}

Herrn Prof. Dr. U. Groß möchte ich an erster Stelle für die Überlassung des interessanten Themas und die konstruktive Betreuung danken. Ebenso möchte ich Herrn PD Dr. Carsten Lüder für die intensive praktische Betreuung und dauernde Ansprechbarkeit bei Problemen danken. Auch die netten Gespräche und Anekdoten an den Abenden einiger gemeinsam besuchter Kongresse werden mir in guter Erinnerung bleiben.

Für die Übernahme des Korreferates danke ich Herrn Prof. Dr. J. Stülke.

Mein großer Dank geht an die Mitglieder der Toxoplasmose-Arbeitsgruppe (besonders Tine Lang, Tobias Fleige, Karin Rönnebäumer und Nicole Beinert), und an die „Pilze" (besonders Pia Schmidt, Oliver Bader und Valeska Simon), sowie an Alexander Pairan, ohne die ich mich in Göttingen sehr einsam gefühlt hätte und die auch spät abends bei Federweißer und Zwiebelkuchen, einem schönen Cocktail oder beim Sport nicht müde wurden über die Arbeit zu diskutieren und so für ein herzliches Arbeitsklima sorgten.

Natürlich möchte ich mich auch bei meiner Familie bedanken. Besonders bei meinem Mann Marcus, der mich immer unterstützt und ermutigt hat, insbesondere nach erfolglosen Versuchen. Ohne seine Unterstützung hätte ich Dissertation und Baby nie unter einen Hut bekommen. Bei meiner Schwiegermutter und meiner Schwester möchte ich mich für das Babysitten und die vielen Kleinigkeiten bedanken, die sie mir abgenommen haben.

Außerdem möchte ich mich noch bei meinen "Sandkastenfreundinnen“ Sonja Bockemühl, Isabel Schoch und Katharina Zoll für die tausend Kommafehler, überflüssigen Leerzeichen und vergessenen Buchstaben etc. bedanken, die sie in dieser Arbeit gefunden haben. Sabine Bernhard möchte ich für die vielen Tipps bezüglich der Formatierung danken. 


\section{Inhaltsverzeichnis}

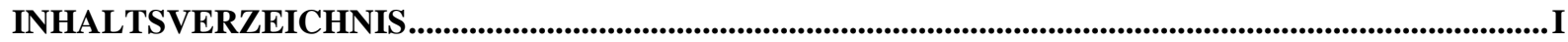

ABBILDUNGSVERZEICHNIS ........................................................................................................................ IV

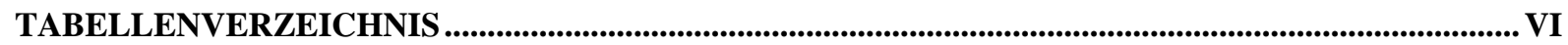

ABKÜRZUNGSVERZEICHNIS............................................................................................................................. VII

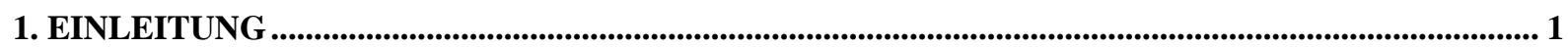

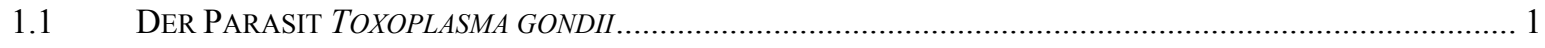

1.2 LEBENSZYKLUS VON TOXOPLASMA GONDII ………................................................................... 2

1.3 KLINISCHE RELEVANZ VON TOXOPLASMA GONDII INFEKTIONEN ........................................................ 5

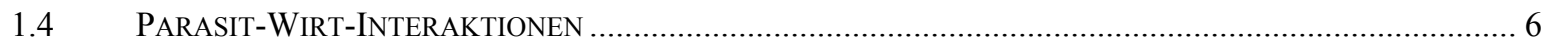

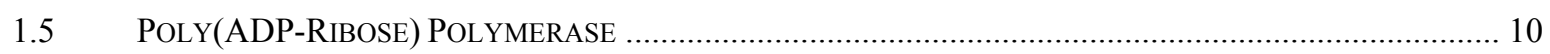

1.6 PARP-1 UND DIE PATHOGENESE ENTZÜNDLICHER ERKRANKUNGEN ………................................. 13

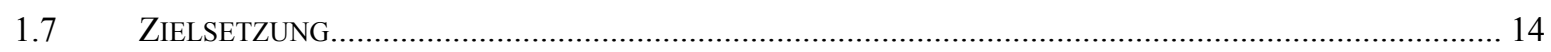

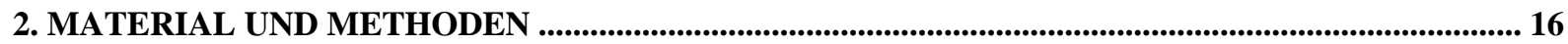

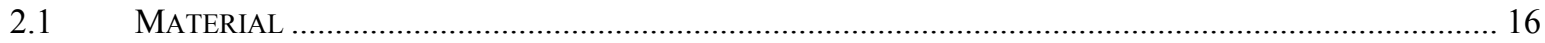

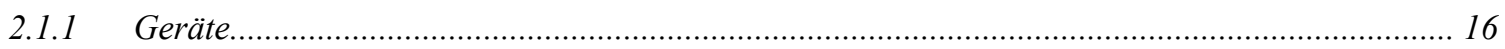

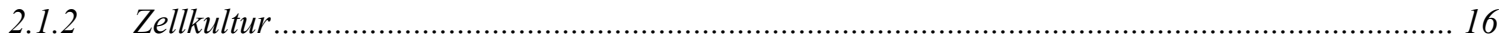

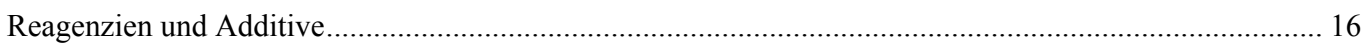

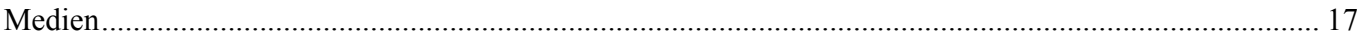

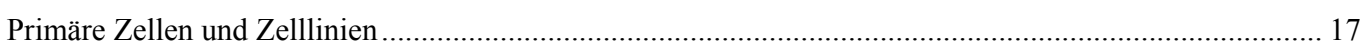

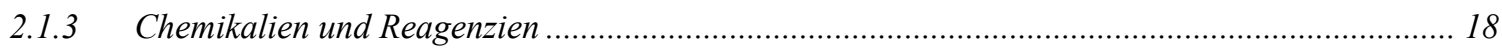

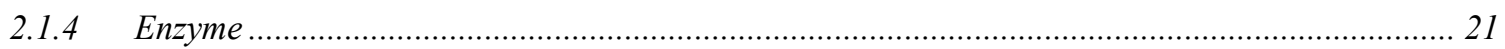

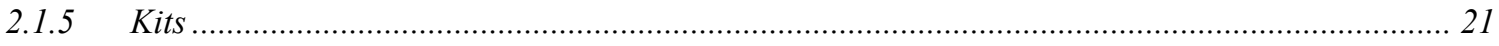

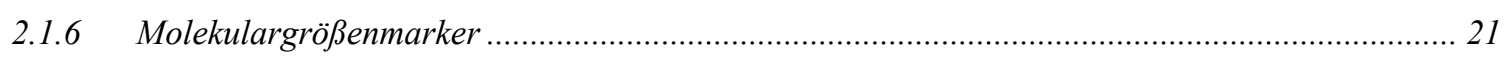

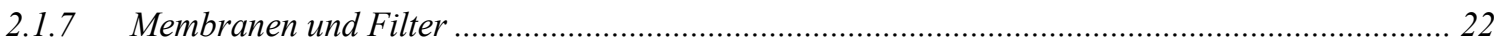

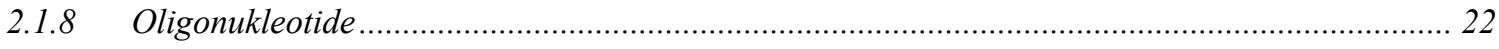

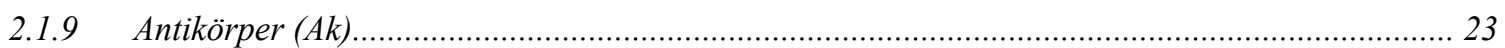

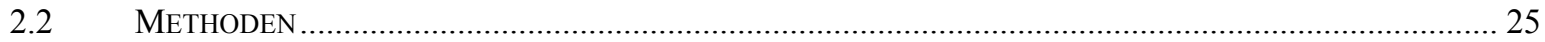

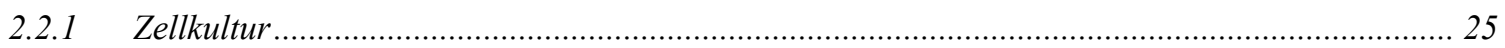

2.2.1.1 Kultur und Isolierung von Toxoplasma gondii Tachyzoiten ......................................................... 25

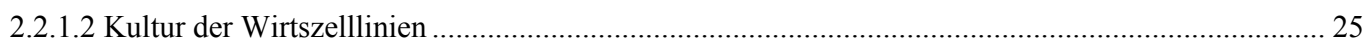

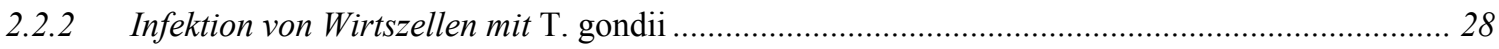

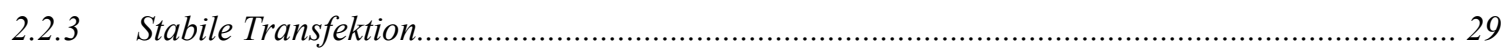

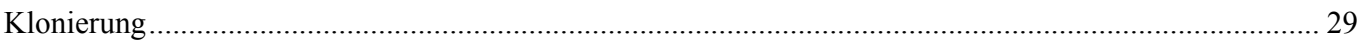

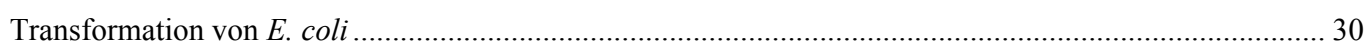

Transfektion von RAW 264.7 Makrophagen................................................................................... 30 
2.2.4 Herstellung von UV-behandelten und Hitze-inaktivierten T. gondii .................................. 31

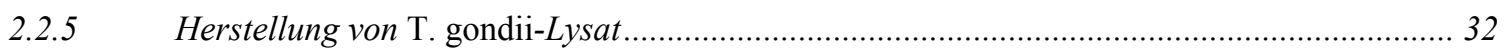

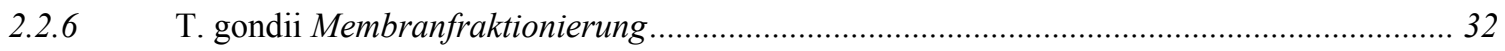

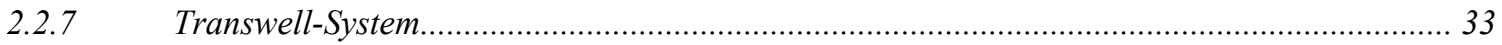

2.2.8 Präparation von Gesamtproteinextrakten infizierter und nicht-infizierter Wirtszellen............ 34

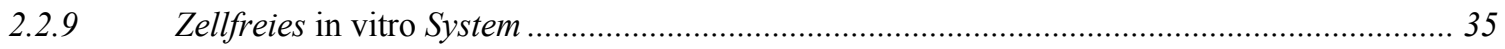

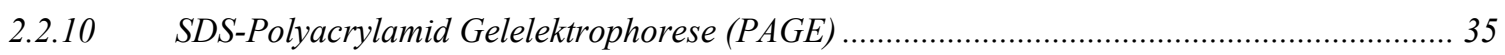

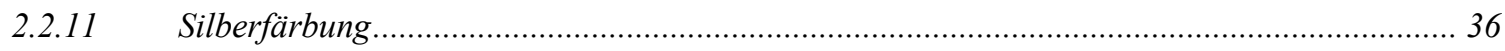

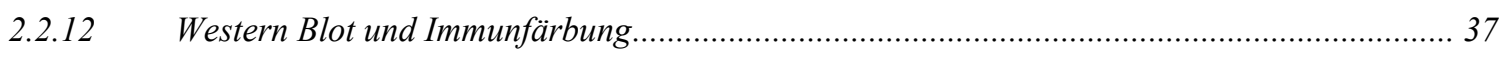

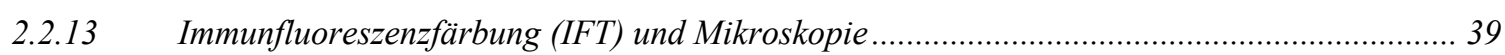

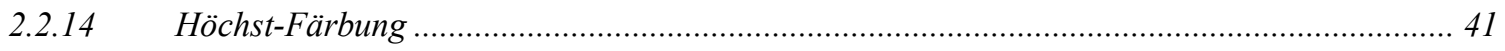

2.2.15 Zell-ELISA zum Nachweis von PARP-Aktivität .................................................................. 42

2.2.16 PARP-1 Aktivitätsdetektion auf Einzelzellebene ................................................................ 43

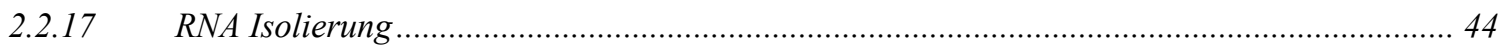

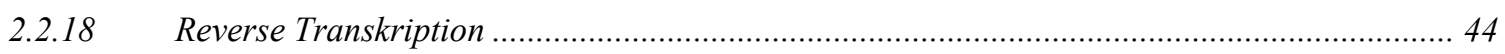

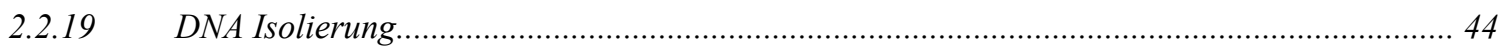

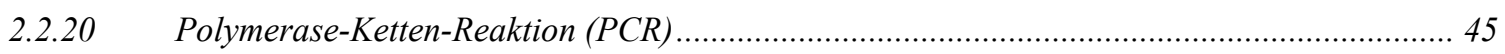

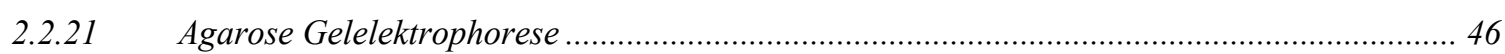

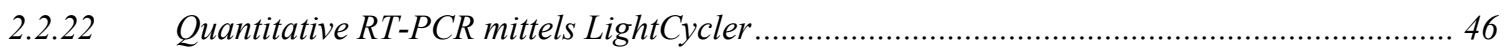

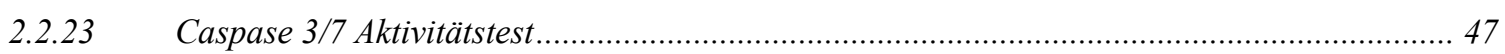

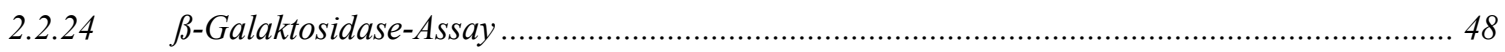

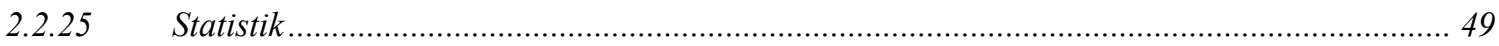

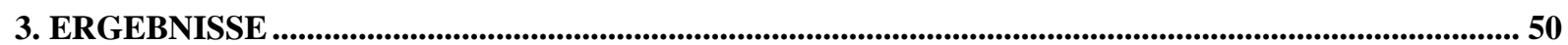

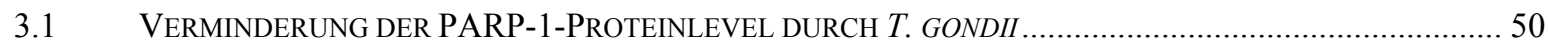

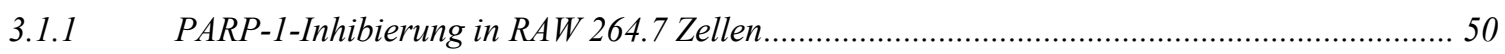

3.1.2 PARP-1-Inhibierung nach T. gondii-Infektion von murinen Fibroblasten.............................. 53

3.1.3 PARP-1-Inhibierung nach T. gondii-Infektion von humanen Zellen ................................... 55

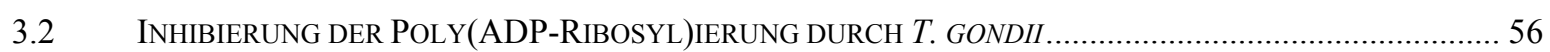

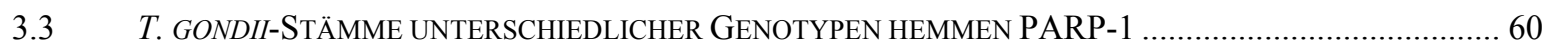

3.4 REGULATIONSMECHANISMEN DER PARP-1-INHIBIERUNG DURCH T. GONDII AUF WIRTSZELLEBENE . 61

3.4.1 Beteiligung von Wirtszellmolekülen an der Inhibierung der Expression von PARP-1 ............ 61

3.4.2 Einfluss von Transkription und Translation der Wirtszelle auf die PARP-1-Inhibierung....... 63

3.4.1 Inhibierung der Expression von PARP-1 durch $\mathrm{T}$. gondii in Gegenwart von Proteasominhibitoren

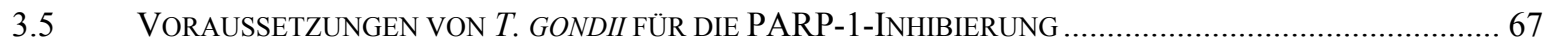

3.6 FRAKTIONIERUNG VON PBS-UNLÖSLICHEN T. GONDII-BESTANDTEILEN .......................................... 72

3.7 PARP-1-ÜBEREXPRESSION IN RAW 264.7 MONOCYTEN/ MAKROPHAGEN..................................... 76

3.8 AUSWIRKUNG DER PARP-1 ÜBEREXPRESSION AUF DAS PARASIT-WIRT-VERHÄLTNIS ......................82

3.8.1 Invasion und Replikation von T. gondii in PARP-1 überexprimierenden RAW 264.7-Mutanten. 
3.8.2 Einfluss der PARP-1 Überexpression auf die Koaktivatorfunktion von PARP bei NF- $\kappa B-$ vermittelter Genexpression.

3.8.3 Apoptose und deren Veränderung durch T. gondii in PARP-1 überexprimierenden RAW 264.7 Zellen.

4.1 DIE PARP-1-INHIBIERUNG NACH T. GONDII-INFEKTION IST EIN GENERELLES PHÄNOMEN

4.2 DIE INHIBIERUNG DER EXPRESSION VON PARP-1 DURCH T. GONDII IST NICHT VON DER VIRULENZ DES TOXOPLASMA-STAMMES ABHÄNGIG

4.3 REGULATION DER PARP-1-INHIBIERUNG DURCH T. GONDII IN WIRTSZELLEN .................................. 99

4.4 VORAUSSETZUNGEN SEITENS DES PARASITEN T. GONDII ZUR PARP-1-INHIBIERUNG....................... 103

4.5 AUSWIRKUNGEN DER PARP-1 ÜBEREXPRESSION IN WIRTSZELlEN AUF PARASIT-WIRT-

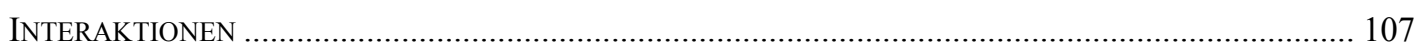

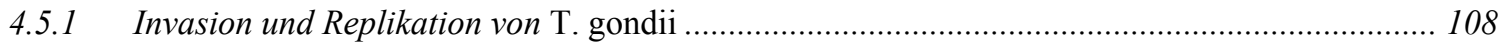

4.5.2 NF-кB regulierte Gene in der infizierten Wirtszelle....................................................... 109

4.5.3 Apoptose in infizierten Wirtszellen................................................................................. 114

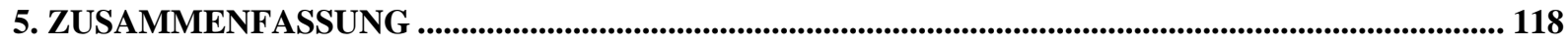

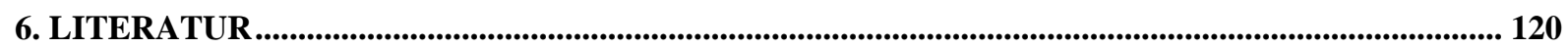

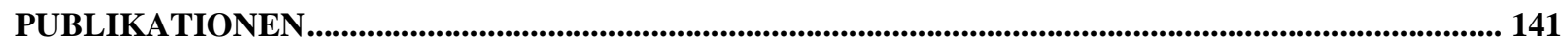

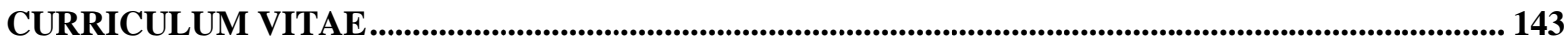




\section{Abbildungsverzeichnis}

Abb. 1: Lebenszyklus des obligat intrazellulären Parasiten Toxoplasma gondii. ................................................ 3

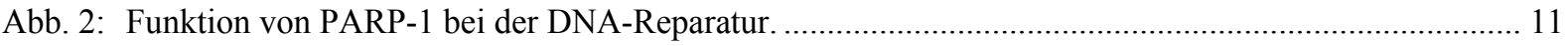

Abb. 3: PARP-1-Inhibierung in RAW 264.7 Monocyten/Makrophagen nach Infektion mit $T$. gondii................ 51

Abb. 4: Die PARP-1-Inhibierung in Wirtszellen durch T. gondii ist von der Infektionsdosis abhängig. ............ 53

Abb. 5: PARP-1-Inhibierung in unterschiedlichen murinen Zelltypen nach Infektion mit $T$. gondii.................. 54

Abb. 6: PARP-1-Inhibierung in unterschiedlichen humanen Zelltypen nach Infektion mit T. gondii.................. 56

Abb. 7: Inhibierung der PARP-1 Aktivität in RAW 264.7 Monocyten/Makrophagen nach Infektion mit T. gondii.

Abb. 8: Das T. gondii Enzym Katalase ist nicht für die Inhibierung der enzymatischen Aktivität von PARP-1 verantwortlich

Abb. 9: Die Inhibierung der Expression von PARP-1 in Wirtszellen durch T. gondii ist unabhängig von der Parasitenvirulenz.

Abb. 10: PARP-1 wird nicht durch ein von infizierten Wirtszellen sekretiertes Molekül inhibiert.

Abb. 11: Die Inhibierung der Expression von PARP-1 nach Infektion mit $T$. gondii erfolgt unabhängig von Transkription und Translation der Wirtszelle.

Abb. 12: PARP-1 wird nach Infektion mit $T$. gondii nicht durch Wirtszellproteasomen abgebaut.

Abb. 13: Von Wirtszellen durch eine semipermeable Membran getrennte Parasiten vermitteln keine Inhibierung der Expression von PARP-1.

Abb. 14: Effektivität von UV-Behandlung und Hitze-Inaktivierung auf Replikation und Wirtszellinvasion durch T. gondii.

Abb. 15: T. gondii Tachyzoiten inhibieren unabhängig von Wirtszellinvasion und intrazellulärer Replikation den PARP-1-Proteinlevel.

Abb. 16: Ein peripher assoziiertes Membranprotein von $T$. gondii ist an der Hemmung von PARP-1 beteiligt. . 73

Abb. 17: Elektrophoretische Analyse der Membranfraktionen S1 bis S3 von T. gondii mittels SDS-PAGE....... 74

Abb. 18: SAG-1 von T. gondii ist nicht an der Inhibierung der Expression von PARP-1 beteiligt. .................... 75

Abb. 19: Nachweis einer zusätzlichen PARP-1-Kopie in RAW 264.7 Monocyten/Makrophagen....................... 77

Abb. 20: Überexpression von PARP-1 in RAW 264.7 Monocyten/Makrophagen............................................... 78

Abb. 21: Vergleich der PARP-1 Expression zwischen Wildtyp und PARP-1-überexprimierender Mutante A12 nach T. gondii-Infektion.

Abb. 22: Vergleich der PARP-1 Expression zwischen Wildtyp und PARP-1-überexprimierender C6 Mutante nach $T$. gondii-Infektion.

Abb. 23: Vergleich der PARP-1 Expression zwischen Wildtyp und PARP-1-überexprimierenden Mutanten nach T. gondii-Infektion mittels Immunfluoreszenzfärbung.

Abb. 24: Entwicklung von T. gondii in PARP-1 überexprimierenden RAW 264.7-Mutanten............................. 83

Abb. 25: Einfluss einer PARP-1 Überexpression in Wirtszellen auf Invasion und Replikation von T. gondii..... 84

Abb. 26: Expressionsprofile NF-kB-regulierter Gene.

Abb. 27: Zeitabhängige Inhibierung der Caspase 3/7 Aktivität von PARP-1 überexprimierenden RAW 264.7 Klonen A12, C6 und E6 und Wildtypzellen nach T. gondii-Infektion. 
Abb. 28: Auswirkung der PARP-1 Überexpression auf die Parasit-Wirt-Interaktion in apoptotischen Zellen $4 \mathrm{~h}$ nach Infektion. 89

Abb. 29: Auswirkung der PARP-1 Überexpression auf die Parasit-Wirt-Interaktion in apoptotischen Zellen 24.5 h nach Infektion. 90

Abb. 30: Auswirkung der PARP-1 Überexpression auf die Parasit-Wirt-Interaktion in apoptotischen Zellen. ... 91 


\section{Tabellenverzeichnis}

Tab. 1: Verdünnung primärer und sekundärer Antikörper für Immunfärbung von Western Blots ......................... 39

Tab. 2: Verdünnung primärer und sekundärer Antikörper für IFT 


\section{Abkürzungsverzeichnis}

Abb.

Ac-DEVD-AMC

ADP

AIDS

AIF

Ak

APS

ATP

bp

BP

BL-Puffer

BRCT

BSA

CIITA

ca.

$\mathrm{CD}^{+}$

CHAPS

$\mathrm{CO}_{2}$

$\mathrm{cm}$

CMV

CPRG

DAB

DEVD

DMEM

DMSO
Abbildung

N-acetyl-Asp-Glu-Val-Asp-AMC (7-amino-4methylcoumarin)

Adenosindiphosphat

engl. Acquired Immune Deficiency Syndrome Apoptose induzierender Faktor

Antikörper

Ammonium Persulfat

Adenosintriphosphat

Basenpaare

Blockierpuffer

Bindepuffer für DNA-Isolierung

(BRCA1-caboxyterminus)-Motiv

bovines Serum Albumin

class II transactivator

circa

cluster of differentiation

3-[(3-Cholamidopropyl)dimethylammonium] propansulfatsäure

Kohlendioxid

Zentimeter

humanes Cytomegalievirus

engl. Chlorophenolred-ß-D-

galactopyranoside

Diaminobenzidin

Einbuchstabencode für die Aminosäuresequenz aus Asparaginsäure-

Glutaminsäure-Valin-Asparaginsäure (AspGlu-Val-Asp)

Dulbecco's MEM

Dimethylsulfoxid 


\begin{tabular}{|c|c|}
\hline DNA & Desoxiribonukleinsäure \\
\hline dNTP & desoxy Nukleotidtriphosphat \\
\hline DTT & Dithiothreitol \\
\hline E. coli & Escherichia coli \\
\hline EDTA & Ethylendiamintetraessigsäure \\
\hline EGTA & Ethylenglycoltetraessigsäure \\
\hline EIV & Pferde-Grippe-Virus \\
\hline ELISA & engl. Enzym-linked-immuno-sorbent-assay \\
\hline ESM & exkretorische-sekretorische Moleküle \\
\hline et al. & lat. et alia (= und andere) \\
\hline FA & Formaldehyd \\
\hline FCS & fötales Kälberserum \\
\hline g & Gramm \\
\hline gDNA & genomische DNA \\
\hline h & Stunde \\
\hline HBSS & engl. Hank's bufferd Salt Solution \\
\hline $\mathrm{HCl}$ & Salzsäure \\
\hline HEPES Puffer & $\begin{array}{l}\text { 2-(4-(2-Hydroxyethyl)-1-piperazinyl)- } \\
\text { ethansulfonsäure }\end{array}$ \\
\hline HIV & Humanes Immundefizienz-Virus \\
\hline HMG & engl. high mobility group \\
\hline HMW & engl. High molecular weight marker \\
\hline $\mathrm{H}_{2} \mathrm{O}$ & Wasser \\
\hline $\mathrm{H}_{2} \mathrm{O}_{2}$ & Wasserstoffperoxid \\
\hline $\mathrm{H}_{2} \mathrm{SO}_{4}$ & Schwefelsäure \\
\hline ICAM-1 & engl. Intracellular adhesion molecule-1 \\
\hline IFN- $\gamma$ & Interferon gamma \\
\hline IFT & Immunfluoreszenstest \\
\hline IGFBP4 & $\begin{array}{l}\text { engl. Insulin-like Growth Factor-binding } \\
\text { Protein } 4\end{array}$ \\
\hline IL & Interleukin \\
\hline iNOS & induzierbare NO Synthase \\
\hline IKB & inhibitorische kB-Proteine \\
\hline $\mathrm{KCl}$ & Kaliumchlorid \\
\hline
\end{tabular}




\begin{tabular}{|c|c|}
\hline kDA & kilo Dalton \\
\hline $\mathrm{KOH}$ & Kaliumhydroxid \\
\hline I & Liter \\
\hline LB-Medium & engl. lysogeny broth medium \\
\hline LPS & Lipopolysaccharide \\
\hline M & Molar \\
\hline $\mathrm{mA}$ & Milli Ampere \\
\hline MAPK & Mitogen-aktivierte Proteinkinase \\
\hline $\max$. & maximal \\
\hline MEM & engl. Minimum Essential Medium \\
\hline$\mu g$ & Mikrogramm \\
\hline $\mathrm{mg}$ & Milligramm \\
\hline $\mathrm{MgCl}_{2}$ & Magnesiumchlorid \\
\hline MHC Klasse II & $\begin{array}{l}\text { engl. Major Histocompatibility Complex (= } \\
\text { Haupthistokompatibilitätskomplex) }\end{array}$ \\
\hline $\min$ & Minute \\
\hline MIP & engl. Makrophage Inflammatory Protein \\
\hline $\mathrm{mM}$ & milli Molar \\
\hline mRNA & engl. messenger RNA \\
\hline $\mathrm{Na}$ & Natrium \\
\hline $\mathrm{NaCl}$ & Natriumchlorid \\
\hline NAD & Nicotinamidadenindinukleotid \\
\hline $\mathrm{NaHCO}_{3}$ & Natriumhydrogencarbonat \\
\hline $\mathrm{NaF}$ & Natriumfluorid \\
\hline $\mathrm{NaOH}$ & Natronlauge \\
\hline $\mathrm{Na}_{3} \mathrm{VO}_{4}$ & Natrium-Orthovanadat \\
\hline$N F-k B$ & nukleärer (Transkriptions) Faktor kB \\
\hline n.i. & nicht infiziert \\
\hline NLR & engl. Nod-like receptors \\
\hline NLS & nukleäres Lokalisierungssignal \\
\hline $\mathrm{nm}$ & Nanometer \\
\hline NO & Stickstoffmonoxid \\
\hline NR & nukleärer Rezeptor \\
\hline N-terminal & Stickstoff-Ende \\
\hline
\end{tabular}


NTP

$P$.

PAGE

PARG

PARP-1

PBS

PCR

$\mathrm{pH}-$ Wert

p.i.

PIC

PMA

PMSF

PV

PVM

RNA

RT

RT

RPMI

S1

SDS

SDS-PAGE

sec

SOB Medium

SOC Medium

SOCS

STAT-1

TAE-Puffer

TCA

TES

TNF- $\alpha$
Nukleotid-Tri-Phosphat

\section{Plasmodium}

Polyacrylamid Gelelektrophorese

Poly(ADP-ribose) Glykohydrolase

Poly(ADP-ribose) Polymerase 1

engl. phosphate buffered saline

Polymerase Kettenreaktion

lat. pondus Hydrogenii

lat. post infectionem (= nach Infektion)

Proteinase-Inhibitor-Cocktail

Phorbol 12-Myristat 13-Acetat

Phenylmethylsulphonylfluorid

parasitophore Vakuole

Membran der parasitophoren Vakuole

engl. ribonucleic acid (= Ribonukleinsäure)

Raumtemperatur

Reverse Transkription

Roswell Park Memorial Institute

Überstand 1

engl. sodium dodecylsulfate (= Natrium-

Dodecylsulfat)

engl. sodium dodecylsulfate polyacrylamide

gel electrophoresis

Sekunde

engl. Super optimal broth

SOC Medium mit Glucose

engl. suppressor of cytokine signaling-1

engl. Signal Transducers and Activator of

Transcription-1

Tris-Acetat-EDTA-Puffer

Trichloressigsäure

$\mathrm{N}$-Tris(hydroxymethyl)methyl-2-amino-

ethansulfonsäure

Tumornekrosefaktor alpha 


$\begin{array}{ll}\text { T. cruzi } & \text { Trypanosoma cruzi } \\ \text { T. gondii } & \text { Toxoplasma gondii } \\ \text { TL-Puffer } & \text { Lysepuffer bei DNA-Isolierung } \\ \text { TLR } & \text { engl. Toll-like receptor } \\ \text { Tris } & \text { Tris-(Hydroxymethyl)Aminomethan } \\ \text { u.a. } & \text { unter anderem } \\ \text { U } & \text { engl. Units (= Einheiten) } \\ \text { UV-Licht } & \text { Ultraviolettes Licht } \\ \text { WT } & \text { Wildtypzellen } \\ \text { Z.B. } & \text { zum Beispiel } \\ \text { ZNS } & \text { zentrales Nervensystem } \\ { }^{\circ} \mathrm{C} & \text { Grad Celsius }\end{array}$




\section{Einleitung}

\subsection{Der Parasit Toxoplasma gondii}

Toxoplasma gondii ist ein obligat intrazellulärer protozoischer Parasit, der erstmals 1908 von Nicolle und Manceaux beschrieben wurde und der Erreger der Toxoplasmose ist. T. gondii gehört zum Stamm der Apicomplexa, deren Name von einer charakteristischen Struktur am Vorderpol, dem Apikalkomplex, herrührt, und die alle Vertreter dieses Stammes besitzen. Des Weiteren besitzen diese Parasiten neben den üblichen Zellorganellen noch ein besonderes plastid-ähnliches Organell, den Apikoplast (FICHeRA und Roos, 1997; Marechal und Cesbron-Delauw, 2001; SeEber, 2003). Neben Eimera, Cryptosporidium, Neospora, Sarcocystis und Theileria gehört auch Plasmodium, der Erreger der Malaria, zu diesem Stamm. Während die meisten apikomplexen Parasiten durch ihr enges Wirtsspektrum entweder human- (Plasmodium) oder tierpathogen (Eimeria, Sarcocystis, Neospora, Theileria) sind, kann $T$. gondii jede kernhaltige Zelle einer Vielzahl von warmblütigen Wirbeltieren befallen (WERK, 1985). Dabei ist der Invasionsprozess bei allen Apikomplexen sehr ähnlich und zeichnet sich dadurch aus, dass es ein aktiver Prozess ist (MORISAKI et al., 1995). Angetrieben wird dieser durch das so genannte Glidosome (OPITZ und SoldatI, 2002). Es besteht unter anderem aus Aktin, Myosin und sezernierten Proteinen des Parasiten (DobrowolskI und SIBLEY, 1996; DoBROWOLSKI et al., 1997; SoldATI et al., 2001). Bei der Invasion der Apikomplexen in eine Wirtszelle spielen vor allem drei charakteristische Organellen und ihre Proteine eine große Rolle: die Mikronemen, die Rhoptrien und die Dichten Granula (CARRUthers und Sibley, 1997; Dubremetz et al., 1998). Diese drei Organellen finden sich im apikalen Pol aller Parasiten dieses Stammes (DUBREMETZ et al., 1998). Bei der Invasion kommt es zunächst zu einer Anheftung des Parasiten an die Wirtszelloberfläche und zur Ausrichtung des apikalen Pols zur Wirtszelle hin (MITCHELL et al., 2004). Anschließend werden Mikronemen- und Rhoptrienproteine aus dem apikalen Pol sezerniert (CARRUTHERS und SiBLEY, 1997; MoRdue et al., 1999), die einen Proteinkomplex bilden und sich mit der "Moving Junction“, einer Verbindung zwischen Parasit und Wirtszellplasmamembran, verbinden (ALEXANDER et al., 2005). Durch die Einstülpung der Wirtszellmembran kommt es zur Bildung 
einer parasitophoren Vakuole um den Parasiten, in deren Membran keine Transmembranproteine der Wirtszelle eingelagert sind (MICHEL et al., 1980; JOINER, 1991; Suss-ToвY et al., 1996). Weitere Proteine aus den Rhoptrien werden sezerniert und in die parasitophore Vakuole integriert (NICHOLS et al., 1983; JOINER, 1991; BECKERS et al., 1994). Zuletzt werden Proteine aus den Dichten Granula freigesetzt, die durch Bildung eines tubulären Netzwerkes die parasitophore Vakuole ebenfalls modifizieren (SIBLEY et al., 1986; SIBLEY et al., 1995).

Die parasitophore Vakuole verhindert einen direkten Kontakt zwischen Parasit und Wirtszellzytoplasma, allerdings ist ein Austausch kleiner Moleküle durch passive Diffusion über die Vakuolenmembran möglich (ScHWAB et al., 1994). Des Weiteren wird durch die besondere Beschaffenheit der parasitophoren Vakuole eine Verschmelzung mit Lysosomen, Endosomen und anderen Vesikeln der Wirtszelle, sowie die Ansäuerung der parasitophoren Vakuole, verhindert (JONES und HIRSCH, 1972; Sibley et al., 1985; JoINER et al., 1990; MoRdue et al., 1999; BeYER et al., 2002). Dies ist eine wichtige Voraussetzung für das Überleben des Parasiten innerhalb der Wirtszelle.

\subsection{Lebenszyklus von Toxoplasma gondii}

Der Lebenszyklus von T. gondii wurde erstmals 1970 vollständig beschrieben (FRENKEL et al., 1970), nachdem neben der bereits bekannten asexuellen Phase auch die sexuelle Phase des Lebenszyklus aufgedeckt wurde (DUBEY et al., 1970; FRENKEL et al., 1970).

Der Lebenszyklus von T. gondii läuft zwischen Endwirt, in dem unter anderem der sexuelle Abschnitt des Lebenszyklus stattfindet und Zwischenwirt, in dem nur eine asexuelle Vermehrung stattfindet, ab. Endwirte von T. gondii sind Katzen und andere Mitglieder der Familie Felidae. Zwischenwirt können alle warmblütigen Vertebraten, vor allem kleine Säuger, Vögel, Nutztiere und der Mensch, sein (TENTER et al., 2000). Der Lebenszyklus von T. gondii schließt sich, wenn Mäuse, andere Kleinsäuger oder Vögel als Zwischenwirte fungieren, die dann von der Katze gefressen werden.

Im Lebenszyklus von T. gondii gibt es drei infektiöse Stadien: Tachyzoiten, Bradyzoiten und Sporozoiten (DUBEY et al., 1998), die während der drei Entwicklungsphasen des Parasiten (Schizogonie, Gamogonie und Sporogonie) 
entstehen und sowohl für den Zwischenwirt, als auch für den Endwirt infektiös sind (TENTER et al., 2000).

Der Endwirt von T. gondii infiziert sich durch die Aufnahme von zystenhaltigem Fleisch des Zwischenwirts (Abb. 1). Diese Zysten sind Magensaft-resistent (JACOBS et al., 1960) und beinhalten Bradyzoiten, die chronische und wenig stoffwechselaktive Form des Parasiten. Die Bradyzoiten vermehren sich im Endwirt

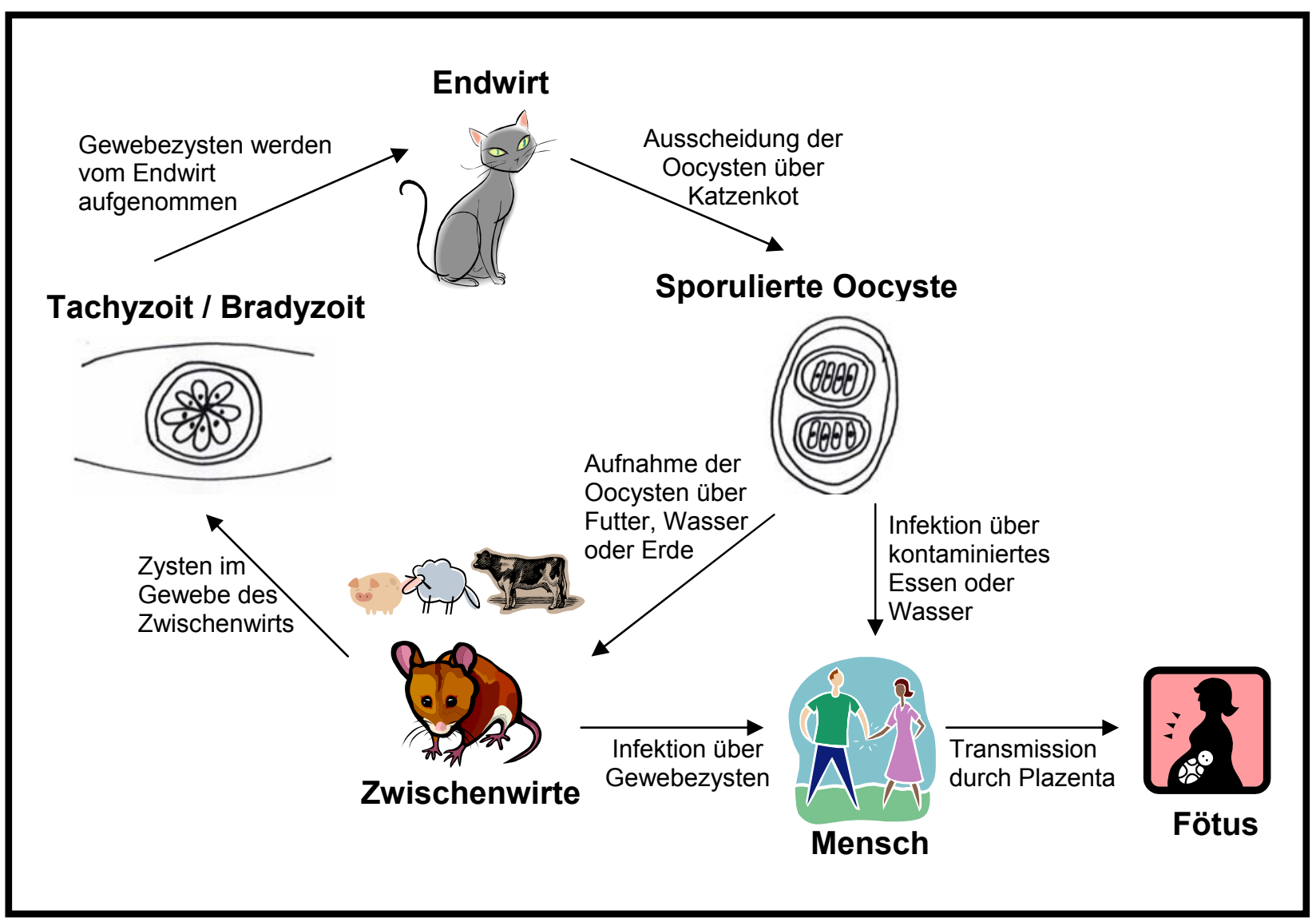

Abb. 1: Lebenszyklus des obligat intrazellulären Parasiten Toxoplasma gondii.

Der Endwirt scheidet unsporulierte Oocysten aus, die anschließend sporulieren und über verschiedene Wege vom Zwischenwirt oder dem Menschen aufgenommen werden. Im Zwischenwirt vermehrt sich der Parasit im Zuge einer akuten Infektion sehr schnell in Form von Tachyzoiten. Reagiert das Immunsystem des Wirtes auf die Infektion, bilden sich bei einer chronischen Infektion stoffwechselinaktive Bradyzoiten, die Zysten im Gewebe und im Gehirn bilden. Durch die Aufnahme zystenhaltigen Fleisches infiziert sich wiederum der Endwirt, wodurch der Zyklus geschlossen wird. Allein im Endwirt findet die sexuelle Vermehrung des Parasiten statt. Die Infektion des Menschen über nicht ausreichend gegartes Fleisch des Zwischenwirtes oder durch mit Oocysten infiziertes Wasser oder Essen kann bei Schwangeren mittels Transmission über die Plazenta zu einer Infektion des Fötus führen. Dies kann mehr oder weniger starke Krankheitsverläufe und sogar den Tod des Fötus bzw. Babys auslösen. 
zunächst asexuell durch Endodyogenie, gefolgt von einer Endopolygenie in Dünndarm-Epithelzellen, es entstehen Merozoiten. Daran schließt sich die sexuelle Phase der Gamogonie mit Oocystenbildung im Dünndarm an. Während der Gamogonie entstehen Mikro- und Makrogamonten innerhalb von 3 - 15 Tagen nach dem Verzehr von zystenhaltigem Fleisch (QuINN und MCCRAW, 1972). Mikrogamonten (männliche Form) bilden wiederum $10-21$ Mikrogameten, die je zwei Flagellen besitzen (DUBEY et al., 1998). Mit Hilfe der Flagellen können sie sich fortbewegen und die Makrogamonten (weibliche Form) zur Befruchtung erreichen (FERGUSON et al., 1975). Während der Befruchtung verschmilzt ein Mikrogamet mit einem Makrogameten und aus der Zygote entwickelt sich eine Oocyste. Die Epithelzellen zerplatzen und entlassen die Oocysten ins Darmlumen. Zu Beginn der Sporogonie werden unsporulierte Oocysten über den Kot ausgeschieden und diese sporolieren außerhalb des Wirtes in 1 - 5 Tagen (FERGuson et al., 1979; DubeY et al., 1998). Jede Oocyste enthält jeweils zwei Sporozysten, von denen jede wiederum 4 Sporozoiten besitzt (FERGUSON et al., 1979). In dieser Form ist die Oocyste hoch infektiös und kann relativ lange außerhalb eines Wirtes überdauern.

Werden die Oocysten nun vom Zwischenwirt aufgenommen, kommt es zu einer asexuellen Vermehrung der Sporozoiten, der Schizogonie, durch Endodyogenie und es entstehen Tachyzoiten. Diese vermehren sich in der Wirtszelle durch wiederholte asexuelle Teilung (ShefField und MELTON, 1968). Durch die starke intrazelluläre Vermehrung der Tachyzoiten platzt die Wirtszelle nach einigen Teilungszyklen und die freigesetzten Tachyzoiten können umliegende Wirtszellen infizieren. Während der akuten Infektion kommt es so zur Bildung einer großen Anzahl von Tachyzoiten. Im Zuge einer sich entwickelnden adaptiven Immunantwort ist der Wirt zunehmend in der Lage, die Replikation des Parasiten zu behindern und dies schützt den immunkompetenten Wirt meist vor starken klinischen Symptomen. Tachyzoiten wandeln sich dann in Bradyzoiten um (KNOLL und BOOTHROYD, 1998; BOHNE et al., 1999), die während der chronischen Form der Infektion Zysten vor allem im Gehirn und Muskelgewebe bilden (DUBEY et al., 1998; TENTER et al., 2000). Diese sehr widerstandsfähigen Zysten, mit sehr langsam replizierenden und weitgehend stoffwechselinaktiven Bradyzoiten, führen zu einer lebenslangen Persistenz des Parasiten (DUBEY et al., 1998). 


\subsection{Klinische Relevanz von Toxoplasma gondii Infektionen}

In den späten 30er Jahren wurde die Toxoplasmose erstmals als Krankheit erkannt, die auch beim Menschen auftreten kann (TENTER et al., 2000). Weltweit sind ca. 30 \% der Bevölkerung mit Toxoplasma gondii infiziert (JACKSON und HUTCHISON, 1989), wobei die Seroprevalenz stark vom jeweiligen Land, den ethnischen Gruppen und dem Alter des Menschen abhängt (JOYNSON and WREGHITT, 2005). Infektionen können hauptsächlich durch den Verzehr von rohem oder ungenügend gegartem, zystenhaltigem Fleisch, durch den Kontakt mit Fäkalien infizierter Katzen, durch transplazentale Übertragung von Tachyzoiten (JACKSON und HUTCHISON, 1989; DUBEY, 1991; DuBEY et al., 1998) oder seltener durch Muttermilch (BONAMETTI et al., 1997 ) oder unpasteurisierte Milch (RIEMANN et al., 1975) verursacht werden. In immunkompetenten Menschen verläuft eine Infektion mit $T$. gondii meist asymptomatisch, seltener kommt es zu leichten Erkältungssymptomen oder Retinochorioditiden. Schwere Verläufe sind sehr selten (TENTER et al., 2000), aber nicht auszuschließen.

Bei immunsupprimierten Patienten, wie z.B. AIDS-Patienten (LUFT et al., 1984), Patienten nach Organtransplantation (LUFT et al., 1983), oder bei Erstinfektion während der Schwangerschaft kann es jedoch zu besonders schweren Verläufen kommen, die auch zum Tod führen können.

Bei immunsupprimierten Patienten kann die Reaktivierung einer chronisch persistierenden Toxoplasmose oder - in seltenen Fällen - die Neuinfektion zu einer Toxoplasma-Enzephalitis mit anschließendem Tod führen (LUFT und REMINGTON, 1992). Bei bis zu 40\% der HIV-infizierten Patienten kommt es zu diesem Verlauf und 10 - 30\% dieser Patienten sterben daran (LUFT et al., 1984; LUFT und REMINGTON, 1992). Häufig führen zusätzliche Infektionen neben der Toxoplasmose zu schwerwiegenden Komplikationen. Mittlerweile kann die Reaktivierung einer chronischen Toxoplasmose durch dauerhafte Therapie mit entsprechenden Chemotherapeutika weitgehend verhindert werden (TENTER et al., 2000).

Nach einer Erstinfektion der Frau während der Schwangerschaft kann der Parasit durch vertikale Transmission durch die Plazenta auf den Fötus übertragen werden (TENTER et al., 2000). Diese so genannte kongenitale Toxoplasmose kann zu Abort, zu neonatalem Tod oder zu schweren Missbildungen führen. Dabei hängt die Schwere der kongenitalen Toxoplasmose vom Zeitpunkt der Infektion ab: je früher im Verlauf der Schwangerschaft die Infektion erfolgt, desto schwerwiegender sind die 
klinischen Folgen. Etwa 10\% der pränatalen Infektionen enden mit Abort oder neonatalem Tod, 10 - 23\% der Kinder zeigen bei der Geburt schwere Symptome wie Encephalomyelitis, Hydrocephalus, Retinochoroiditis und unspezifische Symptome (Feldman, 1968; Koskiniemi et al., 1989; LebeCH et al., 1996), und 12 - 16\% der infizierten Neugeborenen sterben daran. Kommt es im letzten Trimester der Schwangerschaft zu einer Erstinfektion der Mutter sind die Neugeborenen meist asymptomatisch bei der Geburt, entwickeln aber später Defekte an Augen, Ohren und am Zentralen Nervensystem, wobei etwa ein Drittel dieser Kinder deutliche Beeinträchtigungen aufweist (TENTER et al., 2000).

Neben der Infektion von Menschen stellt die Toxoplasmose in Nutztieren ein weiteres Problem dar. Durch Abort oder neonatalen Tod von Nutztieren, verursacht durch die Aufnahme der Oocysten aus der Umwelt und transplazentale Übertragung (QUINN und MCCRAW, 1972; DuBEY und ROMmEL, 1992), kommt es weltweit zu hohen ökonomischen und finanziellen Verlusten, vor allem bei der Schaf-, Ziegen- und Schweinezucht (BUXTON, 1993).

\subsection{Parasit-Wirt-Interaktionen}

Für T. gondii als obligat intrazellulärem und lebenslang persistierendem Parasiten ist es, wie für andere derartige Pathogene, wie Bakterien und andere Parasiten, unerlässlich, die eigene Nährstoffversorgung nach der Invasion des Wirtes sicher zu stellen. T. gondii ist z.B. für Arginin und auch für Cholesterol, welches aus Lipoproteinen niedriger Dichte freigesetzt wird, auxotroph und daher auf den Wirt angewiesen (Fox et al., 2004; SeHGAL et al., 2005). Außerdem muss der Parasit bestimmte Abwehrmechanismen der Wirtszelle entweder umgehen oder manipulieren können. Dies ist notwendig um ein Gleichgewicht zu schaffen, dass sowohl das Überleben des Wirtes gewährleistet als auch Überleben, Wachstum und Replikation des Parasiten ermöglicht (LANG et al., 2007). Zu den wichtigen bisher bekannten Immunevasions-Strategien von T. gondii gehören: Veränderung der parasitophoren Vakuole in ein geeignetes Wirtszell-Kompartiment, Modulation von Wirtszell-Signalwegen, Beeinträchtigung der Wirtszellapoptose und die Inhibierung von für den Parasiten toxischen Metaboliten. 
Durch die besondere Beschaffenheit der parasitophoren Vakuole (PV), die den Parasiten nach der Invasion umgibt, ist $T$. gondii in der Lage, den lysosomalen Verdau durch die Wirtszelle zu verhindern. Hierbei spielen vor allem der Aufbau der Membran der PV (PVM) aus der Wirtszellmembran (Suss-ToBY et al., 1996) und das Fehlen von Wirtszelltransmembranproteinen eine wichtige Rolle (JOINER et al., 1990; MORDUE et al., 1999). Dadurch wird ein Verschmelzen der PV mit Endosomen und Lysosomen, sowie die Ansäuerung der PV verhindert (SACKS und SHER, 2002), indem die Wirtszelle die PV nicht als Endosom oder Phagosom erkennt und keine Protonenpumpen und Elektronenkanäle einlagert.

Durch die Infektion mit $T$. gondii in Makrophagen kommt es außerdem zu einer starken Inhibierung des NF-kB-Signaltransduktionsweges, was wiederum zu einer reduzierten Menge an IL-12 und einer erniedrigten Produktion von TNF- $\alpha$ führt (DENKERS et al., 2004). Bei einer pro-inflammatorischen Reaktion auf Infektionen spielen zwei Signalkaskaden, die nukleäre Faktor KB- (NF-KB) und Mitogen-aktivierte Proteinkinase- (MAPK) Signalkaskaden zentrale Rollen. Diese aktivieren die Expression von verschiedenen pro-inflammatorischen Genen, wie IL-12, TNF- $\alpha$, IL-6 und iNOS. $T$. gondii inhibiert direkt die NF-kB-Signalkaskade, unter anderem indem die Translokation von NF-KB zum Nukleus verhindert wird (SACKS und SHER, 2002; DENKERS et al., 2004). Auch bei der MAPK-Signalkaskade greift $T$. gondii direkt ein, indem die Aktivierung vor allem der p38 MAPK verhindert wird (DENKERs et al., 2004). Dadurch kommt es während einer $T$. gondii-Infektion zu deutlich verminderten Mengen von IL-12 und TNF- $\alpha$, zwei wichtigen regulatorischen und Effektorzytokinen einer effektiven Immunantwort gegen intrazelluläre Infektionserreger.

Des Weiteren konnte gezeigt werden, dass T. gondii die MHC Klasse II Expression und die Antigen-Präsentation inhibiert (LÜDER et al., 1998; LÜDER et al., 2001b; LÜDER et al., 2003b; LANG $C$ et al., 2006). Bei der Einleitung einer adaptiven Immunantwort als Reaktion auf einen Infektionserreger präsentieren Antigenpräsentierende Zellen, wie Z.B. Makrophagen, dendritische Zellen und B-Zellen, Antigen-Peptide des Erregers auf ihrer Oberfläche. Diese Fremdpeptide sind unter anderem mit $\mathrm{MHC}$ Klasse II Molekülen assoziiert und aktivieren $\mathrm{CD}^{+}{ }^{+} \mathrm{T}$ Lymphozyten. Die MHC Klasse II-assoziierte Antigenpräsentation kann durch IFNauf einer Reihe von Zelltypen induziert werden. Viren, sowie intrazelluläre Bakterien und Parasiten interagieren auf unterschiedliche Weise mit der MHC II-vermittelten Antigenpräsentation, um das eigene Überleben und die Replikation im Wirt zu 
sichern. Für T. gondii konnte gezeigt werden, dass in IFN- $\gamma$-stimulierten Makrophagen (LÜDER et al., 2001b; LANG C et al., 2006) und in Zellen des Zentralen Nervensystems (ZNS) (LÜDER et al., 2003b) die Expression von MHC Klasse II Molekülen nach einer Infektion mit dem Parasiten stark reduziert ist. Dies führt wiederum zu einer reduzierten $\mathrm{CD}^{+}$T-Lymphozyten Aktivierung auf Grund der verminderten Antigen-Präsentation (LÜDER et al., 2001b). Je nachdem, ob es sich um lebende Parasiten oder um ein Parasiten-Lysat handelt, sind zwei verschiedene Mechanismen für die Reduzierung der Expression von MHC Klasse II Molekülen verantwortlich (LANG C et al., 2006). Dabei reduziert T. gondii die Transkriptionslevel des durch IFN-ү regulierten Transkriptionsfaktor Klasse II Transaktivators (CIITA), dem Hauptregulator der MHC Klasse II Expression (LÜDER et al., 2001b; LÜDER et al., 2003b). Außerdem induziert T. gondii die Expression von SOCS (suppressor of cytokine signaling)-1 in Makrophagen, was zu einer Inhibierung der IFN- $\gamma$-induzierten STAT-1 Tyrosinphosphorylierung, mRNA Expression von Zielgenen und der Stickoxid (NO) Sekretion führt (ZIMmERMANN et al., 2006). Von 127 Genen, die durch IFN-ץ reguliert werden, konnte keines in mit $T$. gondii infizierten Fibroblasten durch IFN- $\gamma$ aktiviert werden, wie Mikroarray-Analysen zeigten (KIM et al., 2007). Der Parasit hat auf diese Weise gleich mehrere Möglichkeiten das Immunsystem des Wirtes zu modulieren und ein Überleben zu gewährleisten.

T. gondii ist in der Lage, die Apoptose von Wirtszellen auf verschiedenen Ebenen zu inhibieren (GoEbel et al., 1998; NASH et al., 1998; Goebel et al., 1999; Goebel et al., 2001; Heussler et al., 2001; LÜDER et al., 2001a; PAYNE et al., 2003; KeLLER et al., 2006; Schaumburg et al., 2006; Vutova et al., 2007), aber auch zu induzieren (LÜDER et al., 2001a; SchaumbuRg et al., 2006). Die Art der Apoptosemodulation scheint dabei von verschiedenen Faktoren wie Parasitenvirulenz, Wirtszelltyp, Anfälligkeit des Wirtes u.a. abzuhängen (LANG et al., 2007). Die Apoptose, eine Form des „programmierten Zelltodes“ von Wirtszellen, ist ein wichtiger antimikrobieller Mechanismus, um infizierte Zellen effektiv zu eliminieren und eine Ausbreitung des Pathogens zu verhindern. Darüber hinaus ist die Apoptose ein fundamentaler Mechanismus in Entwicklung und Gewebehomöostase von mehrzelligen Organismen. Die Apoptose kann durch drei Hauptwege induziert werden, durch den Granzym B/Perforin Weg, den „Todesrezeptor“ vermittelten Weg und den mitochondrialen Weg (HEUSSLER et al., 2001). Bei allen drei Signalwegen kommt es zur Aktivierung bestimmter Proteasen, den so genannten Caspasen. Diese wiederum 
spalten bestimmte Zielproteine (z.B. die Poly(ADP-ribose) Polymerase-1 (PARP-1)). Die Caspaseaktivierung führt dann letztendlich zur Chromatin-Kondensation, Zellschrumpfung und Abschnürung in apoptotische Vesikel, die von Phagozyten aufgenommen werden (LANG et al., 2007). Es ist bekannt, dass T. gondii an mehreren Punkten der Apoptose-Signalwege eingreifen kann. Zunächst interagiert der Parasit bei der Apoptoseinduktion, indem der Todesrezeptor-vermittelte Weg durch Inhibierung der Caspase 8 unterbunden wird (VUTOVA et al., 2007). Beim mitochondrialen Weg greift der Parasit gleich an mehreren Punkten ein: zum einen verursacht $T$. gondii die Inhibierung der Cytochrom-c Freisetzung, wodurch es zu einer verminderten Caspase 3 und 9 Spaltung kommt. Außerdem zeigt sich eine Reduktion des PARP-1-Proteinlevels sowohl in apoptotischen und infizierten Zellen, als auch in nicht-apoptotischen infizierten Zellen (GOEBEL et al., 2001). Zum anderen inhibiert der Parasit die Cytochrom-c vermittelte Aktivierung der Caspase 3/7 (KELLER et al., 2006). Auch ist die Effektorkinase B des Phosphoinositid 3-Kinase Signalweges in mit $T$. gondii infizierten Mausmakrophagen in vitro und in vivo aktiviert und verhindert dadurch die Apoptose in infizierten Zellen (KIM und DENKERS, 2006). Zudem führt eine Infektion mit $T$. gondii in Mausfibroblasten zu einer Aktivierung von NF-KB über die nukleäre Translokation der p50 und p65 Untereinheiten von NF-kB, zu einer Phosphorylierung von IKB und dessen Konzentration an der PVM und einer Induktion der Expression antiapoptotischer Gene. Dies führt ebenfalls zu einer $T$. gondii-vermittelten Blockade der Apoptose (Molestina et al., 2003).

Ein weiterer antimikrobieller Abwehrmechanismus der Wirtszelle, die induzierbare NO Synthase (iNOS) und die Freisetzung von NO in aktivierten Makrophagen, wird ebenfalls durch $T$. gondii inhibiert (LÜDER et al., 2003a). Die induzierbare NO Synthase produziert nach Aktivierung von Makrophagen mit LPS oder IFN-ץ NO und verhindert so Wachstum und Replikation von intrazellulären Pathogenen. T. gondii greift auf transkriptioneller Ebene in diesen Prozess ein, indem mRNA Level und Proteinlevel von iNOS reduziert werden (LÜDER et al., 2003a). Dadurch ist der NOGehalt in der Wirtszelle niedrig genug, um dem Parasiten Überleben und Replikation zu sichern. Allerdings führt das Vorhandensein von NO in der Zelle auch dazu, dass sich der schnell replizierende Tachyzoit in den langsam replizierenden Bradyzoiten umwandelt (BOHNE et al., 1994). 
Auch die Freisetzung von Wasserstoffperoxid $\left(\mathrm{H}_{2} \mathrm{O}_{2}\right)$ und anderen reaktiven Sauerstoffintermediaten („oxidativ burst“) durch den Wirt als weiterer Abwehrmechanismus umgeht $T$. gondii, da der Parasit eine Katalase und verschiedene Peroxidasen besitzt, die detoxifizierend wirken (DOBROWOLSKI und SIBLEY, 1996; DING et al., 2004).

Diese Modulationen der Abwehrmechanismen des Wirtes durch T. gondii stellen eine empfindliche Balance dar, um das Immunsystem des Wirtes soweit zu schwächen, dass das Überleben und die Replikation des Parasiten gewährleistet sind ohne dabei den Wirt zu töten. Auch wird dadurch die enge Adaption von T. gondii an seine Wirte deutlich, die letztendlich zu einer lebenslangen Persistenz führt.

\subsection{Poly(ADP-Ribose) Polymerase}

Die Poly(ADP-Ribose) Polymerasen (PARP) sind eine Familie von Proteinen, die für die post-translationale Modifizierung von Proteinen verantwortlich sind (AME et al., 2004). Bei dieser Modifizierung handelt es sich um die Bildung von ADP-Ribose Polymeren, die unter Verbrauch von $\mathrm{NAD}^{+}$gebildet und auf Glutamat- oder Aspartatreste von verschiedenen Zielproteinen, wie z.B. Histone, Topoisomerasen, HMG (high mobility group)-Proteine und PARP selbst, übertragen werden. Dabei können sich lange, verzweigte poly(ADP-Ribose) Ketten bilden und man spricht von einer poly(ADP-Ribosyl)ierung der Zielproteine (BURKLE et al., 2005). Diese Modifizierung dient als Signal für diverse zelluläre Prozesse. Angehörige der PARP Proteinfamilie finden sich in allen höheren Eukaryonten, mit Ausnahme von Hefe (HeRceg und WANG, 2001). Unter den 18 bisher bekannten Angehörigen dieser Familie (AME et al., 2004) ist PARP-1 das zuerst entdeckte (MULLER et al., 1974) und am besten untersuchte Protein. PARP-1 ist ein nukleäres Protein, welches eine Molekularmasse von $113 \mathrm{kDa}$ besitzt und in großer Menge in der Zelle vorkommt (0.5 $-5 \times 10^{6}$ Moleküle / Nukleus) (DURIEZ und SHAH, 1997). Es konnten verschiedene Domänen des Proteins identifiziert und bestimmten Funktionen zugeordnet werden. $\mathrm{N}$-terminal befindet sich eine DNA-bindende Domäne mit zwei Zinkfinger-Motiven. Daran schließen sich die Caspase 3-Spaltungsstelle (DEVD-Motiv) und ein nukleäres Lokalisierungssignal (NLS) an. Besonders wichtig ist die Automodifizierungsdomäne mit BRCT (BRCA1-caboxyterminus)-Motiv, welches für Protein-Protein-Interaktionen 
wichtig ist. Carboxy-terminal liegt die katalytische Domäne (AME et al., 2004), die bei allen Mitgliedern der PARP-Familie eine hohe Homologie aufweist. Sie ist die einzige Domäne, die in allen PARPs vorkommt. Die Angehörigen der PARP Familie besitzen neben dieser gemeinsamen Domäne aufgrund ihrer unterschiedlichen zellulären Funktionen noch weitere unterschiedliche Domänen (SMITH, 2001), allerdings zeigen einige Familienmitglieder untereinander große Homologien.

PARP-1 spielt eine zentrale Rolle bei der DNA-Reparatur nach DNA-Einzel- oder Doppelstrangbrüchen (Abb. 2). Es liegt im Nukleoplasma in inaktiver Form vor und wird durch DNA-Strangbrüche aktiviert (SMITH, 2001). Auslöser für DNAStrangbrüche können Strahlung, alkylierende Agentien oder freie Radikale z.B. im Zuge des „oxidativen Bursts“ sein. PARP-1 bindet an die geschädigte DNA über die DNA-bindende Domäne und bildet mit $\mathrm{NAD}^{+}$als Substrat, mittels der katalytischen Domäne, ADP-Ribose-Einheiten. Diese führen dann über die Automodifizierungsdomäne zur Modifizierung von PARP-1 selbst. Die poly(ADPRibosyl)ierung von PARP-1 dient als Signal für die Aktivierung der DNA Reparaturmaschinerie. Durch die zunehmend hohe negative Ladung löst sich poly(ADP-Ribosyl)iertes PARP-1 von der DNA. Die poly(ADP-Ribose) Glykohydrolase (PARG), der Antagonist von PARP, spaltet die poly(ADP-Ribose) Einheiten anschließend wieder ab.

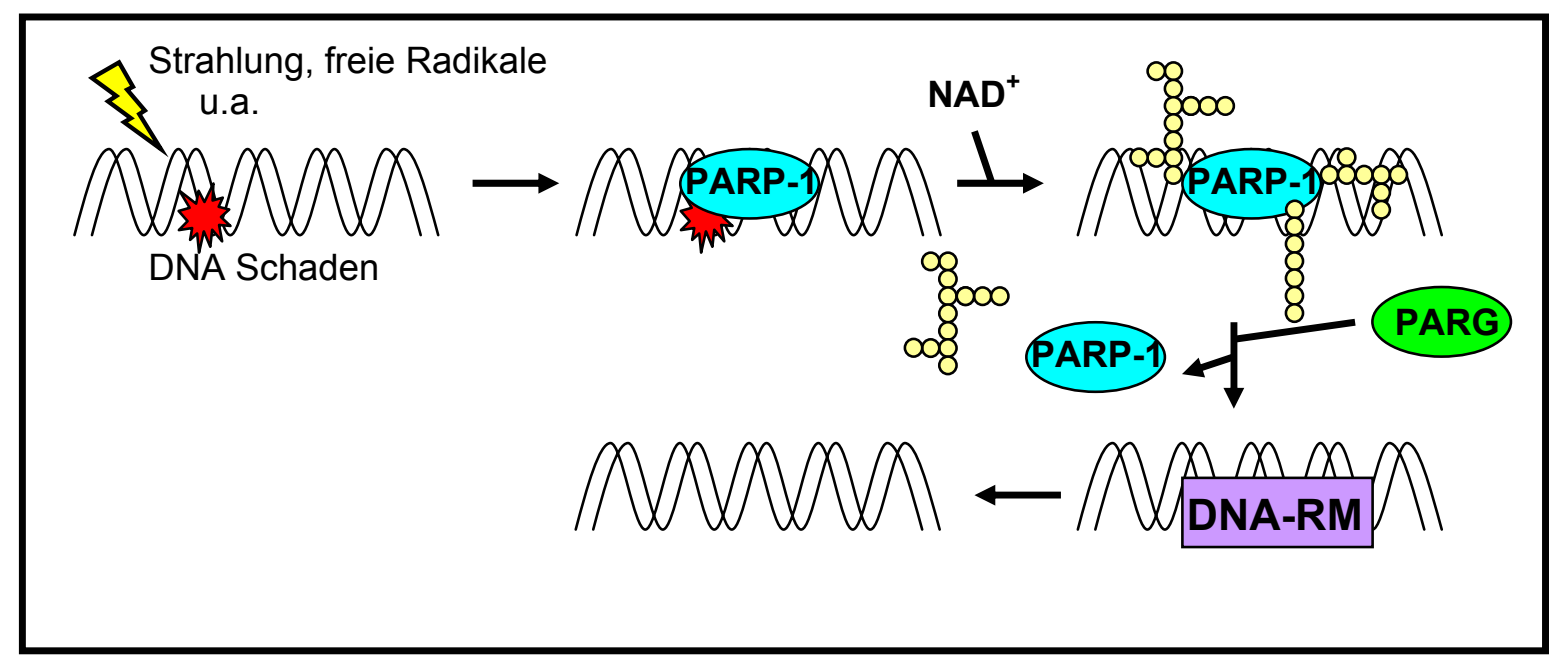

Abb. 2: Funktion von PARP-1 bei der DNA-Reparatur.

PARP-1 wird durch DNA Schäden aktiviert und bildet unter Verbrauch von NAD+ ADP-Ribose Polymere, die in diesem Fall zur Automodifikation von PARP-1 führen. Dies dient als Signal für DNA Reparaturmechanismen (DNA-RM). PARP-1 löst sich durch die negative Ladung der ADP-Ribose Polymere von der DNA und PARG spaltet die ADP-Ribose Einheiten. 
Dieser ganze Prozess läuft innerhalb weniger Minuten ab (HERCEG und WANG, 2001). PARP-1 wurde als erstes Protein beschrieben, welches während der Apoptose durch Effektorcaspasen, z.B. Caspase 3 und 7, gespalten wird (KAUFMANN, 1989; KaUfmann et al., 1993; HeRceg und Wang, 2001). Die Spaltung von PARP-1 ist dadurch als eine der wichtigsten Indikatoren eines apoptotischen Zelltodes bekannt. PARP-1 wird dabei zu einem frühen Zeitpunkt im Verlauf der Apoptose an der DEVDSpaltungsstelle in ein $89 \mathrm{kDA}$ und ein $24 \mathrm{kDa}$ Fragment proteolytisch gespalten (Kaufmann, 1989; Kaufmann et al., 1993). Auch durch Granzym B und Perforin kann PARP-1 im Verlauf der Apoptose gespalten werden (FROELICH et al., 1996), allerdings mit abweichenden Größen der Fragmente. Es wird vermutet, dass die frühe Caspase-vermittelte Spaltung von PARP-1 während der Apoptose eine Art „Point of no Return" darstellt, an dem die Zelle die Möglichkeit verliert ihre ursprüngliche Vitalität zurück zu erlangen (DURIEZ und SHAH, 1997). Darüber hinaus wurde auch angenommen, dass die frühe PARP-Spaltung während der Apoptose wichtig ist, um den Verbrauch von $\mathrm{NAD}^{+}$und die ATP-Depletierung zu verhindern und so spätere apoptotische Reaktionen zu ermöglichen (SMULSON et al., 2000). Außerdem spielt PARP-1 eine Rolle in einem Caspase-unabhängigen Apoptoseweg. So kommt es durch eine Überaktivierung von PARP-1 zur Freisetzung des Apoptoseinduzierenden Faktors (AIF) aus den Mitochondrien. AIF induziert im Nukleus Chromatinkondensation, Fragmentierung der DNA und Zytotoxizität (HONG et al., 2004).

Während es sich bei der Apoptose, einer Form des so genannten programmierten Zelltodes, um eine strikt kontrollierte zelluläre Reaktion von endogenen Proteasen handelt, zeichnet sich die Nekrose durch akute zelluläre Verletzungen aus, die eine Lyse der Zelle unter Auslösung einer Entzündungsreaktion hervorruft. Kommt es durch DNA-Schäden zu einer Überaktivierung von PARP-1 und damit auch zu einem starken Verbrauch von NAD ${ }^{+}$und zu ATP-Depletierung (PIEPER et al., 1999; Boulu et al., 2001; YING et al., 2005), kann die Zelle aufgrund des hohen Energieverlustes nekrotisch werden (SIMS et al., 1983; BERGER, 1985; HERCEG und WANG, 2001). 


\subsection{PARP-1 und die Pathogenese entzündlicher}

\section{Erkrankungen}

Aufgrund der Bedeutung von PARP-1 für zentrale Prozesse der Zellphysiologie spielt PARP-1 auch bei der Pathogenese verschiedener Krankheiten eine wichtige Rolle (ZHANG et al., 1994; SZABO und DAwson, 1998; HASSA und HotTIGeR, 2002; ClaRK und CoWden, 2003; CLARK et al., 2004; HASSA et al., 2005). Verschiedene Arbeitsgruppen konnten an Hand von Versuchen mit PARP-1 knockout Mäusen zeigen, dass diese Tiere gegen induzierbare chronische Entzündungskrankheiten, wie z.B. Typ-1 Diabetes, Septischer Schock, Multiorganversagen und Schlaganfall, bei denen NF-KB als Transkriptionsregulator eine zentrale Rolle spielt, resistent sind (HASSA und HOTTIGER, 2002; HASSA et al., 2005). Tatsächlich konnte anhand dieser PARP-defizienten Mäuse die Rolle von PARP-1 als Koaktivator der NF-kBregulierten Transkription belegt werden, da in innen auch die pro-inflammatorischen Moleküle des NF-kB-Signalweges stark reduziert waren (HASSA et al., 2005). Der Koaktivator der NF-kB-regulierten Genexpression scheint dabei den entscheidenden Ausschlag zu geben, ob die NF-kB-Aktivierung zum Überleben der Zelle, zum nekrotischen Zelltod oder zur Apoptose führt. Der genaue molekulare Mechanismus ist bisher unbekannt, allerdings bildet PARP-1 einen Komplex mit den beiden Untereinheiten p65 und p50 von NF-kB (HASSA et al., 2005).

Obwohl die Grunderkrankungen sehr verschieden sind, weisen mehrere entzündliche Erkrankungen deutliche pathogenetische Parallelen auf. Dabei kommt es zur Aktivierung von NF-KB und der Produktion von pro-inflammatorischen Mediatoren, wie z.B. IL-12, TNF- $\alpha$ oder IL-6, die die Bildung von freien Sauerstoffradikalen anregen. Dies führt zu DNA-Strangbrüchen, die eine Überexpression von PARP-1 und einen hohen Verbrauch von $\mathrm{NAD}^{+}$und darauf hin eine ATP-Depletion auslösen (SzABO et al., 1996; SZABO und DAWson, 1998; Boulu et al., 2001; YING et al., 2005). Die Folgen sind nekrotischer Zelltod und Gewebeschäden, die mit den Krankheitsbildern von septischem Schock, Schlaganfall, Multiorganversagen und Diabetes verbunden sind. PARP-1 greift in die Pathogenese dieser Prozesse an zwei Stellen ein, erstens als Koaktivator von NF-kB und zweitens durch Auslösung eines hohen Energieverlustes und ATP-Depletierung (HASSA et al., 2005).

Plasmodium, der Erreger der Malaria, gehört ebenso wie $T$. gondii zu den apikomplexen Parasiten. Plasmodium falciparum verursacht, vor allem bei Kindern, 
die meist lebensbedrohlich verlaufende Malaria tropica, während $P$. vivax, $P$. ovale und $P$. malariae zu milderen Krankheitsverläufen führen (KAYSER et al., 2001).

Makrophagen und Monozyten setzen TNF- $\alpha$ und andere Cytokine als Antwort auf eine Infektion mit Plasmodium frei. Der TNF- $\alpha$ Gehalt im Blut von akut infizierten Patienten korreliert dabei mit dem Schweregrad der Malaria (KAYSER et al., 2001). PARP-1 ist beteiligt an der Pathogenese der zerebralen Malaria und es wird vermutet, dass durch die TNF- $\alpha$-stimulierte NO-Freisetzung Einzelstrangbrüche der DNA entstehen und dies zur starken Aktivierung von PARP-1 führt (CLARK et al., 2004). Dadurch könnte es zu einem Verlust von $\mathrm{NAD}^{+}$und zur ATP-Depletierung kommen, wodurch Sauerstoff, der durch die eventuell auftretende Anämie während der Malaria tropica nur noch in niedrigen Konzentrationen im Blut vorkommt, nicht effektiv verarbeitet werden kann. Dies könnte unter anderem für schwere Verläufe bei Malaria, bis hin zu Sepsis und Tod, mitverantwortlich sein. Zusätzlich dürfte PARP-1 aufgrund seiner Funktion als Koaktivator auch die NF-kB-vermittelte Genexpression verstärken und dadurch vermehrt zur Bildung pro-inflammatorischer Cytokine führen, was eine Entzündungsreaktion unter anderem auch im Zentralnervensystem von Malariapatienten zur Folge hätte (CLARK und COWDEN, 2003; CLARK et al., 2004).

\subsection{Zielsetzung}

Für T. gondii als obligat intrazellulären Parasiten, dessen Übertragung von Zwischenwirt auf Endwirt und von Zwischenwirt auf Zwischenwirt von der Etablierung persistierender Infektionen abhängt, ist es von größter Bedeutung, das eigene Überleben und die Vermehrung innerhalb der Wirtszelle zu sichern, ohne dabei die Wirtszelle zu töten (SACKS und SHER, 2002). Eine wichtige Voraussetzung spielen dabei strikt regulierte Parasit-Wirt-Interaktionen, die ein balanciertes Gleichgewicht zwischen Parasit und Wirt bilden. Neben Veränderungen von WirtszellKompartimenten, Inhibierung von Wirtszell-Signalwegen und Inhibierung der Produktion von toxischen Metaboliten spielt die Interaktion des Parasiten mit verschiedenen Apoptosewegen eine wichtige Rolle (LANG et al., 2007). In vorherigen Arbeiten konnte gezeigt werden, dass $T$. gondii die Expression der Poly(ADP-Ribose) Polymerase-1 (PARP-1) in humanen HL-60 und U937-Zellen, bei denen Apoptose 
induziert worden war und auch bei nicht-apoptotischen Zellen, sehr deutlich inhibiert (GoEBel et al., 2001). PARP-1 besitzt neben Funktionen bei der Apoptose auch wichtige Aufgaben in anderen zellulären Prozessen, wie poly(ADP-Ribosyl)ierung, DNA-Reparatur, Nekrose und Koaktivatorfunktion bei der Transkription verschiedener Gene (SMULSON et al., 2000; HASSA et al., 2005). Daneben wurde PARP-1 auch eine wichtige Rolle im Verlauf entzündlicher Erkrankungen, u.a. Malaria tropica, verursacht durch Plasmodium falciparum, zugeschrieben (CLARK et al., 2004).

Da die Inhibierung der PARP-1 Expression durch T. gondii sowohl in apoptotischen als auch in nicht-apoptotischen Zellen nachgewiesen wurde (GOEBEL et al., 2001), könnte es sich um einen generellen Mechanismus der Parasit-Wirt-Interaktion handeln. Ziele dieser Arbeit waren deshalb

- die PARP-1 Expression in nicht-apoptotischen Zellen nach Infektion mit dem Parasiten $T$. gondii eingehend zu charakterisieren,

- Untersuchungen zu möglichen Auswirkungen eines veränderten PARP-1 Gehaltes nach Parasiten-Infektion auf die Physiologie der Wirtszelle zu bestimmen,

- eine Charakterisierung des Mechanismus der Modulation von PARP-1 durch T. gondii vorzunehmen, sowie

- die Auswirkungen der veränderten PARP-1 Expression auf die Parasit-WirtInteraktion zu untersuchen.

Die Identifizierung und Charakterisierung der PARP-1-Inhibierung durch $T$. gondii als möglichen weiteren Mechanismus der Parasit-Wirt-Interaktion könnte dabei neue Einsichten in die Pathogenese der Toxoplasmose liefern. 


\section{Material und Methoden}

\subsection{Material}

\subsubsection{Geräte}

Fluoreszenzmikroskop

Konfokales Laserscan-

Mikroskop

LightCycler

Waagen

Zellkulturmikroskope

Zentrifugen
Leica DMR, Leica, Heidelberg

Modell TCS SP2, Leica, Heidelberg

LightCycler ${ }^{\circledR} 2.0$ Real-Time PCR System, Roche, Mannheim

Feinwaage: CP 224S, Satorius, Göttingen

SAC 62, Satorius, Göttingen

Leica DM IL, Leica, Heidelberg

Zeiss Axiostar Plus, Zeiss, Göttingen

Omnifuge 2.0 ORS, Heraeus, Hanau

Modell 5417 R, Eppendorf, Hamburg

Modell 5417 C, Eppendorf, Hamburg

\subsubsection{Zellkultur}

Alle Zellkulturmedien, -reagenzien und -zusätze stammten von Biochrom (Berlin), falls nicht anders beschrieben.

\section{Reagenzien und Additive}

Dulbecco's Phosphat-gepufferte Saline (PBS)

EDTA, $1 \%$

FCS (fötales Kälberserum)

G418 Sulfat, $50 \mathrm{mg} / \mathrm{ml}(\mathrm{w} / \mathrm{v})$

Glukose, $10 \%(\mathrm{w} / \mathrm{v})$

HEPES Puffer, $1 \mathrm{M}$

Natriumpyruvat, $100 \mathrm{mM}$

Nicht-essentielle Aminosäuren, 100x

Penicillin-Streptomycin, $10.000 \mathrm{U} / \mathrm{ml}-10.000 \mu \mathrm{g} / \mathrm{ml}$ 
Trypanblau, $0.5 \%$ in PBS

Trypsin, $0.25 \%$

\section{Medien}

\section{RPMI 1640 (Roswell Park Memorial Institute)}

RPMI 1640 Instantpulver (Instamed T121-10) mit 300 mg/l L-Glutamin, ergänzt mit $2000 \mathrm{mg} / \mathrm{l} \mathrm{NaHCO}_{3}$, eingestellt auf $\mathrm{pH}$ 7.2, sterilfiltriert.

\section{DMEM (Dulbecco's MEM)}

DMEM Instantpulver (Instamed T 043-10) mit $4.5 \mathrm{~g} / \mathrm{l}$ Glukose, 580 mg/l L-Glutamin, ergänzt mit 3700 mg/l $\mathrm{NaHCO}_{3}$, eingestellt auf $\mathrm{pH}$ 7.2, sterilfiltriert.

SOC Medium (super optimal broth medium + Glukose):

Zur Transformation von TOP10 E. coli:

$2 \%$ Trypton, $0.5 \%$ Hefeextrakt, $10 \mathrm{mM} \mathrm{NaCl}, 2.5 \mathrm{mM} \mathrm{KCl}, 10 \mathrm{mM} \mathrm{MgCl}$, $10 \mathrm{mM}$ $\mathrm{MgSO}_{4}, 20 \mathrm{mM}$ Glukose

\section{Primäre Zellen und Zelllinien}

Murine L929 Fibroblasten

Murine Leukämie Monocyten/Makrophagen, RAW 264.7 (TIB 71; ATCC, Rockville MD)

Primäre humane Vorhaut-Fibroblasten (HFF)

Murine NIH 3 T3 Fibroblasten (ECACC, Salisbury, UK)

Humane Jurkat T-Zellen

Humane Monocyten, THP-1

Toxoplasma gondii BK Stamm (Maus-virulent)

Toxoplasma gondii RH Stamm (Maus-virulent)

Toxoplasma gondii NTE Stamm (Maus-avirulent)

Toxoplasma gondii DX Stamm (Maus-avirulent)

Toxoplasma gondii CEP Stamm (Maus-avirulent)

Toxoplasma gondii C56 Stamm (Maus-avirulent)

Toxoplasma gondii PRUhxgprt 
Toxoplasma gondii PRUcat' (beide freundlicherweise von D. Soldati, Genf, Schweiz zur Verfügung gestellt)

Toxoplasma gondii P Stamm

Toxoplasma gondii SAG1 defizient $(\Delta)$ (beide freundlicherweise von S. Tomavo, Villeneuve d'Ascq, Frankreich, zur Verfügung gestellt)

Toxoplasma gondii RH/HX'/UPRT'/Sag1/lacZ

Verbrauchsmaterial für die Zellkultur wurde von Nunc (Roskilde, Denmark), Corning/Costar (Bodenheim), Greiner (Frickenhausen), Falcon (Becton Dickinson, Heidelberg) oder Eppendorf (Hamburg) bezogen.

\subsubsection{Chemikalien und Reagenzien}

Ac-DEVD-AMC

Agarose

6-Aminocapronsäure

Ammonium Persulfat (APS)

3-Aminobenzamide

Aprotinin

6-Biotin-17-NAD

Bromphenolblau Natriumsalz

1-Butanol

Chlorophenolred-ß-D-

galactopyranoside (CPRG)

3-[(3-cholamidopropyl)-

dimethylammonio]-1-

Propan-Sulfonat (CHAPS)

Colchicin

Digitonin

Dimethylsulfoxid (DMSO)

Dithiothreitol (DTT)

Einmach-Folie
Bachem, Heidelberg

Roth, Karlsruhe

Fluka, Neu-Ulm

BioRad, München

Alexis Biochemicals, San Diego, Kalifornien, USA

Boehringer, Mannheim

Biozol, Eching

Merck, Darmstadt

Merck, Darmstadt

Sigma, München

Roth, Karlsruhe

Sigma, München

Sigma, München

Sigma, München

Sigma, München

Deti, Meckesheim 
Enhanced Chemiluminescence

(ECL)-kit

Essigsäure

Ethanol

Ethidiumbromid

Ethylendiamintetraessigsäure (EDTA)

Formaldehyd

Glutaraldehyd

Glycerin

Glycin

Höchst-Farbstoff 33258

Hyperfilm ECL

Immersionsöl für Mikroskopie

Isopropanol / 2-Propanol

Kaliumchlorid $(\mathrm{KCl})$

Lactacystin

Leupeptin

Magermilchpulver

Magnesiumchlorid $\left(\mathrm{MgCl}_{2}\right)$

Methanol

MG-132

Mowiol

Natriumchlorid ( $\mathrm{NaCl})$

Natriumacetat

Natriumazid $\left(\mathrm{NaN}_{3}\right)$

Natriumcarbonat

Natriumcitrat

Natrium-Deoxycholat (NaDOC)

Natrium-Dodecylsulfat (SDS)

Natrium-Othovanadat

Natriumthiosulfat

Nickel-Diaminobenzidine (Nickel-DAB)

Nonidet P-40

Ortho-Phenylendiamin
Amersham Biosciences, Freiburg

Roth, Karlsruhe

Merck, Darmstadt

Merck, Darmstadt

AppliChem, Darmstadt

Sigma, München

Merck, Darmstadt

Merck, Darmstadt

Roth, Karlsruhe

Sigma, München

Amersham Biosciences, Freiburg

Merck, Darmstadt

Merck, Darmstadt

Merck, Darmstadt

Calbiochem, München,

Sigma, München

Sucofin, Zeven

Merck, Darmstadt

Merck, Darmstadt

Calbiochem, München,

Calbiochem, München,

Merck, Darmstadt

Merck, Darmstadt

Merck, Darmstadt

Roth, Karlsruhe

Merck, Darmstadt

Sigma, München

Merck, Darmstadt

Sigma, München

Sigma, München

Sigma, München

Fluka, Neu-UIm

Sigma, München 
Paraformaldehyd

PBS (phosphate buffered saline)

Pepstatin A

Phenylmethylsulphonylfluorid (PMSF)

Phorbol 12-Myristat 13-Acetat (PMA)

PJ34 [N-(6-oxo-5,6-

dihydrophenanthridin-2-yl)-

$\mathrm{N}, \mathrm{N}$-dimethylacetamide. $\mathrm{HCl}]$

Ponceau S-Lösung

Prestained Protein Marker,

Broad Range

Propidiumjodid

Proteinase-Inhibitor-Cocktail (PIC)

Rinderserum-Albumin

(bovine serum albumin, BSA)

RNAse A

Rothiphorese Gel 30

Acrylamid/Bisacrylamid

Saccharose

Saponin

Silbernitrat

SOC Medium

(super optimal broth + Glukose)

Staurosporin

Temed

Trichloressigsäure (TCA)

Tris-(Hydroxymethyl)Aminomethan

$$
\text { (=Tris) }
$$

Triton X-100

Triton X-114

Tween-20

Urea
Merck, Darmstadt

Biochrom, Berlin

Sigma, München

Sigma, München

Sigma, München

Calbiochem, Darmstadt

Sigma, München

New England Biolabs, Frankfurt

Sigma, München

Roche, Mannheim

Sigma, München

Sigma, München

Roth, Karlsruhe

Merck, Darmstadt

Sigma, München

Sigma, München

Invitrogen, Hilden

Sigma, München

Serva, Heidelberg

Merck, Darmstadt

Roth, Karlruhe

Sigma, München

Sigma, München

Merck, Darmstadt

Calbiochem, München 


\subsubsection{Enzyme}

Pfu DNA Polymerase von Pyrococcus furiosus (Promega, Mannheim)

Restriktionsenzyme Hind III und Not I (New England Biolabs, Frankfurt)

Taq Polymerase von Thermus aquaticus (Roche, Mannheim)

\subsubsection{Kits}

DNA Isolierung

Light Cycler PCR

Transfektionsreagenz

Klonierungskit

PCR Aufreinigung

Plasmid Isolierung

Proteinbestimmung

Ligation

Reverse Transkription

RNA Isolierung

RNase Inhibitor

Mycoplasmentest
E.Z.N.A. ${ }^{\circledR}$ Tissue DNA Mini Kit (Peqlab, Erlangen)

LightCycler FastStart DNA Master Plus SYBR Green I (Roche, Mannheim)

Metafectene $^{\mathrm{TM}}$ (Biontex, Martiensried)

pcDNA3.1/N5-His ${ }^{\oplus} \mathrm{TOPO}^{\circledR} \mathrm{TA}$ Expression Kit (Invitrogen, Karlsruhe)

QIAquick PCR Purification Kit (Qiagen, Hilden)

GenElute $^{T M}$ Plasmid Mini Prep Kit (Sigma, München)

BCA Protein Assay (Pierce, Rockford, USA)

Quick Ligation ${ }^{\mathrm{TM}}$ Kit (New England Biolabs, Frankfurt)

Omniscript reverse transcriptase (Qiagen, Hilden)

GenElute Mammalian Total RNA Kit (Sigma, München)

RNasin $40 \mathrm{U} / \mu \mathrm{l}$ (Promega, Mannheim)

Venor GeM, Mycoplasma PCR detection kit (Minerva biolabs, Berlin)

\subsubsection{Molekulargrößenmarker}

\section{DNA Standard:}

GeneRuler 100bp-DNA Leiter: 80, 100, 200, 300, 400, 500, 600, 700, 800, 900, 1000 bp (MBI Fermentas, St. Leon-Rot)

GeneRuler 1kb-DNA Leiter: 250, 500, 750, 1000, 1500, 2000, 2500, 3000, 3500, 4000, 5000, 6000, 8000, 10000 bp (MBI Fermentas, St. Leon-Rot)

\section{Protein Standard:}

High molecular weight marker (HMW): 212, 170, 116, 76, 53 kDa (Amersham Bioscience, Freiburg) 
Prestained protein marker: 175, 83, 62, 47.5, 32.5, 25, 16.5, 6.5 kDa (New England Biolabs, Frankfurt)

\subsubsection{Membranen und Filter}

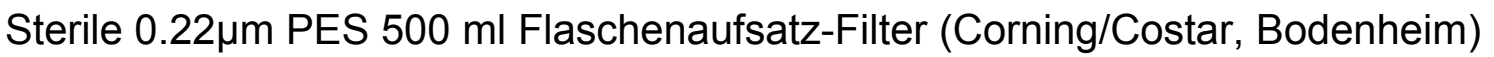

Sterile $0.20 \mu \mathrm{m}$ Spritzen-Filter (Corning/Costar, Bodenheim)

$3.00 \mu \mathrm{m}$ Isopore, Membranfilter (Millipore, Bedford, USA)

10 kDA Centriprep YM-10 Centrifugal Filter Devices (Millipore, Bedford, USA)

Nitrocellulose Membran, Hybond ECL (Amersham Biosciences, Freiburg)

$0.4 \mu \mathrm{m}$ Transwell Membraneinsätze (Corning/Costar, Bodenheim)

\subsubsection{Oligonukleotide}

Alle Oligonukleotide wurden von Sigma-Genosys (Darmstadt) hergestellt.

Oligonukleotide

3'PARP+Stop

3'PARP

5'Start*neu4*

ß-actin_for

ß-actin_rev

Cyclin-B2up

Cyclin-B2low

ICAM-1 forward

ICAM-1 reverse

IL-6up*2*

IL-6low*2*

iNOS forward

iNOS reverse

MM_HMG2_for

MM_HMG2_rev

MM_IGFBP4_for

MM_IGFBP4_rev

\section{Sequenz 5'-3'}

tta cca cag gga tgt ctt aaa att gaa ctt gag cca cag gga tgt ctt aaa att gaa ctt gag ttt cca cca tgg cgg agg cct cgg aga

gag acc cag atc atg ttt gag a

tgc tcg aag tct aga gca aca tag

tat ccg gcg ggc agt ttt aga

tca ggg gcg gga gga cga $t$

gac cca gct ctc agc agt get gct

aca gag tca ctg ctg ttt gtg ctc

gac ttc cat cca gtt gcc ttc ttg

gtt tct gta tct ctc tga agg act C

tct gga gga get cct gcc tca $t$

cat ccc ctc tga tgg tgc cat $\mathrm{C}$

gaa gca tcc cga ctc gtc

cca gtt tct tcg cag tat ctc c

gag gag aag ctg gca cgc

ggc cat atg ctt ctg cag 


\begin{tabular}{ll} 
mmMIP2_for & cat tgg tcc tgc tgc tgc \\
mmMIP2_rev & gcc ttg cct ttg ttc agt atc ttt \\
MM_TROPO_for & cca cct act cat cca tcc atc cat \\
MM_TROPO_rev & gtg aga cat gct ctg taa gag tg \\
Oligo dT & ttt ttt ttt ttt tt \\
PARP-861/for & tga cct gaa gga gct gct cat \\
PARP-861/rev & atg agc agc tcc ttc agg tca \\
PARP-1779/for & gaa ctc cta tta caa act gca \\
PARP-1779/rev & gct gca gtt tgt aat agg agt \\
PARP-2511/for & ggc cga ggt cat cag gaa \\
PARP-2511/rev & ttc ctg atg acc tcg gcc \\
PARP-3054/for & ctc aaa tac ctg ctg aaa ctc aag \\
PARPup & cca gga cga aga ggc agt aaa gaa \\
PARPlow & cat ggg gga tca gag tgt aga agc \\
TNF-a forward & tcg agt gac aag cct gta gcc ca \\
TNF-a reverse & cag agc aat gac tcc aaa gta gac c \\
V5-Epitop*2* & ccg agg aga ggg tta ggg at \\
\hline
\end{tabular}

\subsubsection{Antikörper (Ak)}

Primäre Antikörper:

Kaninchen anti-Toxoplasma, Serum

Kaninchen anti-T. gondii Katalase

Maus anti-Aktin, Klon C4

Maus anti-PARP, Klon C2-10 (m)

Maus anti-SAG1, KIon DG 52

Maus anti-V5-Epitop (m)

Maus anti-His (m)

Ziege anti-Aktin, Klon I-19 (p)
Eigenherstellung

freundlicherweise von D. Soldati, Genf, Schweiz, bereitgestellt

freundlicherweise von J. Lessard, Cincinnati, $\mathrm{OH}, \mathrm{USA}$, bereitgestellt

BD Phamingen, Hamburg

freundlicherweise von F. Seeber, Marburg,

Deutschland, bereitgestellt

Invitrogen, Karlsruhe

Invitrogen, Karlsruhe

SantaCruz, Santa Cruz, Californien, USA 
Sekundäre Antikörper und Konjugate:

Alle sekundären Antikörper und Konjugate wurden von Dianova, Hamburg bezogen.

Cy 2-(Carbocyanin-)konjugiertes Esel $\mathrm{F}\left(\mathrm{ab}^{\prime}\right)_{2}$ anti-Maus IgG

Cy 2-(Carbocyanin-)konjugiertes Esel $\mathrm{F}\left(\mathrm{ab}^{\prime}\right)_{2}$ anti-Kaninchen IgG

Cy 3-(Indocarbocyanin-)konjugiertes Esel $F\left(a b^{\prime}\right)_{2}$ anti-Kaninchen IgG

Meerrettichperoxidase (HRP)-konjugiertes Esel $F\left(a b^{\prime}\right)_{2}$ anti-Kaninchen IgG $(\mathrm{H}+\mathrm{L})$

Meerrettichperoxidase (HRP)-konjugiertes Esel $F\left(a b^{\prime}\right)_{2}$ anti-Ziege IgG $(\mathrm{H}+\mathrm{L})$

Meerrettichperoxidase (HRP)-konjugiertes Streptavidin

Meerrettichperoxidase (HRP)-konjugiertes Ziege $F\left(a^{\prime}\right)_{2}$ anti-Maus IgG $(\mathrm{H}+\mathrm{L})$

(m): monoklonal; $(p)$ : polyklonal; $H+L$ : schwere und leichte Ketten (heavy and light chain) 


\subsection{Methoden}

\subsubsection{Zellkultur}

Die Kultivierung der Zellen wurde ausschließlich unter sterilen Bedingungen durchgeführt. Des Weiteren wurden die Zellen regelmäßig auf Kontaminationen mit Mycoplasmen mittels des Mycoplasmen PCR Nachweises von Venor GeM getestet. Die Zellen wurden in einem Inkubator bei $37^{\circ} \mathrm{C}$ und $5 \% \mathrm{CO}_{2}$ mit befeuchteter Atmosphäre kultiviert.

\subsubsection{Kultur und Isolierung von Toxoplasma gondii Tachyzoiten}

T. gondii Tachyzoiten der maus-avirulenten Stämme NTE (GRoss et al., 1991), C56, CEP und DX sowie der maus-virulenten Stämme RH und BK (PARMLEY et al., 1994) wurden in murinen L929-Fibroblasten als Wirtszellen vermehrt. Wirtszellen und Parasiten wurden in verschiedenen Verhältnissen zueinander in 12-Lochplatten gegeben und in T. gondii Medium kultiviert. Dabei handelte es sich um RPMI 1640 Medium, welches zusätzlich mit 1\% Hitze-inaktiviertem fötalem Kälberserum (FCS), $100 \mathrm{U} / \mathrm{ml}$ Penicillin und $100 \mu \mathrm{g} / \mathrm{ml}$ Streptomycin ergänzt wurde.

Kurz nach der Lyse eines Großteils der Wirtszellen wurden die Parasiten zweimal pro Woche wieder auf frische Wirtszellen umgesetzt.

Zur Gewinnung frischer Parasiten für Infektionsversuche wurden Tachyzoiten aus L929-Kokulturen, die ca. zu 80\% lysiert waren, isoliert. Hierzu wurden kontaminierende Wirtszellen bei $35 \mathrm{xg}$ für $5 \mathrm{~min}$ von den Parasiten getrennt und die Toxoplasmen anschließend bei 1.300 x g für 10 min abzentrifugiert. Die Tachyzoiten wurden im Anschluss zweimal mit Medium gewaschen und bei $1.300 \mathrm{xg}$ für $10 \mathrm{~min}$ abzentrifugiert. Die Anzahl isolierter Toxoplasmen wurde mittels einer NeubauerZählkammer ermittelt.

\subsubsection{Kultur der Wirtszelllinien}

\section{$\underline{\underline{L} 929}$}

Bei L929 Zellen handelt es sich um murine Fibroblasten, die zur Kultivierung von $T$. gondii verwendet werden. Die Zellen wurden in 6 Loch-Platten in DMEM Medium, welches mit $100 \mathrm{U} / \mathrm{ml}$ Penicillin, $100 \mu \mathrm{g} / \mathrm{ml}$ Streptomycin, 3\% Hitze-inaktiviertem 
FCS, $1 \mathrm{mM}$ Natriumpyruvat und 1x nicht-essentiellen Aminosäuren komplementiert wurde, kultiviert. Die Zellen wurden zweimal pro Woche gesplittet, indem sie mittels eines Zellschabers vom Boden der Platte abgekratzt wurden. Nach dem Resuspendieren der Zellen wurden 6 Tropfen der Zellsuspension pro Loch mit jeweils $5 \mathrm{ml}$ frischem Medium weiter kultiviert.

\section{RAW 264.7}

RAW 264.7 Zellen (RASCHKE et al., 1978), eine Monozyten/Makrophagen-TumorZelllinie aus BALB/c Mäusen, wurden verwendet, um die veränderten PARP-1Proteinlevel nach Infektion mit Toxoplasma gondii zu charakterisieren. RAW 264.7 Zellen wurden außerdem mit dem murinen PARP-1-Gen stabil transfiziert, um die Auswirkung von PARP-1-Überexpression auf die Parasit-Wirt-Interaktion zu untersuchen.

Die adhärenten RAW 264.7 Zellen wurden in RPMI 1640 Medium kultiviert, das mit 10\% (v/v) Hitze-inaktiviertem FCS, $100 \mathrm{U} / \mathrm{ml}$ Penicillin und $100 \mu \mathrm{g} / \mathrm{ml}$ Streptomycin, 1 mM Natriumpyruvat, $10 \mathrm{mM}$ HEPES und zusätzlich mit $2.5 \mathrm{~g} / \mathrm{l}$ Glukose versetzt wurde. Die Zellen wurden in Zellkulturflaschen kultiviert und 2 - 3 Mal pro Woche gesplittet, indem sie nach einem Medienwechsel mittels eines Zellschabers vom Boden der Flasche abgeschabt und je nach Zelldichte im Verhältnis 1:5 bis 1:15 in einem entsprechendem Volumen an frischem Medium resuspendiert wurden.

Die mit dem murinen PARP-1-Gen stabil transfizierten RAW 264.7 Zellen wurden wie oben beschrieben kultiviert. Das Kultivierungsmedium enthielt zusätzlich $700 \mu \mathrm{g} / \mathrm{ml}$ G418 (Biochrom, Berlin).

\section{$\underline{\mathrm{NIH} / 3 \mathrm{~T} 3}$}

Murine NIH/3T3 Fibroblasten wurden verwendet, um die veränderten PARP-1Proteinlevel nach Infektion mit Toxoplasma gondii im Vergleich zu murinen Makrophagen zu charakterisieren.

NIH/3T3 Fibroblasten wurden in DMEM Medium, welches mit 10\% (v/v) Hitzeinaktiviertem FCS, $100 \mathrm{U} / \mathrm{ml}$ Penicillin, $100 \mu \mathrm{g} / \mathrm{ml}$ Streptomycin, $1 \mathrm{mM}$ Natriumpyruvat und 1x nicht-essentielle Aminosäuren ergänzt wurde, kultiviert. Die Zellen wurden zweimal pro Woche subkultiviert, in dem sie mit 1\% EDTA gewaschen und mit $0.25 \%$ Trypsin abgelöst wurden. Die Zellen wurden für 5 min bei $400 \times \mathrm{g}$ zentrifugiert, in frischem Medium resupendiert und je nach Zelldichte im Verhältnis 
1:2 bis 1:5 in eine neue Zellkulturflasche mit dem entsprechenden Volumen an frischem Medium überführt.

\section{$\underline{\mathrm{HFF}}$}

HFF, eine primäre Zelllinie humaner Vorhautfibroblasten, wurden auf Grund ihrer Kontaktinhibierung verwendet, um Toxoplasma gondii Tachyzoiten nach dem Auftauen zu vermehren und ein Überwachsen durch Wirtszellen zu verhindern.

Die Zellen wurden in DMEM Medium, welches mit 10\% (v/v) Hitze-inaktiviertem FCS, $100 \mathrm{U} / \mathrm{ml}$ Penicillin, $100 \mu \mathrm{g} / \mathrm{ml}$ Streptomycin, $1 \mathrm{mM}$ Natriumpyruvat und $1 \mathrm{x}$ nichtessentielle Aminosäuren versetzt wurde, kultiviert. Die Zellen wurden zur Subkultivierung mit 1\% EDTA gewaschen und mit $0.25 \%$ Trypsin abgelöst. Nach dem Zentrifugieren bei $400 \times \mathrm{g}$ für $5 \mathrm{~min}$ wurden die Fibroblasten in einem entsprechenden Volumen frischen Mediums (1:10 bis 1:20) resuspendiert und in eine frische Zellkulturflasche überführt.

\section{Jurkat-Zellen}

Bei Jurkat-Zellen handelt es sich um eine humane Suspensions-T-ZellTumorzelllinie, die als Vergleich zu den murinen Zellen auf ihre PARP-1-Proteinlevel nach $T$. gondii-Infektion getestet wurde.

Die Zellen wurden in RPMI 1640 Medium, welches mit 10\% (v/v) Hitze-inaktiviertem FCS, $100 \mathrm{U} / \mathrm{ml}$ Penicillin und $100 \mu \mathrm{g} / \mathrm{ml}$ Streptomycin versetzt wurde, kultiviert. Zur Subkultivierung wurde im Verhältnis 1:5 Zellsuspension entnommen und mit frischem Medium gemischt.

\section{THP-1-Zellen}

THP-1-Zellen, eine humane monocytische Tumorzellinie, wurden ebenfalls verwendet, um im Vergleich zu den murinen Zellinien ihre PARP-1 Level nach Infektion mit Toxoplasma gondii zu untersuchen. Die Zellen wurden in RPMI 1640 Medium, welches mit 10\% (v/v) Hitze-inaktiviertem FCS, $100 \mathrm{U} / \mathrm{ml}$ Penicillin und 100 $\mu \mathrm{g} / \mathrm{ml}$ Streptomycin versetzt wurde, kultiviert. Die Zellen wurden zweimal pro Woche im Verhältnis 1:10 passagiert. 


\subsubsection{Infektion von Wirtszellen mit $T$. gondii}

Die Wirtszellen wurden für die Infektion mit $T$. gondii Tachyzoiten am Vortag der Infektion in $\varnothing 96 \mathrm{~mm}$-Zellkulturschalen oder in 6, 12 oder 24 Loch-Platten in entsprechendem Medium und Wirtszellanzahl ausgesät. Am Tag der Infektion wurden frisch isolierte Tachyzoiten aus L929-Kokulturen isoliert (siehe 2.2.1.1) und die Wirtszellen im Parasit-Wirt-Verhältnis von 0.5, 1, 2, 4, 8, 10, 12 bzw. 30:1, abhängig von Wirtszelllinie und Versuchsaufbau, infiziert. Die Infektionsdauer betrug meist $1 \mathrm{~h}$, aber auch 2, 4, 8, 11, 12, 24 und 48 h, abhängig vom Versuchsaufbau. Um frühe Effekte einer Toxoplasmose-Infektion zu untersuchen, betrugen die Infektionszeiten von RAW 264.7 Zellen 2.5, 5, 7.5, 10 und 30 min. RAW 264.7 Zellen wurden meist 4:1 bzw. 8:1 infiziert. Für eine Infektionsreihe mit verschiedenen Infektionsraten wurden RAW 264.7 Zellen auch in den Parasit-Wirt-Verhältnissen von 0.5, 1, 2, 4, 8 und 12:1 infiziert. Für Versuche mit Proteasom-Inhibitoren wurden die Zellen 10 min mit $10 \mu \mathrm{M}$ Lactazystin bzw. 50 nM MG132 vorinkubiert, bevor die Zellen für 1 Stunde (h) mit frisch isolierten Tachyzoiten infiziert oder mit $50 \mu \mathrm{g} \mathrm{T}$. gondii-Lysat (siehe 2.2.5) inkubiert wurden.

$\mathrm{NIH} / 3$ T3 Zellen wurden, ebenso wie RAW 264.7 Zellen, mit einer Zelldichte von 0.3 $\mathrm{x}$ $10^{7}$ Zellen pro $\varnothing 96 \mathrm{~mm}$-Zellkulturschale in $10 \mathrm{ml}$ Medium am Vortag der Infektion ausgesät und am nächsten Tag im Parasit-Wirt-Verhältnis von 4:1 für $1 \mathrm{~h}$ bis $36 \mathrm{~h}$ infiziert.

$0.3 \times 10^{7}$ Jurkat-Zellen wurden sofort nach dem Überführen in $\varnothing 96 \mathrm{~mm}$ Zellkulturschalen mit $T$. gondii Tachyzoiten im Parasit-Wirt-Verhältnis von 4, 10 bzw. 30:1 für unterschiedliche Zeiten infiziert.

THP-1 Zellen wurden am Vortag der Infektion mit $0.3 \times 10^{7}$ Zellen pro $\varnothing 96 \mathrm{~mm}$ Zellkulturschalen in $10 \mathrm{ml}$ Medium, welches mit $5 \mathrm{nM}$ Phorbol 12-Myristat 13-Acetat (PMA) zur Ausdifferenzierung ergänzt wurde, ausgesät. Am nächsten Tag wurden die Zellen zunächst zweimal mit Medium gewaschen und anschließend im ParasitWirt-Verhältnis von 4:1 für 1, 4, 24 und 36 h infiziert. 


\subsubsection{Stabile Transfektion}

\section{Klonierung}

Um die Auswirkung eines erhöhten PARP-1-Proteinlevels in den Wirtszellen von $T$. gondii auf das Parasit-Wirt-Verhältnis zu untersuchen, wurden PARP-1 überexprimierende RAW 264.7 Makrophagen hergestellt. Dazu wurde das murine PARP-1 Gen in den Expressionsvektor pcDNA3.1/V5-His ${ }^{\circledR} \mathrm{TOPO}^{\circledR} \mathrm{TA}$ kloniert und in RAW 264.7 Zellen transfiziert. Hierfür wurden zunächst Primer (5'Start*neu4*; 3'PARP+Stop bzw. 3'PARP) ausgewählt, die den gesamten Leserahmen des murinen PARP-1 Gens (NCBI-Datenbank: BC012041) amplifizieren. Zusätzlich wurde in den 5'Primer eine Kozak Konsensussequenz ((G/A)NNATGG) für eine effektive Translationsinitiation eingefügt, da der Vektor selbst kein ATG Initiationscodon besitzt. Einer der 3'Primer (3'PARP+Stop) enthielt das STOP-Codon des PARP-Genes, so dass das später exprimierte Protein kein His-Tag oder V5Epitop besaß. Dagegen enthielt der andere 3'Primer (3'PARP) kein Stop-Codon, wodurch das später exprimierte Fusionsprotein sowohl ein Penta-His-Tag als auch ein V5-Epitop als Erkennungssequenz besitzen würde.

Durch PCR (siehe 2.2.20) wurde das murine PARP-1-Gen aus RAW 264.7 Makrophagen/Monocyten mittels Pfu Polymerase amplifiziert. Der pcDNA3.1/N5$\mathrm{His}^{\circledR} \mathrm{TOPO}{ }^{\circledR} \mathrm{TA}$ Expression Kit ermöglichte eine direkte Klonierung des DNAFragments in den Vektor, da dieser einzelne überhängende 3'Deoxythymidinreste, sowie eine Topoisomerase besitz, die kovalent an den Vektor gebunden ist. Da die Pfu Polymerase an das Ende des PCR-Produktes kein einzelnes 3'Deoxyadenosin anhängt, wie es die Taq Polymerase macht, wurde dies in einem separaten Schritt nachgeholt. Dazu wurden poly-A-Schwänze an das PCR-Produkt angehängt. Hierfür wurden die PCR-Produkte zunächst in einem 1\% Agarose-Gel (siehe 2.2.21) aufgetrennt und mittels des PCR Purification Kits (Qiagen, Hilden) aufgereinigt. Im Anschluß wurden $1 \mu \mathrm{l}$ 10xTaq Puffer, 0,2 $\mu \mathrm{l}$ dNTPs, 0,2 $\mu \mathrm{l}$ Taq Polymerase und 8,6 $\mu \mathrm{l}$ des aufgereinigten PCR-Produktes für $40 \mathrm{~min}$ bei $72^{\circ} \mathrm{C}$ inkubiert. Danach wurde das PCR-Produkt direkt mit dem Vektor verbunden. Dazu wurden $4 \mu \mathrm{l}$ des frischen poly-A-PCR-Produktes mit $1 \mu \mathrm{l}$ Salzlösung, sowie $1 \mu \mathrm{l}$ Vektor aus dem pcDNA3.1/V5$\mathrm{His}^{\circledR} \mathrm{TOPO}^{\circledR} \mathrm{TA}$ Expression Kit für $30 \mathrm{~min}$ bei RT (Raumtemperatur) inkubiert. Anschließend wurde der Klonierungsansatz auf Eis gelagert und direkt zur Transformation von chemisch kompetenten E. coli Zellen verwendet. 


\section{Transformation von E. coli}

Aus den Klonierungsansätzen wurden je $2 \mu$ direkt zu den auf Eis gehaltenen One Shot ${ }^{\circledR}$ TOP10 chemisch kompetenten E. coli gegeben, vorsichtig gemischt und 30 min auf Eis inkubiert. Anschließend wurde ein Hitzeschock für $30 \mathrm{sec}$ bei $42^{\circ} \mathrm{C}$ durchgeführt und die Zellen sofort wieder auf Eis gelagert. Nachdem je $250 \mu \mathrm{l}$ vorgewärmtes SOC Medium zu den E. coli Zellen zugegeben worden war, wurden die Transformationsansätze für $1 \mathrm{~h}$ bei $37^{\circ} \mathrm{C}$ geschüttelt. Pro Transformationsansatz wurden $100 \mu$ l auf vorgewärmte LB-Platten, die zusätzlich Ampicillin zur Selektion enthielten, ausplattiert und bei $37^{\circ} \mathrm{C}$ über Nacht inkubiert. Als Negativkontrolle wurde eine Transformation mit Wasser anstelle des Klonierungsansatzes versehen und die Positivkontrolle wurde mit einem dem Kit beiliegenden Vektor anstelle des Klonierungsansatzes durchgeführt. Am nächsten Tag wurden die Platten auf Kolonien überprüft. Pro Platte wurden 10 Kolonien gepickt, in LB-Medium mit Ampicillin überführt und über Nacht bei $37^{\circ} \mathrm{C}$ geschüttelt. Am nächsten Tag erfolgte eine Plasmidisolierung mit dem GenElute ${ }^{\mathrm{TM}}$ Plasmid Mini Prep Kit nach Herstellerprotokoll (Sigma, Mannheim). Die isolierten Plasmide wurden mit den Restriktionsenzymen Hind III und Not I verdaut, in einem Agarosegel (siehe 2.2.20) aufgetrennt und unter UV-Licht auf die Anwesenheit des PARP-1-Genes überprüft. Von positiven E. coli Kolonien wurden Glycerinkulturen hergestellt, indem Übernachtkulturen 1:2 mit Glycerin versetzt und bei $-80^{\circ} \mathrm{C}$ gelagert wurden. Die isolierten Plasmide der positiven E. coli Kolonien wurden zur Transfektion von RAW 264.7 Makrophagen verwendet.

\section{Transfektion von RAW 264.7 Makrophagen}

Die Transfektion der RAW 264.7 Makrophagen erfolgte mit Hilfe des Metafectene Transfektionsreagenz. Dabei bildet das Reagenz zusammen mit der Plasmid-DNA einen DNA-Lipidkomplex, der sehr effizient in eukaryontische Zellen eingeschleust werden kann. Dazu wurden $0.5 \times 10^{5}$ RAW 264.7 Zellen in $1 \mathrm{ml}$ Medium in 12 LochPlatten ausgesät. Am nächsten Tag wurden $1.5 \mu \mathrm{g}$ Plasmid-DNA in $50 \mu \mathrm{l}$ RPMlMedium ohne Zusätze in einer Vertiefung einer 96 Loch-Platte gemischt und $4.5 \mu \mathrm{l}$ Metafectene Reagenz in $50 \mu$ RPMI-Medium ohne Zusätze in einer zweiten Vertiefung ebenfalls gemischt. Danach wurde der Metafectene / Medium-Mix zur Plasmid-DNA gegeben, vorsichtig gemischt und $15-20$ min bei RT inkubiert. 
Anschließend wurde der DNA-Lipidkomplex langsam zu den konfluenten RAW 264.7 Zellen getropft, vorsichtig gemischt und im Brutschrank bei $37^{\circ} \mathrm{C}$ für max. $8 \mathrm{~h}$ inkubiert. Anschließend wurde das Medium durch normales RAW 264.7 Kulturmedium ersetzt. Nach $48 \mathrm{~h}$ wurde wiederum ein Medienwechsel durchgeführt,

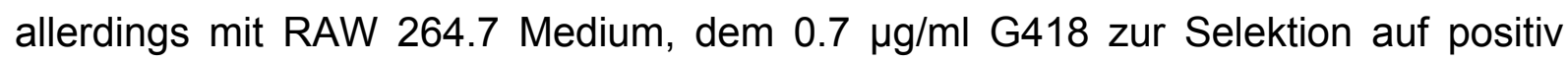
transfizierte Zellen beigefügt worden war. In den folgenden Tagen wurde täglich ein Medienwechsel mit G418-haltigem RAW 264.7 Medium durchgeführt, um abgestorbene Zellen zu entfernen. Nachdem sich aus einzelnen positiv transfizierten Zellen Kolonien gebildet hatten, wurde jede Kolonie vorsichtig in eine Vertiefung einer 24 Loch-Platte in G418-haltiges RAW 264.7 Medium überführt. Nachdem die Zellen konfluent gewachsen waren, wurden sie isoliert und eine Verdünnung hergestellt, so dass in $100 \mu \mathrm{l}$ Medium rechnerisch $0.5 \mathrm{bzw}$. 1 Zelle vorhanden waren. Je eine halbe 96 Loch-Platte pro Verdünnung wurde mit je $100 \mu \mathrm{l}$ pro Loch bestückt und für mehrere Wochen im Brutschrank inkubiert. Nach mehrmaligem Umsetzen der Zellen und erfolgreicher Anzucht in größeren Kultivierungsgefäßen, wurde sowohl die genomische DNA als auch die RNA isoliert und auf das Vorhandensein der zusätzlichen PARP-1-Kopie bzw. auf deren Transkription überprüft (siehe 2.2.17 21).

\subsubsection{Herstellung von UV-behandelten und Hitze-inaktivierten}

\section{T. gondii}

Um die Auswirkungen von Wirtszellinvasion und intrazellulärer Replikation auf die PARP-1-Inhibierung nach Infektion mit Toxoplasma gondii zu untersuchen, wurden frisch isolierte Parasiten $\left(1 \times 10^{8} / \mathrm{ml}\right)$ mit Hitze (SIBLEY et al., 1985) oder mit UV-Licht (ENDO et al., 1981) behandelt. Um die intrazelluläre Replikation der Parasiten zu verhindern, wurden sie $70 \mathrm{sec}$ in Zellkulturschalen UV-Licht von $254 \mathrm{~nm}$ ausgesetzt, wobei die UV-Lampe (NU-4KL Faust, Konrad Benda, Wiesloch) mit einem Abstand von $20 \mathrm{~cm}$ über der Zellkulturplatte aufgebaut wurde. Danach wurden die Parasiten zur Infektion von RAW 264.7 Zellen verwendet. Ein Immunfluoreszenztest (siehe unten), der $24 \mathrm{~h}$ und $48 \mathrm{~h}$ nach Infektion von Wirtszellen durchgeführt wurde, bestätigte die Replikationsinhibierung mittels UV-Licht.

Um die Wirtszellinvasion der Parasiten zu inhibieren, wurde die Parasitensuspension entweder für 30 min bei $60^{\circ} \mathrm{C}$ in einem Thermomixer (Modell 5436 Eppendorf, 
Hamburg) Hitze-behandelt oder abzentrifugiert und das Pellet $\left(1 \times 10^{8}\right.$ Parasiten) mind. $24 \mathrm{~h}$ bei $-20^{\circ} \mathrm{C}$ tiefgefroren. Die Parasiten wurden ebenfalls danach für Infektionsversuche verwendet. Auch bestätigte wiederum ein Immunfluoreszenztest die Inhibierung der Wirtszellinvasion.

\subsubsection{Herstellung von T. gondii-Lysat}

Toxoplasmen aus frisch lysierten L929 Kokulturen wurden von kontaminierenden L929 Zellen durch Zentrifugation bei $35 \mathrm{xg}$ für 5 min getrennt. Um die Wirtszellen möglichst vollständig zu entfernen, wurde die Parasitensuspension zusätzlich durch einen Filter mit $3 \mu \mathrm{m}$ Porengröße gegeben. Anschließend wurden die Parasiten bei $1.340 \mathrm{x} g$ für 10 min pelletiert und zweimal in sterilem PBS gewaschen. Nach einer weiteren Zentrifugation wurde das Parasitenpellet in $500 \mu \mathrm{l}$ bis $750 \mu \mathrm{l}$ PBS resuspendiert und jeweils dreimal in flüssigem Stickstoff eingefroren und im Wasserbad bei $37^{\circ} \mathrm{C}$ wieder aufgetaut. Die Parasitensuspension wurde jeweils zweimal auf Eis für 10 min mit Ultraschall (30\% Unterbrechungszyklus, Output Stufe 3) (Ultraschallgerät Cell Disruptor B15, Branson Sonifier, Dietzenbach) behandelt und dazwischen $20 \mathrm{~min}$ auf Eis ruhen gelassen. Nach einem anschließenden Zentrifugationsschritt bei $20.000 \times \mathrm{g}$ für $20 \mathrm{~min}$ bei $4^{\circ} \mathrm{C}$ wurde der Überstand abgenommen, mittels eines $0.20 \mu \mathrm{m}$ Spritzen-Filters steril filtriert und einer Proteinbestimmung mit dem BCA Protein Assay (Pierce, Rockford, USA) nach Herstellerprotokoll unterzogen. Das resultierende Pellet wurde in $500 \mu \mathrm{l}$ sterilem PBS resuspendiert. Sowohl der Überstand als auch das Pellet wurden bis zur weiteren Verwendung bei $-80^{\circ} \mathrm{C}$ tiefgefroren.

\subsubsection{T. gondii Membranfraktionierung}

$1 \times 10^{10} \mathrm{~T}$. gondii Tachyzoiten wurden aus frisch lysierten L929 Kokulturen isoliert und zweimal in sterilem PBS gewaschen. Die Parasiten wurden in $500 \mu \mathrm{l}$ PBS mit Proteinase-Inhibitor-Cocktail (Roche, Mannheim) (1:200) resuspendiert und jeweils dreimal in flüssigem Stickstoff eingefroren und im Wasserbad bei $37^{\circ} \mathrm{C}$ wieder aufgetaut. Die Parasitensuspension wurde bei $20.000 \times \mathrm{g}$ für 20 min bei $4^{\circ} \mathrm{C}$ zentrifugiert und das resultierende Pellet wurde einmal in PBS gewaschen. Das Pellet wurde in $500 \mu \mathrm{l}$ Carbonatpuffer resuspendiert und $30 \mathrm{~min}$ auf Eis inkubiert, wobei alle 10 min kräftig gemixt wurde. Nach einem weiteren Zentrifugationsschritt 
bei $20.000 \mathrm{xg}$ für $20 \mathrm{~min}$ bei $4^{\circ} \mathrm{C}$ wurde der Überstand (= S1) abgenommen und bei $20^{\circ} \mathrm{C}$ bis zur weiteren Verwendung tiefgefroren. Das Pellet wurde wiederum einmal in sterilem PBS gewaschen, in $500 \mu \mathrm{l} 8 \mathrm{M}$ Harnstoff-Extraktionspuffer resuspendiert und für $1 \mathrm{~h}$ bei $4^{\circ} \mathrm{C}$ geschüttelt. Dann wurde wieder bei $20.000 \times \mathrm{g}$ für 20 min bei $4^{\circ} \mathrm{C}$ zentrifugiert, der Überstand auf $1 \mathrm{M}$ Harnstoff mit $50 \mathrm{mM}$ Tris/HCl pH 8.0 verdünnt und in einer Centricon Säule (10 kDA Ausschlussporengröße) mittels Zentrifugation auf ca. $600 \mu \mathrm{l}$ eingeengt (= S2). Die Harnstoff-Fraktion wurde ebenfalls bis zur weiteren Verwendung eingefroren. Das Pellet wurde wieder in PBS gewaschen, in $1 \%$ Triton X-100 resuspendiert und $1 \mathrm{~h}$ auf Eis inkubiert. Der resultierende Überstand aus der anschließenden Zentrifugation wie oben angegeben (= S3) wurde wie die S1- und S2-Fraktion mittels Zugabe von Trichloressigsäure auf $10 \%$ Endkonzentration und Inkubation auf Eis für 30 min gefällt. Die Ansätze wurden wieder bei $20.000 \mathrm{xg}$ für $20 \mathrm{~min}$ bei $4^{\circ} \mathrm{C}$ zentrifugiert, um die präzipitierten Proteine zu pelletieren. Die Pellets wurden jeweils in $100 \mu \mathrm{PBS}$ resuspendiert und bis zur weiteren Verwendung bei $-20^{\circ} \mathrm{C}$ eingefroren. Das von S3 resultierende Pellet (= P1) wurde ein letztes Mal in PBS gewaschen und ebenfalls eingefroren (PRZYBORSKI et al., 2005). S1 - S3 sowie P1 wurden entweder mit Wirtszellen oder dem nukleären Lysat der Wirtszellen inkubiert oder direkt mittels SDS-PAGE aufgetrennt.

Carbonat-Extraktionspuffer

$0,1 \mathrm{M}$ Natriumcarbonat $\mathrm{pH} 11.0$

Harnstoff-Extraktionspuffer

$8 \mathrm{M}$ Harnstoff

$50 \mathrm{mM}$ Tris/HCl pH 8.0

\section{Triton X-100-Puffer}

$1 \%$ Triton $\mathrm{X}-100$ in $\mathrm{ddH}_{2} \mathrm{O}$

\subsubsection{Transwell-System}

Um feststellen zu können, ob ein von $T$. gondii sekretiertes Protein für die Inhibierung des PARP-1 Protein Levels verantwortlich ist, wurden $0.4 \mu \mathrm{m}$ TranswellZellkultureinsätze für 6 Loch-Platten (Corning/Costar, Bodenheim) verwendet. Auf

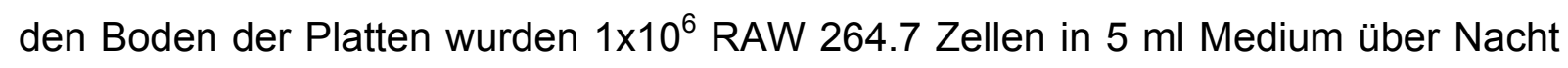
ausgesät. Am nächsten Tag wurden Toxoplasma gondii Tachyzoiten im Parasit-WirtVerhältnis von 4:1 auf die Transwell-Membran oder direkt zu den Zellen als Kontrolle 
gegeben, oder die Zellen blieben uninfiziert. Durch die Membran wird ein direkter Kontakt der Parasiten mit den Zellen verhindert, es können aber vom Parasiten sekretierte Moleküle durch die Membran diffundieren.

Nach $1 \mathrm{~h}$ erfolgte eine Gesamtproteinisolierung aus den RAW 264.7 Zellen (siehe 2.2.8) mit anschließender SDS-PAGE (siehe 2.2.10) und Western Blot Analyse (siehe 2.2.11).

\subsubsection{Präparation von Gesamtproteinextrakten infizierter und nicht-infizierter Wirtszellen}

Zellen wurden je nach Zelllinie entweder mit Zellschabern vom Boden der Petrischale abgekratzt oder mit EDTA und Trypsin vom Schalenboden gelöst. Nachdem die Zellen bei $400 \times \mathrm{g}$ abzentrifugiert worden waren, wurden sie in $1 \mathrm{ml}$ sterilem PBS resuspendiert und nach Anfärbung eines Aliquots mit Trypanblau in einer Neubauer Zählkammer gezählt. Anschließend wurden die Zellen mit einer Dichte von $1 \times 10^{6}$ Zellen pro $1 \mathrm{ml}$ in einem entsprechenden Volumen Lysepuffer resuspendiert und für $1 \mathrm{~h}$ auf Eis inkubiert. Die Zellsuspension wurde bei $20.000 \times \mathrm{g}$ für $10 \mathrm{~min}$ bei $4^{\circ} \mathrm{C}$ zentrifugiert, der Überstand wurde sofort im Verhältnis 5:1 mit $5 \times$ SDS-Probenpuffer versetzt und 5 min bei $99^{\circ} \mathrm{C}$ aufgekocht. Bis zur weiteren Verwendung in SDS-PAGE und Western Blot wurden die Proben bei $-20^{\circ} \mathrm{C}$ gefroren.

\begin{tabular}{ll}
\multicolumn{1}{c}{ Lysepuffer } & \\
$1 \%$ & Triton X-100 \\
$150 \mathrm{mM}$ & $\mathrm{NaCl}$ \\
$50 \mathrm{mM}$ & Tris, pH 8.0 \\
$50 \mathrm{mM}$ & $\mathrm{NaF}$ \\
$5 \mathrm{mM}$ & Natriumpyrophosphat \\
$1 \mathrm{mM}$ & PMSF \\
$10 \mu \mathrm{M}$ & Leupeptin \\
$5 \mu \mathrm{g} / \mathrm{ml}$ & Aprotinin \\
$1 \mathrm{mM}$ & $\mathrm{Na}_{3} \mathrm{VO}_{4}$ \\
$1 \mathrm{mM}$ & EDTA, pH 8.0 \\
& in dd $\mathrm{H}_{2} \mathrm{O}$
\end{tabular}




\subsubsection{Zellfreies in vitro System}

Um zu überprüfen, ob $T$. gondii die PARP-1-Proteinlevel auch in Wirtszellextrakten ohne funktionsfähige Transkription und Translation zu inhibieren vermag, wurden die nukleären Proteine aus RAW 264.7 Zellen isoliert (MARINOVICH et al., 1996). Hierfür wurden die Makrophagen mittels eines Zellschabers vom Boden der Zellkulturflaschen abgeschabt, bei $400 \times \mathrm{g}$ zentrifugiert und in sterilem PBS gewaschen. Anschließend wurden die Zellen in $1 \mathrm{ml}$ PBS resuspendiert, ein Aliquot mit Trypanblau angefärbt und in einer Neubauer Zählkammer gezählt. $3 \times 10^{7}$ RAW 264.7 Zellen wurden dann bei $15.300 \times \mathrm{g}$ für $30 \mathrm{sec}$ abzentrifugiert, in $2000 \mu \mathrm{l}$ hypotonem Lysepuffer aufgenommen und $15 \mathrm{~min}$ auf Eis inkubiert. Bevor das Zelllysat für $15 \mathrm{sec}$ stark gemixt wurde, wurden $125 \mu \mathrm{l}$ 10\% Nonidet P40 zugegeben und anschließend wieder bei 15.300 x g für $30 \mathrm{sec} z e n t r i f u g i e r t$. Das Pellet, welches die Nuklei enthielt, wurde in $250 \mu \mathrm{l}$ Puffer $\mathrm{C}$ resuspendiert und für $20 \mathrm{~min}$ bei $4^{\circ} \mathrm{C}$ geschüttelt. Nach einem abschließenden Zentrifugationsschritt bei $15.300 \times \mathrm{g}$ für 5 min befanden sich im Überstand die nukleären Proteine, die dann mit Parasiten oder dem Parasiten-Lysat inkubiert wurden. Bis zur weiteren Verwendung wurde das Zelllysat bei $-80^{\circ} \mathrm{C}$ tiefgefroren.

$\begin{array}{ll}\text { Lysepuffer } & \text { Puffer } \mathrm{C} \\ 10 \mathrm{mM} \mathrm{HEPES}, \mathrm{pH} 7.8 & 50 \mathrm{mM} \mathrm{HEPES}, \mathrm{pH} 7.8 \\ 10 \mathrm{mM} \mathrm{KCl} & 50 \mathrm{mM} \mathrm{KCl} \\ 2 \mathrm{mM} \mathrm{MgCl} 2 & 50 \mathrm{mM} \mathrm{NaCl} \\ 0,1 \mathrm{mM} \mathrm{EDTA} & 0,1 \mathrm{mM} \text { EDTA } \\ \text { Proteinase-Inhibitor-Cocktail }(1: 100) & \text { Proteinase-Inhibitor-Cocktail (1:100) } \\ & 10 \%(\mathrm{v} / \mathrm{v}) \text { Glycerin }\end{array}$

2.2.10 SDS-Polyacrylamid Gelelektrophorese (PAGE)

Um Proben nach ihrem Gehalt bestimmter Proteine zu vergleichen, wurden sie mittels SDS-PAGE aufgetrennt und entweder die Gesamtproteine durch Silberfärbung angefärbt oder spezifische Proteine durch Western Blot Analyse und Immunfärbung mittels Antikörper nachgewiesen.

Zunächst wurde ein 10\% Polyacrylamid Trenngel in eine vertikale Mini Protean 3 Gelkammer (BioRad, München) mit einem Abstand von $0.75 \mathrm{~mm}$ zwischen den 
Glasplatten gegossen und mit 1-Butanol überschichtet. Sobald das Gel auspolymerisiert war, wurde das Butanol entfernt, die Geloberfläche gründlich mit $\mathrm{ddH}_{2} \mathrm{O}$ gewaschen und ein 5\% Sammelgel aufgegossen, in das ein Probenkamm für 10 Proben eingesetzt wurde.

Die Proteinproben wurden mit SDS-Probenpuffer versetzt und für 5 min bei $99^{\circ} \mathrm{C}$ aufgekocht. Die Trennung der Proteine erfolgte mittels eines Probenpuffers bei 25 $\mathrm{mA}$ pro Gel für ungefähr $1 \mathrm{~h}$ in einer Gelkammer (Modell Mini-Protean III, BioRad, München). Ein Proteinstandard, der Prestained Protein Marker, wurde zum Größenvergleich in einer Spur des Gels parallel aufgetrennt.

10\% Tenngel

$0,94 \mathrm{ml} \quad 2 \mathrm{M}$ Tris $\mathrm{pH} 8.8$

$0,1 \mathrm{ml} \quad 10 \% \mathrm{SDS}$

$2,26 \mathrm{ml}$ Aqua bidest.

$1,67 \mathrm{ml} \quad 30 \%$ Acrylamid

$20 \mu \mathrm{l}$

$10 \mu \mathrm{l}$

$10 \%$ APS

TEMED
5\% Sammelgel

$0,625 \mathrm{ml} \quad 0,5 \mathrm{M} \mathrm{pH} 6.8$

$50 \mu \mathrm{l}$

$10 \%$ SDS

$1,38 \mathrm{ml}$ Aqua bidest.

$0,42 \mathrm{ml} \quad 30 \%$ Acrylamid

$10 \mu \mathrm{l} \quad 10 \%$ APS

$10 \mu \mathrm{l}$ TEMED

$20 \mu \mathrm{l} \quad$ Bromphenolblau
Elektrophoresepuffer

$25 \mathrm{mM} \quad$ Tris, $\mathrm{pH} 8.3$

$192 \mathrm{mM} \quad$ Glycin

$0,1 \% \quad$ SDS

\section{SDS-Probenpuffer}

$62,5 \mathrm{mM}$ Tris- $\mathrm{HCl}, \mathrm{pH} 6.8$

$10 \% \quad$ Glycerin

$32,5 \mathrm{mM}$ DTT

$2 \% \quad$ SDS

0,01\% Bromphenolblau

\subsubsection{Silberfärbung}

Die Silberfärbung nach SDS-PAGE diente dazu, das Gesamtproteinprofil anzufärben. Das Polyacrylamidgel wurde dazu nach dem Auftrennen der Proteine in einem Lichtgeschützten Behälter mit Fixierlösung 1 für 60 min bei RT fixiert. Anschließend wurde in Fixierlösung 2 bei RT über Nacht inkubiert. Am nächsten Morgen wurde dreimal je $30 \mathrm{~min}$ in demineralisiertem Wasser gewaschen. Danach wurde für $1 \mathrm{~h}$ bei RT in Silbernitratlösung inkubiert, in Entwicklerlösung bis zum Erscheinen der Banden gebadet und nach max. 4 min mit 0,05 M EDTA abgestoppt. Die Gele 
wurden entweder sofort in einer Gel-Dokumentationsanlage (BioDoc I| Digital Imaging System, Biometra, Göttingen) fotografiert oder zwischen zwei mit Wasser und einem Tropfen Glycerin befeuchteten Blättern Cellophan-Folie aufgespannt und trocknen gelassen.

\section{Fixierlösung 1}

$30 \% \quad$ Isopropanol

$10 \% \quad$ Essigsäure

in $\mathrm{dH}_{2} \mathrm{O}$
Fixierlösung 2

$0,5 \mathrm{M} \quad$ Natriumacetat

$0,2 \% \quad$ Natriumthiosulfat

$0,5 \% \quad$ Glutaraldehyd

$30 \% \quad$ Ethanol

in $\mathrm{dH}_{2} \mathrm{O}$

Entwicklerlösung

2,5\% Natriumcarbonat

$0,01 \% \quad$ Formaldehyd

in $\mathrm{dH}_{2} \mathrm{O}$

\subsubsection{Western Blot und Immunfärbung}

Nachdem Proteine mittels SDS-PAGE aufgetrennt worden waren, wurden sie im Semi Dry Blot Verfahren auf eine Nitrozellulosemembran (Hybond $E C L$ ) übertragen. Dazu wurde die so genannte "Sandwich-Methode" angewandt, bei dem die einzelnen Komponenten wie folgt in einem Semi-Dry Elektroblotter (Sartorius, Göttingen) übereinander geschichtet wurden:

\section{Anode}

6 Whatman Filterpapiere, getränkt in $0.3 \mathrm{M} \mathrm{Tris-HCl,} \mathrm{pH} 10.4$ und $20 \%$ Methanol

3 Whatman Filterpapiere, getränkt in $25 \mathrm{mM}$ Tris- $\mathrm{HCl}$, pH 10.4 und $20 \%$ Methanol

Nitrozellulosemembran

SDS-PAGE Gel

9 Whatman Filterpapiere, getränkt in 40 mM Aminocapronsäure, pH 7.6 und $20 \%$ Methanol

Kathode 
Die Proteine wurden mit $0.8 \mathrm{~mA}$ pro $\mathrm{cm}^{2}$ Gelfläche für $90 \mathrm{~min}$ übertragen. Das Anfärben der Membran mit Ponceau S Lösung für 2 min als Kontrolle, ob und wie gut die Proteine auf die Membran transferiert wurden und ob die Gesamtproteinmengen in jeder Spur etwa gleich waren. Die Hintergrundfärbung wurde durch Waschen in destilliertem Wasser entfernt.

Zum Nachweis spezifischer Proteinbanden mittels Immunfärbung wurden zunächst unspezifische Bindungsstellen durch Inkubation der Membran für $30 \mathrm{~min}$ in Blockierlösung abgesättigt. Nach fünf-minütigem Waschen in Waschlösung wurde für 1,5 h mit Primärantikörper (siehe unten) in Inkubationslösung inkubiert. Im Anschluss wurde dreimal mit Waschlösung für je 5 min gewaschen und danach mit entsprechendem Sekundärantikörper in Inkubationslösung für $1 \mathrm{~h}$ inkubiert. Nachfolgend wurde die Membran wieder dreimal in Waschlösung für je 5 min gewaschen und mit der ECL Nachweislösung nach Herstellerangaben inkubiert. Überschüssige Mengen an ECL-Lösung wurden entfernt und die Membran mit einer Plastikfolie ohne Luftblasenbildung abgedeckt. Der Nachweis erfolgte durch Auflegen eines Chemilumineszenz sensitiven Hyperfilm ECL auf die Membran. Die quantitative Auswertung der Bandenintensitäten erfolgte mittels der Dokumentatiosanlage BioDoc II Digital Imaging System (Biometra, Göttingen) und dem Programm Scan Pack 3. Um Unterschiede in der Proteinbeladung der einzelnen Proben auszugleichen, wurde als interner Standard Aktin angefärbt und die Bandenintensitäten auf Aktin normiert.

\begin{tabular}{lll} 
Blockierlösung & Waschlösung & Inkubationslösung \\
\cline { 2 - 3 } 5\% Magermilchpulver & $0.05 \%$ Tween-20 & $5 \%$ Magermilchpulver \\
$0.2 \%$ Tween & in PBS, pH 7.4 & $0.05 \%$ Tween-20 \\
$0.02 \% \mathrm{NaN}_{3}$ & & in PBS, pH 7.4 \\
in PBS, pH 7.4 & &
\end{tabular}




\begin{tabular}{|c|c|c|c|}
\hline Primärer Antikörper & Verdünnung & Sekundärer Antikörper & Verdünnung \\
\hline $\begin{array}{c}\text { Kaninchen } \\
\text { anti-Toxoplasma } \\
\text { (Serum) }\end{array}$ & $1: 2.000$ & $\begin{array}{l}\text { Peroxidase-konjugiertes } \\
\mathrm{F}\left(\mathrm{ab} \mathrm{b}^{\prime}\right)_{2} \text { Esel anti- } \\
\text { Kaninchen IgG }\end{array}$ & $1: 10.000$ \\
\hline $\begin{array}{c}\text { Kaninchen anti-T. } \\
\text { gondii-Katalase }\end{array}$ & $1: 500$ & $\begin{array}{l}\text { Peroxidase-konjugiertes } \\
F\left(a b^{\prime}\right)_{2} \text { Esel anti- } \\
\text { Kaninchen IgG }\end{array}$ & $1: 10.000$ \\
\hline $\begin{array}{l}\text { Maus anti-Aktin } \\
\text { (Klon C4) }\end{array}$ & $1: 10.000$ & $\begin{array}{l}\text { Peroxidase-konjugiertes } \\
\mathrm{F}\left(\mathrm{ab}^{\prime}\right)_{2} \text { Ziege anti-Maus } \\
\lg \mathrm{g}\end{array}$ & $1: 10.000$ \\
\hline $\begin{array}{c}\text { Maus anti-PARP } \\
\text { (Klon C2-10) }\end{array}$ & $1: 2.000$ & $\begin{array}{l}\text { Peroxidase-konjugiertes } \\
\mathrm{F}\left(\mathrm{ab}^{\prime}\right)_{2} \text { Ziege anti-Maus } \\
\lg \mathrm{G}\end{array}$ & $1: 10.000$ \\
\hline $\begin{array}{c}\text { Maus anti-SAG1 } \\
\text { (Klon DG52) }\end{array}$ & $1: 1.000$ & $\begin{array}{c}\text { Peroxidase-konjugiertes } \\
\mathrm{F}\left(\mathrm{ab}^{\prime}\right)_{2} \text { Ziege anti-Maus } \\
\lg \mathrm{G}\end{array}$ & $1: 10.000$ \\
\hline Maus anti-V5-Epitop & $1: 5.000$ & $\begin{array}{l}\text { Peroxidase-konjugiertes } \\
\mathrm{F}\left(\mathrm{ab}^{\prime}\right)_{2} \text { Ziege anti-Maus } \\
\lg \mathrm{g}\end{array}$ & $1: 10.000$ \\
\hline $\begin{array}{l}\text { Maus anti-Penta-His } \\
\lg G\end{array}$ & $1: 1.000$ & $\begin{array}{c}\text { Peroxidase-konjugiertes } \\
\mathrm{F}\left(\mathrm{ab}^{\prime}\right)_{2} \text { Ziege anti-Maus } \\
\lg \mathrm{G}\end{array}$ & $1: 10.000$ \\
\hline $\begin{array}{l}\text { Ziege anti-Aktin } \\
\text { (Klon I-19) }\end{array}$ & $1: 250$ & $\begin{array}{c}\text { Peroxidase-konjugiertes } \\
\mathrm{F}\left(\mathrm{ab}^{\prime}\right)_{2} \text { Esel anti-Ziege } \\
\lg \mathrm{g}\end{array}$ & $1: 10.000$ \\
\hline
\end{tabular}

Tab. 1: Verdünnung primärer und sekundärer Antikörper für Immunfärbung von Western Blots

\subsubsection{Immunfluoreszenzfärbung (IFT) und Mikroskopie}

Um die Auswirkung der Infektion von RAW 264.7 Zellen mit Toxoplasma gondii auf die PARP Proteinmenge auf Einzelzellebene zu untersuchen und um die Wirtszellinvasion bzw. -replikation des Parasiten zu bestimmen, wurde eine Immunfärbung der Zellen mit anschließender mikroskopischer Analyse durchgeführt. 
Auf runden Deckgläschen wurden zunächst $1 \times 10^{5}$ RAW 264.7 Zellen in 24 LochPlatten ausgesät. Am nächsten Tag erfolgte die Infektion mit frisch isolierten, vorbehandelten oder unbehandelten $T$. gondii Tachyzoiten (siehe 2.2.1.1) im ParasitWirt-Verhältnis von 4:1, Inkubation mit T. gondii-Lysat $(50 \mu \mathrm{g})$ (siehe 2.2.5), dem Pellet des $T$. gondii-Lysates oder die Zellen blieben als Kontrolle uninfiziert. Die Infektionszeit variierte je nach Fragestellung des Versuches zwischen $1 \mathrm{~h}$ und $48 \mathrm{~h}$. Danach wurden die Zellen zweimal in sterilem PBS gewaschen, für $1 \mathrm{~h}$ mit $4 \%$ Paraformaldehyd in $0.1 \mathrm{M}$ Natriumcacodylat $/ \mathrm{HCl}$, pH 7.4 bei $\mathrm{RT}$ fixiert und nochmals zweimal in sterilem PBS gewaschen. Im Anschluss wurden die Zellen für $10 \mathrm{~min}$ in $50 \mathrm{mM} \mathrm{NH}{ }_{4} \mathrm{Cl}$ in PBS inkubiert und danach einmal in PBS gewaschen. Mittels Inkubation bei RT für $1 \mathrm{~h}$ in $1 \%$ BSA in PBS wurden unspezifische Bindungsstellen blockiert und durch $0,1 \mathrm{mg} / \mathrm{ml}$ Saponin im Blockierungspuffer wurden die Zellen gleichzeitig permeabilisiert. Danach wurden die Deckgläschen für $1 \mathrm{~h}$ mit einem oder mehreren Antikörpern (siehe unten) bei RT inkubiert. Hierfür wurden die Deckgläschen mit der Zellseite in je einen Tropfen von $30 \mu \mathrm{l}$ Antikörper verdünnt in Blockierlösung gelegt. Nach dreimaligem Waschen in $0,1 \mathrm{mg} / \mathrm{ml}$ Saponin in PBS für je 10 min wurden die Deckgläschen für $1 \mathrm{~h}$ bei RT mit dem oder den entsprechenden Sekundärantikörpern in Blockierlösung, auf die gleiche Weise wie der Primärantiköper, inkubiert. Danach wurden die Zellen zuerst dreimal in $0,1 \mathrm{mg} / \mathrm{ml}$ Saponin in PBS für je 10 min gewaschen und danach einmal in PBS gewaschen. Um die Infektions- und Replikationsrate des Parasiten in den Wirtszellen bestimmen zu können, wurde die Gesamtzellpopulation bei Bedarf für $5 \mathrm{~min}$ in $5 \mu \mathrm{g} / \mathrm{ml}$ Propidiumiodid in PBS inkubiert, wodurch doppelsträngige Nukleinsäuren angefärbt wurden. Nach zweimaligem Waschen in PBS für je 5 min wurden die Deckgläschen kurz in demineralisiertem Wasser gewaschen, mit der Zellseite auf einem Objektträger in einem $10 \mu \mathrm{l}$ Tropfen Mowiol fixiert und über Nacht bei RT getrocknet. Bis zur Betrachtung mittels eines Leica TCS SP2 Konfokalmikroskops (Leica, Heidelberg) wurden die Deckgläschen bei $4^{\circ} \mathrm{C}$ im Kühlschrank gelagert. 


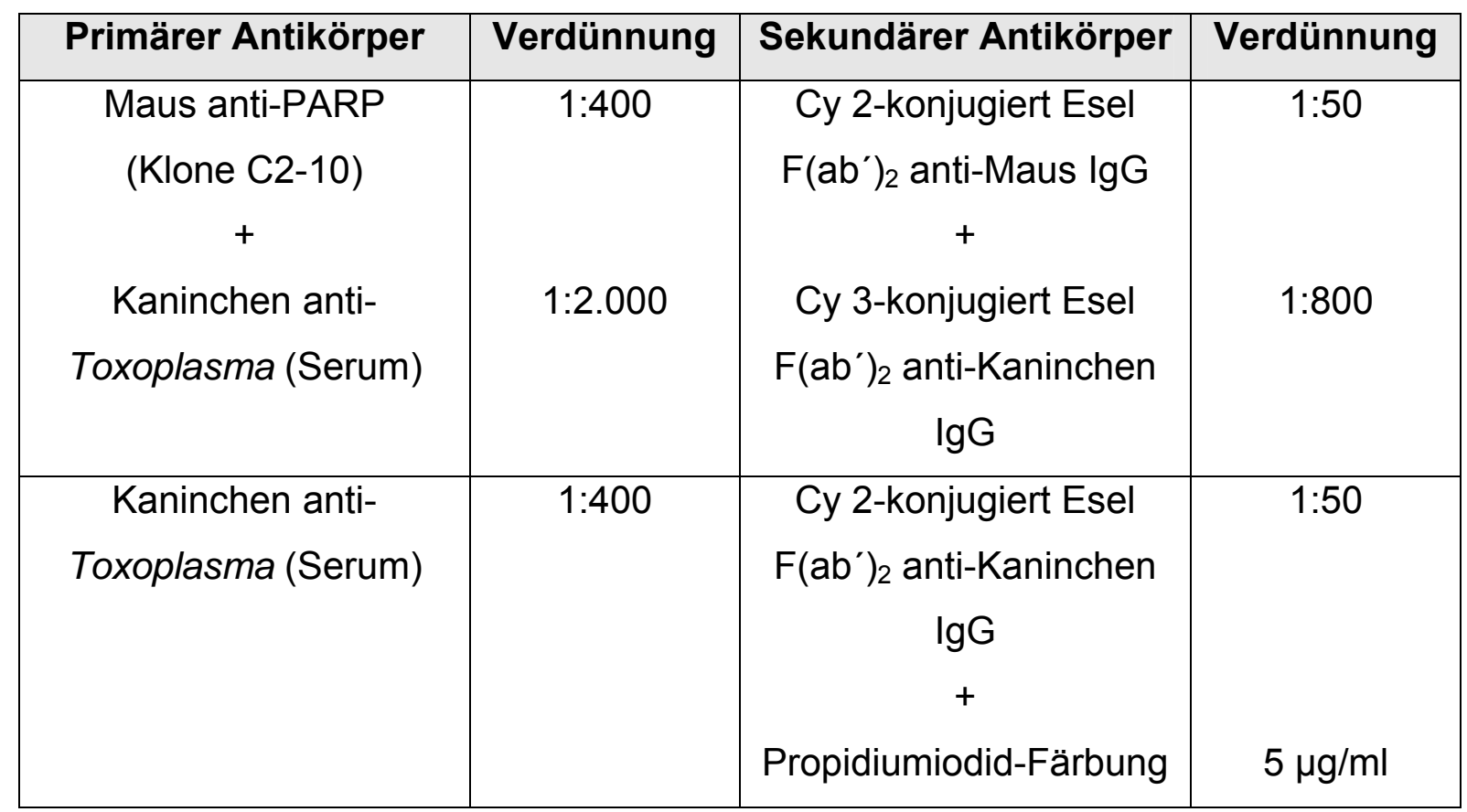

Tab. 2: Verdünnung primärer und sekundärer Antikörper für IFT

\subsubsection{Höchst-Färbung}

Mittels des Höchst-Farbstoffes 33258 können auf Einzelzellebene die morphologischen Veränderungen nach Apoptose-Stimulierung, z.B. mit Staurosporin, sichtbar machen. In apoptotischen Zellen zeigen sich dabei deutliche Abschnürungen des Zellkerns durch das stark kondensierte Chromatin, wo hingegen in nicht-apoptotischen Zellen eine gleichmäßige Färbung des Zellkerns nachweisbar ist. Hierfür wurden zunächst auf runden Deckgläschen 1×105 RAW 264.7 Zellen in 24 Loch-Platten ausgesät. Am nächsten Tag erfolgte die Infektion mit frisch isolierten $T$. gondii Tachyzoiten (siehe 2.2.1.1) im Parasit-Wirt-Verhältnis von 4:1, oder die Zellen blieben uninfiziert. $3.5 \mathrm{~h}$ vor Ablauf der Infektionsdauer folgte eine Behandlung mit 1 $\mu \mathrm{M}$ Staurosporin oder die Zellen blieben unstimuliert. 4, 11 und $24.5 \mathrm{~h}$ p.i. wurden die Deckgläschen zweimal mit sterilem PBS gewaschen und für $1 \mathrm{~h}$ mit $4 \%$ Paraformaldehyd in $0.1 \mathrm{M}$ Natriumcacodylat/HCl, $\mathrm{pH} 7.4$ bei RT fixiert. Nach erneutem Waschen in PBS wurden die Deckgläschen mit 50 ng/ml Höchst-Farbstoff 33258 in PBS mit $0.1 \mathrm{mg} / \mathrm{ml}$ Saponin bei $37^{\circ} \mathrm{C}$ für $1-1.5 \mathrm{~h}$ inkubiert. Die Deckgläschen wurden kurz mit demineralisiertem Wasser abgespült, in $10 \mu \mathrm{l}$ Mowiol auf Objektträgern fixiert und bis zur mikroskopischen Analyse bei $4^{\circ} \mathrm{C}$ gelagert. 


\subsubsection{Zell-ELISA zum Nachweis von PARP-Aktivität}

Um neben dem Proteinlevel von PARP-1 auch dessen Aktivität zu messen, wurde unter anderem ein Zell-ELISA eingesetzt (BAKONDI et al., 2002). Dazu wurden $8 \times 10^{4}$ RAW 264.7 Zellen pro Loch in einer 96-Lochplatte mit Flachboden in $200 \mu \mathrm{l}$ Medium für $48 \mathrm{~h}$ ausgesät. Anschließend erfolgte die Infektion mit $T$. gondii in einem Parasit zu Wirt-Verhältnis von 4:1 oder 8:1 für $1 \mathrm{~h}$ oder die Zellen blieben als Kontrolle uninfiziert. Als Kontrolle wurde ein Teil der infizierten oder nicht-infizierten Zellen zum Zeitpunkt 30 min nach Infektion mit 5 MM PJ34 [N-(6-oxo-5,6-dihydrophenanthridin-2$\mathrm{yl})-\mathrm{N}, \mathrm{N}$-dimethylacetamide. $\mathrm{HCl}$ ], einem PARP-Inhibitor, für weitere 30 min inkubiert. Nachdem die Zellen für 20 min mit verschiedenen Konzentrationen $(0 \mu \mathrm{M}, 125 \mu \mathrm{M}$, $250 \mu \mathrm{M}$ und $500 \mu \mathrm{M}$ ) Wasserstoffperoxid stimuliert wurden, wurde das Medium durch PARP Reaktionspuffer, der 6-Biotin-17-NAD enthielt, ersetzt und die Zellen für 30 min bei $37^{\circ} \mathrm{C}$ ohne $\mathrm{CO}_{2}$ inkubiert. Im Folgenden wurde mit eiskaltem $95 \%$ Ethanol für 10 min bei $-20^{\circ} \mathrm{C}$ fixiert. Nach 15 -minütiger Blockierung endogener Peroxidase mittels $0,5 \% \mathrm{H}_{2} \mathrm{O}_{2}$ in Methanol wurden die Zellen zweimal mit PBS gewaschen und unspezifische Bindungsstellen durch Inkubation mit Blockierpuffer (BP) für 30 min bei RT blockiert. Nachdem einmal für 5 min mit 0,1\% Triton X-100 in PBS gewaschen worden war, schloss sich eine Inkubation mit Peroxidase-gekoppeltem Streptavidin (1:1.000 in BP) für 30 min bei RT an. Danach wurde viermal für je 10 min mit 0,1\% Triton X-100 in PBS gewaschen. Zum Nachweis gebundener Peroxidase wurde ortho-Phenylendiaminpuffer direkt vor der Inkubation mit den Zellen mit $5 \mu \mathrm{l} 30 \%$ $\mathrm{H}_{2} \mathrm{O}_{2}$ auf 10 ml Puffer aktiviert. Nach erkennbarer Farbreaktion wurde mit $2 \mathrm{M} \mathrm{H}_{2} \mathrm{SO}_{4}$ abgestoppt und in einem Photometer bei einer Wellenlänge von 490/630 nm die Optische Dichte gemessen.

\begin{tabular}{|c|c|c|c|c|}
\hline \multicolumn{2}{|c|}{ PARP Reaktionspuffer } & & \multicolumn{2}{|c|}{ Blockierpuffer (BP) } \\
\hline $56 \mathrm{mM}$ & HEPES & & $0,1 \%$ & Triton $\mathrm{X}-100$ \\
\hline $28 \mathrm{mM}$ & $\mathrm{KCl}$ & & $1 \%$ & BSA \\
\hline $28 \mathrm{mM}$ & $\mathrm{NaCl}$ & & & in PBS \\
\hline $2 \mathrm{mM}$ & $\mathrm{MgCl}_{2}$ & & & \\
\hline $0,005 \%$ & Digitonin & & \multicolumn{2}{|c|}{ ortho-Phenylendiaminpuffer } \\
\hline $25 \mu \mathrm{M}$ & 6-Biotin-17-NAD ${ }^{+}$ & & $15 \mathrm{mM}$ & ortho-Phenylendiamin \\
\hline \multicolumn{2}{|c|}{ in $\mathrm{dH}_{2} \mathrm{O}, \mathrm{pH} 8.0$} & $0,1 \mathrm{M}$ & \multicolumn{2}{|c|}{$\mathrm{Na}-\mathrm{C}$ itratpuffer, pH 5.0} \\
\hline & & & $5 \mu \mathrm{l} / 10$ & $30 \% \mathrm{H}_{2} \mathrm{O}_{2}$ \\
\hline
\end{tabular}




\subsubsection{PARP-1 Aktivitätsdetektion auf Einzelzellebene}

Zur Bestimmung der PARP-1 Aktivität auf Einzelzellebene (BAKONDI et al., 2002)

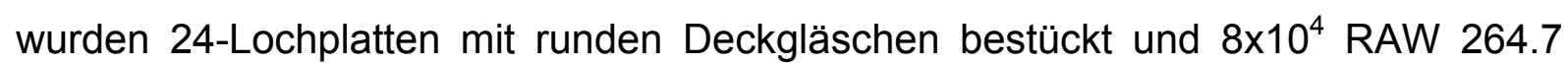
Zellen in $500 \mu \mathrm{l}$ Medium ausgesät. Nach $48 \mathrm{~h}$ wurde mit $T$. gondii im Parasit zu WirtVerhältnis von 4:1 oder 8:1 für $1 \mathrm{~h}$ infiziert, oder die Zellen blieben nicht infiziert. Ein Teil der Zellen wurde 30 min später für 30 min mit dem PARP-Inhibitor PJ34 (5 $\mu \mathrm{M})$ inkubiert. Anschließend wurden die Zellen wie unter 2.2.15 beschrieben für $20 \mathrm{~min}$ mit $\mathrm{H}_{2} \mathrm{O}_{2}(0 \mu \mathrm{M}, 125 \mu \mathrm{M}, 250 \mu \mathrm{M}$ und $500 \mu \mathrm{M})$ stimuliert, mit PARP Reaktionspuffer inkubiert und mit Ethanol fixiert. Nach 10 minütiger Inkubation in $10 \%$ TCA bei $-20^{\circ} \mathrm{C}$ wurden die Deckgläschen 10 min in PBS gewaschen und dann mit $0.5 \% \mathrm{H}_{2} \mathrm{O}_{2}$ in Methanol für 15 min die endogene Peroxidase blockiert. Nach zweimaligem Waschen mit PBS wurde mit Blockierpuffer für 30 min bei $37^{\circ} \mathrm{C}$ inkubiert und anschließend zweimal mit $0.1 \%$ Triton X-100 in PBS gewaschen. Anschließend wurde für $30 \mathrm{~min}$ bei RT mit Peroxidase-konjugiertem Streptavidin in Blockierungspuffer (1:250) inkubiert und viermal für 5 min mit $0.1 \%$ Triton X-100 in PBS gewaschen. Für die Farbreaktion wurden $6 \mathrm{mg}$ Nickel-DAB in $10 \mathrm{ml} 50 \mathrm{mM}$ Tris pH 7.6 gelöst und mit $10 \mu \mathrm{l} 30 \% \quad \mathrm{H}_{2} \mathrm{O}_{2}$ aktiviert. Die Zellen wurden $5 \mathrm{~min}$ in Färbelösung inkubiert und die Reaktion mit PBS gestoppt. Die Auswertung erfolgte mikroskopisch mit einem Leica DMR Mikroskop (Leica, Heidelberg).

\begin{tabular}{|c|c|c|c|}
\hline \multicolumn{2}{|c|}{ PARP Reaktionspuffer } & \multicolumn{2}{|c|}{ Blockierpuffer (BP) } \\
\hline $56 \mathrm{mM}$ & HEPES & $0,1 \%$ & Triton $\mathrm{X}-100$ \\
\hline $28 \mathrm{mM}$ & $\mathrm{KCl}$ & $1 \%$ & BSA \\
\hline $28 \mathrm{mM}$ & $\mathrm{NaCl}$ & & in PBS \\
\hline $2 \mathrm{mM}$ & $\mathrm{MgCl}_{2}$ & & \\
\hline $0,005 \%$ & Digitonin & \multicolumn{2}{|c|}{ Färbelösung } \\
\hline $25 \mu \mathrm{M}$ & 6-Biotin-17-NAD ${ }^{+}$ & $6 \mathrm{mg}$ & Nickel-DAB \\
\hline \multirow{2}{*}{\multicolumn{2}{|c|}{ in $\mathrm{dH}_{2} \mathrm{O}, \mathrm{pH} 8.0$}} & $10 \mathrm{ml}$ & $50 \mathrm{mM}$ Tris $\mathrm{pH} 7.6$ \\
\hline & & $10 \mu \mathrm{l}$ & $30 \% \mathrm{H}_{2} \mathrm{O}_{2}$ \\
\hline
\end{tabular}




\subsubsection{RNA Isolierung}

Zur Kontrolle der Genaktivität des stabil transfizierten PARP-1 Gens in RAW 264.7 Zellen, sowie zum direkten Vergleich der Expression von Genen (IL-6, TNF- $\alpha$, MIP2), für die PARP-1 als Koaktivator beschrieben wurde (HA et al., 2002; HASSA und

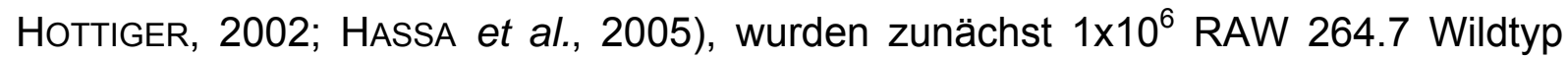
Zellen oder stabil transfizierte Zellen in 6 Loch-Platten ausgesät. Am nächsten Tag erfolgte je nach Fragestellung entweder direkt die RNA Isolierung mit Hilfe des GenElute Mammalian Total RNA Kits nach Herstellerprotokoll (Sigma). Im Falle des Expressionsvergleichs von Genen, für die PARP-1 als Koaktivator beschrieben wurde, wurden die Zellen vor der RNA-Isolierung für $1 \mathrm{~h}$ bzw. $3 \mathrm{~h}$ mit LPS $(1 \mu \mathrm{g} / \mathrm{ml}$ Endkonzentration) vorstimuliert, oder blieben unstimuliert. Anschließend wurden die Zellen mit frisch isolierten $T$. gondii Tachyzoiten (siehe 2.2.1.1) für $1 \mathrm{~h}$ infiziert oder blieben uninfiziert. Nach der Lyse und dem Zerkleinern der Zellfragmente mittels Shreddersäulchen wurde die RNA an die vom Hersteller mitgelieferten Säulchen gebunden, mehrfach gewaschen und in $100 \mu \mathrm{l}$ RNAse-freiem Wasser eluiert. Anschließend wurden die Proben in einem Photometer (Eppendorf BioPhotometer, Hamburg) auf ihren RNA-Gehalt gemessen. Dafür wurden je $10 \mu \mathrm{l}$ der RNA-Proben mit je $90 \mu$ LEPC-Wasser verdünnt (1:10) und bei einer Extinktion von 260/280 nm der RNA-Gehalt der Probe vom Photometer errechnet.

\subsubsection{Reverse Transkription}

Die isolierte RNA wurde durch reverse Transkription mit Hilfe des Qiagen Omniscript reverse transcription Kits in cDNA umgeschrieben. Hierfür wurde ein Reaktionsmix aus $2 \mu \mathrm{g}$ RNA, $1 \times$ RT Puffer, $0.5 \mathrm{mM}$ je dNTP, $1 \mu \mathrm{M}$ oligo-dT Primer, $10 \mathrm{U}$ RNase Inhibitor, $4 \mathrm{U}$ Omniscript Reverse Transcriptase (Endkonzentrationen) in RNasefreiem Wasser in einem Gesamtvolumen von $20 \mu \mathrm{l}$ pro Probe hergestellt. Anschließend wurden die Ansätze für $1.5-2 \mathrm{~h}$ bei $37^{\circ} \mathrm{C}$ inkubiert. Die resultierende cDNA wurde bei $-20^{\circ} \mathrm{C}$ bis zur weiteren Verwendung gelagert.

\subsubsection{DNA Isolierung}

Um genomische DNA (gDNA) aus Monolayer-Zellen zu isolieren wurde der DNA Isolierungskit von PeqLab nach Herstellerangaben verwendet. Hierfür wurden $0.5 \mathrm{x}$ $10^{7}$ transfizierte oder Wildtyp RAW 264.7 Zellen in $\varnothing 96 \mathrm{~mm}$-Zellkulturschalen in 
entsprechendem Medium ausgesät. Einen Tag später wurde das Kulturmedium der Zellen abgesaugt und die Zellen mittels $600 \mu \mathrm{l}$ TL-Puffer vom Boden der Kulturschale abgelöst. Nach Zugabe von $25 \mu \mathrm{OB}^{\mathrm{TM}}$ Protease wurde kräftig gemixt und für $1 \mathrm{~h}$ bei $55^{\circ} \mathrm{C}$ in einem Eppendorf Thermomixer geschüttelt. Anschließend wurden $660 \mu \mathrm{BL}-$ Puffer zugegeben und bei $70^{\circ} \mathrm{C}$ für 10 min inkubiert. Nach der Zugabe von $660 \mu \mathrm{l}$ absolutem Ethanol wurde die Zellsuspension auf die mitgelieferten Säulchen aufgetragen, um die DNA zu binden und bei $8.000 \times \mathrm{g}$ für 1 min zentrifugiert. Nach mehreren Waschschritten wurde die DNA eluiert, indem $200 \mu \mathrm{l} 70^{\circ} \mathrm{C}$ heißer Elutionspuffer $3 \mathrm{~min}$ auf den Säulchen inkubierten. Anschließend wurde bei $8.000 \mathrm{xg}$ für 1 min zentrifugiert. Die gDNA wurde bei $-20^{\circ} \mathrm{C}$ bis zum weiteren Gebrauch eingefroren.

\subsubsection{Polymerase-Ketten-Reaktion (PCR)}

Die PCR wurde verwendet um aus der hergestellten cDNA oder der isolierten gDNA mit Hilfe von spezifischen Primern bestimmte Gensequenzen zu amplifizieren. Dies diente als Nachweis der stabilen Transfektion der RAW 264.7 Zellen oder als Vorversuche für die Expressionsvergleiche der verschiedenen, von PARP-1 regulierten Gene durch quantitative RT-PCR.

Bei jedem PCR-Lauf wurde parallel eine Negativkontrolle mitgeführt, die anstelle der cDNA oder der gDNA dd $\mathrm{H}_{2} \mathrm{O}$ enthielt. Die Reaktionsansätze wurden in einem Gesamtvolumen von $50 \mu \mathrm{l}$ angesetzt und bestanden aus folgenden Komponenten:
$5 \mu \mathrm{l} \quad 10 \times$ PCR-Puffer
$1 \mu \mathrm{l} \quad$ dNTP (jeweils $10 \mu \mathrm{M}$ )
$0.5 \mu \mathrm{l} \quad$ Vorwärts-Primer $(50 \mu \mathrm{M})$
$0.5 \mu \mathrm{l} \quad$ Rückwärts-Primer $(50 \mu \mathrm{M})$
$0.3 \mu \mathrm{l} \quad$ Pfu- bzw. Taq-Polymerase $(5 \mathrm{U} / \mu \mathrm{l})$
$2-5 \mu \mathrm{l} \quad$ cDNA bzw. gDNA
dd $\mathrm{H}_{2} \mathrm{O}$ ad $50 \mu \mathrm{l}$

Die PCR wurde in einem T3 Thermocycler (Biometra, Göttingen) durchgeführt. Für jedes Primer-Paar wurden in Vorversuchen die optimalen Amplifikationsbedingungen wie Annealing-Temperatur und Zyklenzahl ausgetestet. 


\subsubsection{Agarose Gelelektrophorese}

PCR- und Klonierungsprodukte wurden in Agarosegelen elektrophoretisch nach ihrer Größe aufgetrennt. Hierfür wurden jeweils $18 \mu$ l Probe mit 10x Probenpuffer auf ein $1 \%$ Agarosegel in TAE Puffer, welches mit $1 \mu \mathrm{g} / \mathrm{ml}$ Ethidiumbromid versetzt worden war, aufgetragen und in TAE Puffer aufgetrennt. Zur genauen Größenbestimmung der PCR- und Klonierungsprodukte wurde eine 100 Basenpaar oder 1.000 Basenpaar (1kbp)-DNA Leiter, abhängig von der erwarteten Bandengröße der Proben, parallel mit aufgetrennt. Die Banden wurden mittels UV-Licht sichtbar gemacht und bei Bedarf mit einem BioDoc II Digital Imaging System und dokumentiert.

\section{$\underline{\text { TAE Puffer }}$}

$40 \mathrm{mM} \quad$ Tris

$1 \% \quad$ Essigsäure

$1 \mathrm{mM} \quad$ EDTA, $\mathrm{pH} 8.0$ 10x Probenpuffer

0.07\% Bromphenolblau

33\% Glycerin

$7 \% \quad$ SDS

in TES

\section{$\underline{\text { TES }}$}

$\begin{array}{ll}0.05 \mathrm{M} & \text { Tris } \\ 0.005 \mathrm{M} & \text { EDTA } \\ 0.05 \mathrm{M} & \mathrm{NaCl} \\ & \mathrm{pH} 8.0\end{array}$

\subsubsection{Quantitative RT-PCR mittels LightCycler}

Um die Expression verschiedener NF-KB- regulierter Gene, für die PARP-1 als Koaktivator beschrieben wurde (HASSA und HOTTIGER, 2002) in RAW 264.7 WildtypZellen sowie in den stabil transfizierten Zellen zu vergleichen, wurde eine quantitative RealTime-PCR im LightCycler durchgeführt. Hierfür wurden die Proben wie unter 2.2.17 und 2.2.18 beschrieben, hergestellt. Die resultierende cDNA wurde entweder 1:10 verdünnt oder unverdünnt eingesetzt. Für die quantitative $P C R$ wurde der LightCycler FastStart DNA Master ${ }^{\text {Plus }}$ SYBR Green I-Kit (Roche, Mannheim) 
verwendet. Pro Ansatz mit einem Endvolumen von $20 \mu \mathrm{l}$ wurden folgende Reagenzien verwendet:

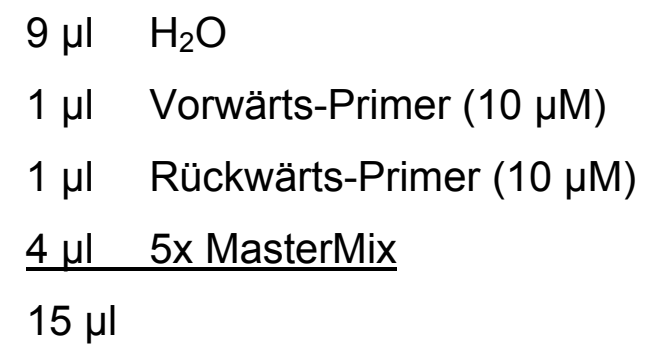

Dieser Mix wurde nach sorgfältigem Mischen in je eine LightCycler Kapillare gegeben und zuletzt $5 \mu \mathrm{l}$ cDNA ( $\approx 500 \mu \mathrm{g}$ bzw. $50 \mu \mathrm{g}$ cDNA) hinzu gefügt. Anschließend wurden die Kapillaren $15 \mathrm{sec}$ bei $700 \mathrm{x}$ g zentrifugiert. Die LightCycler Läufe wurden unter zuvor mit normaler PCR (siehe 2.2.20) optimierten Bedingungen durchgeführt. Für eine optimale Auswertung wurde eine relative Quantifikation mit externem Standard durchgeführt. Hierzu wurden von allen Proben 1:10 Verdünnungen hergestellt, die dann zusammen mit der unverdünnten Probe eine Standardkurve bildeten. Die daraus resultierende absolute Konzentration des Zielgenes, die mittels slope- und Intercept-Werten ermittelt worden war, wurde dann mit der Konzentration des Housekeeping-Gens Aktin ins Verhältnis gesetzt. Das resultierende Zielgen I Referenz Verhältnis stellt die Expression des Zielgens normiert mit dem Housekeeping-Gen Aktin dar. Folgende Formeln wurden hierfür verwendet:

$$
\begin{gathered}
\mathrm{E}=10^{(-1 / \text { Slope })} \mathrm{cp}=- \text { slope }+ \text { intercep } \\
\text { Normierte Expression }=\frac{E_{\text {Zielgen n.i. }}{ }^{c p \text { n.i. }} / E_{\text {Zielgen inf. }}{ }^{c p \text { inf }}}{E_{\text {Aktin n.i. }}^{\text {cp n.i. }} / E_{\text {Aktin inf. }}^{c \text { inf }}}
\end{gathered}
$$

\subsubsection{Caspase 3/7 Aktivitätstest}

Da bekannt ist, dass Toxoplasma gondii in infizierten Wirtszellen die Apoptose verhindern kann (GOEBEL et al., 1998) und weil PARP-1 Regulationsfunktionen während der Apoptose besitzt, sollte mittels eines Caspase 3/7 Aktivitätstests (KELLER et al., 2006) überprüft werden, ob die mit einer weiteren PARP-Kopie 
transfizierten RAW 264.7 Zellen auf Apoptose-Stimuli anders reagieren als Wildtypzellen. Hierfür wurden über Nacht $1 \times 10^{6}$ transfizierte oder Wildtyp RAW 264.7 Zellen in 6 Loch-Platten ausgesät und am nächsten Tag mit frisch isolierten T. gondii Tachyzoiten (siehe 2.2.1.1) im Parasit-Wirt-Verhältnis von 4:1 infiziert oder nicht infiziert belassen. Nach 0.5, 7.5 und $21 \mathrm{~h}$ p.i. wurden die Zellen mit Staurosporin, einem Apoptose-Induktor, für je $3.5 \mathrm{~h}$ inkubiert. Danach wurden die Zellen mit Hilfe eines Zellschabers vom Boden der Platte abgelöst, bei $400 \mathrm{x} \mathrm{g}$ für 5 min zentrifugiert und in $1 \mathrm{ml}$ sterilem PBS gewaschen. Das Zellpellet wurde anschließend in $50 \mu \mathrm{l}$ Lysepuffer resuspendiert und $15 \mathrm{~min}$ auf Eis inkubiert. Die Proben wurden anschließend bei $10.000 \times \mathrm{g}$ für $10 \mathrm{~min}$ zentrifugiert und die Überstände bis zur weiteren Verwendung bei $-80^{\circ} \mathrm{C}$ aufbewahrt. Die Spaltung des Caspase $3 / 7$ spezifischen Substrates DEVD-AMC wurde anschließend in Triplikaten wie folgt gemessen. Zu $10 \mu \mathrm{l}$ Zelllysat wurden $90 \mu \mathrm{l}$ des Spaltungspuffers gegeben und bei $37^{\circ} \mathrm{C}$ über $1 \mathrm{~h}$ alle $5 \mathrm{~min}$ in einem Victor $\mathrm{V}$ Multifunktionsplattenmessgerät die Spaltung des Substrates anhand der Fluoreszenzzunahme bei einer Anregungswellenlänge von $380 \mathrm{~nm}$ und einer Emissionswellenlänge von $460 \mathrm{~nm}$ aufgezeichnet. Die Fluoreszenzzunahme über die Zeit war dabei der Substratspaltung und damit der Caspaseaktivität proportional. Für die Auswertung wurde aus dem Mittelwert der Triplikate die absolute Fluoreszenzzunahme bestimmt.

$\begin{array}{ll}\text { Lysepuffer (NP-40 Puffer) } & \text { Spaltungspuffer } \\ 150 \mathrm{mM} \mathrm{NaCl} & 50 \mathrm{mM} \mathrm{NaCl} \\ 50 \mathrm{mM} \mathrm{Tris-HCl} & 10 \mathrm{mM} \mathrm{HEPES}, \mathrm{pH} 7.0 \\ 1 \% \text { Nonidet P40 } & 40 \mathrm{mM} \mathrm{B-Glycerophosphat} \\ \mathrm{pH} 8.0 & 2 \mathrm{mM} \mathrm{Mg} \mathrm{Cl}^{-} \\ 1: 25 \text { Proteinase-Inhibitor-Cocktail } & 5 \mathrm{mM} \mathrm{EGTA} \\ & 0.1 \mathrm{mg} / \mathrm{ml} \mathrm{BSA} \\ & 0.1 \% \text { CHAPS } \\ & 10 \mu \mathrm{M} \mathrm{Ac-DEVD-AMC}\end{array}$

\subsubsection{4 ß-Galaktosidase-Assay}

Der ß-Galaktosidase-Assay sollte durch den Einsatz von ß-Galaktosidasetransfizierte T. gondii (SEeber und Boothroyd, 1996; MCFADDEN et al., 1997) photometrisch zeigen, ob es einen Unterschied in Infektions- und Replikationsrate 
zwischen den Wildtyp RAW 264.7 Zellen und den mit PARP-1 transfizierten Zellen gab. Hierzu wurden $1 \times 10^{5}$ RAW 264.7 Zellen (Wildtyp und Transfektanten) in $100 \mu \mathrm{l}$ RAW 264.7 Medium in 96 Loch-Platten über Nacht in Triplikaten ausgesät. Am nächsten Tag wurden die Zellen für $1 \mathrm{~h}$ mit frisch isolierten Tachyzoiten des Stammes Toxoplasma gondii RH/HXGPRT/Sag1/lacZ infiziert oder verblieben uninfiziert. Anschließend wurde das Medium durch frisches ersetzt. Nach 4, 24 bzw. $48 \mathrm{~h}$ wurden die Zellen für 20 min bei RT fixiert. Danach wurde einmal mit HBSS gewaschen und für 15 - 60 min die Reaktionslösung zu den Zellen gegeben. Die Farbreaktion wurde photometrisch bei $37^{\circ} \mathrm{C}$ wurde anschließend bei einer Wellenlänge von $570 \mathrm{~nm}$ photometrisch gemessen.

$\begin{array}{ll}\text { Fixierlösung }(25 \mathrm{ml}) \\ 2.7 \mathrm{ml} & 37 \% \mathrm{FA} \\ 1.25 \mathrm{ml} & 5 \mathrm{M} \mathrm{NaCl} \\ 200 \mu \mathrm{l} & 3 \mathrm{~N} \mathrm{NaOH} \\ 20.85 \mathrm{ml} & \text { HBSS }\end{array}$

\begin{tabular}{ll}
\multicolumn{2}{l}{ Reaktionslösung $(10 \mathrm{ml})$} \\
$100 \mu \mathrm{l}$ & $10 \%$ Triton X-100 \\
$10 \mu \mathrm{l}$ & $100 \mathrm{mM} \mathrm{CPRG}$ \\
$50 \mu \mathrm{l}$ & $1 \mathrm{M} \mathrm{MgCl}_{2}$ \\
& ad $10 \mathrm{ml}$ with HBSS
\end{tabular}

\subsubsection{Statistik}

Für die statistische Auswertung der Versuche wurden Mittelwerte \pm Standardfehler des Mittelswerts von mind. 3 unabhängigen Versuchen verwendet.

Für die statistische Auswertung der IFTs und der Höchst-Färbungen wurden jeweils mindestens 500 Zellen pro Ansatz gezählt und die Mittelwerte \pm Standardfehler des Mittelswerts von mindestens drei unabhängigen Versuchen verwendet.

Bei photometrischen Auswertungen wurden pro Ansatz die Mittelwerte der MehrfachAnsätze von 3 unabhängigen Versuchen gemittelt und davon Mittelwerte \pm Standardfehler des Mittelswerts dargestellt.

Der Student's t-Test wurde verwendet, um Unterschiede zwischen experimentellen Gruppen auf statistische Signifikanz zu prüfen. P-Werte kleiner als 0.05 wurden als statistisch signifikant beurteilt. 


\section{Ergebnisse}

\subsection{Verminderung der PARP-1-Proteinlevel durch T. gondii}

Untersuchungen zur Inhibierung der Wirtszellapoptose durch $T$. gondii zeigen, dass der Parasit sowohl in Zellen, die mit einem Apoptose-Stimulus inkubiert werden, als auch in unbehandelten Zellen eine Abnahme des PARP-1-Proteinlevels verursachen (Goebel et al., 2001). Um die Bedeutung dieser bisher wenig untersuchten Wirtzellmodulation für die Parasit-Wirt-Interaktion zu untersuchen, sollte zunächst eine genauere Charakterisierung der PARP-1-Inhibierung erfolgen. Nach Infektion mit $T$. gondii Tachyzoiten konnte dabei unter anderem in verschiedenen humanen und murinen Wirtszelllinien eine Inhibierung des PARP-1-Proteinlevels beobachtet werden.

\subsubsection{PARP-1-Inhibierung in RAW 264.7 Zellen}

In murinen RAW 264.7 Makrophagen/Monocyten wurden nach Infektion mit Tachyzoiten des Maus-avirulenten $T$. gondii Stammes NTE Gesamtzellextrakte auf den PARP-1-Proteinlevel mittels SDS-PAGE und Western Blot überprüft. Es zeigte sich eine starke Inhibierung der Expression von PARP-1 um mehr als $90 \%$ innerhalb weniger Minuten nach Infektion mit den Parasiten (Abb. 3A). Der verwendete monoklonale PARP-1 Antikörper C2-10 erkennt dabei sowohl das $113 \mathrm{kDa}$ Gesamtprotein PARP-1 als auch ein Spaltprodukt mit der Größe von 89 kDa, das während der Apoptose durch Caspase-vermittelte Proteolyse auftritt. Da nach Infektion von RAW 264.7 Zellen mit T. gondii kein Spaltprodukt von PARP-1 mit 89 kDa oder einem anderen Molekulargewicht auftrat (Abb. 3B), konnte eine parasiteninduzierte Spaltung von PARP-1 wie im Verlauf der Apoptose ausgeschlossen werden. Eine Kontrollfärbung des Western Blots mit einem Antikörper gegen Aktin zeigte, dass in allen Spuren der SDS-PAGE die gleichen Mengen an Gesamtprotein aufgetragen worden waren (Abb. 3A und 3B). Semiquantitative Analysen von PARP$1 \mathrm{im}$ Verhältnis zu Aktin ergaben, dass der PARP-1-Gehalt nach $1 \mathrm{~h}$ Infektionszeit um etwa 75\% reduziert war (Abb. 3B). Da 8 - 12 h nach Infektion der PARP-1Proteinlevel wieder auf etwa 55\% anstieg, handelte es sich insgesamt allerdings um 
A
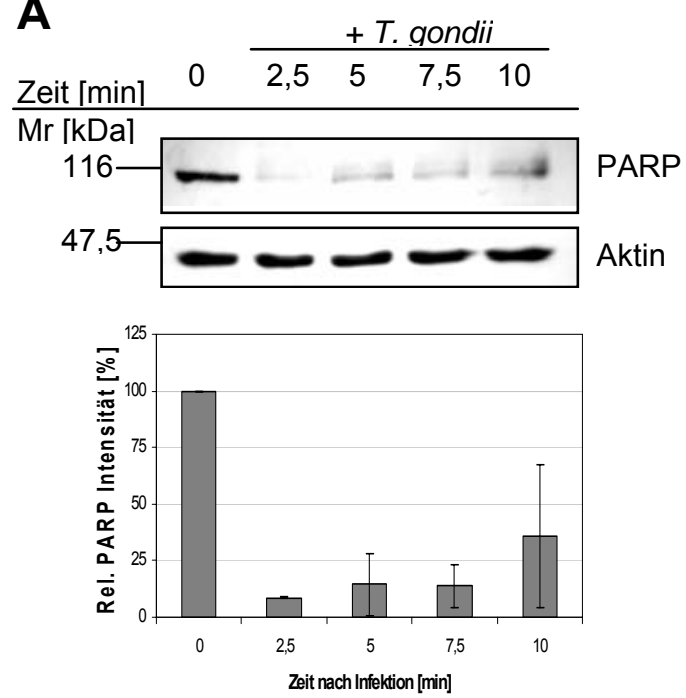

C
T. gondii 1 h p.i.

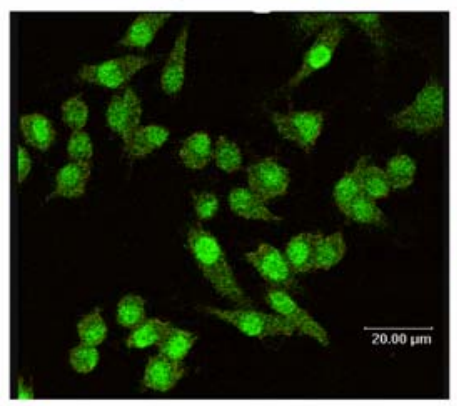

B
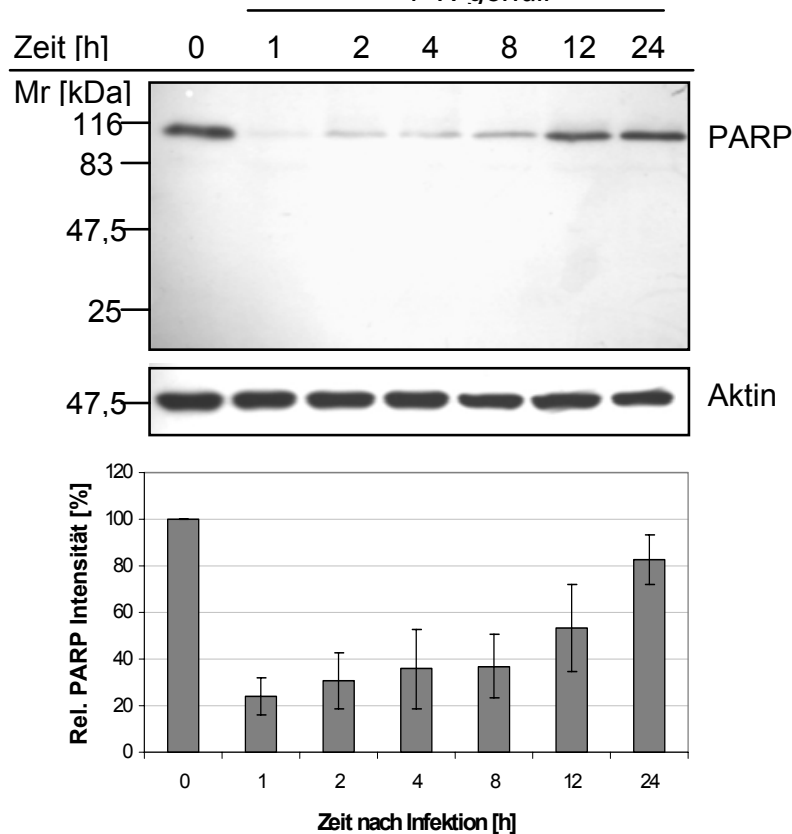

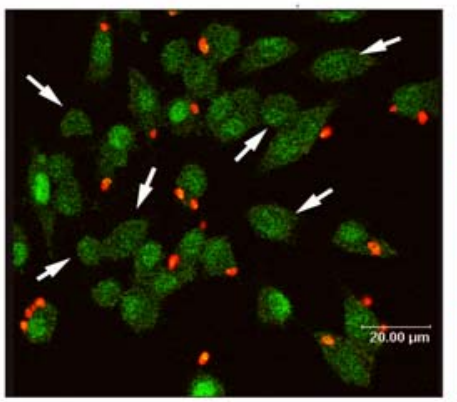

T. gondii 24 h p.i.

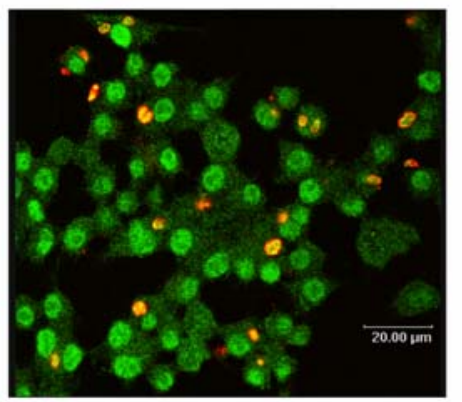

Abb. 3: PARP-1-Inhibierung in RAW 264.7 Monocyten/Makrophagen nach Infektion mit T. gondii.

(A) und (B) RAW 264.7 Monocyten/Makrophagen wurden für unterschiedliche Zeiten im Parasit-WirtVerhältnis von 4:1 mit Tachyzoiten des NTE Stammes von T. gondii infiziert oder blieben nichtinfiziert. Ein Gesamtproteinextrakt der RAW 264.7 Zellen wurde durch SDS-PAGE aufgetrennt und auf Nitrozellulosemembran übertragen. PARP-1 und Aktin wurden mittels entsprechender Primärantikörper und Meerrettichperoxidase-gekoppelter Sekundärantikörper durch „enhanced chemiluminescence" sichtbar gemacht. Die Graphen stellen die densitometrische Auswertung der Western Blots dar, dazu wurden jeweils die relativen PARP-Intensitäten berechnet (PARP/Aktin $x$ 100). Die PARP-Intensität zum Zeitpunkt 0 wurde als 100\% definiert und alle anderen Werte im Verhältnis dazu bestimmt. Die Balken entsprechen dem Mittelwert von mindestens drei unabhängigen Versuchen, die Fehlerbalken stellen den Standardfehler $( \pm)$ des Mittelwertes dar. Mr: Molekulargewichtsmarker (C) RAW 264.7 Monocyten/Makrophagen wurden auf Deckgläschen ausgesät und für unterschiedliche Zeiten im Parasit-Wirt-Verhältnis von 4:1 mit Tachyzoiten des NTE Stammes von T. gondii infiziert oder blieben nicht-infiziert. Durch Immunfluoreszenzfärbung wurden PARP-1 und T. gondii Tachyzoiten mittels spezifischer Primärantikörper und Cy-2-konjugiertem (PARP-1: grüne Fluoreszenz) oder Cy-3-konjugiertem ( $T$. gondii: rote Fluoreszenz) Sekundärantikörper sichtbar gemacht. Die Proben wurden mikroskopisch mit einem Leica TCS SP2 Konfokalmikroskop ausgewertet. Weiße Pfeile: Nicht infizierte Zellen, die deutlich verminderte PARP1-Proteinlevel aufweisen sind zum Teil mit einem weißen Pfeil markiert. P.i.: Nach Infektion (post infectionem) 
eine transiente Verminderung von PARP-1 nach Infektion mit $T$. gondii. Tatsächlich war nach $24 \mathrm{~h}$ Infektion der PARP-1-Proteinlevel nur geringfügig niedriger als in nicht-infizierten Kontrollen (Abb. 3B).

Diese Ergebnisse konnten auch auf Einzelzellebene mittels Immunfluoreszenztest bestätigt und erweitert werden. In einer nicht-infizierten Kultur wurde PARP-1 wie erwartet hauptsächlich im Zellkern exprimiert, während im Zytoplasma nur eine schwache Fluoreszenz auftrat (Abb. 3C). Nach $1 \mathrm{~h}$ Infektion mit $T$. gondii war PARP1 dagegen nur schwach in Zellkernen nachweisbar und es war keine Umverteilung von PARP-1 z.B. ins Zytosol oder in andere Zellkompartimente festzustellen (Abb. 3C). Außerdem zeigte sich, dass nicht nur in parasit-positiven Zellen, sondern auch in parasit-negativen Zellen einer infizierten Kultur PARP-1 inhibiert war (Abb. 3C). 24 h nach Infektion mit $T$. gondii exprimierten RAW 264.7 Zellen dagegen nukleäres PARP-1 wie nicht-infizierte Kontrollzellen (Abb. 3C).

Da die vorhergehenden Experimente gezeigt hatten, dass PARP-1 unabhängig von einer Wirtszellinvasion durch $T$. gondii vermindert wird (Abb. $3 C$ ), wurde in einer weiteren Versuchsreihe der Einfluss der Infektionsdosis auf die PARP-1-Proteinlevel untersucht. Dazu wurden RAW 264.7 Wirtszellen für $1 \mathrm{~h}$ in unterschiedlichen ParasitWirt-Verhältnissen mit Tachyzoiten des Maus-avirulenten T. gondii Stammes NTE infiziert. Western Blot Analysen zeigten, dass der Parasit den zellulären Gehalt von PARP-1 in den Wirtszellen dosisabhängig verminderte, da mit zunehmender Parasitenanzahl PARP-1 kontinuierlich abnahm (Abb. 4). Bereits bei einem Parasit zu Wirtszellverhältnis von 0.5:1 wurde PARP-1 um durchschnittlich $20 \%$ vermindert, bei einem Parasit zu Wirtszellverhältnis von $4: 1$ sogar durchschnittlich um $80 \%$. Aufgrund der starken Hemmung von PARP-1 bei einer Infektionsdosis von 4:1 und der relativ geringen weiteren Reduzierung bei höheren Infektionsdosen wurden die folgenden Versuche meist bei einem Parasit zu Wirtszellverhältnis von 4:1 durchgeführt. Zusammenfassend zeigten diese Experimente deutlich, dass eine Infektion mit $T$. gondii in vitro dosisabhängig zu einer starken aber transienten Erniedrigung der PARP-1 Level seiner Wirtszellen führte, die unabhängig von einer Wirtszellinvasion stattfand. 


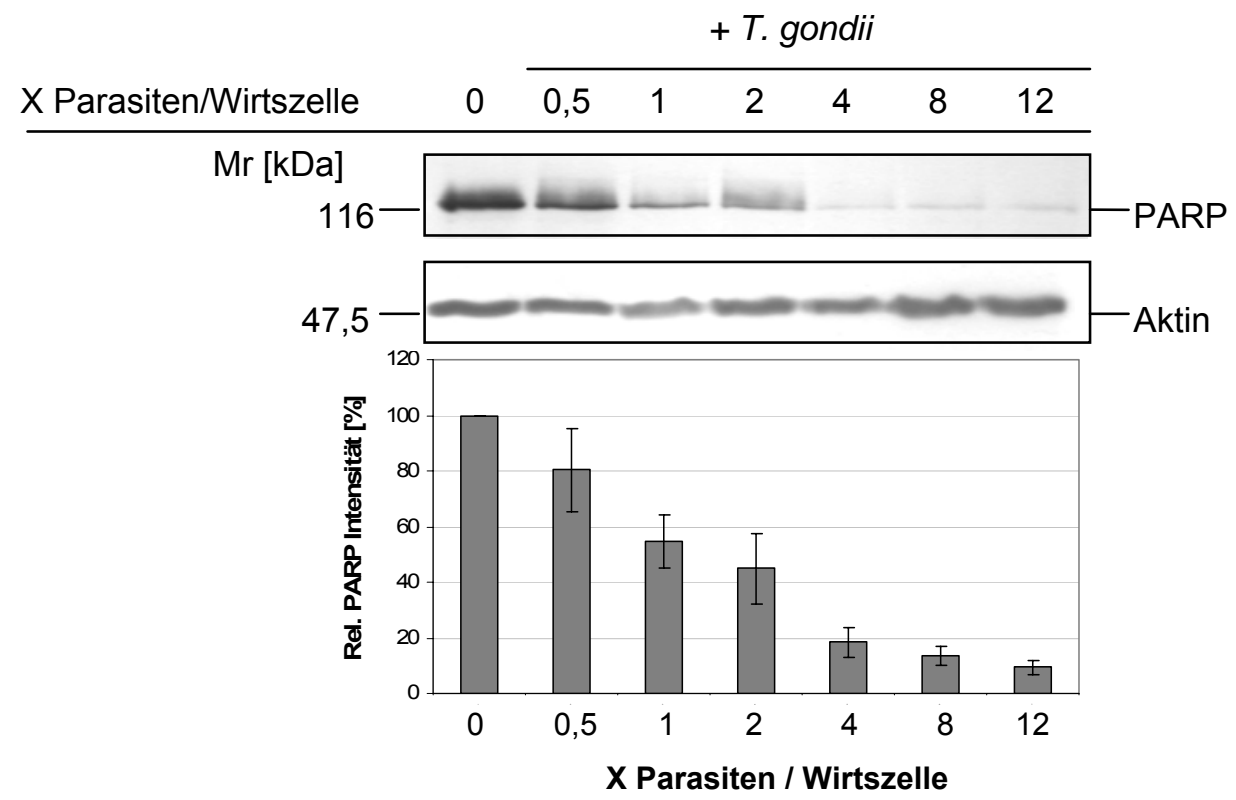

Abb. 4: Die PARP-1-Inhibierung in Wirtszellen durch $T$. gondii ist von der Infektionsdosis abhängig.

RAW 264.7 Monocyten/Makrophagen wurden für $1 \mathrm{~h}$ in unterschiedlichen Parasit-Wirt-Verhältnissen mit Tachyzoiten des NTE-Stammes von $T$. gondii infiziert oder blieben nicht-infiziert. Gesamtproteinextrakte der Wirtszellen wurden durch SDS-PAGE aufgetrennt und auf Nitrozellulosemembran übertragen. PARP-1 und Aktin wurden mittels entsprechender Primärantikörper und Meerrettichperoxidase-gekoppelter Sekundärantikörper durch „enhanced chemiluminescence" sichtbar gemacht. Der Graph stellt die densitometrische Auswertung der Western Blots dar, dazu wurden jeweils die relativen PARP-Intensitäten berechnet (PARP/Aktin x 100). Die PARP-Intensität zum Zeitpunkt 0 wurde als 100\% definiert und alle anderen Werte im Verhältnis dazu bestimmt. Die Balken entsprechen dem Mittelwert von drei unabhängigen Versuchen, die Fehlerbalken stellen den Standardfehler ( \pm ) des Mittelwertes dar. Mr: Molekulargewichtsmarker

\subsubsection{PARP-1-Inhibierung nach T. gondii-Infektion von murinen Fibroblasten}

Neben Monocyten bzw. Makrophagen werden Fibroblasten als wichtiger Wirtszelltyp von $T$. gondii angesehen. Um zu überprüfen, ob eine Infektion mit $T$. gondii den Proteingehalt von PARP-1 auch in diesem Zelltyp reduziert, wurden Gesamtproteinextrakte von murinen NIH/3T3 Fibroblasten mittels SDS-PAGE und Western Blot untersucht. Dazu wurden NIH/3T3 Fibroblasten im Parasit-WirtVerhältnis von 4:1 für unterschiedliche Zeiten mit frisch isolierten Tachyzoiten des Maus-avirulenten T. gondii Stammes NTE infiziert. Ähnlich wie bei murinen RAW 264.7 Makrophagen/Monocyten (Abb. 5A) war auch bei murinen NIH/3T3 Fibroblasten der PARP-1-Proteinlevel nach Infektion mit $T$. gondii erniedrigt (Abb. 5B). Allerdings unterschied sich der zeitliche Verlauf der PARP-1-Verminderung nach 
Infektion zwischen Monocyten/Makrophagen einerseits und Fibroblasten andererseits deutlich. So wurde in murinen Fibroblasten $1 \mathrm{~h}$ nach Infektion noch durchschnittlich 65\% des PARP-1 Gehaltes nicht-infizierter Kontrollen nachgewiesen (Abb. 5B), wohingegen RAW 264.7 Zellen zu diesem Zeitpunkt nur durchschnittlich etwa $30 \%$ der PARP-1 Proteinmenge von Kontrollzellen enthielten (Abb. 5A). Der PARP-1 Gehalt war in NIH/3T3 Fibroblasten $12 \mathrm{~h}$ nach Infektion am stärksten gehemmt, als auch in diesem Zelltyp durchschnittlich nur noch etwa 30\% des PARP1-Proteinlevels nicht-infizierter Kontrollen nachgewiesen wurden (Abb. 5B). Mit zunehmender Infektionsdauer stieg der PARP-1-Gehalt dann wie bereits bei Monocyten/Makrophagen beobachtet auch in murinen Fibroblasten wieder deutlich an (Abb. 5B).

A

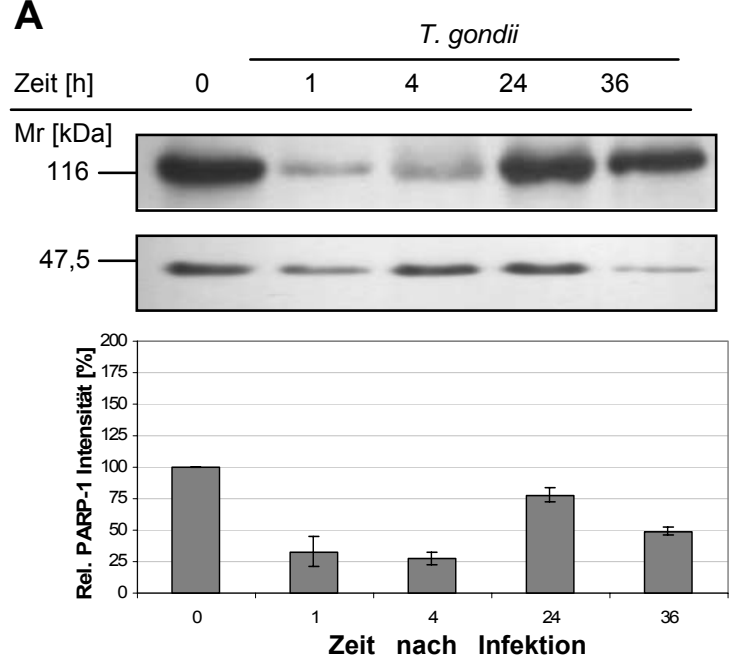

B

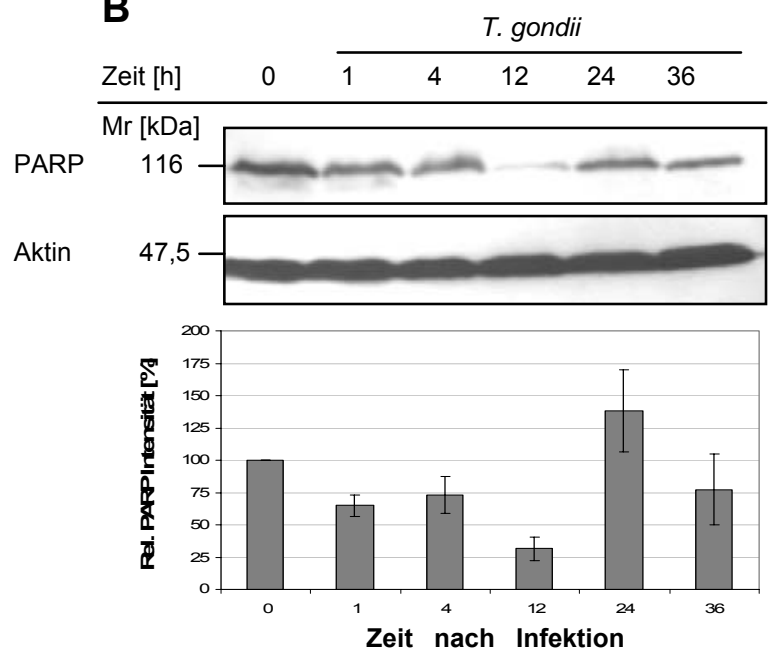

Abb. 5: PARP-1-Inhibierung in unterschiedlichen murinen Zelltypen nach Infektion mit $T$. gondii.

RAW 264.7 Monocyten/Makrophagen (A) und NIH 3T3 Fibroblasten (B) wurden im Parasit-WirtVerhältnis von 4:1 für unterschiedliche Zeiten mit Tachyzoiten des NTE-Stammes von $T$. gondii infiziert oder blieben nicht-infiziert. Gesamtproteinextrakte der Wirtszellen wurden durch SDS-PAGE aufgetrennt und auf Nitrozellulosemembran übertragen. PARP-1 und Aktin wurden mittels entsprechender Primärantikörper und Meerrettichperoxidase-gekoppelter Sekundärantikörper durch „enhanced chemiluminescence" sichtbar gemacht. Der Graph stellt die densitometrische Auswertung der Western Blots dar, dazu wurden jeweils die relativen PARP-Intensitäten berechnet (PARP/Aktin $x$ 100). Die PARP-Intensität zum Zeitpunkt 0 wurde als $100 \%$ definiert und alle anderen Werte im Verhältnis dazu bestimmt. Die Balken entsprechen dem Mittelwert von mindestens drei unabhängigen Versuchen, die Fehlerbalken stellen den Standardfehler $( \pm)$ des Mittelwertes dar. Mr: Molekulargewichtsmarker 
Grundsätzlich führte $T$. gondii also auch in murinen Fibroblasten zu einer Inhibierung des PARP-1-Proteinlevels, die sich im zeitlichen Verlauf jedoch von der in Monocyten/Makrophagen unterschied.

\subsubsection{PARP-1-Inhibierung nach T. gondii-Infektion von humanen Zellen}

Um zu überprüfen, ob es sich bei der Inhibierung des PARP-1 Proteingehaltes um einen spezifischen Effekt bei murinen Zellen oder um ein generelles Phänomen handelt, wurden zwei humane Zelllinien, Jurkat Leukämie-T-Zellen und THP-1Monocyten mittels Gesamtproteinextraktion, SDS-PAGE und Western Blot auf ihre PARP-1-Proteinlevel nach Infektion mit $T$. gondii überprüft. Da es sich bei humanen Jurkat T-Zellen im Gegensatz zu Monocyten/Makrophagen und Fibroblasten um Suspensionszellen handelt und sie sich weniger gut mit $T$. gondii infizieren lassen, wurden diese Zellen im Parasit-Wirtszell Verhältnis von 30:1 mit frisch isolierten Tachyzoiten des Maus-avirulenten T. gondii Stammes NTE infiziert. Die THP-1Monocyten wurden dagegen wie in den vorangegangenen Versuchen 4:1 mit NTE Tachyzoiten infiziert. In beiden Zelltypen waren die PARP-1-Proteinlevel nach $1 \mathrm{~h}$ Infektion mit $T$. gondii um ca. 20\% (Abb. 6A) bis 25\% (Abb. 6B) reduziert. Während T. gondii in Jurkat T-Zellen jedoch $8 \mathrm{~h}$ nach Infektion die PARP-1-Menge auf etwa $10 \%$ des Gehaltes vor Infektion reduzierte (Abb. 6A), waren die PARP-1-Proteinlevel in THP-1-Zellen maximal auf nur etwa $60 \%$ vermindert (Abb. 6B). Allerdings muss einschränkend erwähnt werden, dass bei den Infektionsversuchen mit THP-1-Zellen keine Proteinextraktionen $8 \mathrm{~h}$ nach Infektion erfolgten, so dass eine stärkere transiente Inhibierung der Expression von PARP-1 zu diesem Zeitpunkt nicht ausgeschlossen werden kann. In beiden Zelllinien nahmen die PARP-1-Proteinlevel $36 \mathrm{~h}$ nach Infektion um etwa $50 \%$ ab. Insgesamt zeigte vor allem der zeitliche Verlauf der PARP-1-Inhibierung in Jurkat T-Zellen eine deutliche Heterogenität, was sich auch in den relativ großen Standardfehlern des Mittelwertes zum Zeitpunkt $4 \mathrm{~h}$ nach Infektion äußerte. Zusammenfassend zeigten aber auch humane Zelllinien, ebenso wie murine, eine Inhibierung des PARP-1 Proteingehaltes nach Infektion mit $T$. gondii, auch wenn sich die Intensität und der zeitliche Ablauf der Inhibierung deutlich unterschieden. 
A

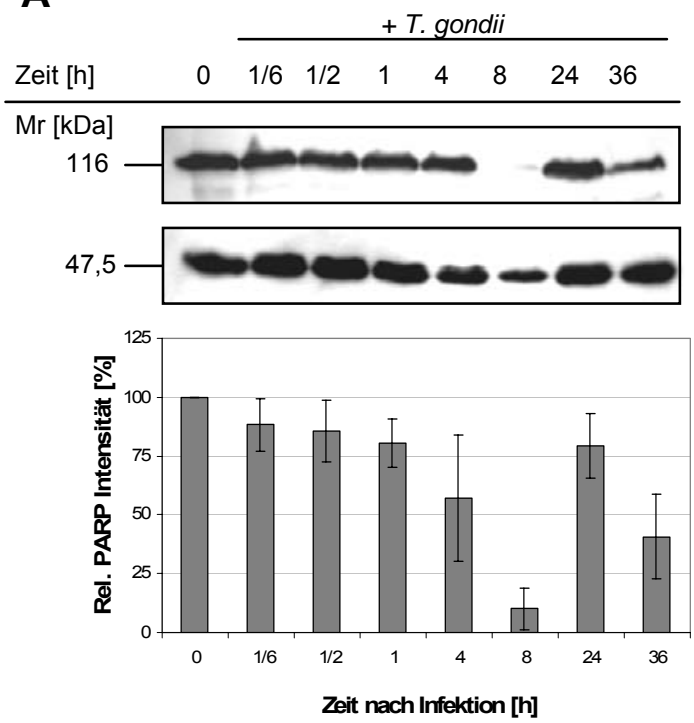

B

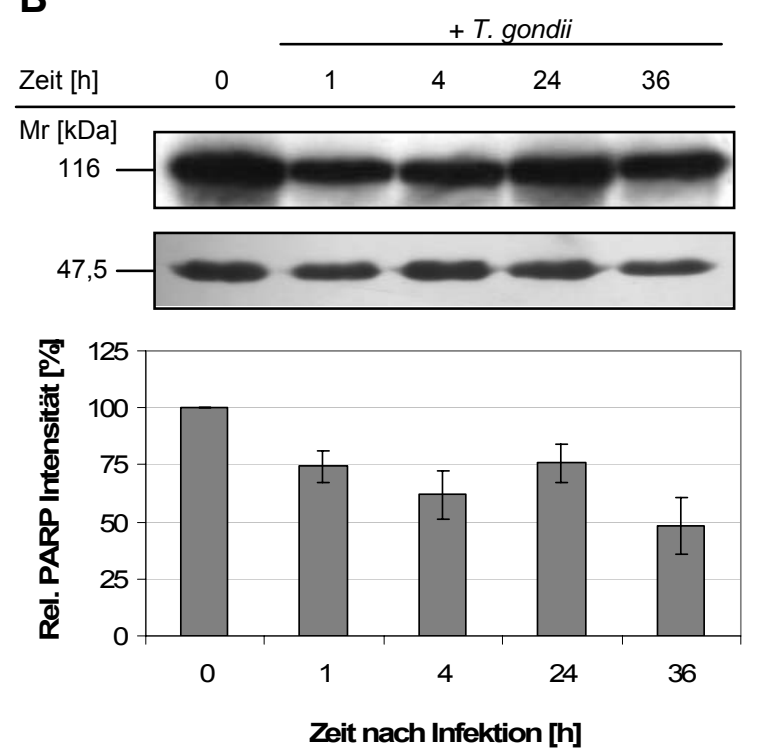

Abb. 6: PARP-1-Inhibierung in unterschiedlichen humanen Zelltypen nach Infektion mit $T$. gondii.

Humane Jurkat T-Zellen (A) und humane THP-1-Monocyten (B) wurden im Parasit-Wirt-Verhältnis von 30:1 (A) oder 4:1 (B) für unterschiedliche Zeiten mit Tachyzoiten des NTE Stammes von T. gondii infiziert oder blieben nicht-infiziert. Gesamtproteinextrakte der Wirtszellen wurden durch SDS-PAGE aufgetrennt und auf Nitrozellulosemembran übertragen. PARP-1 und Aktin wurden mittels entsprechender Primärantikörper und Meerrettichperoxidase-gekoppelter Sekundärantikörper durch "enhanced chemiluminescence" sichtbar gemacht. Der Graph stellt die densitometrische Auswertung der Western Blots dar, dazu wurden jeweils die relativen PARP-Intensitäten berechnet (PARP/Aktin $x$ 100). Die PARP-Intensität zum Zeitpunkt 0 wurde als $100 \%$ definiert und alle anderen Werte im Verhältnis dazu bestimmt. Die Balken entsprechen den Mittelwerten von mindestens drei unabhängigen Versuchen, die Fehlerbalken stellen den Standardfehler ( \pm ) des Mittelwertes dar. Mr: Molekulargewichtsmarker

\subsection{Inhibierung der Poly(ADP-Ribosyl)ierung durch T. gondii}

In weiteren Versuchen wurde untersucht, ob die nach Infektion mit T. gondii verminderte PARP-1 Expression auch zu einer reduzierten enzymatischen Aktivität in RAW 264.7 Makrophagen/Monocyten führt. Dies geschah mittels Quantifizierung der Poly(ADP-Ribosyl)ierung durch einen Zell-ELISA und durch PARP-1 Aktivitätsnachweis auf Einzelzellebene (BAKONDI et al., 2002). Hierfür wurden RAW 264.7 Zellen mit frisch isolierten T. gondii Tachyzoiten im Parasit-Wirtszell Verhältnis von 4:1 und 8:1 infiziert. PARP-1 wurde mit steigenden Konzentrationen an Wasserstoffperoxid aktiviert und den Zellen gleichzeitig biotinyliertes $\mathrm{NAD}^{+}$zur Verfügung gestellt. Die Bildung von biotinylierten ADP-Ribose Polymeren konnte anschließend mittels Peroxidase-konjugiertem Streptavidin und orthoPhenylendiamin beim Zell-ELISA photometrisch bzw. mittels Peroxidase-Streptavidin 
und Nickel-DAB auf Einzelzellebene mikroskopisch nachgewiesen werden. Durch steigende Wasserstoffperoxid-Konzentrationen nahm die Poly(ADP-Ribosyl)ierung in nicht-infizierten Zellen dosisabhängig zu (Abb. 7B).
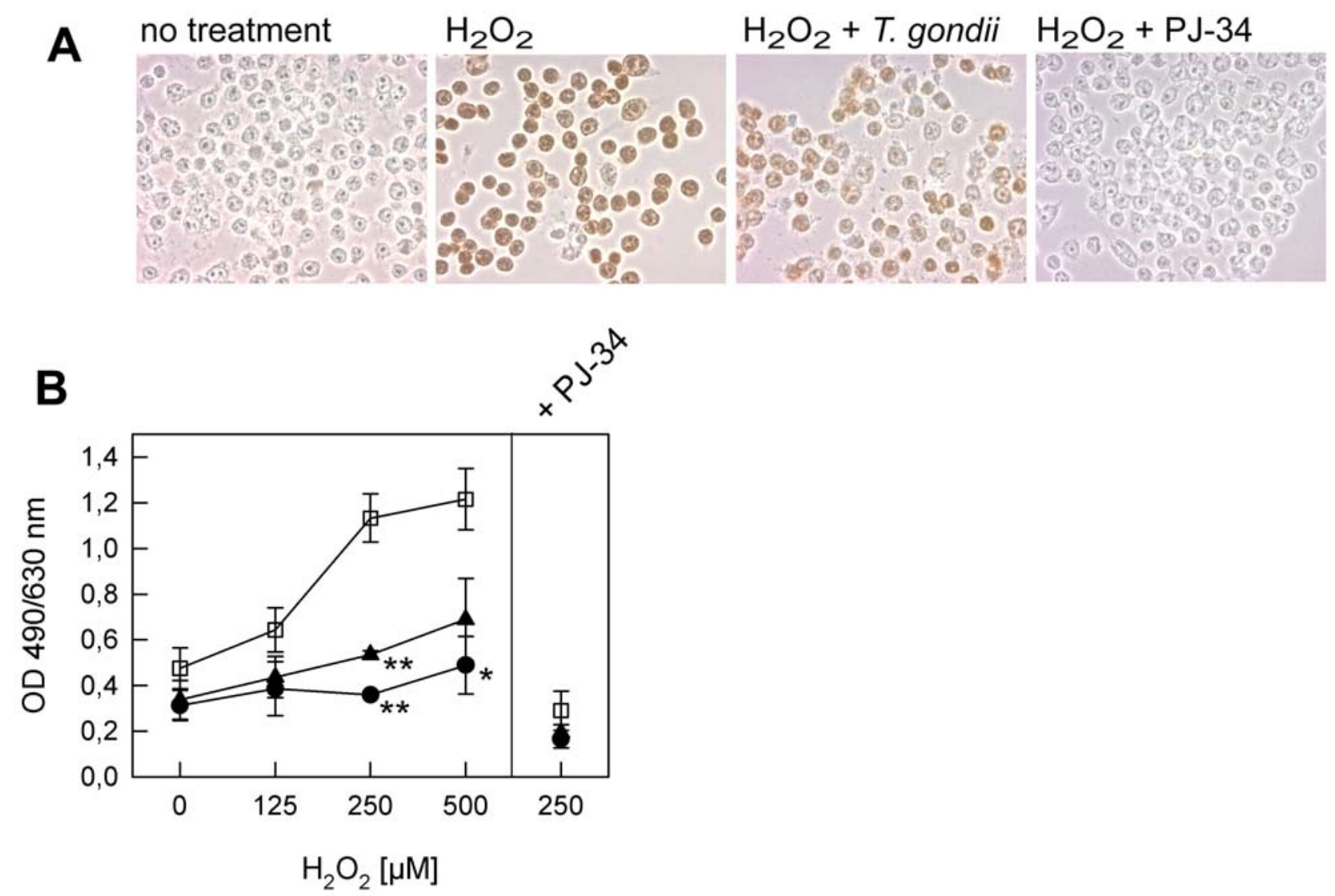

Abb. 7: Inhibierung der PARP-1 Aktivität in RAW 264.7 Monocyten/Makrophagen nach Infektion mit T. gondii.

(A) Für den Nachweis der PARP-1 Aktivität auf Einzelzellebene wurden RAW 264.7 Monocyten/Makrophagen auf Deckgläschen ausgesät, mit $T$. gondii Tachyzoiten des Stammes NTE im Parasit-Wirt-Verhältnis 8:1 infiziert oder nicht-infiziert belassen. Die Zellen wurden mit $500 \mu \mathrm{M} \mathrm{H}_{2} \mathrm{O}_{2}$ behandelt. Als Kontrolle wurde die $\mathrm{H}_{2} \mathrm{O}_{2}$-induzierte Poly(ADP-Ribosyl)ierung durch Inkubation mit dem PARP-spezifischen Inhibitor PJ34 vermindert. Im Anschluß wurden die Zellen mit biotinyliertem NAD+ inkubiert und biotinylierte (ADP-Ribose) Polymere mit Meerrettichperoxidase-konjugiertem Streptavidin und Nickel-DAB mikroskopisch nachgewiesen. (B) Für den Nachweis der PARP-1 Aktivität durch Zell-ELISA wurden RAW 264.7 Monocyten/Makrophagen in 96-Lochplatten ausgesät, mit $T$. gondii Tachyzoiten des Stammes NTE im Parasit-Wirt-Verhältnis 4:1 (schwarze Dreiecke) oder 8:1 (schwarze Kreise) infiziert oder nicht-infiziert (weiße Vierecke) belassen und PARP-1 durch unterschiedliche Konzentrationen $\mathrm{H}_{2} \mathrm{O}_{2}$ aktiviert. Der Nachweis der biotinylierten (ADP-Ribose) Polymere erfolgte durch Meerrettichperoxidase-konjugiertes Streptavidin und ortho-Phenylendiamin und photometrische Messungen bei 490/630 nm. Die Daten entsprechen den Mittelwerten von mindestens 3 unabhängigen Versuchen, die Fehlerbalken stellen den Standardfehler $( \pm)$ des Mittelwertes dar. Die anschließende Statistik erfolgte mittels Students t-test, $\left({ }^{* *} p<0,01\right.$ und ${ }^{*} p<$ $0,05)$ 
In $T$. gondii-infizierten Zellen war die $\mathrm{H}_{2} \mathrm{O}_{2}$-induzierte Poly(ADP-Ribosyl)ierung im Vergleich zu nicht-infizierten Zellen signifikant erniedrigt (Abb. 7A und 7B). Quantitative Analysen mittels Zell-ELISA ergaben, dass die Poly(ADP-Ribosyl)ierung nach Infektion von RAW 264.7 Zellen im Parasit-Wirtszell Verhältnis von 8:1 stärker gehemmt war als in Zellen, die 4:1 infiziert worden waren (Abb. 7B).

Mit PJ34 inkubierte nicht-infizierte Zellen, die mit $\mathrm{H}_{2} \mathrm{O}_{2}$ behandelt worden waren, zeigten eine komplette Inhibierung der Poly(ADP-Ribosyl)ierung (Abb. 7A und 7B). Da PJ34 ein für PARP spezifischer Inhibitor ist (SORIANO et al., 2001), kann davon ausgegangen werden, dass die hier gemessene Poly(ADP-Ribosyl)ierung ausschließlich auf die Aktivität von PARP-1 zurückzuführen ist. Die Ergebnisse wurden durch einen PARP-1 Aktivitätsnachweis auf Einzelzellebene bestätigt bzw. erweitert. In nicht-infizierten Zellen war im Zellkern nach Behandlung mit $\mathrm{H}_{2} \mathrm{O}_{2}$ deutlich eine ADP-Ribosylierung nachweisbar (Abb. 7A). Dies deckte sich mit den Ergebnissen der Immunfluoreszenzfärbung, die PARP-1 vor allem im Zellkern nachwies (Abb. $3 C$ ). Nach Infektion mit $T$. gondii war die $\mathrm{H}_{2} \mathrm{O}_{2}$-induzierte Poly(ADPRibosyl)ierung in der überwiegenden Mehrzahl der Zellen deutlich vermindert, so dass auch die PARP-1-Aktivität unabhängig von einer Wirtszellinvasion durch den Parasiten inhibiert zu sein schien. Durch Inkubation nicht-infizierter Zellen mit PJ34 konnte die PARP-1 Aktivität in allen Zellen trotz vorheriger Stimulierung mit $\mathrm{H}_{2} \mathrm{O}_{2}$ komplett inhibiert werden (Abb. 7A).

T. gondii exprimiert verschiedene Enzyme, unter anderen eine Katalase, die den Parasiten vor dem so genannten „Oxidativen Burst“, einem Abwehrmechanismus der Wirtszelle gegenüber Pathogenen, effektiv schützt. Das T. gondii Enzym Katalase ist dabei in der Lage, von der Wirtszelle abgegebenes $\mathrm{H}_{2} \mathrm{O}_{2}$ zu detoxifizieren (MURRAY et al., 1980). Aus diesem Grund wurde der Zell-ELISA auch mit Katalase-defizienten Parasiten (DING et al., 2004) durchgeführt. Dies diente zur Bestätigung, dass die Abnahme der enzymatischen Aktivität von PARP-1 nach Infektion mit $T$. gondii nicht durch einen Katalase-vermittelten Abbau des Wasserstoffperoxids durch den Parasiten verursacht wurde. Zunächst wurden Katalase-negative Parasiten des Stammes PRU (PRUcat'), sowie die Katalase-positiven Parasiten des parentalen Stammes PRUhxgprt, auf ihren Katalase-Gehalt mittels SDS-PAGE und Western Blot überprüft. Während der parentale Stamm PRUhxgprt Katalase deutlich exprimierte, konnte bei PRUcat' keine Katalase nachgewiesen werden (Abb. 8B). 


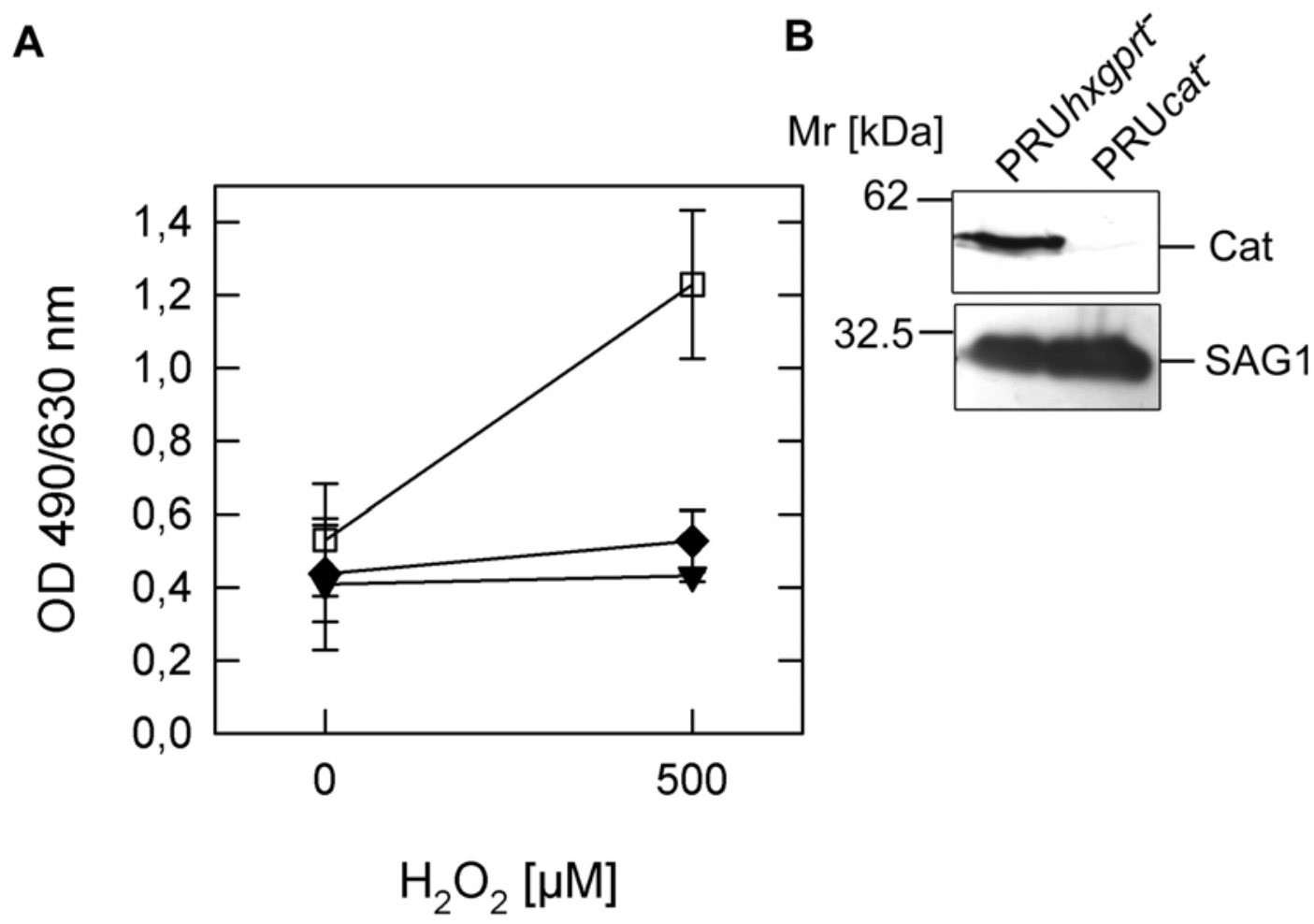

Abb. 8: Das T. gondii Enzym Katalase ist nicht für die Inhibierung der enzymatischen Aktivität von PARP-1 verantwortlich

(A) RAW 264.7 Monocyten/Makrophagen wurden mit dem T. gondii Stamm PRUhxgprt (schwarze Rauten) oder PRUcat (schwarze umgekehrte Dreiecke) im Parasit-Wirt-Verhältnis von 8:1 infiziert oder blieben nicht infiziert (weiße Rechtecke). Der Nachweis der biotinylierten (ADP-Ribose) Polymere erfolgte durch Meerrettichperoxidase-konjugiertes Streptavidin und ortho-Phenylendiamin photometrisch bei 490/630 nm. Die Daten entsprechen den Mittelwerten von 3 unabhängigen Versuchen, die Fehlerbalken stellen den Standardfehler ( \pm ) des Mittelwertes dar. (B) Zum Nachweis der Katalase-Defizienz von PRUcat wurde $1 \times 10^{8}$ Tachyzoiten von Mutante und Parentalstamm (PRUhxgprt) lysiert, lösliche Proteine durch SDS-PAGE aufgetrennt und auf Nitrocellulosemembran übertragen. Katalase und SAG1 wurden durch entsprechende Primärantikörper und Meerrettichperoxidase-gekoppelte Sekundärantikörper durch „enhanced chemiluminescence" sichtbar gemacht. Mr: Molekulargewichtsmarker

Dagegen konnte das Hauptoberflächenprotein von T. gondii, SAG-1, in beiden Parasiten-Stämmen gleichermaßen nachgewiesen werden (Abb. 8B). Im Zell-ELISA war die $\mathrm{H}_{2} \mathrm{O}_{2}$-induzierte PARP-1-Aktivität sowohl bei Zellen, die mit den Katalasenegativen PRUcat Parasiten infiziert worden waren, als auch bei Zellen, die mit dem parentalen Stamm PRUhxgprt infiziert worden waren, ähnlich stark reduziert. Dagegen führte $\mathrm{H}_{2} \mathrm{O}_{2}$ in nicht-infizierten Kontrollen zu einer deutlichen PARP-Aktivität (Abb. 8A). Dies bestätigte, dass die Abnahme der enzymatischen Aktivität von PARP-1 nicht auf eine Katalase-vermittelte Detoxifizierung von $\mathrm{H}_{2} \mathrm{O}_{2}$ durch den 
Parasiten zurück zu führen war, sondern parallel mit der Reduktion der PARP-1Proteinlevel einherging.

\subsection{T. gondii-Stämme unterschiedlicher Genotypen hemmen PARP-1}

Verschiedene Stämme von $T$. gondii werden unter anderem entsprechend ihrer Virulenz in Mäusen in drei Gruppen unterteilt. Gruppe A enthält $T$. gondii Stämme, die Maus-virulent sind (z.B. die Stämme RH und BK). Die Gruppen B und C enthalten Maus-avirulente Stämme, die sich durch die Abwesenheit (Gruppe B, z.B. NTE und DX) bzw. die Anwesenheit (Gruppe C, z.B. CEP und C56) des Antigens P22 nochmals unterteilen lassen (PARMLEY et al., 1994). Beim apikomplexen Parasiten Plasmodium konnte gezeigt werden, dass PARP-1 unter anderem für die Schwere des Verlaufs der Malaria eine wichtige Rolle zu spielen scheint (CLARK et al., 2004). Aus diesem Grund sollten verschiedene T. gondii Stämme aus allen drei Gruppen auf ihre Auswirkung auf den PARP-1 Proteingehalt in RAW 264.7 Wirtszellen untersucht werden. Dazu wurden Wirtszellen mit frisch isolierten Tachyzoiten von sechs verschiedenen Parasitenstämmen (RH, BK, NTE, DX, CEP und C56) für $1 \mathrm{~h}$ infiziert sowie Gesamtproteinextrakte mittels SDS-PAGE und Western Blot verglichen. Nach Infektion mit jeweils einem der sechs Stämme zeigte sich eine deutliche Verminderung der PARP-1-Proteinlevel in allen Wirtszellen um $45 \%$ bis $75 \%$ im Vergleich zu nicht-infizierten Kontrollen (Abb. 9). Obwohl Parasitenstämme vom Genotyp $C$ bei diesen Versuchen PARP-1 am stärksten inhibierten, konnten keine deutlichen Unterschiede in Bezug auf die PARP-1 Proteininhibierung zwischen Maus-virulenten und Maus-avirulenten Stämmen festgestellt werden. Die Inhibierung der Expression von PARP-1 durch $T$. gondii scheint demnach nicht mit der Virulenz des Parasiten in Mäusen oder anderen genotypischen Stammunterschieden zu korrelieren. 


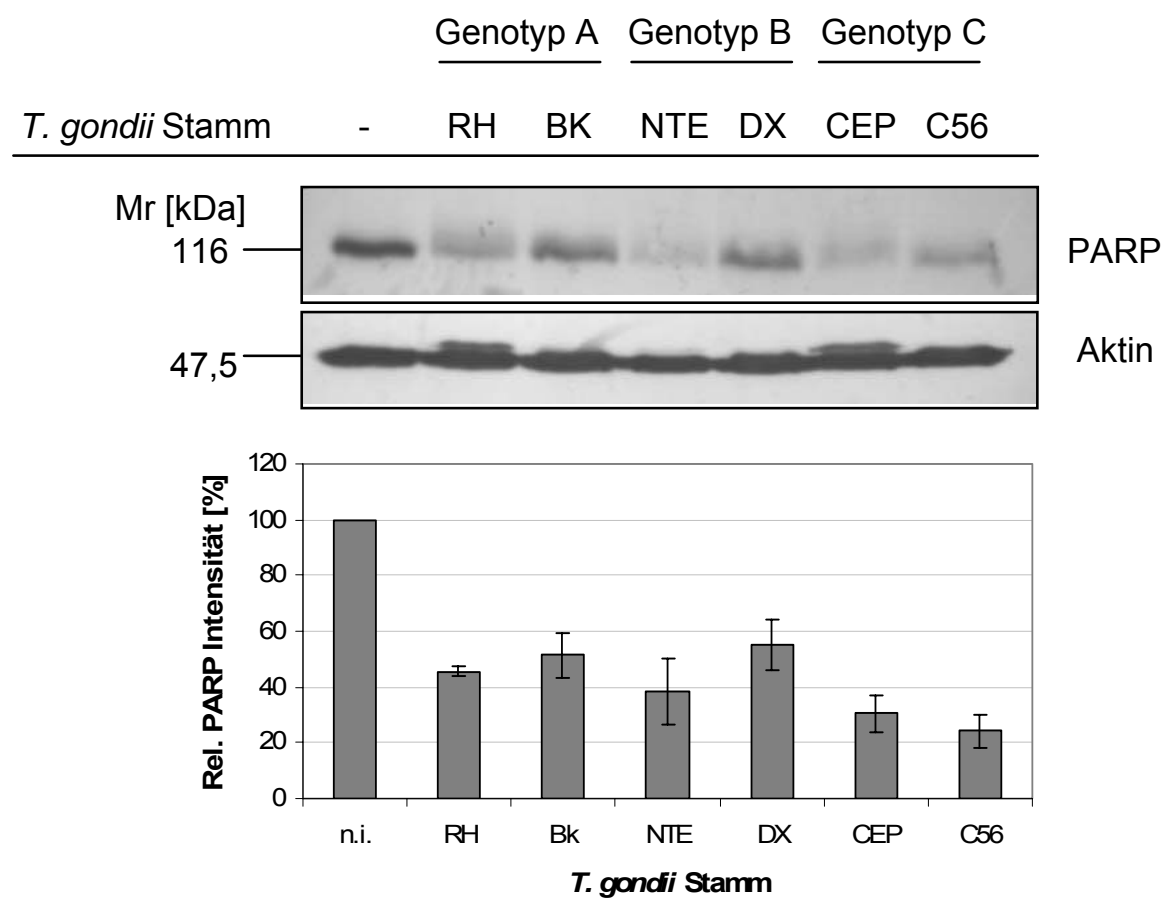

Abb. 9: Die Inhibierung der Expression von PARP-1 in Wirtszellen durch T. gondii ist unabhängig von der Parasitenvirulenz.

RAW 264.7 Monocyten/Makrophagen wurden mit Stämmen der drei Genotypen von T. gondii (RH, BK, NTE, DX, CEP und C56) im Parasit-Wirt-Verhältnis von 4:1 für $1 \mathrm{~h}$ infiziert oder blieben nichtinfiziert. Gesamtproteinextrakte der Wirtszellen wurden durch SDS-PAGE aufgetrennt und auf Nitrozellulosemembran übertragen. PARP-1 und Aktin wurden mittels entsprechender Primärantikörper und Meerrettichperoxidase-gekoppelter Sekundärantikörper durch „enhanced chemiluminescence" sichtbar gemacht. Der Graph stellt die densitometrische Auswertung der Western Blots dar, dazu wurden jeweils die relativen PARP-Intensitäten berechnet (PARP/Aktin x 100). Die PARP-Intensität zum Zeitpunkt 0 wurde als 100\% definiert und alle anderen Werte im Verhältnis dazu bestimmt. Die Balken entsprechen dem Mittelwert von drei unabhängigen Versuchen, die Fehlerbalken stellen den Standardfehler ( \pm ) des Mittelwertes dar. Mr: Molekulargewichtsmarker

\subsection{Regulationsmechanismen der PARP-1-Inhibierung durch}

\section{T. gondii auf Wirtszellebene}

\subsubsection{Beteiligung von Wirtszellmolekülen an der Inhibierung der Expression von PARP-1}

Verschiedene Cytokine und Chemokine werden nach einer Infektion des Wirtes mit T. gondii als direkte Antwort des Immunsystems ausgeschüttet (FISCHER et al., 1997; DENNEY et al., 1999). Die Inhibierung der PARP-1 Expression könnte daher durch einen indirekten Effekt des Parasiten ausgelöst werden. Möglich wäre zum Beispiel 


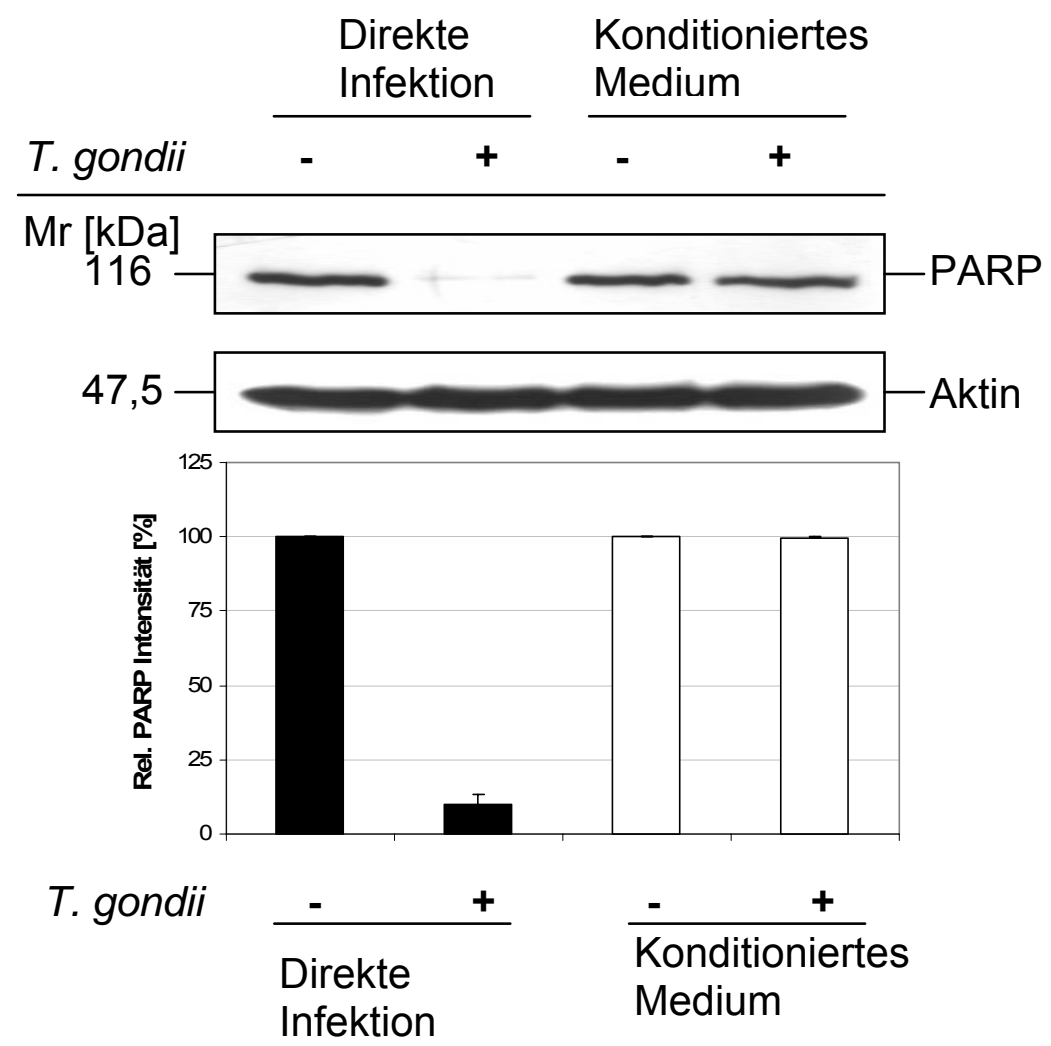

Abb. 10: PARP-1 wird nicht durch ein von infizierten Wirtszellen sekretiertes Molekül inhibiert.

RAW 264.7 Monocyten/Makrophagen wurden mit $1 \times 10^{8} T$. gondii NTE Tachyzoiten für $1 \mathrm{~h}$ infiziert oder blieben nicht-infiziert. Das konditionierte Medium der Zellen wurde steril filtriert, und anschließend RAW 264.7 Monocyten/Makrophagen mit den Zellkulturüberständen der infizierten bzw. nicht-infizierten Zellen für $1 \mathrm{~h}$ inkubiert (weiße Balken). Parallel wurden als Kontrolle RAW 264.7 Monocyten/Makrophagen direkt mit $1 \times 10^{8} \mathrm{~T}$. gondii NTE Tachyzoiten infiziert oder blieben nichtinfiziert (schwarze Balken). Gesamtproteinextrakte der Zellen wurden durch SDS-PAGE aufgetrennt und auf Nitrozellulosemembran übertragen. PARP-1 und Aktin wurden mittels entsprechender Primärantikörper und Meerrettichperoxidase-gekoppelter Sekundärantikörper durch „enhanced chemiluminescence" sichtbar gemacht. Der Graph stellt die densitometrische Auswertung der Western Blots dar, dazu wurden jeweils die relativen PARP-Intensitäten berechnet (PARP/Aktin x 100). Die PARP-Intensität der nicht-infizierten Kontrolle wurde als 100\% definiert und alle anderen Werte im Verhältnis dazu bestimmt. Die Balken entsprechen dem Mittelwert von drei unabhängigen Versuchen, die Fehlerbalken stellen den Standardfehler $( \pm)$ des Mittelwertes dar. Mr: Molekulargewichtsmarker

die Ausschüttung von Molekülen durch die Wirtszelle als Reaktion auf die Infektion mit $T$. gondii, die PARP-1 hemmen. Um diese Hypothese zu überprüfen, wurden RAW 264.7 Zellen mit frisch isolierten Tachyzoiten des T. gondii Stammes NTE $1 \mathrm{~h}$ infiziert oder blieben nicht-infiziert. Anschließend wurde der Zellkulturüberstand steril filtriert, um extrazelluläre Parasiten zu entfernen. Nicht-infizierte RAW 264.7 Zellen wurden danach mit dem T. gondii-konditioniertem RAW-Überstand inkubiert. Als Kontrolle wurden RAW 264.7-Zellen mit frisch isolierten Tachyzoiten des $T$. gondii 
Stammes NTE $1 \mathrm{~h}$ infiziert oder blieben nicht-infiziert. Nach $1 \mathrm{~h}$ wurden Gesamtproteinextrakte hergestellt und durch SDS-PAGE und Western Blot analysiert. Zellen, die mit $T$. gondii-konditioniertem Zellkulturüberstand inkubiert wurden, zeigten im Vergleich zu Zellen, die mit nicht-konditioniertem Überstand kultiviert wurden keine Verminderung des PARP-1 Gehaltes (Abb.10). Dagegen führte eine direkte Infektion von Makrophagen/Monocyten mit $T$. gondii wie in den bisherigen Versuchen zu einer deutlichen Reduktion des PARP-1-Proteinlevels um etwa 90\% (Abb. 10). Diese Ergebnisse waren ein deutlicher Hinweis, dass die PARP-1-Inhibierung durch $T$. gondii auf eine Interaktion des Parasiten mit seinen Wirtszellen beruhte und nicht indirekt durch ein sekretiertes Wirtszellmolekül als Reaktion auf die Infektion vermittelt wurde.

\subsubsection{Einfluss von Transkription und Translation der Wirtszelle auf die PARP-1-Inhibierung}

Als obligat intrazellulärer Parasit greift $T$. gondii in physiologische Prozesse der Wirtszelle ein, um das eigene Überleben sowie die Replikation zu gewährleisten (LANG et al., 2007). Der Parasit hat dafür vielfältige Mechanismen entwickelt. Unter anderem ist es $T$. gondii möglich, auf transkriptioneller (GAlL et al., 2001) und auf post-transkriptioneller Ebene (BELLONI et al., 2003) in die Expression von bestimmten Wirtszellproteinen einzugreifen. Außerdem konnte gezeigt werden, dass $T$. gondii für die Phosphorylierung und den Abbau von Wirtszellproteinen verantwortlich ist (BUTCHER et al., 2001). Da T. gondii PARP-1 nach Infektion sowohl auf Proteinebene als auch auf Ebene der enzymatischen Aktivität inhibiert, sollte nun untersucht werden, ob der Parasit auf transkriptioneller, translationaler oder posttranslationaler Ebene in die PARP-1 Expression eingreift. Die Transkriptlevel von PARP-1 wurden durch RNA-Isolierung aus unterschiedlich lang infizierten RAW 264.7 Zellen mit anschließender Reverser Transkription und quantitativer „Real-time PCR“ analysiert. Die PARP-1 Expression der nicht-infizierten Kontrolle im Verhältnis zur Expression des Housekeeping Gens Aktin wurde als 1 festgelegt. Nach $1 \mathrm{~h}$ Infektion mit $T$. gondii zeigte sich eine Zunahme der PARP-1 mRNA-Level auf 2,2 und nach $4 \mathrm{~h}$ auf 3,1 (Abb. 11A). Allerdings war der PARP-1 Proteingehalt $1 \mathrm{~h}$ nach Infektion deutlich 
$\mathbf{A}$

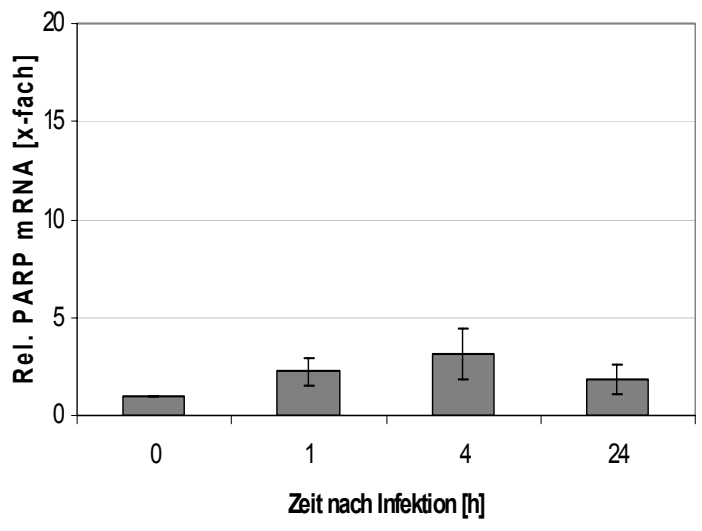

B

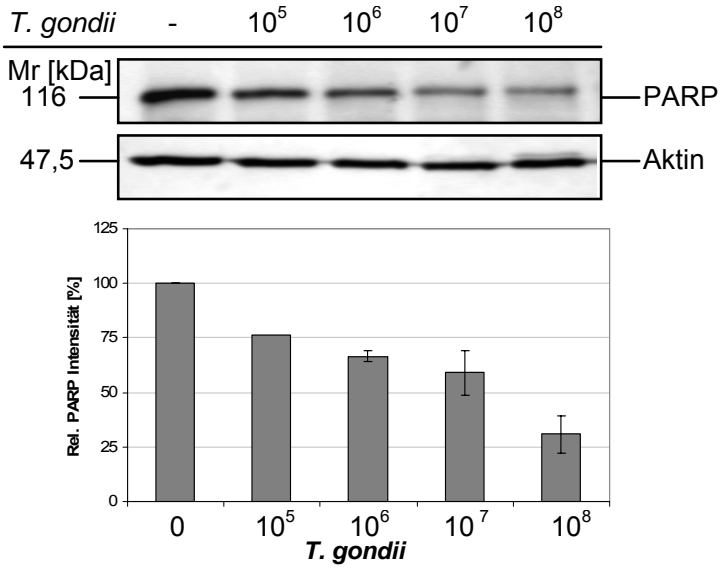

Abb. 11: Die Inhibierung der Expression von PARP-1 nach Infektion mit T. gondii erfolgt unabhängig von Transkription und Translation der Wirtszelle.

(A) RAW 264.7 Monocyten/Makrophagen wurden unterschiedlich lange mit Tachyzoiten des T. gondii Stammes NTE im Parasit-Wirt-Verhältnis von 4:1 infiziert, oder blieben nicht-infiziert. Anschließend wurde die Gesamt-RNA isoliert, die mRNA revers transkribiert und eine RealTime PCR Analyse mit PARP- und B-Aktin-spezifischen Primern und dem MasterPlus SYBR Green 1 Kit im LightCycler durchgeführt. Anhand der CP-Werte wurden die relativen Veränderungen der PARP-1 cDNA-Mengen im Verhältnis zu den ß-Aktin cDNA-Mengen berechnet, wobei die Menge zum Zeitpunkt Null als Eins definiert wurde. Die Balken entsprechen dem Mittelwert von drei unabhängigen Versuchen, die Fehlerbalken stellen den Standardfehler $( \pm)$ des Mittelwertes dar. (B) Für das zellfreie in vitro System wurden nukleäre Proteine aus RAW 264.7 Monocyten/Makrophagen isoliert und mit unterschiedlichen Mengen an T. gondii Tachyzoiten des Stammes NTE für $1 \mathrm{~h}$ inkubiert. Danach wurden die Parasiten mittels Zentrifugation entfernt, die Lysate mittels SDS-PAGE aufgetrennt und auf Nitrozellulosemembran übertragen. PARP-1 und Aktin wurden mittels entsprechender Primärantikörper und Meerrettichperoxidase-gekoppelter Sekundärantikörper durch „enhanced chemiluminescence" sichtbar gemacht. Der Graph stellt die densitometrische Auswertung der Western Blots dar, dazu wurden jeweils die relativen PARP-Intensitäten berechnet (PARP/Aktin x 100). Die PARP-Intensität der nicht-infizierten Kontrolle wurde als 100\% definiert und alle anderen Werte im Verhältnis dazu bestimmt. Die Balken entsprechen dem Mittelwert von drei unabhängigen Versuchen, die Fehlerbalken stellen den Standardfehler $( \pm)$ des Mittelwertes dar. Mr: Molekulargewichtsmarker

reduziert und zeigte im weiteren Verlauf der Infektion eine langsame Zunahme des PARP-1-Proteinlevels, der nach $24 \mathrm{~h}$ Infektionszeit auf dem Niveau der nichtinfizierten Kontrolle anlangte (Abb. 3B). Diese Ergebnisse zeigten deutlich, dass die Inhibierung der PARP-1 Expression nach T. gondii-Infektion nicht auf verminderte Transkriptionslevel zurückzuführen war. Um zusätzliche Hinweise auf mögliche zelluläre Regulationsmechanismen der PARP-Inhibierung durch T. gondii zu erhalten, wurde auch ein zellfreies in vitro System eingesetzt. Hierfür wurden nukleäre Lysate von RAW 264.7 Zellen verwendet, denen sowohl eine funktionierende Translationsmaschinerie als auch intakte Zellmembranen oder membranumhüllte Organellen der Wirtszelle fehlten. So konnte unter anderem ein Einfluss von T. gondii auf die Wirtszelltranslation bei der Inhibierung von PARP 
untersucht werden. Ein Überleben des Parasiten im nukleären Lysat wurde in Vorversuchen für mehrere Stunden nachgewiesen (nicht gezeigte Ergebnisse). Um den Einfluss von $T$. gondii auf PARP-1 zu bestimmen, wurden nukleäre Lysate mit steigender Parasiten-Menge für $1 \mathrm{~h}$ inkubiert und anschließend durch SDS-PAGE und Western Blot analysiert. Bemerkenswerterweise war der Parasit auch im zellfreien in vitro System in der Lage, den PARP-1 Proteingehalt deutlich zu reduzieren (Abb. 11B). So verminderten z.B. $1 \times 10^{8}$ Toxoplasma Tachyzoiten den PARP-1-Gehalt des nukleären Lysates um etwas 70\% (Abb. 11B). Die Stärke der Reduktion von PARP-1 entspricht in etwa dem Parasit-Wirt-Verhältnis von 4:1 in lebenden Zellen (Abb. 4), allerdings handelt es sich im in vitro System um ein ursprüngliches Parasit-Wirt-Verhältnis von etwa 16:1. In Abhängigkeit von der Parasitenmenge konnte außerdem wie in intakten RAW 264.7 Monocyten/Makrophagen (Abb. 4) eine dosisabhängige Abnahme des PARP-1Proteinlevels beobachtet werden (Abb. 11B). Dies zeigte, dass die PARP-1Inhibierung durch $T$. gondii unabhängig von der Translation der Wirtszelle stattfand.

\subsubsection{Inhibierung der Expression von PARP-1 durch T. gondii in Gegenwart von Proteasominhibitoren}

Da T. gondii PARP-1 unabhängig von Transkription und Translation der Wirtszelle vermindert, sollte nachfolgend geprüft werden, inwieweit das Protein nach Infektion mit $T$. gondii durch Wirtszellproteasomen abgebaut wird. Durch das Proteasom werden mit Ubiquitin markierte Proteine, die entweder nicht mehr benötigt werden oder in ihrer dreidimensionalen Faltung Fehler aufweisen, abgebaut (LECKER et al., 2006). Dazu wurden RAW 264.7 Zellen mit den Proteasom-Inhibitoren MG132 oder Lactacystin vorinkubiert und mit Tachyzoiten des $T$. gondii Stammes NTE $1 \mathrm{~h}$ infiziert. Anschließend wurden Gesamtproteinextrakte durch SDS-PAGE und Western Blot analysiert. Sowohl mit MG132 als auch mit Lactacystin vorinkubierte RAW 264.7 Zellen zeigten eine starke Inhibierung des PARP-1-Proteinlevels nach Infektion mit $T$. gondii im Vergleich zu nicht-infizierten RAW 264.7 Kontrollzellen (Abb. 12A). So waren in T. gondii infizierten Zellen, unabhängig von der Vorinkubation mit Proteasom-Inhibitoren, der PARP-1 Proteingehalt um etwa 60-80\% reduziert (Abb. 12A). Allerdings war der PARP-1-Proteinlevel der mit den Proteasom- 
Inhibitoren vorinkubierten Proben auch ohne T. gondii-Infektion um 20-30\% niedriger als in nicht behandelten Kontrollzellen (Abb. 12A). Diese Ergebnisse konnten auch im zellfreien in vitro System bestätigt werden (Abb. 12B). Dabei war in infizierten Proben der PARP-1-Proteinlevel zwischen $60 \%$ und 90\% im Vergleich zu den nichtinfizierten Kontrollen reduziert, unabhängig von einer Vorinkubation mit ProteasomInhibitoren (Abb. 12B). Auch waren die PARP-1 Mengen in mit MG132 und Lactacystin vorinkubierten Zellen, die nicht infiziert worden waren, um 20-25\% niedriger als in nicht behandelten Kontrollen (Abb. 12B). Zusammenfassend zeigten diese Daten, dass die Inhibierung der Expression von PARP-1 nach ToxoplasmaInfektion vermutlich unabhängig von der Aktivität der Wirtszellproteasomen stattfand.

A

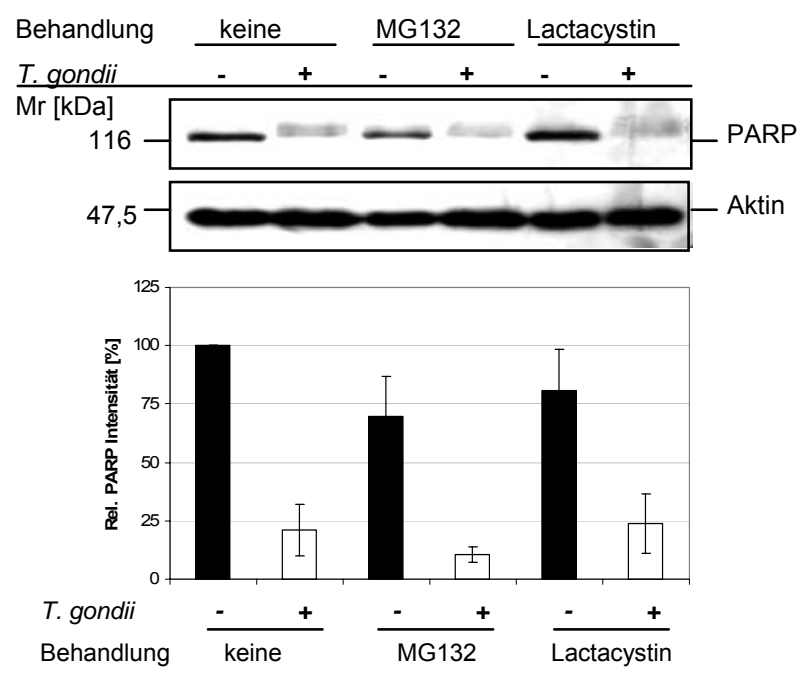

B

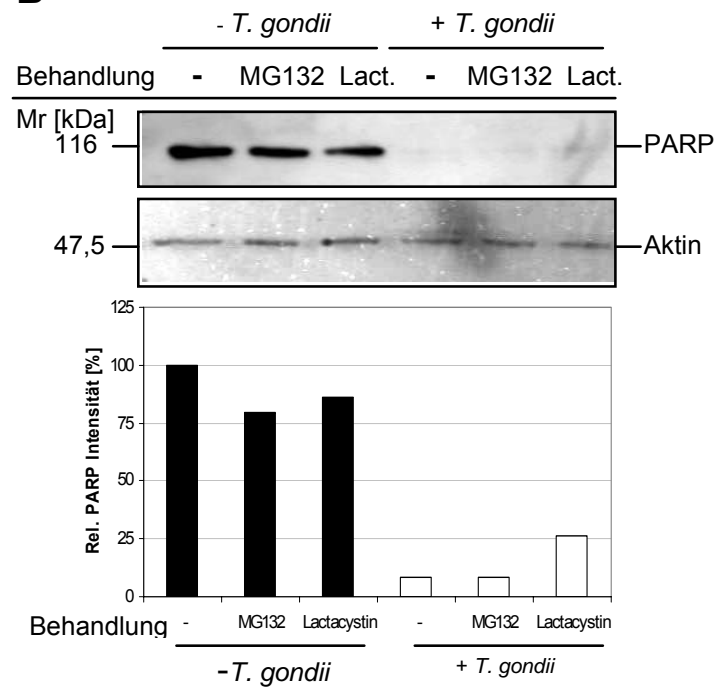

Abb. 12: PARP-1 wird nach Infektion mit $T$. gondii nicht durch Wirtszellproteasomen abgebaut.

(A) RAW 264.7 Monocyten/Makrophagen wurden für 10 min mit den Proteasom-Inhibitoren MG132 $(50 \mathrm{nM})$ oder Lactacystin $(10 \mu \mathrm{M})$ vorinkubiert oder blieben unbehandelt. Anschließend wurden die Zellen im Parasit-Wirt-Verhältnis von 4:1 mit Tachyzoiten des $T$. gondii Stammes NTE infiziert oder blieben nicht-infiziert. Gesamtproteinextrakte der Wirtszellen wurden durch SDS-PAGE aufgetrennt und auf Nitrozellulosemembran übertragen. PARP-1 und Aktin wurden mittels entsprechender Primärantikörper und Meerrettichperoxidase-gekoppelter Sekundärantikörper durch „enhanced chemiluminescence" sichtbar gemacht. Der Graph stellt die densitometrische Auswertung der Western Blots dar, dazu wurden jeweils die relativen PARP-Intensitäten berechnet (PARP/Aktin x 100). Die PARP-Intensität der nicht-infizierten Kontrolle wurde als $100 \%$ definiert und alle anderen Werte im Verhältnis dazu bestimmt. Die Balken entsprechen dem Mittelwert von drei unabhängigen Versuchen, die Fehlerbalken stellen den Standardfehler ( \pm ) des Mittelwertes dar. Mr: Molekulargewichtsmarker (B) Für das zellfreie in vitro System wurden nukleäre Proteine aus RAW 264.7 Monocyten/Makrophagen isoliert, und 10 min mit den Proteasom-Inhibitoren MG132 $(50 \mathrm{nM})$ oder Lactacystin $(10 \mu \mathrm{M})$ inkubiert. Anschließend wurden die nukleären Lysate mit je $1 \times 10^{8} T$. gondii NTE Tachyzoiten oder ohne Tachyzoiten für $1 \mathrm{~h}$ inkubiert. Die Lysate wurde danach wie unter $(\mathrm{A})$ beschrieben weiterbehandelt. Mr: Molekulargewichtsmarker 


\subsection{Voraussetzungen von T. gondii für die PARP-1-Inhibierung}

Zur weiteren Charakterisierung der Mechanismen der Inhibierung der Expression von PARP-1 wurden im Folgenden die Voraussetzungen des Parasiten für diese Wirtszellmodulation untersucht. Da $T$. gondii während der Wirtszellinvasion und während der Bildung der parasitophoren Vakuole eine Reihe von exkretorischensekretorischen Molekülen (ESM) sezerniert (CARRUTHERS und SIBLEY, 1997; CARRUTHERS, 1999) und diese Moleküle zum Teil zur Wirtszellmodulation beitragen (DIANA et al., 2005), könnte eines dieser Moleküle auch die Inhibierung der Expression von PARP-1 verursachen. Die ESM werden teilweise auch von extrazellulären Parasiten spontan sezerniert. Zur Überprüfung eines Einflusses von ESM wurde daher ein Transwell-System mit Membraneinsätzen verwendet. RAW 264.7 Monocyten/Makrophagen wurden dazu entweder direkt mit T. gondii Tachyzoiten im Parasit-Wirt-Verhältnis von 4:1 bzw. 8:1 infiziert, oder die Parasiten wurden im gleichen Verhältnis in das Transwell gegeben, sodass kein direkter Kontakt zwischen Parasit und Wirtszellen zustande kommen konnte. Sekretierte Proteine konnten so durch die Membran des Transwell-Systems gelangen, aber eine Infektion der Wirtszellen wurde verhindert. Als Kontrolle wurden jeweils nichtinfizierte Zellen mit und ohne Transwell-Einsatz mitgeführt. Nach $1 \mathrm{~h}$ wurden Gesamtproteinextrakte der Wirtszellen hergestellt und durch SDS-PAGE und Western Blot analysiert. Parasiten mit direktem Kontakt zu den Wirtszellen reduzierten den PARP-1 Proteingehalt durchschnittlich um 40-65\%, wobei die Inhibierung der Expression von PARP-1 abhängig von der Dosis der Parasiten war (Abb. 13). Parasiten, deren direkter Kontakt zu den Wirtszellen durch die Membran des Transwell-Einsatzes verhindert wurde, konnten den PARP-1-Proteinlevel der Wirtszellen dagegen nicht reduzieren (Abb. 13). Diese Experimente zeigten, dass die Inhibierung der Expression von PARP-1 offensichtlich nicht durch ein von T. gondii spontan sekretiertes Molekül verursacht wird. Die Ergebnisse des Transwell-Systems deuteten darauf hin, dass für die PARP-1 Reduktion ein direkter Kontakt von Parasit und Wirtszelle nötig ist. Daher sollte nachfolgend ermittelt werden, welche weiteren Eigenschaften des Parasiten für die Inhibierung der Expression von PARP-1 wichtig sind. Dazu sollten RAW 264.7 Monocyten/Makrophagen mit unterschiedlich vorbehandelten $T$. gondii Tachyzoiten bzw. mit Parasitenlysaten inkubiert werden und deren Auswirkung auf die PARP-1 Expression untersucht werden. Parasiten, die mit UV-Licht behandelt werden, sind zwar noch in der Lage in die Wirtszelle 
einzudringen, sie können sich aber nicht mehr vermehren (ENDO et al., 1981). Bei $60^{\circ} \mathrm{C}$ inkubierte Parasiten (SIBLEY et al., 1985), ebenso wie bei $-20^{\circ} \mathrm{C}$ eingefrorene Parasiten, werden durch die Behandlung abgetötet und können daher nicht mehr in die Wirtszelle eindringen. Um die Effektivität der verschiedenen Behandlungen zu testen, wurden in Vorversuchen zunächst RAW 264.7 Monocyten/Makrophagen für $24 \mathrm{~h}$ mit Tachyzoiten des T. gondii Stammes NTE infiziert, die unbehandelt blieben, mit UV-Licht bestrahlt oder bei $60^{\circ} \mathrm{C}$ inkubiert worden waren. Der Parasitennachweis durch Immunfluoreszenzfärbung zeigte, dass unbehandelte Parasiten sich wie
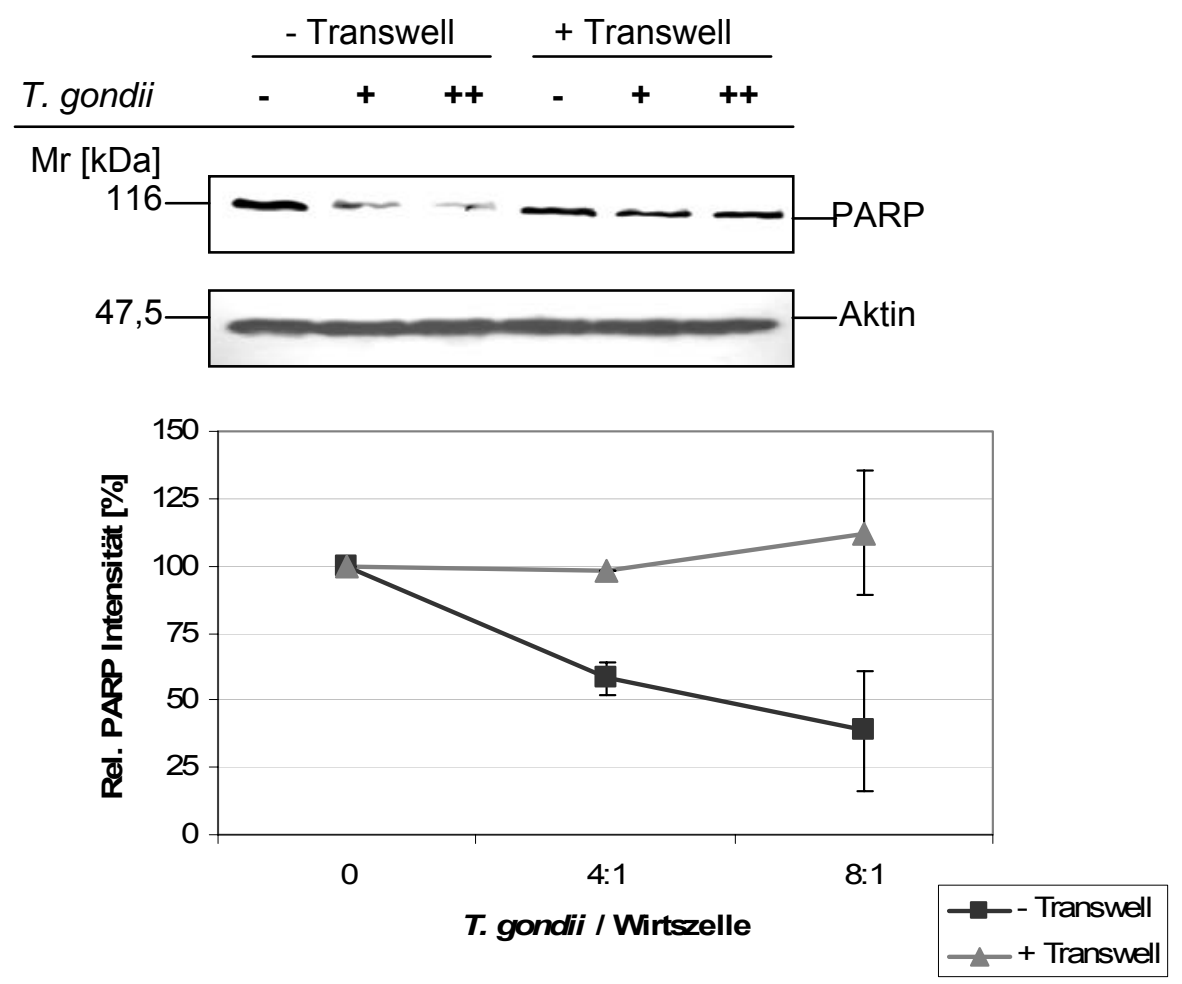

Abb. 13: Von Wirtszellen durch eine semipermeable Membran getrennte Parasiten vermitteln keine Inhibierung der Expression von PARP-1.

RAW 264.7 Monocyten/Makrophagen wurden entweder direkt mit T. gondii NTE Tachyzoiten im Parasit-Wirt-Verhältnis von 4:1 (+) bzw. 8:1 (++) infiziert (schwarze Quadrate) oder mit Parasiten in gleichen Parasit-Wirtszell Verhältnissen inkubiert, die von den Wirtszellen durch die Membran $(0.4 \mu \mathrm{m}$ Porengröße) eines Transwell-Einsatzes getrennt waren (+ Transwell, graue Dreiecke). Wirtszellen ohne Parasiten (-) wurden parallel inkubiert. Gesamtproteinextrakte der Wirtszellen wurden durch SDS-PAGE aufgetrennt und auf Nitrozellulosemembran übertragen. PARP-1 und Aktin wurden mittels entsprechender Primärantikörper und Meerrettichperoxidase-gekoppelter Sekundärantikörper durch "enhanced chemiluminescence" sichtbar gemacht. Der Graph stellt die densitometrische Auswertung der Western Blots dar, dazu wurden jeweils die relativen PARP-Intensitäten berechnet (PARP/Aktin $x$ 100). Die PARP-Intensität der nicht-infizierten Kontrolle wurde als $100 \%$ definiert und alle anderen Werte im Verhältnis dazu bestimmt. Die Datenpunkte entsprechen dem Mittelwert von drei unabhängigen Versuchen, die Fehlerbalken stellen den Standardfehler ( \pm ) des Mittelwertes dar. Mr: Molekulargewichtsmarker 
erwartet $24 \mathrm{~h}$ nach Infektion intrazellular stark vermehrt hatten und deutliche parasitophore Vakuolen mit einer unterschiedlichen Anzahl von Parasiten ausgebildet hatten (Abb. 14). Zellen, die mit UV-behandelten Parasiten inkubiert worden waren, enthielten dagegen nur einzelne intrazelluläre Parasiten, so dass UVbehandelte Parasiten zwar zur Invasion der Wirtszelle, nicht aber zur intrazellulären Vermehrung fähig waren (Abb. 14). In Zellen, die mit Hitze-behandelten T. gondii inkubiert worden waren, konnten dagegen keine intrazellulären Parasiten nachgewiesen werden, sodass auch die Wirtszellinvasion unterbunden war (Abb. 14).

Nachfolgend wurde die Auswirkung der Vorbehandlungen der Parasiten auf den PARP-1-Proteinlevel der Wirtszellen überprüft. Dazu wurden RAW 264.7 Monocyten/Makrophagen entweder für $1 \mathrm{~h}$ mit unbehandelten, mit UV- bzw. Hitzevorbehandelten T. gondii Tachyzoiten oder mit PBS-löslichen oder -unlöslichen $T$. gondii-Lysaten inkubiert. Gesamtproteinextrakte wurden mittels SDS-PAGE aufgetrennt und durch Western Blot auf ihren PARP-1 Gehalt überprüft. Interessanterweise reduzierten UV- und Hitze-behandelte Parasiten die PARP-1Proteinlevel der Wirtszellen ähnlich stark wie unbehandelte T. gondii (Abb. 15A).

Nicht infiziert

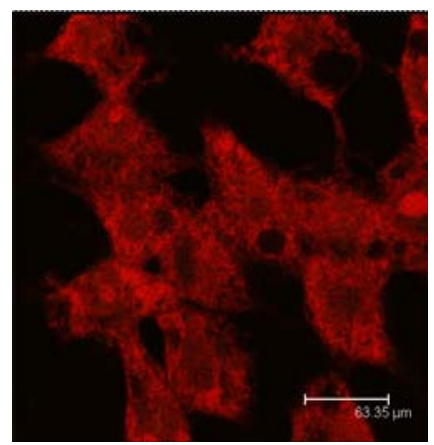

+ T. gondii

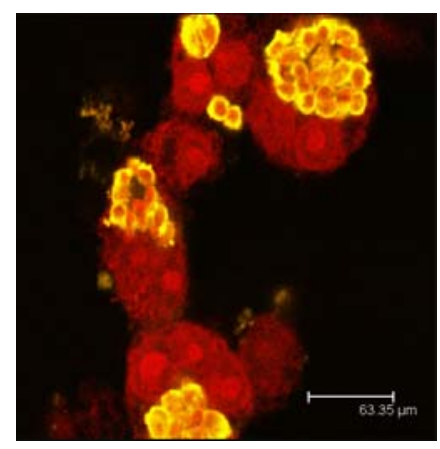

+ T. gondii UV

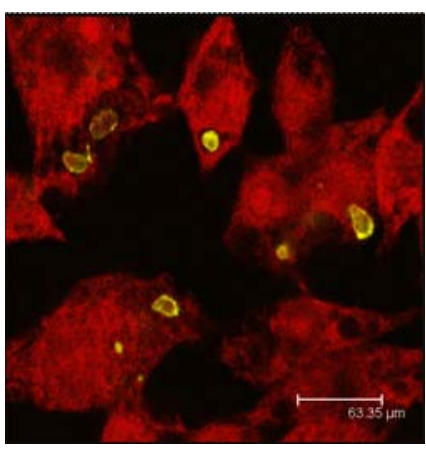

$+T$. gondii $60^{\circ} \mathrm{C}$

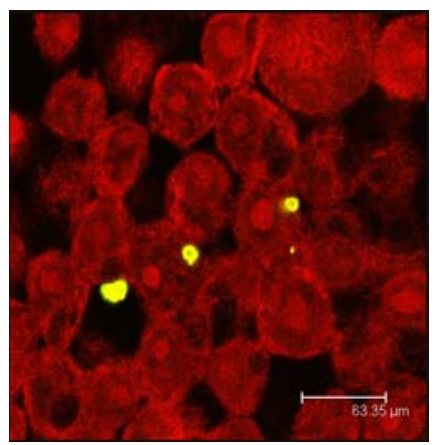

Abb. 14: Effektivität von UV-Behandlung und Hitze-Inaktivierung auf Replikation und Wirtszellinvasion durch $T$. gondii.

Parasiten wurden $70 \mathrm{sec}$ mit UV-Licht bestrahlt, $30 \mathrm{~min}$ bei $60^{\circ} \mathrm{C}$ inkubiert oder unbehandelt belassen. RAW 264.7 Monocyten/Makrophagen wurden für $24 \mathrm{~h}$ mit unterschiedlich vorbehandelten oder unbehandelten Tachyzoiten des $T$. gondii Stammes NTE im Parasit-Wirt-Verhältnis von 4:1 infiziert oder blieben nicht-infiziert. T. gondii wurde mittels eines Parasiten-spezifischen polyklonalen Antiserums und Cy-2-konjugiertem Sekundärantikörper (grüne Fluoreszenz) sichtbar gemacht. Doppelsträngige Nukleinsäuren in Wirtszellen und Parasiten wurden mit Propidiumiodid angefärbt (rote Fluoreszenz). Die Proben wurden mikroskopisch mit einem Leica TCS SP2 Konfokalmikroskop ausgewertet. 
A

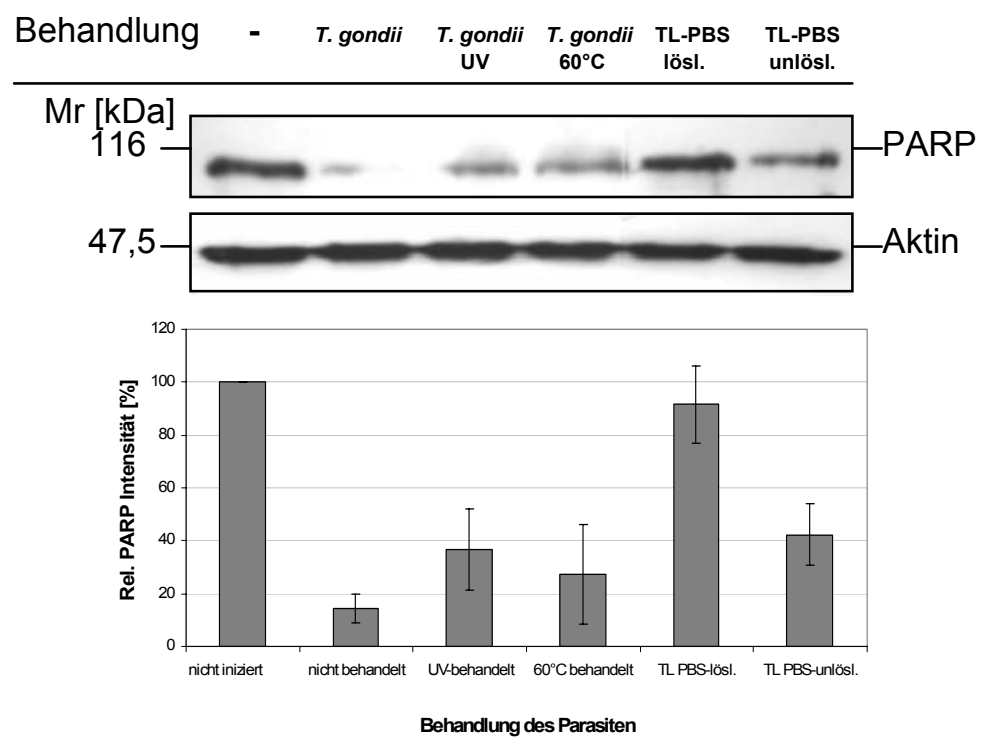

B

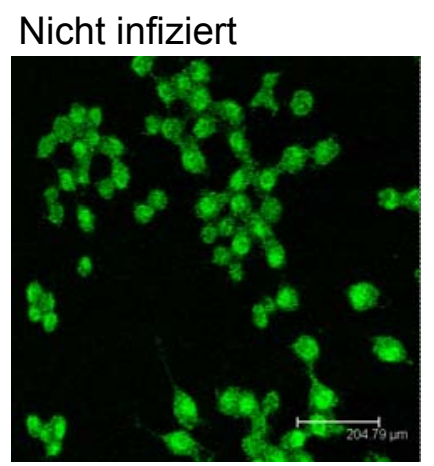

+ T. gondii

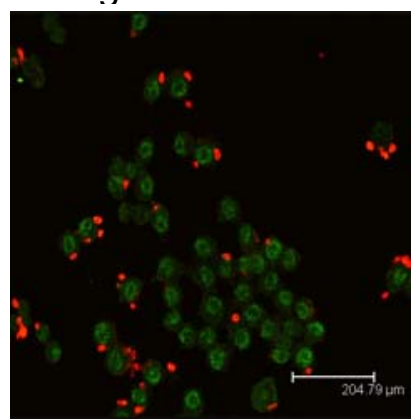

+ T. gondii $-20^{\circ} \mathrm{C}$

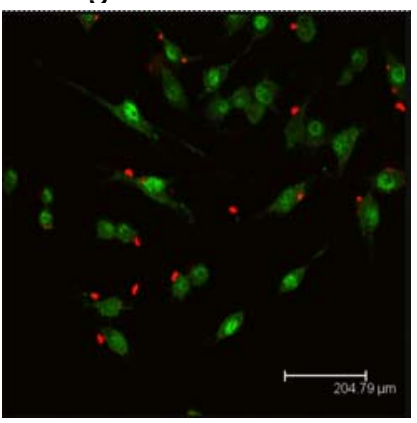

+ T. gondii $60^{\circ} \mathrm{C}$

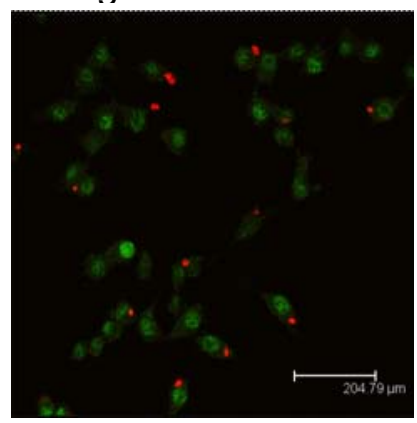

\section{Abb. 15: T. gondii Tachyzoiten inhibieren unabhängig von Wirtszellinvasion und intrazellulärer Replikation den PARP-1-Proteinlevel.}

T. gondii Tachyzoiten des Stammes NTE wurden für $70 \mathrm{sec}$ mit UV-Licht bestrahlt, bei $60^{\circ} \mathrm{C}$ für 30 min inkubiert oder bei $-20^{\circ} \mathrm{C}$ für mindestens $24 \mathrm{~h}$ inkubiert. Außerdem wurden aus Parasiten ein PBSlösliches Lysat (TL-PBS lösl.) hergestellt oder das unlösliche Pellet nach PBS-Extraktion resuspendiert (TL-PBS unlösl.). (A) RAW 264.7 Monocyten/Makrophagen wurden für $1 \mathrm{~h}$ mit den unterschiedlich behandelten oder unbehandelten Parasiten im Parasit-Wirt-Verhältnis von 4:1 oder mit $T$. gondii-Lysaten $(50 \mu \mathrm{g})$ für $1 \mathrm{~h}$ inkubiert. Gesamtproteinextrakte der Wirtszellen wurden durch SDSPAGE aufgetrennt und auf Nitrozellulosemembran übertragen. PARP-1 und Aktin wurden mittels entsprechender Primärantikörper und Meerrettichperoxidase-gekoppelter Sekundärantikörper durch "enhanced chemiluminescence" sichtbar gemacht. Der Graph stellt die densitometrische Auswertung der Western Blots dar, dazu wurden jeweils die relativen PARP-Intensitäten berechnet (PARP/Aktin $x$ 100). Die PARP-Intensität der nicht-infizierten Kontrolle wurde als $100 \%$ definiert und alle anderen Werte im Verhältnis dazu bestimmt. Die Balken entsprechen dem Mittelwert von drei unabhängigen Versuchen, die Fehlerbalken stellen den Standardfehler $( \pm)$ des Mittelwertes dar. Mr: Molekulargewichtsmarker; TL: T. gondii-Lysat (B) RAW 264.7 Monocyten/Makrophagen wurden für 1 h im Parasit-Wirt-Verhältnis von 4:1 mit unterschiedlich vorbehandelten oder unbehandelten Tachyzoiten des NTE Stammes von T. gondii infiziert oder blieben nicht-infiziert. PARP-1 und T. gondii Tachyzoiten wurden durch Immunfluoreszenzfärbung mittels spezifischer Primärantikörper und Cy-2-konjugiertem (PARP-1: grüne Fluoreszenz) oder Cy-3-konjugiertem (T. gondii: rote Fluoreszenz) Sekundärantikörper sichtbar gemacht. Die Proben wurden mikroskopisch mit einem Leica TCS SP2 Konfokalmikroskop ausgewertet. 
Neben der Hitze-Inaktivierung erfolgte auch eine Inaktivierung von T. gondii Tachyzoiten durch Tieffrieren bei $-20^{\circ} \mathrm{C}$ für mindestens $24 \mathrm{~h}$. Diese Parasiten können, ebenso wie die Hitze-inaktivierten T. gondii, nicht mehr in Wirtszellen eindringen. Vergleichbar mit Abb. 14 waren im Immunfluoreszenztest keine intrazellulären Parasiten vorhanden und im Western Blot war die Inhibierung der Expression von PARP-1 ähnlich stark wie mit Hitze-inaktivierten Parasiten (nicht gezeigte Ergebnisse). Ein PBS-lösliches T. gondii-Lysat führte dagegen im Vergleich zu unbehandelten Kontrollzellen nicht zur Reduktion des PARP-1-Proteinlevels (Abb. 15A). Im Gegensatz dazu war der PARP-1 Proteingehalt von Wirtszellen nach Inkubation mit einer PBS-unlöslichen Fraktion eines T. gondii-Extraktes um mehr als $50 \%$ niedriger als in unbehandelten Zellen (Abb. 15A). Durch Immunfluoreszenfärbung und Mikroskopie wurden diese Ergebnisse bestätigt und erweitert. So inhibierten Parasiten, die durch Tieffrieren bei $-20^{\circ} \mathrm{C}$ oder HitzeBehandlung inaktiviert worden waren, die PARP-1 Expression genauso effektiv wie lebende unbehandelte T. gondii Tachyzoiten (Abb. 15B). Dabei war PARP-1 nach Inkubation mit lebenden oder inaktivierten Parasiten auch in solchen Zellen deutlich reduziert, bei denen kein direkter Kontakt zwischen Wirtszelle und einem Parasiten nachgewiesen werden konnte. Allerdings kann nicht ausgeschlossen werden, dass extrazelluläre, an Wirtszellen adhärierte Parasiten durch Waschen während der Immunfluoreszenzfärbung abgespült wurden. Die Inhibierung der Expression von PARP-1 durch inaktivierte Parasiten bestätigte außerdem, dass auch in parasitnegativen Wirtszellen einer infizierten Population der PARP-1 Gehalt stark reduziert war, ohne dass es dabei zu einer Umverteilung von PARP-1 aus dem Zellkern kam (Abb. 3C und Abb. 15B). Zusammenfassend zeigten diese Resultate, dass sowohl das Eindringen in die Wirtszelle als auch die Replikation des Parasiten für die PARP1-Inhibierung offensichtlich ohne Bedeutung war. Allerdings scheinen Moleküle des Parasiten, die sich in einer PBS-unlöslichen Fraktion von Parasitenextrakten befanden und möglicherweise membranassoziiert waren, für die Reduktion von PARP-1 in der Wirtszelle eine wichtige Rolle zu spielen. 


\subsection{Fraktionierung von PBS-unlöslichen T. gondii-}

\section{Bestandteilen}

Die PBS-unlösliche $T$. gondii-Fraktion, die großteils Membranbestandteile des Parasiten enthalten haben dürfte, reduzierte den PARP-1 Proteingehalt ähnlich stark, wie lebende Parasiten. Dies legte die Vermutung nahe, dass ein Membranassoziiertes Protein diesen Effekt verursachen könnte. Zur näheren Untersuchung wurden daher verschiedene Fraktionen Membran-assoziierter Proteine von T. gondii hergestellt (PRZYBORSKI et al., 2005). Die S1-Fraktion enthielt vor allem periphere Membran- assoziierte Proteine, die durch Waschen mit einem NatriumcarbonatPuffer isoliert werden konnten. Harnstoff-haltige Puffer sind in der Lage, komplexere Protein-Aggregate zu lösen, diese waren in der S2-Fraktion enthalten. In der S3Fraktion befanden sich hauptsächlich hydrophobe integrale Membranproteine, die durch einen Triton X-100-haltigen Puffer isoliert werden konnten. In der P1-Fraktion waren die durch diese Behandlungen nicht isolierten Proteine und Membranreste enthalten. Die verschiedenen Fraktionen wurden für 1 h mit RAW 264.7 Monocyten/Makrophagen inkubiert. Anschließend wurden Gesamtproteinextrakte der Wirtszellen mittels SDS-PAGE aufgetrennt und durch Western Blot auf ihren PARP-1 Proteingehalt überprüft. Als Kontrolle dienten Zellen, die mit lebenden Tachyzoiten infiziert worden waren und in denen im Vergleich zu nicht-infizierten Zellen eine Reduzierung des PARP-1-Proteinlevels um über $80 \%$ beobachtet wurde (Abb. 16). Die S1-Fraktion, die hauptsächlich periphere Membran-assoziierte Proteine von $T$. gondii enthielt, führte zu einer Reduktion des PARP-1-Gehaltes um $90 \%$ und damit zu einer stärkeren Hemmung als lebende Tachyzoiten, auch wenn quantitativ kein Mengenvergleich zwischen Parasiten und S1-Fraktion auf Grund der Herstellung der Fraktionen möglich war. Eine leichte Inhibierung um 25\% zeigte auch die S2Fraktion, wo hingegen die S3-Fraktion keine Inhibierung des PARP-1-Proteinlevels verursachen konnte (Abb. 16). Die P1-Fraktion, die die restlichen nicht-isolierten Proteine und Membranreste enthielt, führte zu einer Inhibierung der Expression von PARP-1 um etwa $60 \%$, was entweder auf nicht gelöste periphere Membranproteine oder ein zusätzliches Protein bzw. Molekül, welches ebenfalls PARP-1 inhibieren kann, zurückzuführen sein könnte. Diese Ergebnisse deuteten darauf hin, dass ein Membran-assoziiertes Protein von T. gondii an der Inhibierung der Expression von PARP-1 in Wirtszellen beteiligt war. 


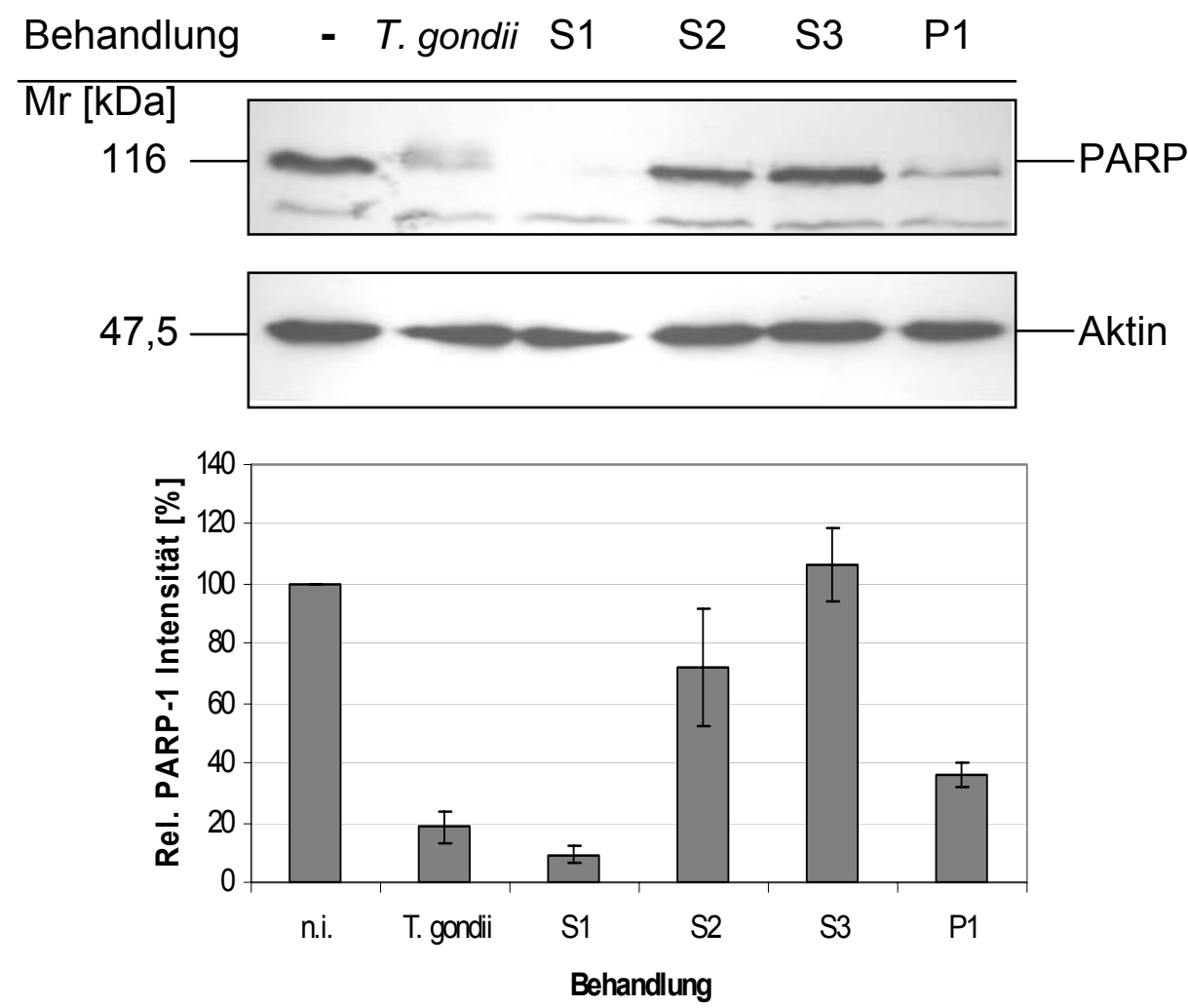

\section{Abb. 16: Ein peripher assoziiertes Membranprotein von T. gondii ist an der Hemmung von PARP-1 beteiligt.}

Eine PBS-unlösliche Fraktion von T. gondii Tachyzoiten des Stammes NTE wurde durch Inkubation in unterschiedlichen Puffern sequentiell fraktioniert. S1-Fraktion: peripher-assoziierte Membranproteine, die mittels eines Natriumcarbonatpuffers, $\mathrm{pH}$ 11, isoliert wurden; S2-Fraktion: durch Harnstoff aus der Membran lösbare Proteine und Proteinkomplexe; S3-Fraktion: hydrophobe integrale Membranproteine, die durch einen Triton X-100 haltigen Puffer gelöst wurden; P1-Fraktion: Suspension des aus dem letzten Fraktionierungsschritt resultierenden Pellets. Je $50 \mu \mathrm{l}$ pro Fraktion wurde jeweils $1 \mathrm{~h}$ mit RAW 264.7 Monocyten/Makrophagen inkubiert. Als Kontrolle dienten RAW 264.7 Monocyten/Makrophagen, die mit T. gondii Tachyzoiten im Parasit-Wirt-Verhältnis von 4:1 infiziert wurden oder nicht-infiziert blieben. Gesamtproteinextrakte der Wirtszellen wurden durch SDSPAGE aufgetrennt und auf Nitrozellulosemembran übertragen. PARP-1 und Aktin wurden mittels entsprechender Primärantikörper und Meerrettichperoxidase-gekoppelter Sekundärantikörper durch "enhanced chemiluminescence" sichtbar gemacht. Der Graph stellt die densitometrische Auswertung der Western Blots dar, dazu wurden jeweils die relativen PARP-Intensitäten berechnet (PARP/Aktin $\mathrm{x}$ 100). Die PARP-Intensität der nicht-infizierten Kontrolle wurde als $100 \%$ definiert und alle anderen Werte im Verhältnis dazu bestimmt. Die Balken entsprechen dem Mittelwert von drei unabhängigen Versuchen, die Fehlerbalken stellen den Standardfehler $( \pm)$ des Mittelwertes dar. Mr: Molekulargewichtsmarker

Zur weiteren Charakterisierung möglicherweise beteiligter Proteine wurden ein PBSlöslicher Parasitenextrakt und die Fraktionen S1 bis S3 durch SDS-PAGE analysiert. Nach anschließender Silberfärbung wurde in der S1-Fraktion eine deutliche Doppelbande von etwa 30 kDa nachgewiesen, die weder im PBS-löslichen T. gondiiLysat noch in den S2- und S3-Fraktionen vorhanden waren, welche im Gegensatz zu 
S1 keinen deutlichen Einfluss auf den PARP-1-Proteinlevel der Wirtszellen besaßen (Abb. 17). Da T. gondii mit SAG1, einem Glycosylphosphatidylinositol (GPI)verankerten Hauptoberflächenprotein ein Molekül ähnlicher Größe aufweist (p30), sollte nachfolgend überprüft werden, ob SAG1 an der Inhibierung der Expression von PARP-1 durch $T$. gondii beteiligt sein könnte. SAG1 ist an der Wirtszellinvasion beteiligt (GRIMWOOD und SMITH, 1992; MINEO und KASPER, 1994) und verursacht starke Immunantworten des Wirtes (CHARDES et al., 1990; CHARDES et al., 1993; SENG et al., 2002). Um zu untersuchen, ob möglicherweise SAG1 die PARP-1Inhibierung vermittelt, wurde eine SAG1-defiziente Parasitenmutante ( $\triangle S A G 1$ ) verwendet und als Kontrolle deren parentaler Stamm verwendet (freundlicherweise von S. Tomavo, Lille, Frankreich, zur Verfügung gestellt).

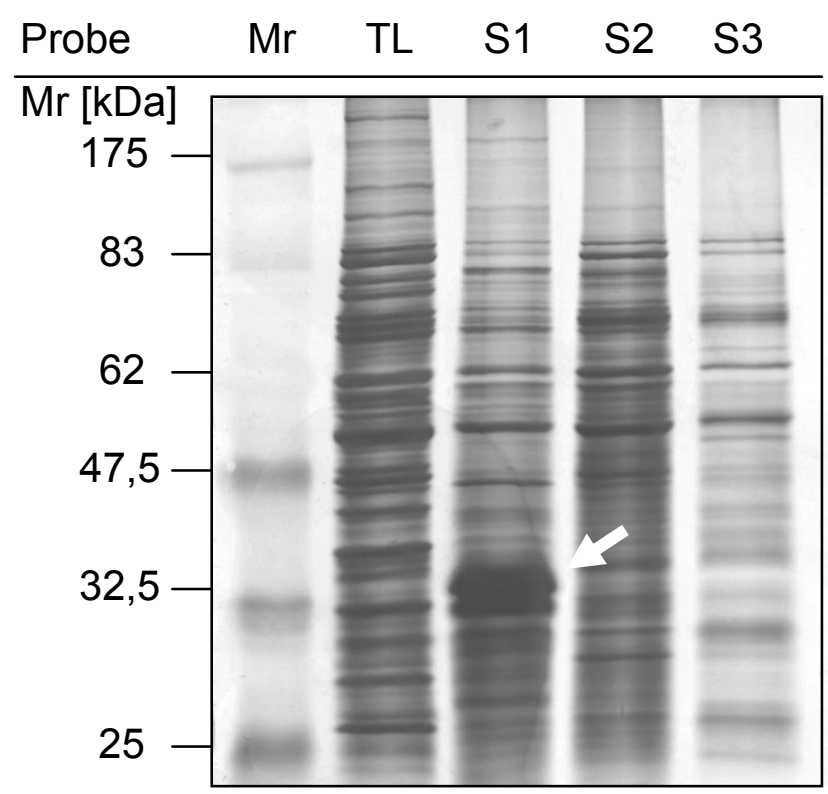

\begin{abstract}
Abb. 17: Elektrophoretische Analyse der Membranfraktionen S1 bis S3 von T. gondii mittels SDS-PAGE.

Eine PBS-unlösliche Fraktion von T. gondii Tachyzoiten des Stammes NTE wurde durch Inkubation in unterschiedlichen Puffern sequentiell fraktioniert. S1-Fraktion: peripher-assoziierte Membranproteine, die mittels eines Natriumcarbonatpuffers, $\mathrm{pH}$ 11, isoliert wurden; S2-Fraktion: durch Harnstoff aus der Membran lösbare Proteine und Proteinkomplexe; S3-Fraktion: hydrophobe integrale Membranproteine, die durch einen Triton X-100 haltigen Puffer gelöst wurden. Die Membranfraktionen sowie ein PBS-lösliches $T$. gondii-Lysat (TL; $50 \mu \mathrm{g}$ ) wurden durch SDS-PAGE aufgetrennt und das Gesamtproteinprofil der Proben durch Silberfärbung sichtbar gemacht. Der weiße Pfeil hebt eine auffällige Doppelbande von etwa $30 \mathrm{kDa}$ hervor, die in S1, nicht aber in den anderen Proben nachweisbar war. Mr: Molekulargewichtsmarker;
\end{abstract}


Dazu wurde zunächst der SAG1-Gehalt von Mutante und Wildtyp mittels Immunoblot überprüft. Im Vergleich zum parentalen P-Stamm war in der $\triangle S A G 1$ Mutante kein SAG1 nachweisbar, während Katalase von beiden Stämmen gleichermaßen exprimiert wurde (Abb. 18A).

$\begin{array}{llllll}\text { Nach dem Nachweis der SAG1-Defizienz wurden } & \text { RAW } 264.7\end{array}$ Monocyten/Makrophagen nun für $1 \mathrm{~h}$ mit Tachyzoiten der $T$. gondii Stämme NTE, $P$ und $\triangle S A G 1$ infiziert und anschließend Gesamtproteinextrakte durch SDS-PAGE und Western Blot analysiert. Parasiten der NTE- und P-Stämme reduzierten den PARP1-Proteinlevel in Wirtszellen um durchschnittlich ca. 50\% (Abb. 18B). Interessanterweise führte auch die Infektion mit der $\triangle S A G 1$ Mutante zu einer Abnahme des PARP-1 Proteingehaltes in der Wirtszelle um etwa 50\% (Abb. 18B).

A

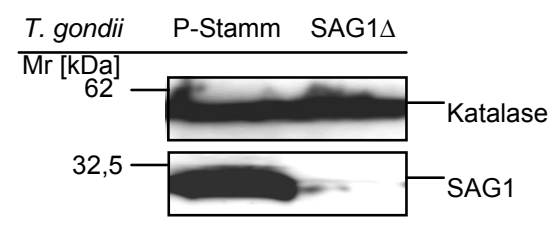

B

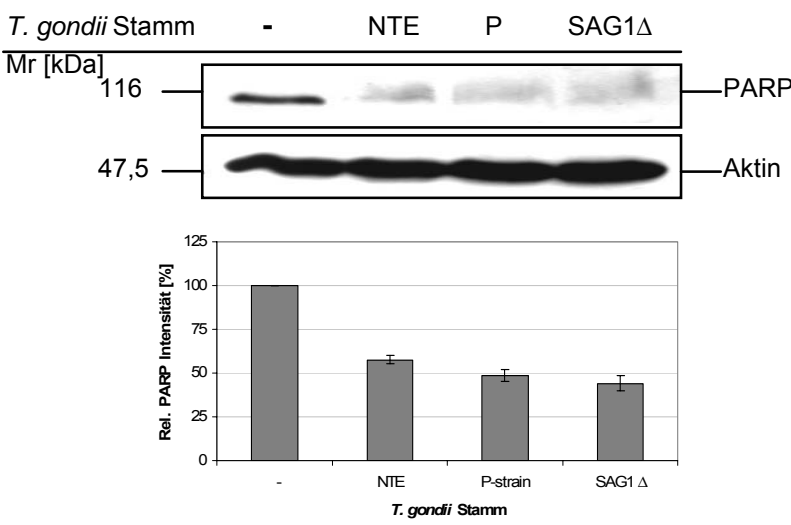

Abb. 18: SAG-1 von T. gondii ist nicht an der Inhibierung der Expression von PARP-1 beteiligt.

(A) $1 \times 10^{8}$ Tachyzoiten der SAG1-defizienten Mutante ( $\triangle$ SAG1) bzw. der parentalen Parasiten des PStammes wurden lysiert, Proteine durch SDS-PAGE aufgetrennt und auf Nitrocellulosemembran übertragen. Katalase und SAG1 wurden durch entsprechende Primärantikörper und Meerrettichperoxidase-gekoppelte Sekundärantikörper durch „enhanced chemiluminescence" sichtbar gemacht. Mr: Molekulargewichtsmarker (B) RAW 264.7 Monocyten/Makrophagen wurden im ParasitWirt-Verhältnis von 4:1 mit Tachyzoiten der $T$. gondii Stämme NTE und P sowie mit der SAG1defizienten Mutante ( $\triangle \mathrm{SAG} 1$ ) für $1 \mathrm{~h}$ infiziert oder blieben nicht-infiziert. Gesamtproteinextrakte der Wirtszellen wurden durch SDS-PAGE aufgetrennt und auf Nitrozellulosemembran übertragen. PARP1 und Aktin wurden durch entsprechende Primärantikörper und Meerrettichperoxidase-gekoppelte Sekundärantikörper durch "enhanced chemiluminescence" sichtbar gemacht. Der Graph stellt die densitometrische Auswertung der Western Blots dar, dazu wurden jeweils die relativen PARPIntensitäten berechnet (PARP/Aktin x 100). Die PARP-Intensität der nicht-infizierten Kontrolle wurde als $100 \%$ definiert und alle anderen Werte im Verhältnis dazu bestimmt. Die Balken entsprechen dem Mittelwert von drei unabhängigen Versuchen, die Fehlerbalken stellen den Standardfehler $( \pm)$ des Mittelwertes dar. Mr: Molekulargewichtsmarker 
Alle drei Stämme zeigten demnach vergleichbare Effekte auf PARP-1. SAG1 konnte daher als Verursacher der PARP-1-Inhibierung ausgeschlossen werden. Welches Molekül in der S1-Fraktion von T. gondii für die PARP-1-Inhibierung verantwortlich war, ist daher zurzeit ungeklärt.

\subsection{PARP-1-Überexpression in RAW 264.7 Monocyten/}

\section{Makrophagen}

PARP-1 hat Einfluss auf verschiedenste zelluläre Prozesse, wie DNA Reparatur, Apoptose, Nekrose, transkriptionelle Regulation und andere. Gleichzeitig ist T. gondii in der Lage, einige dieser Prozesse zu modulieren bzw. sie zu inhibieren. Aufgrund der Reduktion der PARP-1-Proteinlevel nach Infektion mit T. gondii stellte sich daher die Frage, wie sich eine Überexpression von PARP-1 in RAW 264.7 Zellen auf das Parasit-Wirt-Verhältnis auswirken würde. Für die Herstellung von PARP-1überexprimierenden RAW 264.7 Monocyten/Makrophagen wurde das murine PARP1 Gen aus RAW 264.7 Zellen amplifiziert, in den eukaryotischen Expressionsvektor pcDNA3.1/N5-His-TOPO Vektor kloniert und damit RAW 264.7 Monocyten/Makrophagen stabil transfiziert. Nach Isolierung von einzelnen Klonen wurden diese auf das Vorhandensein der zusätzlichen PARP-1 Genkopie im Genom mit spezifischen Primern mittels PCR überprüft. Die zusätzliche PARP-1 Genkopie war im Genom von mehreren Klonen, u.a. den drei Klonen A12, C6 und E6, nachweisbar (Abb. 19A). Bei diesen drei Klonen waren auch Transkripte der zusätzlichen PARP-1 Kopie sowie endogene plus rekombinante PARP-1 Transkripte durch RT-PCR nachweisbar (Abb. 19B). Als Kontrolle der RT-PCR-Analyse diente das Housekeeping-Gen ß-Aktin (Abb. 19B). Bei A12, C6 und E6 handelte es sich dabei um Klone, die mit einer PARP-1 Kopie transfiziert worden waren, die das STOP-Codon des PARP-Genes enthielt, so dass das später exprimierte Protein kein His-Tag oder V5-Epitop besaß. Des Weiteren sollten mittels eines anderen 3 `Primers (3'PARP), der kein Stop-Codon des PARP-1 Gens enthielt, weitere Klone mit einer PARP-1 Kopie hergestellt werden, bei denen das später exprimierte Fusionsprotein sowohl ein Penta-His-Tag als auch ein V5-Epitop als Erkennungssequenz besitzen 
A

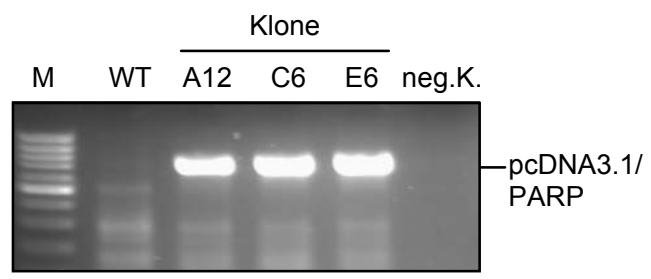

B

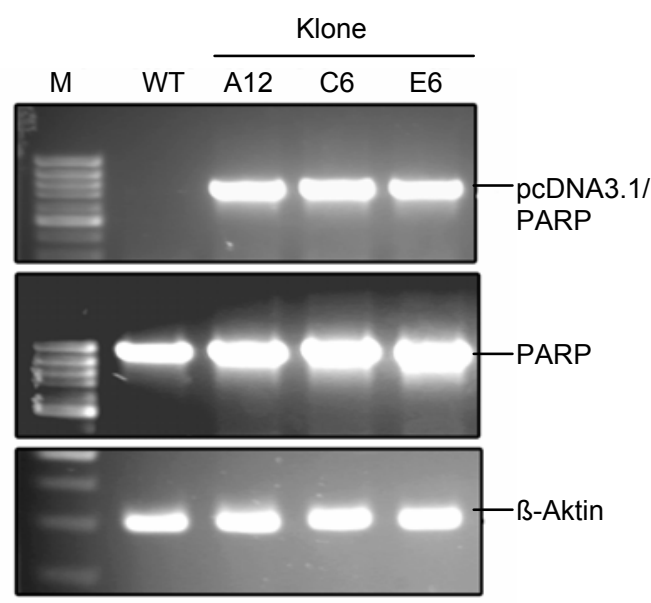

Abb. 19: Nachweis einer zusätzlichen PARP-1-Kopie in RAW 264.7 Monocyten/Makrophagen.

(A) Aus drei PARP-1 transfizierten RAW 264.7 Klonen und Wildtyp Zellen (WT) wurde genomische DNA isoliert. Anschließend wurde die zusätzliche Genkopie mittels PCR und PARP-1/Vektor (pcDNA3.1)-spezifischen Primern in einem 1\% Agarosegel nachgewiesen. M: 1kb DNA Marker; neg.K.: Negativkontrolle (B) Aus den drei PARP-1 transfizierten RAW 264.7 Klonen und WildtypZellen (WT) wurde RNA isoliert und mRNA revers transkribiert. Mit der resultierenden cDNA wurden mit PARP-1- und Vektor-spezifischen (pcDNA3.1/PARP), PARP-1- und B-Aktin-spezifischen Primer Paaren PCRs durchgeführt und anschließend in einem 1\% Agarosegel aufgetrennt. M: $1 \mathrm{~kb}$ DNA Marker (pcDNA3.1/PARP-Amplifikation) bzw. 100 bp DNA Marker (PARP- bzw. B-Aktin-Amplifikation)

würde. Bei den zuletzt genannten Klonen war zwar ein Nachweis auf genomischer Ebene möglich, allerdings konnte weder auf mRNA-Ebene eine Expression dieser zusätzlichen PARP-1 Kopie noch beim Gesamtproteinextrakt die Überexpression auf Proteinebene mit dem PARP-1-, dem V5- oder His-Tag-Antikörper nachgewiesen werden (nicht gezeigte Ergebnisse). Durch Auftrennung von Gesamtproteinextrakten der drei RAW 264.7-Klone A12, C6 und E6 sowie von Wildtyp-Zellen mittels SDSPAGE und anschließendem PARP-1 Nachweis mittels Immunblot wurde die PARP-1 Expression auf Proteinebene nachgewiesen. Die drei Klone exprimierten PARP-1 im Vergleich zu Wildtypzellen deutlich stärker (Abb. 20A). Die Klone A12 und E6 zeigten eine Überexpression um mehr als 50\%, während der Klon C6 sogar mehr als doppelt so viel PARP-1 exprimierte wie Wildtypzellen (Abb. 20A). Diese Ergebnisse konnten mittels Immunfluoreszenzfärbung bestätigt werden (Abb. 20B). Mikroskopische Analysen ergaben dabei, dass die überwiegende Mehrzahl der Zellen der drei Klone A12, C6 und E6 im Zellkern mehr PARP-1 exprimierten als Wildtypzellen (Abb. 20B). Dies wies darauf hin, dass nicht nur einzelne Zellen der Klone PARP-1 verstärkt exprimierten, sondern auch die gesamten Populationen der transfizierten Zellen 
einen erhöhten PARP-1-Gehalt im Zellkern aufwiesen. Zusammenfassend zeigten diese Ergebnisse, dass RAW 264.7 Monocyten/Makrophagen erfolgreich mit einer

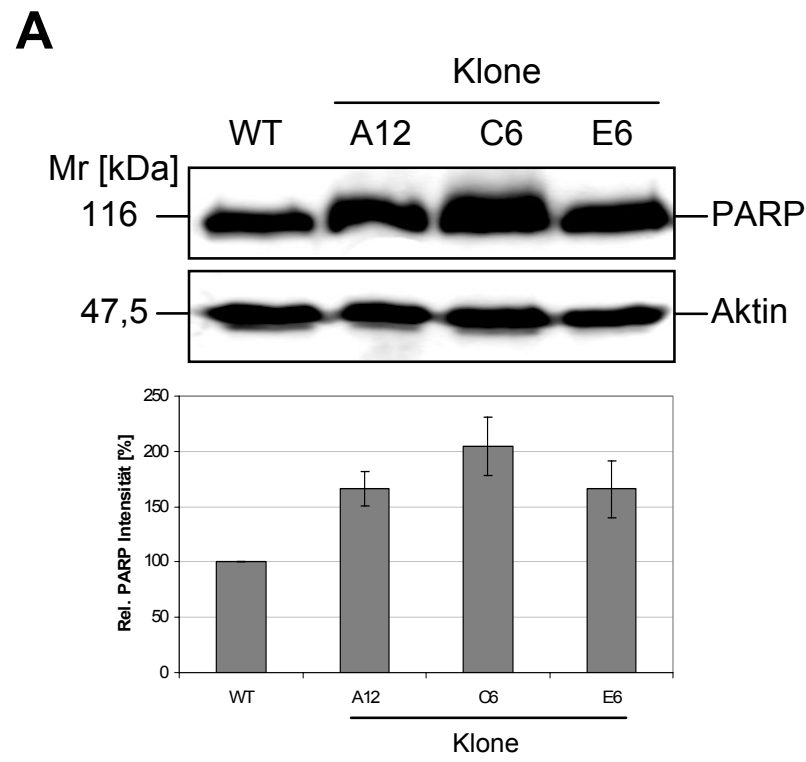

B

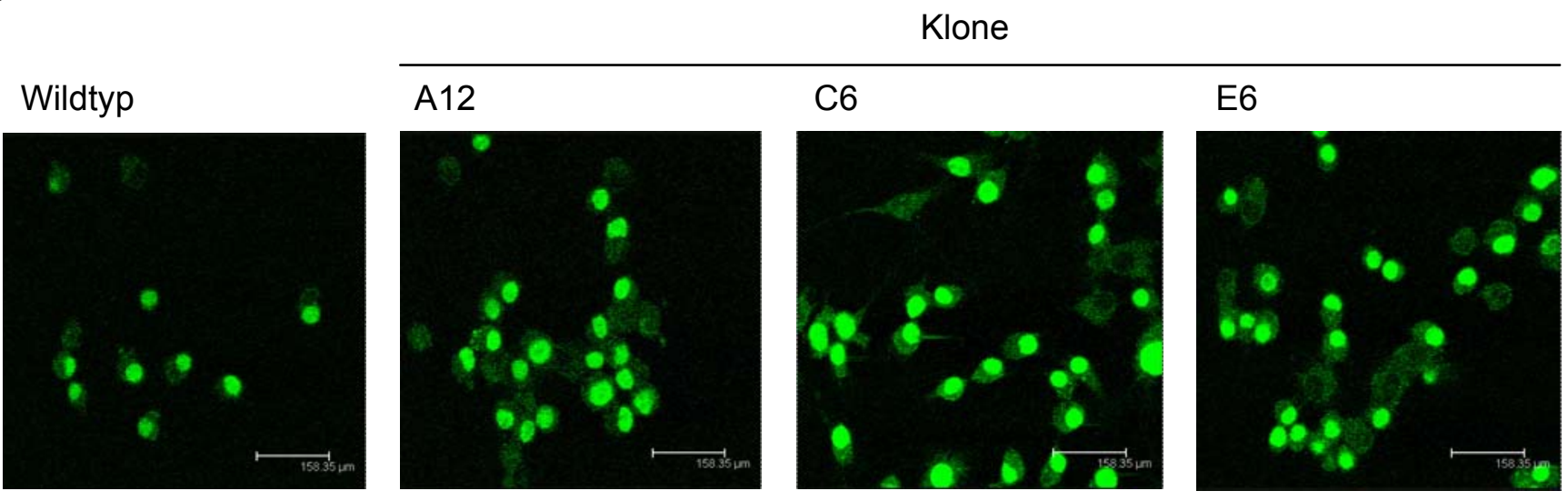

\section{Abb. 20: Überexpression von PARP-1 in RAW 264.7 Monocyten/Makrophagen.}

(A) Gesamtproteinextrakt aus drei Klonen PARP-1 transfizierter RAW 264.7 Monocyten/Makrophagen oder deren Wildtypzellen (WT) wurden durch SDS-PAGE aufgetrennt und auf Nitrozellulosemembran übertragen. PARP-1 und Aktin wurden mittels entsprechender Primärantikörper und Meerrettichperoxidase-gekoppelter Sekundärantikörper durch „enhanced chemiluminescence“ sichtbar gemacht. Der Graph stellt die densitometrische Auswertung der Western Blots dar, dazu wurden jeweils die relativen PARP-Intensitäten berechnet (PARP/Aktin x 100). Die PARP-Intensität der Wildtypzellen wurde als 100\% definiert und alle anderen Werte im Verhältnis dazu bestimmt. Die Balken entsprechen dem Mittelwert von drei unabhängigen Versuchen, die Fehlerbalken stellen den Standardfehler $( \pm)$ des Mittelwertes dar. Mr: Molekulargewichtsmarker (B) Drei Klone PARP-1 transfizierter RAW 264.7 Monocyten/Makrophagen und Wildtypzellen (WT) wurden auf Glasdeckgläschen ausgesät und $24 \mathrm{~h}$ später wurde PARP-1 mittels eines spezifischen Primärantikörpers und Cy-2-konjugiertem Sekundärantikörper (grüne Fluoreszenz) sichtbar gemacht. Die Proben wurden mikroskopisch mit einem Leica TCS SP2 Konfokalmikroskop ausgewertet. 
zusätzlichen Kopie des murinen PARP-1 Gens transfiziert werden konnten und dies in einigen Klonen zur verstärkten Expression von PARP-1 im Vergleich zu Wildtypzellen führte.
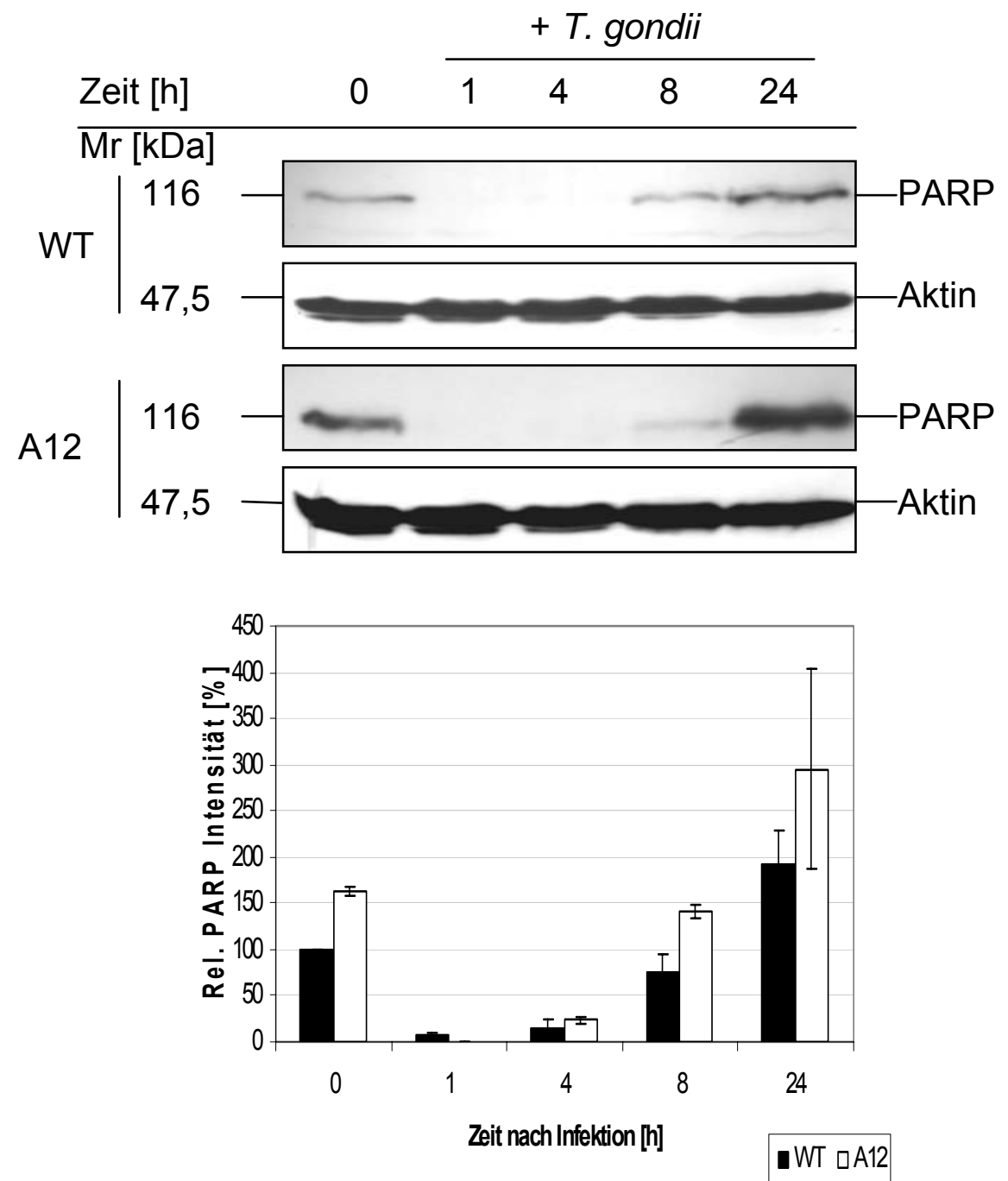

\section{Abb. 21: Vergleich der PARP-1 Expression zwischen Wildtyp und PARP-1-überexprimierender Mutante A12 nach T. gondii-Infektion.}

PARP-1-überexprimierende RAW 264.7 Monocyten/Makrophagen (Klon A12: weiße Balken) und Wildtypzellen (WT: schwarze Balken) wurden mit frisch isolierten Tachyzoiten des T. gondii Stammes NTE im Parasit-Wirt-Verhältnis von 4:1 für unterschiedliche Zeiten infiziert oder blieben nicht-infiziert. Gesamtproteinextrakte der Wirtszellen wurden mittels SDS-PAGE aufgetrennt und auf Nitrozellulosemembran übertragen. PARP-1 und Aktin wurden mittels entsprechender Primärantikörper und Meerrettichperoxidase-gekoppelter Sekundärantikörper durch „enhanced chemiluminescence" sichtbar gemacht. Der Graph stellt die densitometrische Auswertung der Western Blots dar, dazu wurden jeweils die relativen PARP-Intensitäten berechnet (PARP/Aktin x 100). Die PARP-Intensität der Wildtypzellen vor Infektion mit $T$. gondii wurde als $100 \%$ definiert und alle anderen Werte im Verhältnis dazu bestimmt. Die Balken entsprechen dem Mittelwert von drei unabhängigen Versuchen, die Fehlerbalken stellen den Standardfehler $( \pm)$ des Mittelwertes dar. Mr: Molekulargewichtsmarker. 
Um den Einfluss der Überexpression von PARP-1 auf die Parasit-Wirt-Interaktion während Infektionen mit T. gondii bewerten zu können, war es zunächst notwendig die PARP-1 Expression in stabil transfizierten RAW 264.7-Mutanten nach Infektion mit dem Parasiten zu untersuchen. Dazu wurden repräsentativ stabil transfizierte Zellen des Klones A12 sowie RAW 264.7 Wildtypzellen mit T. gondii Tachyzoiten für unterschiedliche Zeiten infiziert. Gesamtproteinextrakte der Zellen wurden danach mittels SDS-PAGE und Western Blot auf ihren PARP-1 Proteingehalt überprüft. Bemerkenswerterweise führte $T$. gondii in transfizierten Zellen zu einer ähnlich starken Hemmung der PARP-1 Expression wie in Wildtypzellen (Abb. 21). Der Verlauf der PARP-1-Inhibierung in den Zellen des A12-Klones durch T. gondii war dabei vergleichbar dem Verlauf der Hemmung in Wildtypzellen. So führte trotz der Überexpression von PARP-1 in nicht-infizierten Zellen des Klones A12 die Infektion

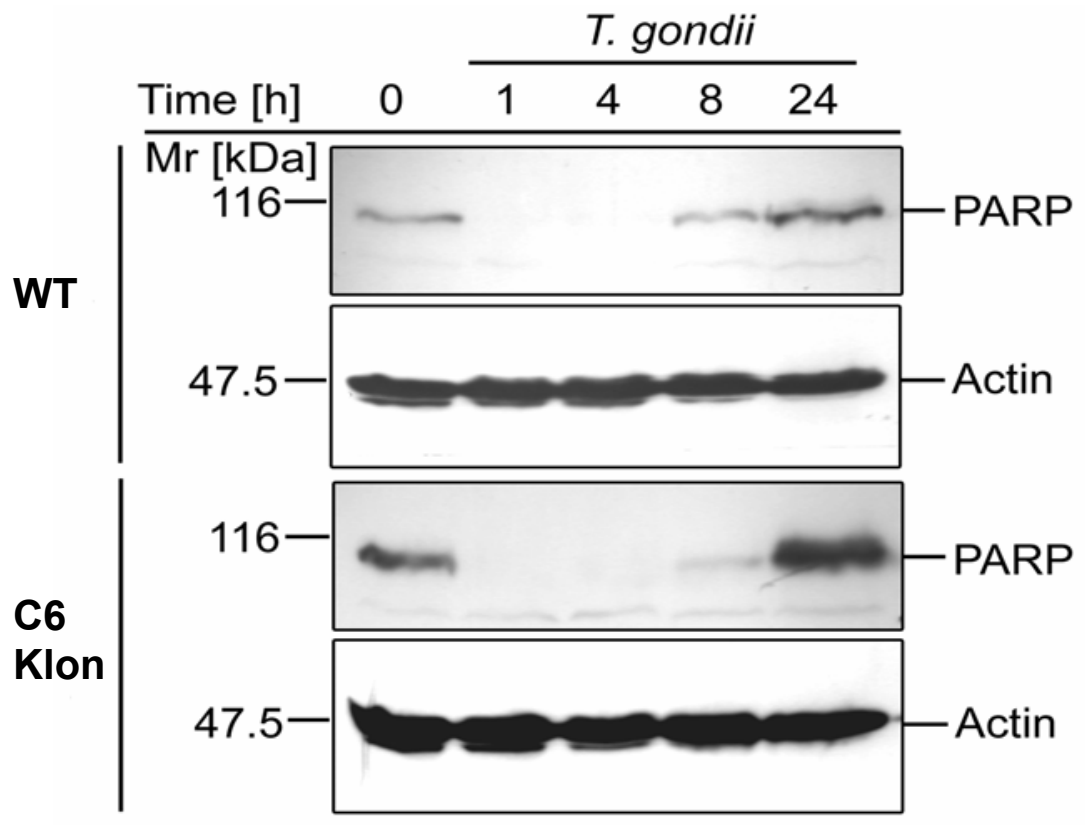
Abb. 22: Vergleich der PARP-1 Expression zwischen Wildtyp und PARP-1-überexprimierender
C6 Mutante nach T. gondii-Infektion.

PARP-1-überexprimierende RAW 264.7 Monocyten/Makrophagen (Klon C6) und Wildtypzellen (WT) wurden mit frisch isolierten Tachyzoiten des $T$. gondii Stammes NTE im Parasit-Wirt-Verhältnis von 4:1 für unterschiedliche Zeiten infiziert oder blieben nicht-infiziert. Gesamtproteinextrakte der Wirtszellen wurden mittels SDS-PAGE aufgetrennt und auf Nitrozellulosemembran übertragen. PARP1 und Aktin wurden mittels entsprechender Primärantikörper und Meerrettichperoxidase-gekoppelter Sekundärantikörper durch "enhanced chemiluminescence“ sichtbar gemacht. Mr: Molekulargewichtsmarker. 
Hemmung auf weniger als $20 \%$ des Wertes nicht-infizierter Kontrollzellen (Abb. 21). Nach 8 h Infektion stieg die PARP-1 Expression sowohl beim Wildtyp und als auch beim A12-Klon an, lag jedoch bei beiden unterhalb der PARP-1 Menge der nichtinfizierten Zellen. Nach 24 h Infektionszeit waren die PARP-1 Proteingehalte in beiden Zellpopulationen höher als die nicht-infizierten Kontrollen (Abb. 21). Trotz Überexpression war T. gondii demnach in der Lage, PARP-1 sehr effektiv und transient in transfizierten Zellen zu hemmen. Vergleichbare Ergebnisse konnten auch für die beiden anderen Klone C6 (Abb. 22) und E6 (nicht gezeigt) beobachtet

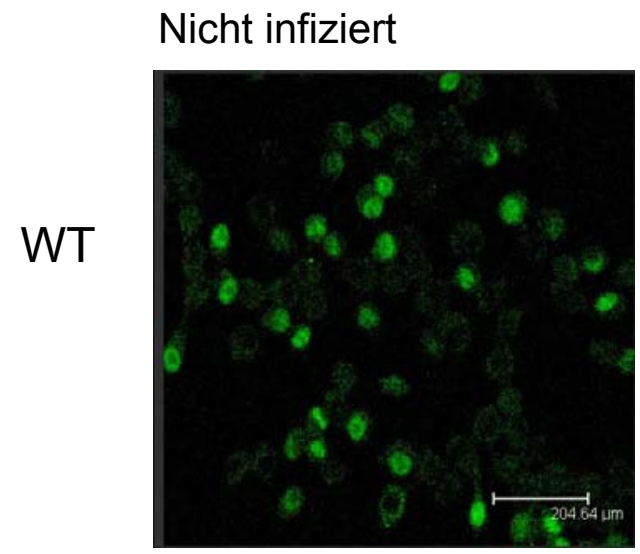

$1 \mathrm{~h}$ nach Infektion
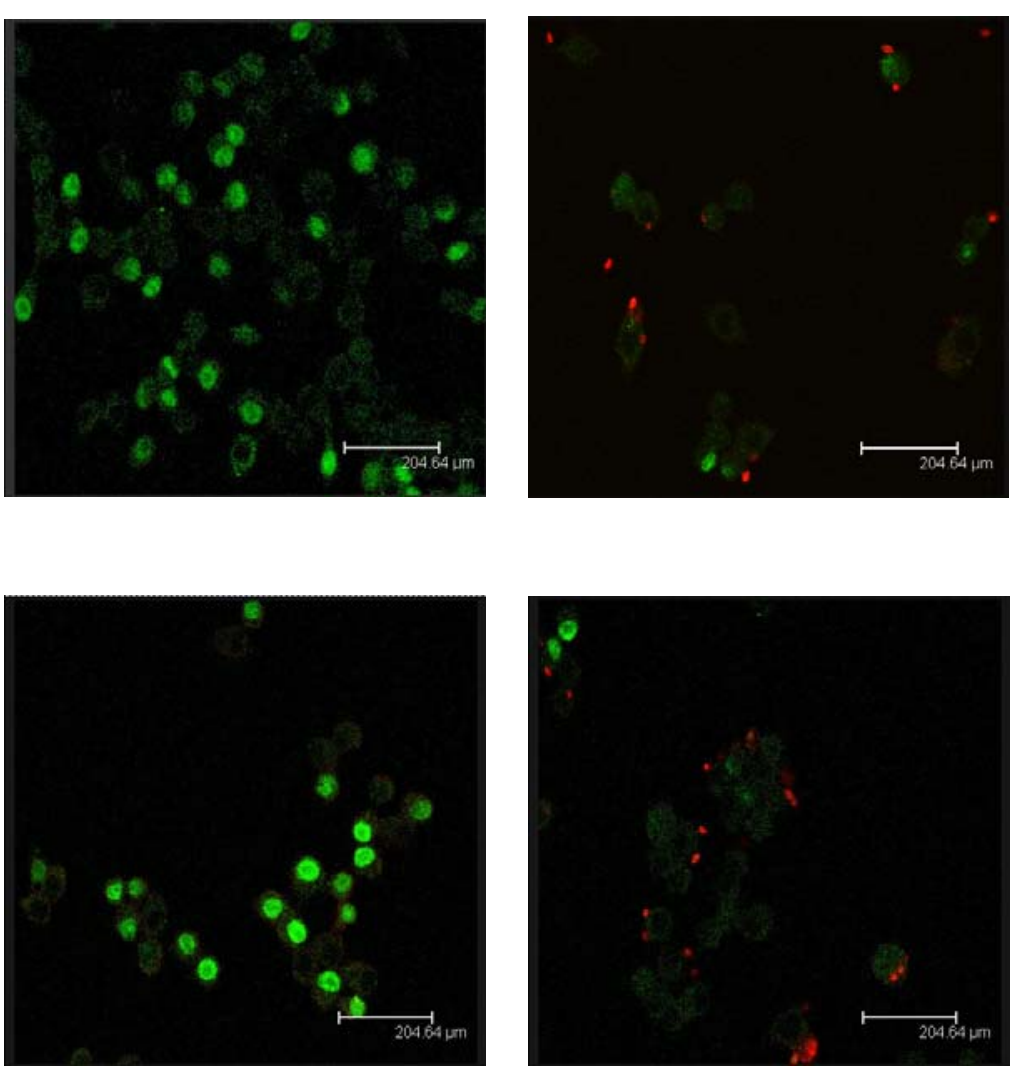

24 h nach Infektion
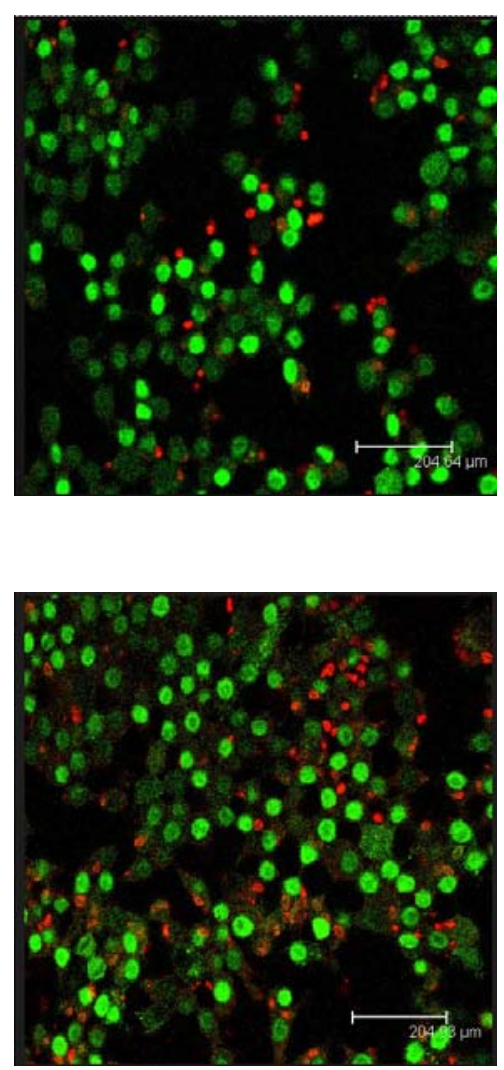

Abb. 23: Vergleich der PARP-1 Expression zwischen Wildtyp und PARP-1-überexprimierenden Mutanten nach T. gondii-Infektion mittels Immunfluoreszenzfärbung.

PARP-1-überexprimierende RAW 264.7 Monocyten/Makrophagen (Klon A12) oder deren Wildtypzellen (WT) wurden 1 oder $24 \mathrm{~h}$ im Parasit-Wirt-Verhältnis von 4:1 mit Tachyzoiten des NTE Stammes von $T$. gondii infiziert oder blieben nicht-infiziert. Durch Immunfluoreszenzfärbung wurden PARP-1 und T. gondii Tachyzoiten mittels spezifischer Primärantikörper und Cy-2-konjugiertem (PARP-1: grüne Fluoreszenz) oder Cy-3-konjugiertem (T. gondii: rote Fluoreszenz) Sekundärantikörper sichtbar gemacht. Die Proben wurden mikroskopisch mit einem Leica TCS SP2 Konfokalmikroskop ausgewertet. 
werden. Diese Ergebnisse wurden auf Einzelzellebene mittels Immunfluoreszenzfärbung bestätigt und erweitert (Abb. 23). So führte $T$. gondii in Zellen des mit PARP-1 transfizierten Klons A12 $1 \mathrm{~h}$ nach Infektion nicht nur in parasit-positiven sondern auch in parasit-negativen Zellen zu einem stark reduziertem PARP-1 Gehalt. Wie bereits an Wildtypzellen gezeigt, kam es dabei nicht zu einer Umverteilung von PARP-1 aus dem Zellkern in andere Zellkompartimente. Dies konnte auch für die anderen PARP-1-transfizierten Klone C6 und E6 nachgewiesen werden (nicht gezeigte Ergebnisse). T. gondii war demnach in der Lage, die deutlich erhöhten PARP-1-Proteinlevel der PARP-1transfizierten Klone schnell, aber transient zu reduzieren.

\subsection{Auswirkung der PARP-1 Überexpression auf das Parasit-}

\section{Wirt-Verhältnis}

\subsubsection{Invasion und Replikation von T. gondii in PARP-1 überexprimierenden RAW 264.7-Mutanten}

Obwohl die Infektion mit $T$. gondii die PARP-1 Expression auch in überexprimierenden RAW 264.7-Mutanten schnell und effektiv hemmte, wiesen diese dennoch vor Infektion und während späterer Infektionszeitpunkte deutlich mehr PARP-1 auf als Wildtypzellen. Die Mutanten wurden daher nachfolgend dazu eingesetzt, um den Einfluss von PARP-1 und dessen Modulation durch T. gondii auf die Parasit-Wirt-Interaktion zu untersuchen. Dazu wurde zunächst ermittelt, ob es Unterschiede im Invasions- und Replikationsverhalten des Parasiten in Abhängigkeit von einer PARP-1 Überexpression gab. Dazu wurden PARP-1 überexprimierende RAW 264.7 Monocyten/Makrophagen und Wildtypzellen mit transgenen T. gondii $\mathrm{RH} / \mathrm{HXGPRT}$ /Sag1/lacZ Tachyzoiten infiziert, die als Reporter mit bakteriellem lacZ unter der Kontrolle des SAG1-Promotors transfiziert waren (SEEBER und BOOTHROYD, 1996). Die Expression der ß-Galaktosidase wurde 24 und 45 h nach Infektion durch Farbreaktion sichtbar gemacht und photometrisch gemessen und war ein Maß für die Anzahl intrazellulärer Parasiten. Während in nicht-infizierten RAW 264.7-Zellen wie erwartet nur eine geringe Hintergrundfärbung gemessen wurde, stieg die 


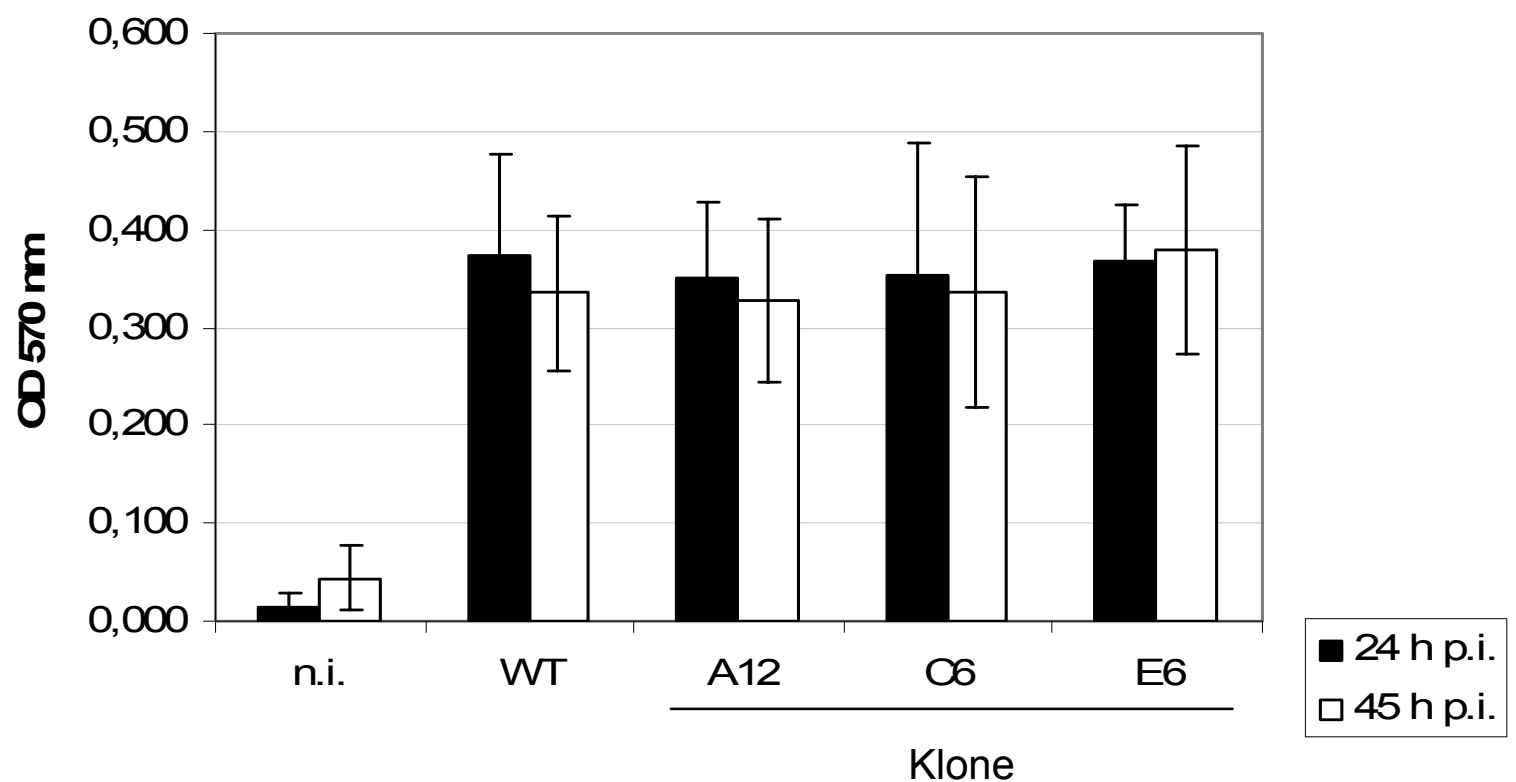

\section{Abb. 24: Entwicklung von T. gondii in PARP-1 überexprimierenden RAW 264.7-Mutanten.}

Die PARP-1-überexprimierenden RAW 264.7-Mutanten A12, C6 und E6 sowie Wildtypzellen wurden mit ß-Galaktosidase-exprimierenden $T$. gondii Tachyzoiten RH/HXGPRT/Sag1/lacZ für $1 \mathrm{~h}$ infiziert oder blieben nicht-infiziert (n.i.). Anschließend wurden extrazelluläre Parasiten entfernt und $24 \mathrm{~h}$ (schwarze Balken) bzw. 45 h (weiß Balken) nach Infektion die ß-Galaktosidaseaktivität nach Zugabe von Chlorophenolred-B-D-galactopyranoside (CPRG) durch Farbreaktion photometrisch bei $570 \mathrm{~nm}$ gemessen. Die Balken des Graphen repräsentieren die Mittelwerte aus drei unabhängigen Versuchen, die Fehlerbalken zeigen den Standardfehler $( \pm)$ des Mittelwertes.

ß-Galaktosidaseaktivität 24 und $45 \mathrm{~h}$ nach Infektion deutlich an (Abb. 24). Die Enzymaktivität unterschied sich dabei jedoch nicht zwischen $T$. gondii-infizierten Wildtypzellen einerseits und Zellen der PARP-1-überexprimierenden RAW-Mutanten A12, C6 und E6 andererseits (Abb. 24). Dabei ist zu beachten, dass die Farbreaktion nach 24 und $45 \mathrm{~h}$ Infektionsdauer bei Erreichen eines ähnlichen Farbumschlages abgestoppt wurde, so dass die photometrische Messung nicht der Zunahme der Parasitenzahl von 24 bis $45 \mathrm{~h}$ p.i. entsprach. Diese Ergebnisse wiesen deutlich darauf hin, dass sich $T$. gondii unabhängig von einer Überexpression von PARP-1 in Wildtypzellen und PARP-1-Mutanten ähnlich gut entwickeln konnte. Der ßGalaktosidase-Test erlaubte quantitative Aussagen über die Entwicklung von $T$. gondii auf Populationsebene, er erlaubte jedoch keine Aussage über mögliche Unterschiede hinsichtlich Wirtszellinvasion und intrazellulärer Replikation von $T$. gondii in Wildtypzellen oder PARP-1-überexprimierenden Mutanten. 


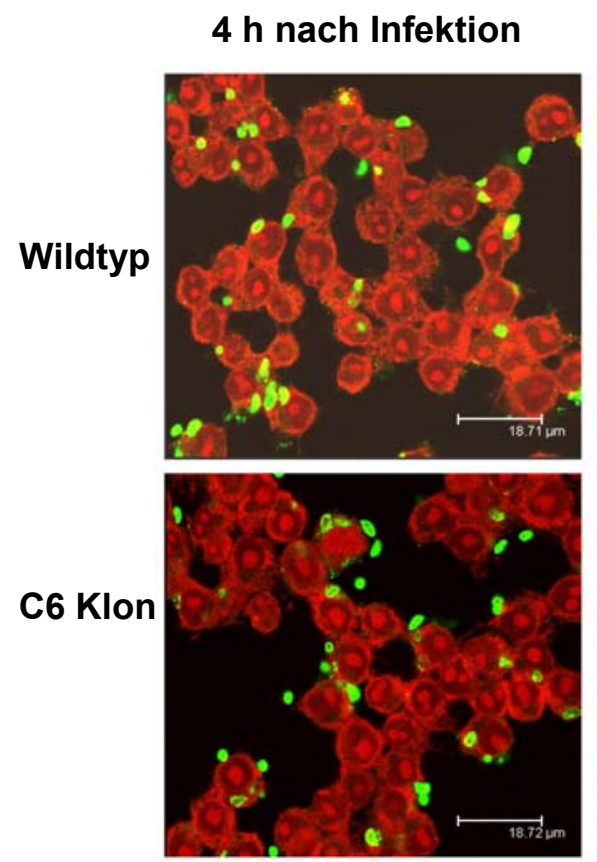

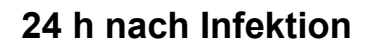
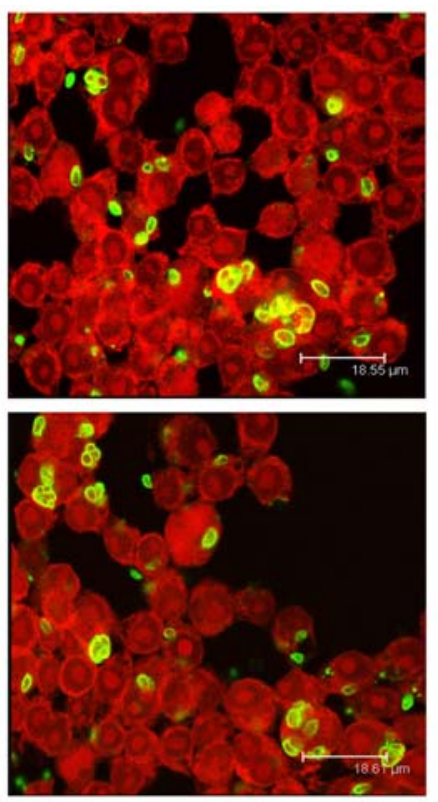

$48 \mathrm{~h}$ nach Infektion
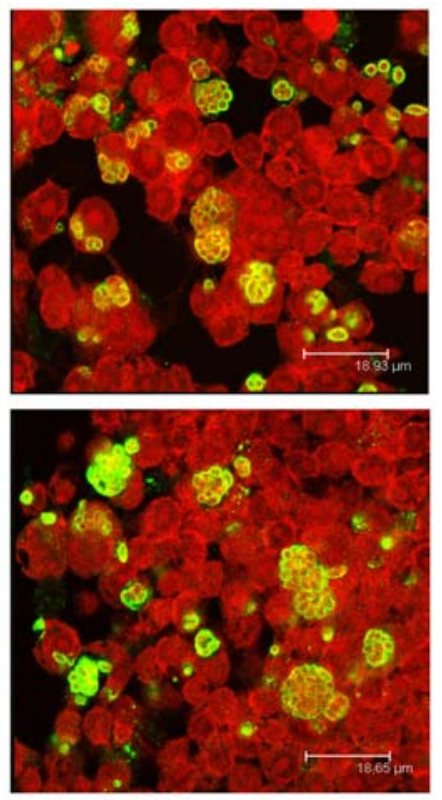

Abb. 25: Einfluss einer PARP-1 Überexpression in Wirtszellen auf Invasion und Replikation von T. gondii.

PARP-1 überexprimierende RAW 264.7 Monocyten/Makrophagen (C6 Klon) oder deren Wildtypzellen (WT) wurden für $4 \mathrm{~h}, 24 \mathrm{~h}$ und $48 \mathrm{~h}$ mit $T$. gondii Tachyzoiten des Stammes NTE im Parasit-WirtVerhältnis 4:1 infiziert. Durch Immunfluoreszenzfärbung wurden $T$. gondii Tachyzoiten mittels eines spezifischen Primärantikörpers und Cy-2-konjugiertem Sekundärantikörpers (grüne Fluoreszenz) sichtbar gemacht. Doppelsträngige Nukleinsäuren wurden mit Propidiumiodid angefärbt (rote Fluoreszenz). Die Proben wurden mikroskopisch mit einem Leica TCS SP2 Konfokalmikroskop ausgewertet.

Daher wurde mittels Immunfluoreszenzfärbung das Invasions- und Replikationsverhalten von T. gondii in Wildtypzellen und PARP-1überexprimierenden RAW 264.7 Monocyten/Makrophagen auf Einzelzellebene untersucht. Nach $4 \mathrm{~h}$ Infektion waren vergleichbar viele Zellen des Wildtyps und des C6-Klons mit T. gondii des Stammes NTE infiziert, was auf eine ähnliche Invasionsrate schließen ließ (Abb. 25). Nach 24 und 48 h Infektionszeit enthielten außerdem die parasitophoren Vakuolen ähnliche Mengen an Parasiten (Abb. 25). Die gleichen Ergebnisse wurden auch mit den beiden PARP-1-überexprimierenden RAW 264.7-Klonen A12 und E6 erzielt (nicht gezeigte Ergebnisse). Dies bestätigte die Ergebnisse des ß-Galaktosidase Tests hinsichtlich der Entwicklung der Parasiten und zeigte, dass zumindest eine zeitweise Überexpression von PARP-1 keinen Einfluss auf die Wirtszellinvasion und die intrazelluläre Entwicklung von T. gondii in RAW 264.7 Monocyten/Makrophagen besaß. 


\subsubsection{Einfluss der PARP-1 Überexpression auf die Koaktivator- funktion von PARP bei NF-kB-vermittelter Genexpression}

Wie bereits beschrieben, ist $T$. gondii in der Lage, in den NF-kB-Signalweg der Wirtszelle einzugreifen, wodurch unter anderem die Expression von TNF- $\alpha$, IL-12, IL6 und iNOS herunterreguliert wird (DENKERS, 2003). PARP-1 ist als Koaktivator von NF-kB bekannt und hat so Einfluss auf die NF-kB-abhängige Genregulation. Experimente mit PARP-1 $1^{-/-}$Mäusen belegen einen PARP-1 abhängigen Einfluss auf einige NF-kB-abhängige Gene wie iNOS und TNF-a. Eine hohe PARP-1 Expression führt zudem zu einer dysregulierenden NF-kB-Aktivität (HASSA und HOTTIGER, 2002). Es ist außerdem bekannt, dass PARP-1 die Expression von NF-kB-regulierten Genen nach LPS-Stimulierung verstärkt. Zu diesen NF-kB-regulierten Genen gehören neben anderen das Intercellular adhesion molecule(ICAM)-1, TNF- $\alpha$, iNOS, MIP-2 (HA et al. , 2002; HASSA und HOTTIGER, 2002; LIAUDET et al., 2002) und Insulinlike Growth Factor-binding protein(IGFBP)-4 (SIMBULAN-ROSENTHAL et al., 2000). Diese Gene sollten nun in RAW 264.7 Monocyten/Makrophagen, die mit PARP-1 transfiziert worden waren, hinsichtlich ihrer Expression nach LPS Stimulierung und/oder nach T. gondii-Infektion untersucht und mit RAW 264.7 Wildtyp Zellen verglichen werden. Dazu wurden Wildtyp-Zellen und stellvertretend für alle Transfektanten Zellen des Klones C6 mit LPS $(1 \mu \mathrm{g} / \mathrm{ml})$ für $4 \mathrm{~h}$ stimuliert oder unstimuliert belassen und $1 \mathrm{~h}$ mit $T$. gondii Tachyzoiten infiziert oder nicht-infiziert belassen. Im Anschluß wurde RNA isoliert und mRNA revers transkribiert. Die resultierende cDNA wurde mit spezifischen Primern für TNF- $\alpha$, MIP-2, ICAM-1 und IGFBP-4 durch RealTime-PCR amplifiziert. Um unterschiedliche Effizientien bei der RNA-Isolierung, der cDNA-Synthese oder Pipettierunterschiede auszugleichen, wurden die Ergebnisse mit Hilfe der Amplifikation des Housekeeping-Gens Aktin normiert. Nach Stimulierung mit LPS nahmen die TNF- $\alpha$-Transkriptmengen sowohl in Wildtypzellen als auch in Zellen des PARP-1 überexprimierenden Klons C6 um durchschnittlich das 75-fache im Vergleich zu den nicht-stimulierten, nicht-infizierten Kontrollen zu. Wurden die Zellen nun mit LPS vorstimuliert und anschließend mit $T$. gondii infiziert, stieg der TNF-a-mRNA-Level nur durchschnittlich um das 25-fache sowohl in Wildtypzellen als auch in Zellen des Klons C6 im Verhältnis zur Kontrolle (Abb. 26A). Zusammenfassend zeigten diese Ergebnisse, dass die TNF- $\alpha$ Transkriptlevel unabhängig von einer Überexpression von PARP-1 in Wildtypzellen 
A

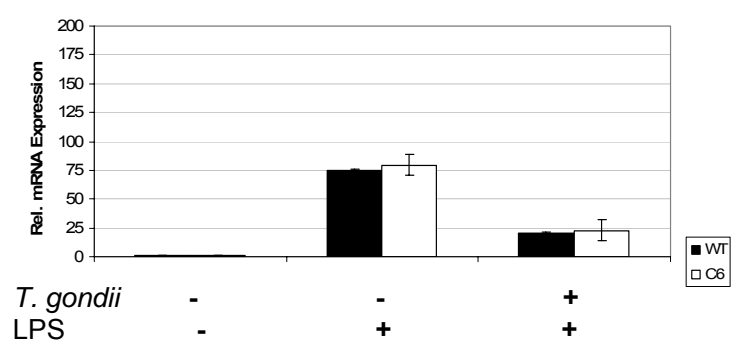

C

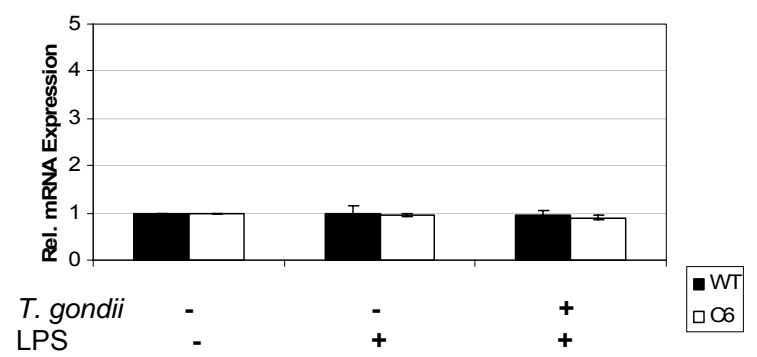

B

MIP-2

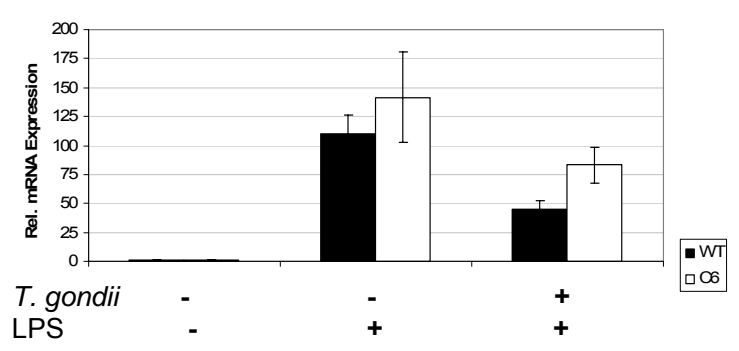

D

IGFBP4

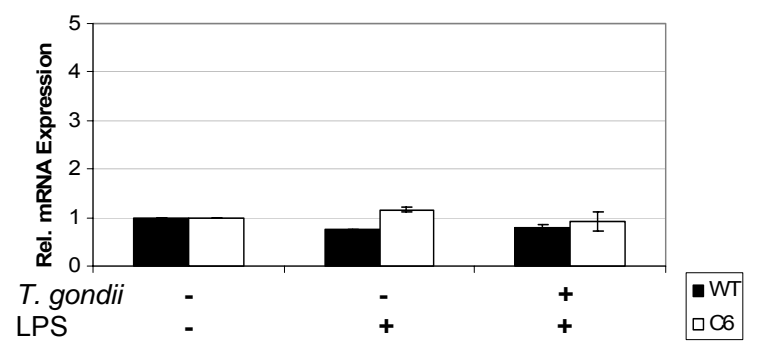

Abb. 26: Expressionsprofile NF-kB-regulierter Gene.

(A), (B), (C) und (D) RAW 264.7 Monocyten/Makrophagen Wildtypzellen (schwarze Säulen) und mit PARP-1 transfizierte Zellen des Klones C6 (weiße Säulen) wurden $4 \mathrm{~h}$ mit LPS $(1 \mu \mathrm{g} / \mathrm{ml}$ ) stimuliert oder blieben unstimuliert und wurden im Parasit-Wirt-Verhältnis von 4:1 mit Tachyzoiten des $T$. gondii Stammes NTE für $1 \mathrm{~h}$ infiziert oder blieben nicht-infiziert. Die RNA wurde isoliert, revers transkribiert und eine RealTime PCR Analyse wurde mit TNF- $\alpha$ - (A), MIP-2- (B), ICAM-1- (C), oder IGFBP4- (D), sowie mit B-Aktin-spezifischen Primern und dem MasterPlus SYBR Green 1 Kit durchgeführt. Die Balken entsprechen dem Mittelwert von zwei unabhängigen Versuchen, die Fehlerbalken stellen den Standardfehler $( \pm)$ des Mittelwertes dar.

und im Klon C6 durch LPS deutlich hochreguliert wurden, während eine Infektion mit T. gondii diesen Anstieg stark hemmte.

Auch die MIP-2 Transkriptlevel stiegen nach Stimulierung mit LPS stark an. Interessanterweise war dabei die Hochregulation in PARP-1 überexprimierenden C6Zellen höher als in Wildtypzellen im Vergleich zu den jeweiligen nicht-stimulierten, nicht-infizierten Kontrollen (Abb. 26B). Nach LPS-Stimulierung und Infektion mit $T$. gondii wiesen C6-Zellen ebenfalls deutlich höhere MIP-2 mRNA-Level auf als Wildtypzellen, wobei in beiden Zellklonen nach Infektion die LPS-induzierten Transkriptmengen niedriger waren als in nicht-infizierten, aber LPS-stimulierten Kontrollen (Abb. 26B). Die Stimulierung mit LPS führte also in Zellen des PARP-1transfizierten C6 Klones unabhängig von einer Toxoplasma-Infektion zu deutlich höheren MIP-2 mRNA-Leveln verglichen mit den Wildtypzellen. Allerdings war $T$. gondii nicht in der Lage, MIP-2 mRNA in PARP-1 überexprimierenden Zellen auf den 
gleichen Level wie in Wildtypzellen zu senken. Dem gegenüber waren in Bezug auf die NF-kB-regulierten Gene ICAM-1 und IGFBP-4 keine Unterschiede hinsichtlich der Transkriptmengen zwischen Wildtypzellen und PARP-1 überexprimierenden Zellen festzustellen (Abb. 26C und D). Dabei führte weder die Stimulierung mit LPS noch eine gleichzeitige Infektion mit $T$. gondii zu veränderten Transkriptmengen im Vergleich zu unbehandelten Kontrollen (Abb. 26C und D). Zusammenfassend wurde die LPS-induzierte Expression von 2 NF-kB-regulierten Genen, nämlich TNF- $\alpha$ und MIP-2, durch eine T. gondii-Infektion deutlich reduziert, wobei eine Überexpression von PARP-1 zu einer verstärkten Expression von MIP-2 führt. Dagegen waren bei zwei anderen NF-kB-regulierten Genen, nämlich ICAM-1 und IGFBP-4, weder durch eine PARP-1 Überexpression noch durch eine T. gondii-Infektion Veränderungen der Transkriptlevel nachweisbar.

\subsubsection{Apoptose und deren Veränderung durch T. gondii in PARP-1 überexprimierenden RAW 264.7 Zellen}

In Zellen, die zuvor mit einem Apoptose-Stimulus behandelt wurden, führt eine Infektion mit T. gondii zu einer deutlichen Inhibierung der Apoptose sowie zu einer Abnahme des PARP-1-Proteinlevels (GoEBEL et al., 2001). Welchen Einfluss veränderte PARP-1-Level auf den Apoptose-inhibierenden Effekt von T. gondii hat, sollte mit PARP-1 überexprimierenden RAW 264.7 Monocyten/Makrophagen ermittelt werden. Dazu wurde zunächst die Caspase 3/7 Aktivität als wichtiges Zeichen von apoptotischen Zellen gemessen. PARP-1 überexprimierende RAW 264.7 Monocyten/Makrophagen und Wildtypzellen wurden mit Toxoplasma Tachyzoiten für 4, 11 (nicht gezeigt) oder 24 h infiziert oder blieben nicht-infiziert. Jeweils $3.5 \mathrm{~h}$ vor Ablauf der Infektionszeit wurde Staurosporin, ein ApoptoseStimulans, zu den Zellen gegeben, oder die Zellen blieben unstimuliert. Danach wurden die Zellen lysiert und im Zellextrakt die Spaltung des Caspase 3/7 spezifischen Substrates DEVD-AMC photometrisch gemessen. In nicht-infizierten Wildtypzellen nahm die Caspase 3/7 Aktivität nach Stimulierung der Apoptose mit Staurosporin sowohl nach $4 \mathrm{~h}$ als auch nach $24 \mathrm{~h}$ stark zu (Abb. 27). 

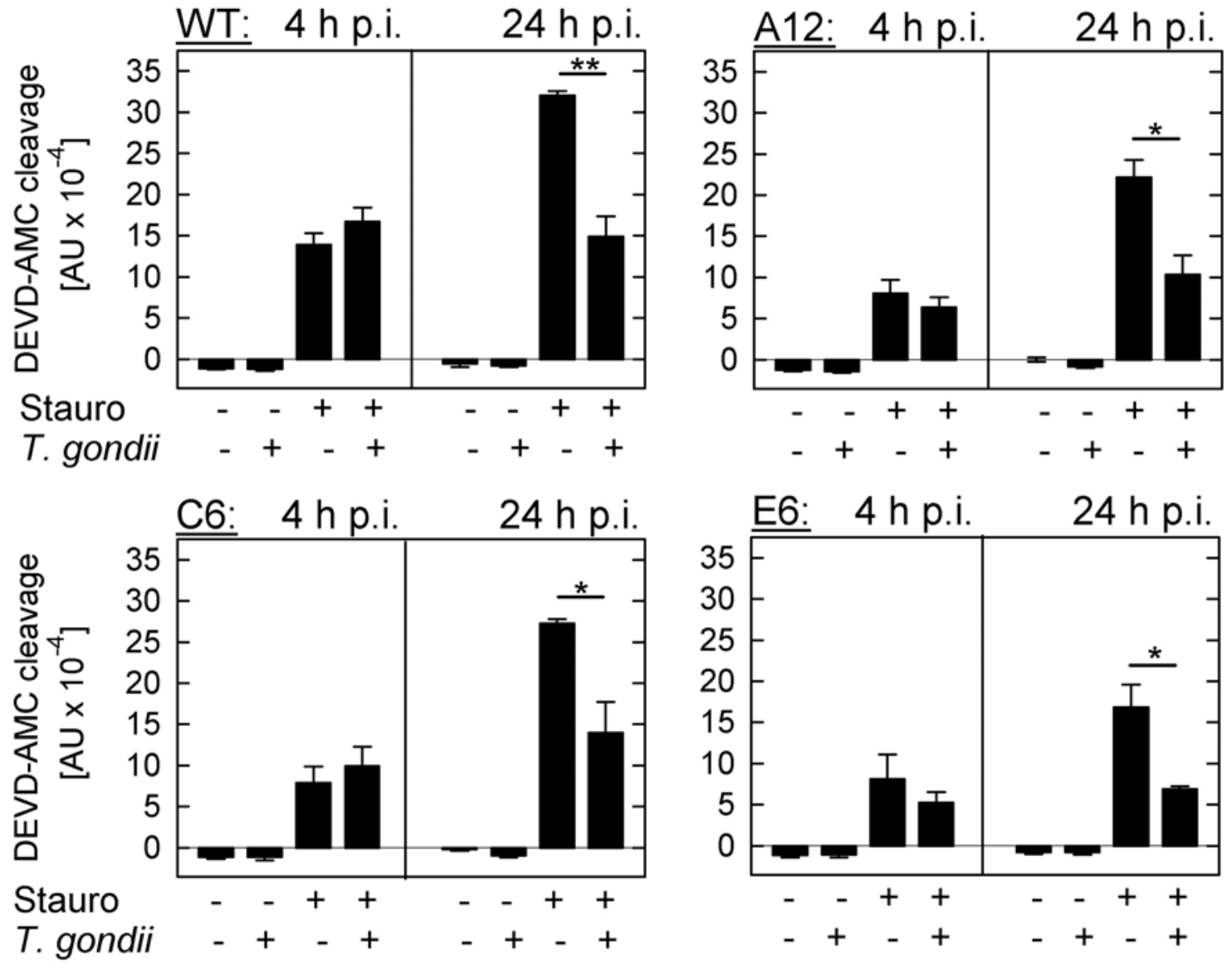

Abb. 27: Zeitabhängige Inhibierung der Caspase 3/7 Aktivität in PARP-1 überexprimierenden RAW 264.7 Klonen A12, C6 und E6 und Wildtypzellen nach T. gondii-Infektion.

PARP-1 überexprimierende Klone und Wildtypzellen wurden für $4 \mathrm{~h}$ oder $24 \mathrm{~h}$ mit $T$. gondii Tachyzoiten im Parasit-Wirt-Verhältnis von 4:1 infiziert oder blieben nicht-infiziert. $3.5 \mathrm{~h}$ vor Ablauf der Infektionszeit wurden die Zellen mit $1 \mu \mathrm{M}$ des Apoptose-Induktors Staurosporin behandelt oder blieben unstimuliert. Zu den angegebenen Zeitpunkten wurden die Zellen lysiert und in den Zelllysaten wurde die Caspase 3/7 Aktivität mittels Spaltung von DEVD-AMC photometrisch bei 380/460 nm ermittelt. Die Balken des Graphen repräsentieren die Mittelwerte aus drei unabhängigen Versuchen, die Fehlerbalken den Standardfehler $( \pm)$ des Mittelwerts. Signifikante Unterschiede zwischen infizierten und nicht-infizierten Zellen wurden mittels Student's t-Test ermittelt $\left({ }^{*} p<0.05,{ }^{* *} p<0.01\right)$.

Eine Infektion mit $T$. gondii für $4 \mathrm{~h}$ hatte keinen Einfluss auf die Staurosporinvermittelte Wirtszellapoptose in Wildtypzellen. Dagegen war die Caspase 3/7Aktivität $24 \mathrm{~h}$ p.i. in infizierten Zellen signifikant niedriger als in nicht-infizierten Kontrollen ( $p<0.01$ ) (Abb. 27). Interessanterweise war die Caspase 3/7-Aktivität nach Behandlung der PARP-überexprimierenden Klone A12, C6 und E6 mit Staurosporin niedriger als in Wildtypzellen. Nach Infektion der PARP-1-transfizierten Klone mit $T$. gondii für $4 \mathrm{~h}$ war die Caspase 3/7-Aktivität gegenüber nicht-infizierten Kontrollen wie in Wildtypzellen nicht deutlich verändert. 


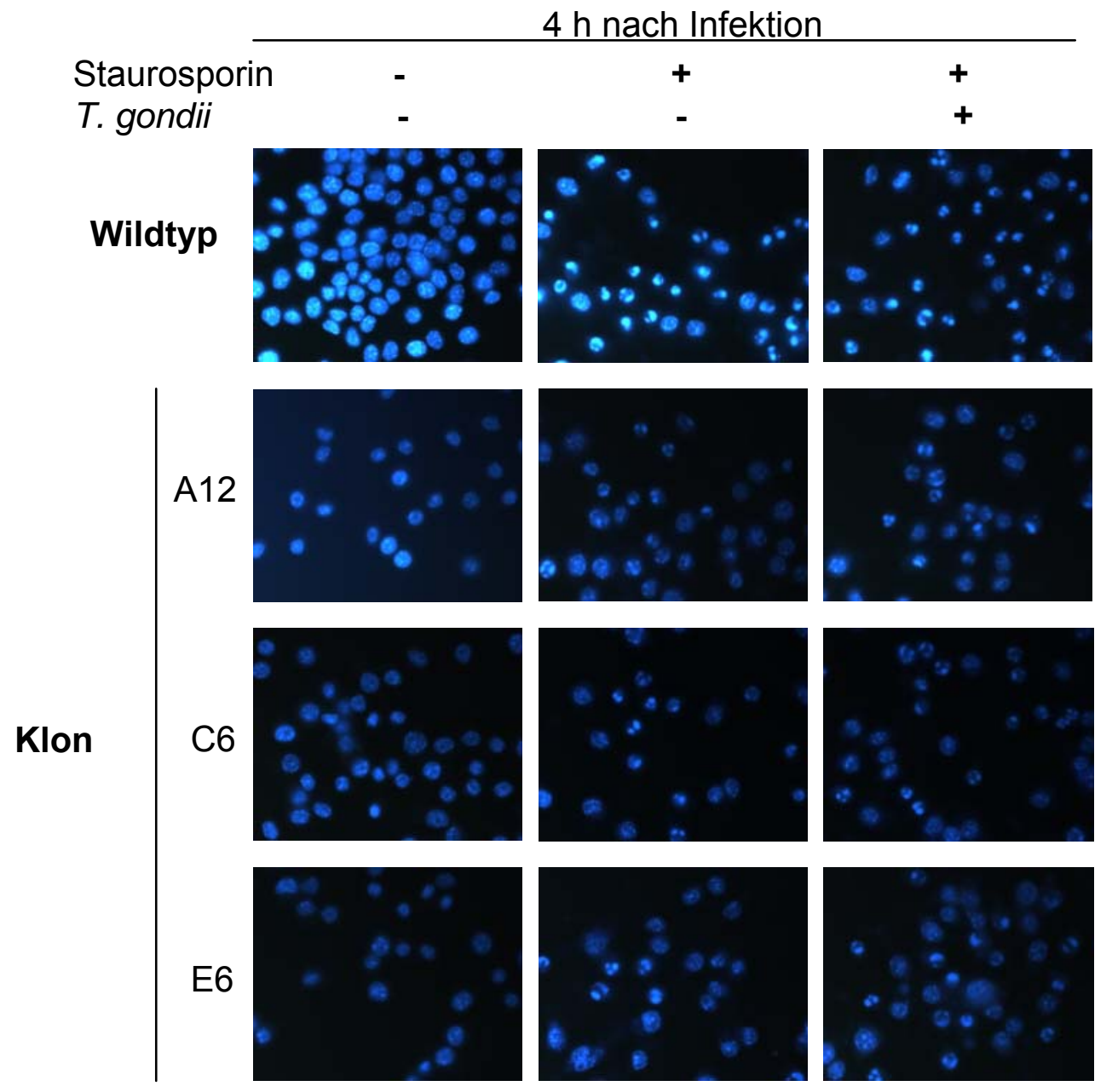

Abb. 28: Auswirkung der PARP-1 Überexpression auf die Parasit-Wirt Interaktion in apoptotischen Zellen $\mathbf{4} \mathrm{h}$ nach Infektion mit $T$. gondii.

PARP-1 überexprimierende Klone A12, C6 und E6 und Wildtypzellen wurden für $4 \mathrm{~h}$ mit $T$. gondii Tachyzoiten infiziert oder blieben nicht-infiziert. $3.5 \mathrm{~h}$ vor Ablauf der Infektionszeit wurden die Zellen mit $1 \mu \mathrm{M}$ Staurosporin behandelt oder blieben unbehandelt. Mittels Höchst-Färbung wurden apoptotische Zellen anhand von kondensiertem Chromatin sichtbar gemacht.

Dagegen führte eine Infektion mit Toxoplasma für $24 \mathrm{~h} \mathrm{zu}$ signifikant niedrigeren Caspase 3/7-Aktivitäten in PARP-1 überexprimierenden Zellen als in den entsprechenden nicht-infizierten Kontrollen $(p<0.05)$. Diese Ergebnisse sprachen eindeutig dagegen, dass die Inhibierung der Expression von PARP-1 durch T. gondii den anti-apoptotischen Effekt des Parasiten vermittelte. Außerdem schien auch die PARP-1 Überexpression die durch den Parasiten verursachte Inhibierung der Apoptose nicht zu beeinflussen. 


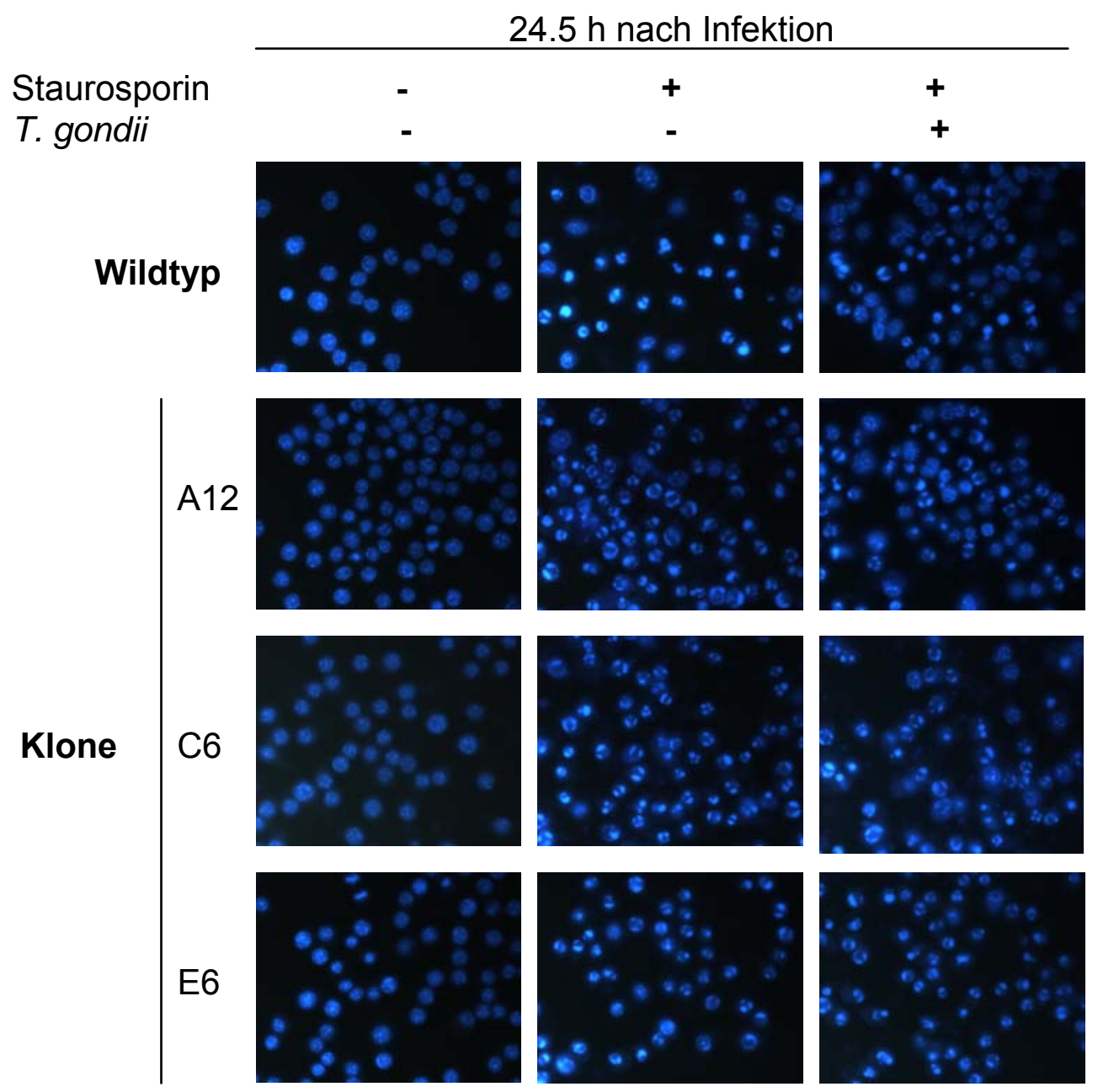

Abb. 29: Auswirkung der PARP-1 Überexpression auf die Parasit-Wirt Interaktion in apoptotischen Zellen $24.5 \mathrm{~h}$ nach Infektion mit $T$. gondii.

PARP-1 überexprimierende Klone A12, C6 und E6 und Wildtypzellen wurden für $24.5 \mathrm{~h}$ mit $T$. gondii Tachyzoiten infiziert oder blieben nicht-infiziert. $3.5 \mathrm{~h}$ vor Ablauf der Infektionszeit wurden die Zellen mit $1 \mu \mathrm{M}$ Staurosporin behandelt oder blieben unbehandelt. Mittels Höchst-Färbung wurden apoptotische Zellen anhand von kondensiertem Chromatin sichtbar gemacht.

Die Auswirkung der PARP-1 Überexpresssion auf Apoptose und deren Veränderung durch Toxoplasma wurde zusätzlich auf Einzelzellebene mittels Höchst-Färbung untersucht. Dafür wurden PARP-1-überexprimierende Klone und Wildtypzellen mit $T$. gondii NTE Tachyzoiten für 4 h (Abb. 28), 11 h (nicht gezeigt) oder 24.5 h (Abb. 29) infiziert oder blieben nicht-infiziert. Jeweils $3.5 \mathrm{~h}$ vor Ablauf der Infektionszeit wurde Apoptose durch $1 \mu \mathrm{M}$ Staurosporin induziert, oder die Zellen blieben unbehandelt. Mittels Höchst-Farbstoff 33258 wurde die DNA angefärbt und die Proben anschließend mikroskopisch analysiert. Zur quantitativen Auswertung der Höchstfärbung wurden 500 Zellen gezählt und die Anzahl der apoptotischen Zellen anhand der Kondensation von Chromatin ermittelt (Abb. 30). In Wildtypzellen 
kondensierte nach Inkubation der Zellen mit Staurosporin das Chromatin sehr deutlich (Abb. 28). Dabei wiesen 4 h p.i. sowohl infizierte, Staurosporin-behandelte als auch nicht-infizierte, behandelte Kulturen zu etwa 60\% Zellen mit stark kondensiertem Chromatin auf (Abb. 30). Staurosporin führte in den PARP-1 überexprimierenden Zellen des Klones A12 zu ähnlichen Mengen von Zellen mit kondensiertem Chromatin wie in Wildtypzellen, und zwar unabhängig von einer Toxoplasma-Infektion (Abb. 28 \& 30). Dagegen war in den Zellen der PARP-1 überexprimierenden Klone C6 und E6 nach Infektion mit $T$. gondii der Prozentsatz von Zellen mit kondensiertem Chromatin um durchschnittlich 17 bzw. 8\% niedriger als in nicht-infizierten

Kontrollen

(Abb.

30).

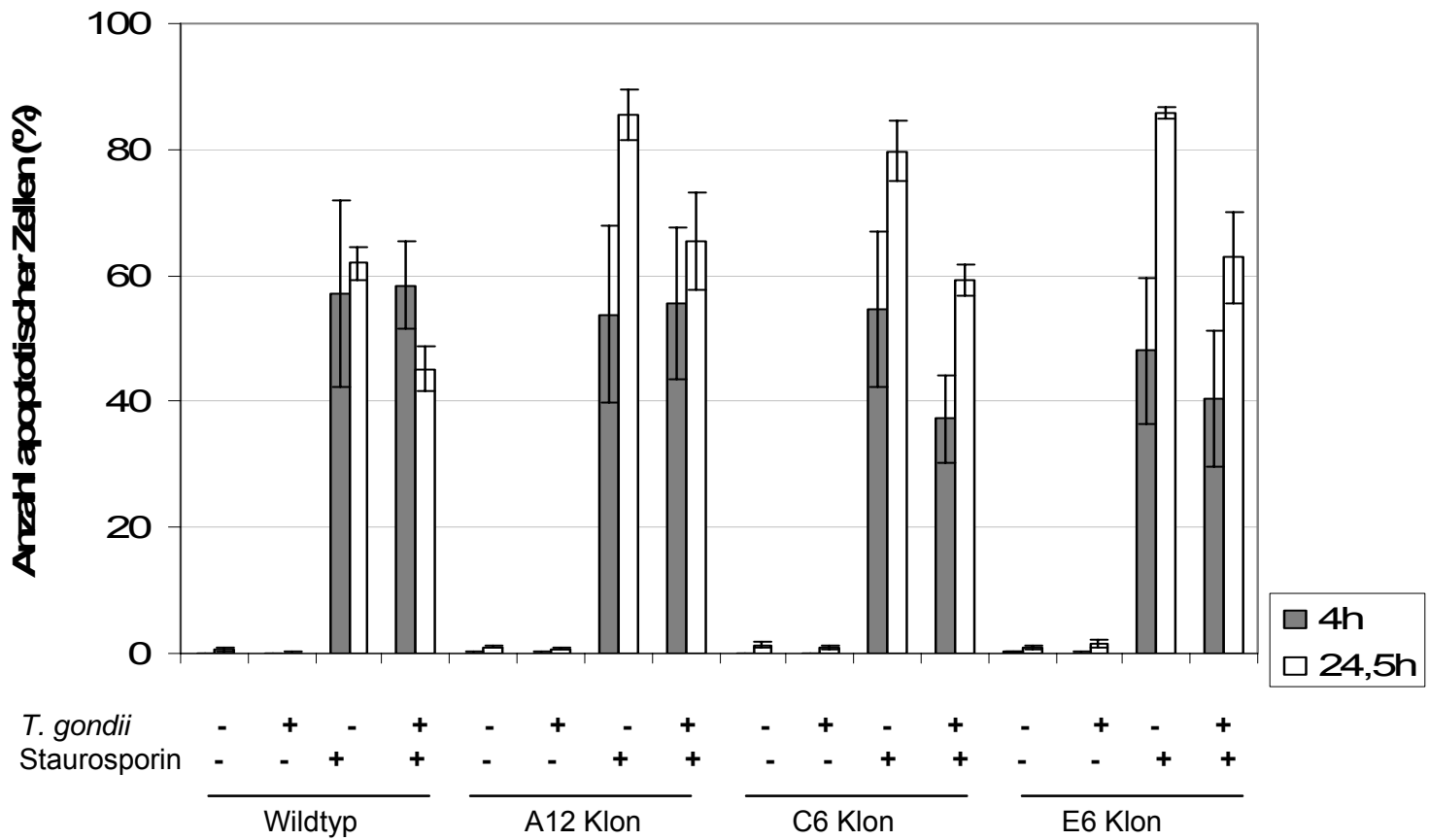

Abb. 30: Auswirkung der PARP-1 Überexpression auf die Parasit-Wirt Interaktion in apoptotischen Zellen.

PARP-1 überexprimierende Klone A12, C6 und E6 und Wildtypzellen wurden für $4 \mathrm{~h}$ (graue Balken) und $24.5 \mathrm{~h}$ (weiße Balken) mit $T$. gondii Tachyzoiten infiziert oder blieben nicht-infiziert. $3.5 \mathrm{~h}$ vor Ablauf der Infektionszeit wurden die Zellen mit $1 \mu \mathrm{M}$ Staurosporin behandelt oder blieben unbehandelt. Mittels Höchst-Färbung wurden apoptotische Zellen anhand von kondensiertem Chromatin sichtbar gemacht. Die quantitative Auswertung erfolgte durch das Auszählen von je 500 Zellen und der Bestimmung des Anteils an apoptotischen Zellen. Die Balken repräsentieren Mittelwerte aus drei unabhängigen Versuchen, die Fehlerbalken stellen den Standardfehler $( \pm)$ des Mittelwerts dar. 
Nach längerer Kulturdauer (24.5 h) waren vor allem die PARP-1 überexprimierenden Zellen deutlich anfälliger gegegenüber einer Behandlung mit Staurosporin, da der Anteil von Zellen mit kondensiertem Chromatin deutlich höher war als nach $4 \mathrm{~h}$ Kulturdauer (Abb. 30). Zu diesem Zeitpunkt war der Anteil apoptotischer Zellen in PARP-1 überexprimierenden RAW 264.7 Zellen um etwa 20\% höher als bei Wildtypzellen (Abb. 30). Eine Infektion mit T. gondii für $24.5 \mathrm{~h}$ führte sowohl bei Wildtypzellen als auch bei den Mutanten zur Hemmung der Staurosporin-induzierten Chromatinkondensation (Abb. 30). Dabei nahm die Anzahl der apoptotischen Zellen durch die Infektion mit T. gondii um etwa 17\% - 20\% ab (Abb. 29 \& 30). Ähnlich führte auch in Wildtypzellen eine Infektion mit $T$. gondii für $24.5 \mathrm{~h}$ zu einer um durchschnittlich 17\% verminderten Anzahl von Zellen mit kondensiertem Chromatin (Abb. 29 \& 30). Grundsätzlich führte also die Überexpression von PARP-1 zu einer niedrigeren Caspase 3/7 Aktivität bzw. zu einer verminderten Apoptose-Anfälligkeit im Vergleich zu Wildtypzellen. Allerdings inhibierte T. gondii in PARP-1 überexprimierenden Zellen die Apoptose deutlich. Zusammenfassend zeigten diese Daten, dass die Inhibierung der Expression von PARP-1 in infizierten Wirtszellen nicht den anti-apoptotischen Effekt von T. gondii erklären konnte. Außerdem verhinderte die Überexpression von PARP-1 in den Mutanten nicht die T. gondiiinduzierte Inhibierung der Apoptose. 


\section{Diskussion}

PARP-1 spielt als nukleäres Protein eine wichtige Rolle in diversen zellulären Prozessen, wie Zellzyklus, DNA-Reparatur, Apoptose und Nekrose (HASSA et al., 2006). Es ist daher nicht verwunderlich, dass PARP-1 bereits 1983 mit krankhaften Veränderungen in Verbindung gebracht wurde (ALtMANN, 1983). Mittlerweile ist bekannt, dass PARP-1 bei einer großen Anzahl von Erkrankungen, wie Asthma und entzündlichen Lungenerkrankungen (SZABO und DAWSON, 1998; LIAUDET et al., 2002; BoulAREs et al., 2003; CuZZOCREA, 2005; VIRAG, 2005a), Arthritis (GonZALEZ-REY et al., 2007; GARCIA et al., 2008), multiplem Organversagen (LIAUDET und ODDO, 2003; Cuzzocrea und Wang, 2005), Diabetes Typ-1 (PACHER und SzABo, 2005; SzABo, 2005), entzündlichen Darmerkrankungen, wie z.B. Morbus Crohn (MARKOWITZ et al., 1988), septischem Schock (CuzzocreA, 2005) und Krebs (CEPEdA et al., 2006; Plummer, 2006; HORVATH und SzABO, 2007) involviert ist. Häufig zeigte sich eine pharmakologische Inhibierung der Expression von PARP-1 in vitro (GARCIA et al., 2008), ein Knockout von PARP-1 im Mausmodell (BOULARES et al., 2003; VIRAG, 2005a) oder eine pharmakologische Inhibierung in der Ratte (OBROsova et al., 2004) als wirksamer Schutz gegen diese Krankheitsbilder. Gerade bei Krebs konnte die Forschung an pharmakologischen Inhibitoren von PARP-1 als Anti-Krebs Medikamente soweit vorangetrieben werden, dass bereits frühe klinische Studien an Krebspatienten durchgeführt werden (CEPEdA et al., 2006; Plummer, 2006; HoRvath und SZABO, 2007). Neben diesen Erkrankungen wird bei HIV-1, dem Epstein-BarrVirus, Chlamydiaceae und Malaria der PARP-1-Gehalt im Wirt bzw. in Wirtszellen mit unterschiedlichen Verläufen der Infektion in Zusammenhang gebracht (TANAKA et al., 1995a; HA et al., 2001; CLARK und COWDEN, 2003; ClARK et al., 2004; YELAMOs et al., 2004; MATtIUSSı et al., 2007). Der intrazelluläre Parasit Toxoplasma gondii nimmt aktiv Einfluss auf den PARP-1 Gehalt seines Wirtes. So kommt es sowohl in apoptotischen als auch in nicht-apoptotischen Wirtszellen nach einer Infektion mit $T$. gondii zu einer starken Inhibierung des PARP-1 Levels (GoEBEL et al., 2001).

Die Ergebnisse der hier vorliegenden Arbeit belegten eine Inhibierung der Expression von PARP-1 in verschiedenen nicht-apoptotischen Wirtszellen und gaben Hinweise darauf, wie die Inhibierung durch T. gondii ausgelöst werden könnte und welche Auswirkungen auf das Parasit-Wirt-Verhältnis zu beobachten waren. Bei der Inhibierung der Poly(ADP-Ribose) Polymerase-1 durch T. gondii, sowohl in 
apoptotischen als auch in nicht-apoptotischen Wirtszellen, handelt es sich um eine weitere bisher wenig untersuchte Interaktion des Parasiten mit der Physiologie seiner Wirtszelle.

\subsection{Die PARP-1-Inhibierung nach T. gondii-Infektion ist ein}

\section{generelles Phänomen}

In früheren Untersuchungen unseres Labors konnte gezeigt werden, dass eine Infektion mit T. gondii in HL-60 bzw. U937 Wirtszellen Auswirkungen auf die Poly(ADP-Ribose) Polymerase-1 hat und dass dieser Effekt nicht nur auf Wirtszellen beschränkt ist, die mit einem Apoptose Stimulans behandelt und durch die Infektion mit T. gondii vor Apoptose geschützt werden (GoEBEL et al., 2001). Zur genaueren Charakterisierung dieses Effektes wurden die Versuche nun darüber hinaus an nichtapoptotischen Wirtszellen von T. gondii fortgesetzt. Es konnte dabei eine deutliche, wenn auch transiente, Inhibierung des PARP-1-Proteinlevels nach Infektion mit $T$. gondii nachgewiesen werden. Da die Inhibierung der Expression von PARP-1 in Monocyten/Makrophagen schon innerhalb von wenigen Minuten nach der Infektion sehr stark ausgeprägt war und erst nach Stunden wieder langsam abnahm, könnte ein Zusammenhang vor allem zwischen dem veränderten PARP-1-Gehalt und der Frühphase der Parasit-Wirt-Interaktion bestehen. T. gondii beeinflusst auch NF-KB in Makrophagen während der frühen Phase der Infektion und verhindert dadurch die Bildung von pro-inflammatorischen Zytokinen (BUTCHER et al., 2001; SHAPIRA et al., 2002).

Daneben konnte gezeigt werden, dass die Stärke der Inhibierung der Expression von PARP-1 in deutlicher Korrelation zur Parasitenmenge, mit der die Wirtszellen infiziert worden waren, stand. Eine Dosisabhängigkeit der Modulation von zellulären Abläufen von der Parasitenmenge wird sowohl bei der Reduzierung der DNAFragmentierung durch Toxoplasma (GoEBEL et al., 2001), als auch bei der Inhibierung der CIITA Expression (LANG C et al., 2006) gezeigt. Sie kann dabei auch als Hinweis auf eine direkte Interaktion des Parasiten mit einer Wirtszelle gewertet werden.

Außerdem wurde durch Versuche auf Einzelzellebene deutlich, dass PARP-1 nach der Infektion mit T. gondii nicht aus dem Zellkern in andere Zellkompartimente 
transportiert wurde. Dies wurde auch von den Ergebnissen der Western Blot Analysen untermauert. Vielmehr scheint es sich bei der Reduktion von PARP-1 um einen schnellen Abbau des Proteins zu handeln.

T. gondii beeinflusst im Verlauf der Apoptose nicht-infizierte Nachbarzellen von infizierten Wirtszellen (WEI et al., 2002; LÜDER und GROSS, 2005). Bei den hier durchgeführten Experimenten auf Einzelzellebene nahm T. gondii ebenfalls Einfluss auf nicht-infizierte Nachbarzellen von infizierten Zellen in Bezug auf PARP. Hierbei wurde deutlich, dass auch in parasit-negativen Zellen einer infizierten Kultur PARP-1 stark inhibiert war. Allerdings muss erwähnt werden, dass durch die Art der Durchführung der Immunfluoreszenzfärbung nicht ausgeschlossen werden kann, dass Parasiten, die nur an die Wirtszelle adhäriert aber nicht eingedrungen waren, nicht ausreichend fixiert und während der verschiedenen Waschschritte unbeabsichtigt entfernt wurden. Diese Zellen wären jedoch als parasit-negativ ausgewertet worden. Dagegen sprach aber, dass auch extrazelluläre Parasiten in den Proben deutlich zu sehen waren.

Da eine Inhibierung der Expression von PARP-1 auch in verschiedenen humanen und murinen Zelllinien beobachtet werden konnte, scheint es sich um ein generelles Phänomen bei der T. gondii-Infektion von Wirtszellen zu handeln. Allerdings waren die Stärke der Inhibierung und deren Zeitpunkt nach der Infektion abhängig vom Wirtszell-Typ und vom Ursprungsorganismus der Wirtszellen. So zeigte sich eine stärkere Inhibierung der Expression von PARP-1 bei murinen Zellen im Vergleich zu humanen Zellen. Im Vergleich von zwei murinen Zelltypen untereinander belegten die Daten dieser Arbeit, dass in Makrophagen PARP-1 nach Infektion mit T. gondii schneller und stärker inhibiert wurde als in Fibroblasten. Ähnliche Beobachtungen wurden schon früher gemacht. Bei der Infektion von Wirtszellen durch T. gondii scheint die Art der Wirtszelle Auswirkungen auf die Modulation der zellulären Prozesse durch den Parasiten zu haben. So werden deutliche Unterschiede zwischen Zellen des Immunsystems und Nicht-Immunzellen in der Reaktion auf eine T. gondii-Infektion beobachtet (MOLESTINA et al., 2003).

Ein Zusammenhang zwischen der Infektion mit Pathogenen und Auswirkungen auf PARP-1 zeigte sich bisher meist im Hinblick auf die Apoptose. So zeigt sich, dass Infektionen mit verschiedenen Viren, wie z.B. beim humanen Rhinovirus (DESzCz et al., 2005), beim Pferde-Grippe-Virus (EIV) (LIN et al., 2002) und beim humanen Cytomegalievirus (CMV) (CHIOU et al., 2002), sowie bei Infektionen mit Bakterien, wie 
Francisella tulariensis (LAI und SJOSTEDT, 2003) und Pseudomonas aeruginosa (ZHANG et al., 2004), zur Aktivierung der Caspase-Kaskade sowie der PARP-1 Spaltung und somit zur Induktion der Apoptose führen. Im Gegensatz dazu gibt es Hinweise, dass PARP-1 bei verschiedenen Viren (TANAKA et al., 1995a; HA et al., 2001) und Bakterien (YELAMOs et al., 2004) eine wichtige von Apoptose unabhängige Rolle im Lebenszyklus dieser Pathogene spielt. Diese Daten belegen, dass PARP-1 eine wichtige Rolle auch bei der Entwicklung intrazellulärer Pathogene zukommt.

Neben dem Proteingehalt in der Zelle, der bei PARP-1 bei bis zu $0.5-5 \times 10^{6}$ Moleküle / Nukleus liegt (DURIEZ und SHAH, 1997), spielt die enzymatische Aktivität von PARP-1 eine entscheidende Rolle. PARP-1 modifiziert viele Proteine, die wiederum auf diverse zelluläre Prozesse Einfluss haben, post-translational durch Poly(ADP-ribosyl)ierung (AME et al., 2004). Dabei ist die enzymatische Grundaktivität in Zellen sehr niedrig und PARP-1 wird erst durch verschiedene Stimuli, zu denen DNA-Strangbrüche gehören, aktiviert (KIM et al., 2005). In der vorliegenden Studie konnte erstmalig nachgewiesen werden, dass die Poly(ADP-ribosyl)ierung nach Stimulierung von $\mathrm{H}_{2} \mathrm{O}_{2}$ durch Infektion mit $T$. gondii signifikant reduziert war. PARP-1 ist für etwa 90\% der Poly(ADP-ribosyl)ierung in der Zelle verantwortlich (VIRAG, 2005b), so dass die verminderte Poly(ADP-ribosyl)ierung auf die verminderten PARP-1-Proteinlevel nach Toxoplasma-Infektion zurückzuführen sein dürfte. Diese Vermutung wurde zudem von Experimenten mit Katalase-knockout Parasiten gestützt. Dabei zeigten Zellen, die mit den Katalase-negativen PRUcat Parasiten infiziert worden waren, im Zell-ELISA eine ähnlich stark reduzierte $\mathrm{H}_{2} \mathrm{O}_{2}$-induzierte PARP-1-Aktivität wie Zellen, die mit dem parentalen Stamm PRUhxgprt infiziert worden waren. Eine Katalase-vermittelte Detoxifizierung von $\mathrm{H}_{2} \mathrm{O}_{2}$ durch $T$. gondii konnte also ausgeschlossen werden. Nicht nur die Inhibierung der PARP-1Proteinlevel durch eine Infektion mit $T$. gondii konnte also in der hier vorliegenden Arbeit bewiesen werden, sondern auch eine starke Abnahme der enzymatischen Aktivität von PARP-1 wurde durch eine Infektion mit T. gondii verursacht. Somit hatte der Parasit nach Infektion neben dem Einfluss auf das Protein PARP-1 auch Einfluss auf die enzymatische Aktivität. Zwar könnten noch andere Mitglieder der PARP Familie theoretisch die Poly(ADP-ribosyl)ierung übernehmen, allerdings sprechen die Daten der hier vorliegenden Arbeit dagegen, da gerade der Nachweis der reduzierten ADP-ribosyltransferase-Aktivität nach Infektion für die wichtige Rolle von PARP-1 bei der ADP-ribosylierung sprach. 


\subsection{Die Inhibierung der Expression von PARP-1 durch T.}

\section{gondii ist nicht von der Virulenz des Toxoplasma-}

\section{Stammes abhängig}

Bei Infektionen mit dem Erreger der zerebraler Malaria (Malaria tropica), Plasmodium falciparum, zeigt sich eine Korrelation unter anderem zwischen der PARP-1 Stimulierung und der Schwere des Verlaufs der Infektion (CLARK et al., 2004). Durch die mit dem Schweregrad des Krankheitsverlaufes korrelierende Freisetzung von TNF- $\alpha$ durch Makrophagen und Monozyten als Antwort auf die Infektion mit Plasmodium kommt es zur NO-Freisetzung, zu Einzelstrangbrüchen der DNA, zur Überaktivierung von PARP-1 und zu einem Verlust von $\mathrm{NAD}^{+}$und ATP. Dadurch kann Sauerstoff, der durch die Anämie bei Malaria tropica ohnehin nur in niedrigen Konzentrationen im Blut vorkommt, nicht effektiv verarbeitet werden. Folge davon sind schwere Krankheitsverläufe aufgrund einer Mangelversorgung von ZNSGewebe bis hin zum Tod der Patienten. Außerdem führt die Überaktivierung von PARP-1 zu einer verstärkten NF-kB-vermittelten Genexpression und zu einer vermehrten Bildung von pro-inflammatorischen Cytokinen, was eine lokale Entzündungsreaktion verstärkt (CLARK und COWDEN, 2003; CLARK et al., 2004). Diese Ergebnisse zeigen, dass die PARP-1-Überaktivierung während entzündlicher Reaktionen bei zerebraler Malaria für die Schwere des Krankheitsverlaufes mitverantwortlich sein könnte. Auch Infektionen mit T. gondii führen zu sehr unterschiedlichen Krankheitsverläufen, die besonders in der Maus von der unterschiedlichen Virulenz des Erregers abhängt. Dies ist anhand von zwei unterschiedlichen T. gondii Stämmen, einem hoch virulenten (S23), und einem anderen signifikant weniger mausvirulenten Stamm (S22), nachgewiesen worden (SAEIJ et al., 2005b). Beide Stämme tragen zusätzlich das Luciferase-Gen, um die Replikationsrate nach der Infektion in Mäusen optisch bestimmen zu können. Die Mäuse, die mit dem virulenten Stamm S23 infiziert werden, zeigen ein exponentielles Replikationsverhalten des Parasiten bis hin zum Tod der Mäuse, während sich der S22 Stamm zunächst auch stark vermehrt, dann aber nicht mehr nachweisbar ist (SAEIJ et al., 2005b). Grundlage für weitere Experimente dieser Arbeit war die Überlegung, dass der entzündungsbedingte Tod der Mäuse eventuell auf eine unterschiedliche Modulation von PARP-1 durch virulente und avirulente Stämme von T. gondii zurück zu führen ist. Die Einteilung der unterschiedlichen Stämme von $T$. 
gondii in drei Gruppen richtet sich unter anderem nach ihrer Virulenz in Mäusen (PARMLEY et al., 1994). Die virulenten Stämme kommen seltener in Tieren vor, wohingegen sie häufig bei congenitaler Toxoplasmose und Augenerkrankungen gefunden werden. Bei diesen Stämmen reicht ein einzelner Erreger, um zum Tod einer Maus innerhalb von 8 - 12 Tagen zu führen. Avirulente Stämme hingegen sind meist in Nutztieren in Form einer chronischen Toxoplasmose zu finden. Hier führen $\geq$ $10^{3}$ Parasiten zu einer chronischen Infektion (SIBLEY et al., 2002). Die hier vorliegenden Daten konnten zeigen, dass sowohl die Stämme aus der Mausvirulenten Gruppe A als auch die Stämme aus den Maus-avirulenten Gruppen B und C die PARP-1-Proteinlevel deutlich inhibierten. Da keine signifikanten Unterschiede in der Stärke der Inhibierung zwischen den Gruppen zu erkennen war, konnte eine Virulenz-abhängige bzw. Genotyp-abhängige Inhibierung der Expression von PARP1 ausgeschlossen werden. Dieses Ergebnis war auch ein erster Hinweis, dass die parasiten-vermittelte Modulation von PARP nicht für stammspezifische Unterschiede bei der Regulation der Immunantwort während der Toxoplasmose verantwortlich ist. Tatsächlich ist die Ausprägung der Immunantwort unter anderem von der Virulenz des $T$. gondii Stammes abhängig. So kann nach Infektion von Makropagen mit $T$. gondii beobachtet werden, dass Maus-avirulente Stämme deutlich größere Mengen IL-12 induzieren als Maus-virulente Stämme (SCHADE und FISCHER, 2001). Allerdings ist keine Unterschiede zwischen den Stämmen bezüglich der induzierten IL-12p40 Produktion in verschiedenen Zellen festzustellen (SAEIJ et al., 2005a). Ein eindeutiger Zusammenhang zwischen der Virulenz der Gruppe A Stämme und einer Überexpression von $\mathrm{T}_{\mathrm{H}} 1$ Zytokinen, die letzendlich zum Tod der Wirte führt, ist vorhanden (SIBLEY et al., 2002). Auch Unterschiede zwischen den Stämmen bezüglich ihrer Interaktion mit den NF-KB- und STAT3-Signalwegen zeigten sich kürzlich (SAEIJ et al., 2005a). Hingegen scheint es sich bei der PARP-1-Inhibierung um einen generellen Effekt bei der Interaktion von $T$. gondii mit seinen Wirtszellen zu handeln. Einschränkend muss allerdings beachtet werden, dass in der vorliegenden Arbeit Makrophagen mit Parasiten unterschiedlicher Genotypen nur für $1 \mathrm{~h}$ infiziert wurden und nicht über einen längeren Zeitraum und auch nicht in vivo. Es ist daher nicht auszuschließen, dass eine unterschiedliche Modulation der PARP-1 Expression an den entzündlichen Reaktionen verschiedenen Schweregrades in vivo durchaus beteiligt sein könnte. 


\subsection{Regulation der PARP-1-Inhibierung durch T. gondii in}

\section{Wirtszellen}

Toxoplasma gondii ist ebenso wie andere intrazelluläre Infektionserreger, z.B. Salmonella typhimurium und Chlamydia trachomatis, in der Lage durch die Invasion der Wirtszelle die Transkription verschiedener Wirtszellgene zu beeinflussen. Dies belegen Daten, die mittels Genarray erbracht wurden (BLADER et al., 2001; GAIL et al., 2001). Aus diesem Grund wurden die Transkriptionslevels von RAW 264.7 Wirtszellen auf ihre PARP-1 mRNA Level mittels Real-Time RT-PCR untersucht. Es zeigte sich jedoch kein deutlicher Unterschied zwischen den PARP-1 mRNA-Leveln der infizierten und nicht-infizierten RAW 264.7 Monocyten/Makrophagen. Die schnelle und starke Herunterregulation des PARP-1 Proteins nach einer Infektion mit T. gondii konnte daher nicht auf reduzierte mRNA Level zurückgeführt werden, da diese im Verlauf der Infektion sogar eher zu- als abnahmen. Die Zunahme der PARP-1-Proteinlevel bis $24 \mathrm{~h}$ nach Infektion könnte daher auf eine verstärkte Transkription zurückzuführen sein. Diese Ergebnisse bestätigen Untersuchungen an HL-60 und U937 Zellen, die zeigen, dass in nicht-apoptotischen Zellen die PARP-1 mRNA-Level mit und ohne $T$. gondii-Infektion unverändert blieben (GoEBEL et al., 2001). Ein transkriptioneller Einfluss auf die Inhibierung der Expression von PARP-1 durch $T$. gondii kann daher ausgeschlossen werden. Vielmehr scheint es sich um eine post-transkriptionelle Regulierung zu handeln (GoEBEL et al., 2001).

Bisherige Ergebnisse deuten darauf hin, dass $T$. gondii in der Lage ist, auf posttranskriptioneller Ebene in die Expression von Wirtszellproteinen einzugreifen. So konnte für den Tumor Necrosis Faktor- $\alpha$ (TNF- $\alpha$ ), ein pro-inflammatorisches Cytokin, eine post-transkriptionelle Regulation durch den Parasiten $T$. gondii nachgewiesen werden (BELLONI et al., 2003). Daher wurde diese Möglichkeit auch für die PARP-1Inhibierung durch $T$. gondii in Betracht gezogen. Um den Regulationspunkt weiter einzugrenzen, wurde ein zellfreies in vitro System verwendet, in dem keine funktionelle Translationsmaschinerie vorhanden war. Dennoch zeigte sich eine dosisabhängige Inhibierung der Expression von PARP-1 nach Inkubation mit $T$. gondii. Dies ließ mehrere Schlüsse zu. Eingriffe in die Prozessierung der mRNA waren unwahrscheinlich, da sowohl das Aufsetzten der 7-Methylguanosinium-Kappe am 5'-Ende der mRNA, als auch das Anheften des Poly(A)-Schwanzes am 3'-Ende der mRNA zu einer Schwächung der RNA-Stabilität und somit zu einem schnelleren 
Abbau der RNA führen würde. Wie bereits dargestellt, waren veränderte Transkriptlevel nicht für die Inhibierung der Expression von PARP-1 verantwortlich. Da ein RNA-Editing bei Säugerzellen eher unwahrscheinlich war und auch die Daten des zellfreien in vitro Systems dagegen sprachen, konnte ein RNA-Editing weitgehend ausgeschlossen werden.

Außerdem könnte T. gondii Wirtszellproteasen aktivieren, vergleichbar der Caspase 3, für die bekannt ist, dass sie PARP-1 spaltet (DURIEZ und SHAH, 1997). Caspase 3 selbst konnte jedoch ausgeschlossen werden, da keine Caspase 3-spezifischen Spaltprodukte von PARP-1 nachweisbar waren und auch keine Induktion der Apoptose vorlag, durch die die Caspase 3 aktiviert worden wäre. Hauptsächlich wird PARP-1, neben Caspase 3, von verschiedenen Proteasen wie Yama/CPP32/Apopain und Caspase $7 \mathrm{im}$ Verlauf der Apoptose gespalten und inaktiviert (DECKER und MULLER, 2002). Auch nach Induktion von Nekrose konnte eine Spaltung von PARP-1 in verschieden große Fragmente durch lysosomale Proteasen wie Cathepsin B und G nachgewiesen werden (GoBEIL et al., 2001). Allerdings konnten auch diese Proteasen weitgehend ausgeschlossen werden, da der in der hier vorliegenden Arbeit verwendete PARP-1-spezifische Antikörper C2-10 ebenfalls zum Nachweis der durch Cathepsin B und G hervorgerufenen PARP-1-Spaltprodukte verwendet wurde (GOBEIL et al., 2001) und nach Infektion mit T. gondii keine Spaltprodukte nachweisen konnte.

Da die PARP-1-spezifischen Transkriptlevel im Gegensatz zu den Proteinleveln nach Infektion mit $T$. gondii nicht abnahmen, könnten Wirtszellproteasomen bei der Degradierung von PARP-1 eine Rolle spielen. Deren Beteiligung konnte auch bei der Modulation der NF-KB-abhängigen Genexpression durch T. gondii nachgewiesen werden. Als Reaktion auf Infektionen wird häufig NF-kB aktiviert, was zu einer Expression verschiedener pro-inflammatorischer Cytokine (IL-12, TNF- $\alpha$ ) führt. Die Aktivierung von NF-kB erfolgt dabei indirekt durch Inaktivierung von I-kB. NF-kB liegt im Zytoplasma inaktiv und gebunden an den NF-kB-Inhibitor I-kB vor. Eine Infektion mit Pathogenen kann zu einer Phosphorylierung, Ubiquitinierung und Degradation von I-KB durch das Proteasom führen, wodurch NF-KB aktiviert wird und in den Nukleus wandert (WANG et al., 2002). Bei einer Infektion mit T. gondii kommt es zur Phosphorylierung, Ubiquitinierung und Degradation von I-KB durch das $26 S$ Proteasom, allerdings wird eine Translokation von NF-kB in den Nukleus, und die Expression von verschiedenen pro-inflammatorischen Cytokinen, zumindest 
zeitweise verhindert (BUTCHER et al., 2001). Als Reaktion auf die Infektion mit T. gondii könnte es auch bei PARP-1 zu einer Ubiquitinierung sowie zum Abbau durch das Proteasom kommen. Vergleichbares konnte bei Infektionen mit anderen Pathogenen schon gezeigt werden. Eine Infektion mit Leishmania donovani verursacht in Makrophagen einen Proteasomen-vermittelten Abbau von STAT1a (FORGET et al., 2005). In Zellen, die mit Chlamydia trachomatis infiziert sind, kommt es zum Abbau von CD1d durch das Proteasom (KAWANA et al., 2007). In unseren Versuchen zeigten mit Proteasom-Inhibitoren (MG132 oder Lactacystin) vorinkubierte und mit T. gondii infizierte Zellen allerdings ebenso wie infizierte und unbehandelte Kontrollzellen eine starke Inhibierung des PARP-1-Proteinlevels. Der Abbau von CD1d bei C. trachomatis Infektionen kann nicht durch MG132 inhibiert werden, wohl aber mit Lactacystin (KAWANA et al., 2007). Bei der RPG1 (Protein des „stem rust resistance“ Genes) Proteolyse nach Infektion mit dem Pilz Puccinia graminis zeigt einzig MG132 eine Inhibierung des Proteasoms (NIRMALA et al., 2007). Unsere Ergebnisse zeigten aber weder einen Effekt mit dem Inhibitor Lactacystin noch mit MG132. Dies sprach gegen den Abbau von PARP-1 durch das Proteasom.

Indessen könnten Wirtszellen als Reaktion auf die Anwesenheit des Parasiten dazu angeregt werden, Moleküle zu sezernieren, die die Inhibierung der Expression von PARP-1 induzieren. Ein Beispiel hierfür wäre, dass T. gondii-Infektionen die Freisetzung von IL-12 durch Makrophagen und Dentritische Zellen verursachen (DENKERS, 2003) und auch bei Plasmodium falsciparum Infektionen zeigen THP-1 Zellen eine deutliche Sekretion von TNF- $\alpha$ als Reaktion auf die Infektion (CRUZ CuBAs et al., 1994). Kürzlich wurde gezeigt, dass es durch die Infektion mit T. gondii auch zur Sekretion von CCL2 (Chemokine Ligand 2) durch die Wirtszellen kommt. Mittels einer SAG1 Knockout Mutante von T. gondii wurde SAG1 als Auslöser der CCL2 Sekretion von Wirtszellen identifiziert (BRENIER-PINCHART et al., 2006). Und auch die Chemokine Interleukin (IL)-8, GROa und MCP-1 werden nach Infektion mit T. gondii von HeLa Epithelzellen und Fibroblasten verstärkt sekretiert (DENNEY et al., 1999). Außerdem produzieren T. gondii-infizierte Astrocyten Prostaglandin $\mathrm{E}_{2}$ $\left(\mathrm{PGE}_{2}\right)$, welches die Herunterregulation der NO Produktion von IFN- $\gamma$ aktivierten Mikrogliazellen auslöst und neuronale Degeneration verhindert (ROZENFELD et al., 2003). Es wäre also denkbar, dass auch die PARP-1-Inhibierung durch die Sekretion eines Moleküls von der Wirtszelle als Antwort auf die Infektion verursacht wurde. 
Allerdings zeigten RAW 264.7 Zellen, die mit steril filtriertem Medium von infizierten RAW 264.7 Zellen inkubiert wurden, unveränderte PARP-1 Level im Vergleich zu einer nicht-infizierten Kontrolle. Und auch die Ergebnisse aus dem zellfreien in vitro System sprachen gegen diese Hypothese.

Rezeptoren wie Toll-like Rezeptoren (TLR) oder Nod-like Rezeptoren (NLR) binden extra- bzw. intrazelluläre Signalmoleküle, Pathogen-assoziierte molekulare Proben (PAMPs) genannt, die diverse Signalkaskaden aktivieren. Während es sich bei der Familie der TLR um membranständige Rezeptoren handelt, sind NLR im Inneren der Zelle lokalisiert (SIRARD et al., 2007). TLR 2 und TLR 11 z. B. wurden als wichtige Moleküle in der Abwehr von T. gondii-Infektionen beschrieben (MUN et al., 2003; YAROVINSKY et al., 2005; YAROVINSKY und SHER, 2006). Nukleäre Rezeptoren (NR) binden entweder direkt oder indirekt über andere Transkriptionsfaktoren an die ZielDNA und regulieren deren Transkription (KININIS und KRAUS, 2008). Die Ergebnisse aus dem zellfreien in vitro System belegten, dass es sich bei der Inhibierung der Expression von PARP-1 nicht um eine Membranrezeptor-vermittelte Regulation handelte. Im nukleären Lysat befanden sich keine intakten Membranen der Wirtszelle, obwohl dennoch eine Reduktion des PARP-1-Proteinlevels zu beobachten war. NLR sind nicht membranständig und binden PAMPs im Cytosol (STROBER et al., 2006; SIRARD et al., 2007). Da in dem für diese Arbeit verwendeten Lysat allerdings nur die Nuklei enthalten waren, konnte eine Beteiligung von NLRs oder anderen intrazellulären Rezeptoren weitgehend ausgeschlossen werden. NR kämen als Rezeptoren in Betracht. Sie waren sicherlich im nukleären Lysat vorhanden, allerdings bleibt die Frage, wie das Signalmolekül in die Zelle und zu den NR gelangte, vor allem in Bezug auf die sehr schnelle Inhibierung von PARP innerhalb von 2.5 min nach Infektion mit T. gondii (Abb. 3A).

Zusammenfassend zeigten diese Daten, dass die PARP-1-Inhibierung posttranskriptional und unabhängig von einer funktionsfähigen Translationsmaschinerie der Wirtszelle erfolgte. Auch ein Toxoplasma-induzierter PARP-1-Abbau durch Wirtszellproteasomen, sowie ein Abbau von PARP-1 durch von der Wirtszelle sezernierte Moleküle und eine Beteiligung von intrazellulären Wirtszell-Rezeptoren konnten weitgehend ausgeschlossen werden. 


\subsection{Voraussetzungen seitens des Parasiten T. gondii zur}

\section{PARP-1-Inhibierung}

Während der Invasion einer Wirtszelle kommt es zur Sekretion einer ganzen Reihe von Proteinen aus den verschiedenen Organellen von T. gondii (CARRUTHERS, 1999). Diese sind zur Anheftung an die Wirtszelle, zur Invasion und zur Bildung der parasitophoren Vakuole unerlässlich (SIBLEY et al., 1986; SIBLEY et al., 1995; CarRuthers und Sibley, 1997; Mordue et al., 1999). Außerdem erlaubt die Beschaffenheit der parasitophoren Vakuole als molekulares Sieb einen Austausch von Molekülen bis zu einer Größe von 1300 - 1900 Da (SchWAB et al., 1994). Für ROP16, ein Protein der Rhoptrien von T. gondii, das während der Wirtszellinvasion abgegeben wird, wurde nachgewiesen, dass es die Expression von IL-12 durch die Wirtszelle beeinflusst (SAEIJ et al., 2006; SAEIJ et al., 2007). Aus diesem Grund wurde die Möglichkeit einer Molekül- bzw. Proteinsekretion durch den Parasiten, die die PARP-1-Inhibierung verursacht, in Betracht gezogen. Denkbar wäre auch, dass eine von T. gondii während der Wirtszellinvasion sekretierte Protease, wie das 42kDa Rhoptrienprotein (AHN et al., 2001), PARP-1 in der Wirtszelle abbaut. Dies könnte die Tatsache erklären, dass PARP-1 auch in parasit-negativen Zellen einer infizierten Population inhibiert war. Ein von extrazellulären Parasiten sekretiertes Protein könnte von nicht-infizierten Wirtszellen aufgenommen werden und die PARP1-Inhibierung verursachen. Zur Überprüfung der Hypothese wurde ein so genanntes Transwell-System verwendet. Dabei wurde ein direkter Kontakt zwischen Wirtszellen und Parasiten durch eine Membran mit einer Porengröße von $0.4 \mu \mathrm{m}$ verhindert. Dennoch konnten von $T$. gondii sekretierte Moleküle durch die Membran gelangen und auf die Wirtszellen Einfluss nehmen. Der PARP-1 Proteingehalt der Zellen blieb jedoch unverändert, unabhängig davon, ob sie von $T$. gondii durch die Membran des Transwell-Systems getrennt waren, oder nicht-infiziert blieben. Die Zellen, die direkt mit Tachyzoiten infiziert worden waren, zeigten hingegen eine starke Inhibierung des PARP-1-Proteinlevels. Von T. gondii sekretierte Moleküle haben demnach keinen Einfluss auf PARP-1, vielmehr ist der direkte Kontakt zwischen Wirtszelle und Parasit für die Inhibierung der Expression von PARP-1 nötig. Einschränkend muss jedoch erwähnt werden, dass der Einfluss eines vom Parasiten sekretierten Moleküls mit geringer Halbwertszeit nicht ausgeschlossen werden konnte. Ferner könnte auch die Sekretion eines parasitären Moleküls erst durch den direkten Kontakt zwischen $T$. 
gondii und der Wirtszelle ausgelöst werden. Um diese Möglichkeiten auszuschließen, müssten weitere Experimente durchgeführt werden, da dies im Rahmen des Transwell-Systems nicht möglich war.

Sowohl für die Inhibierung der Wirtszellapoptose, als auch für die Inhibierung der MHC-Klasse II Expression durch T. gondii ist die Fähigkeit des Parasiten zur Replikation unbedeutend. Allerdings sind für beide Mechanismen lebende Parasiten, die die Wirtszelle aktiv infizieren können, unerlässlich (GOEBEL, 2000; LANG et al., 2006). Um zu überprüfen, ob lebende und/oder zur Replikation fähige Parasiten für die PARP-1-Inhibierung notwendig sind, wurden die Parasiten vor der Infektion von Wirtszellen entweder mit UV-Licht behandelt, wodurch die Replikationsfähigkeit des Parasiten verloren ging (ENDO et al., 1981), oder bei $60^{\circ} \mathrm{C}$ (SIBLEY et al., 1985) bzw. bei $-20^{\circ} \mathrm{C}$ abgetötet. Für die PARP-1-Inhibierung war die Replikationsfähigkeit des Parasiten nicht nötig. Im Gegensatz zur Inhibierung der Wirtszellapoptose und der MHC-Klasse II Expression durch $T$. gondii führten interessanterweise aber auch abgetötete Parasiten zu einer deutlichen Inhibierung der Expression von PARP-1. Dies bedeutete, dass die Wirtszellinvasion des Parasiten für die PARP-1-Inhibierung keine notwendige Voraussetzung war und dass auch tote Parasiten den Effekt verursachten. Beobachtungen auf Einzelzellebene, die zeigten, dass auch parasitnegative Zellen einer infizierten Population eine deutliche Reduktion der PARP-1 Menge aufwiesen, untermauerten dies. Die Tatsache, dass PARP-1 auch durch tote Parasiten inhibiert wurde, zeigte, dass es sich nicht um einen aktiven Prozess des Parasiten handelte.

Zusammenfassend kann festgehalten werden, dass für die PARP-1-Inhibierung ein enger Kontakt zwischen Parasit und Wirtszelle offensichtlich wichtig war, wie die Versuche mit dem Transwell-System belegten. Allerdings waren intrazelluläre Replikation und Wirtszellinvasion ohne Bedeutung für die Inhibierung der PARP-1Proteinlevel. Ferner wurde durch die Versuche mit den Hitze-behandelten Parasiten deutlich, dass es sich bei dem Effekt auf PARP-1 um keinen aktiven Prozess des Parasiten handelte, wie z.B. das Ausrichten des apikalen Pols zur Wirtszelle hin (Mitchell et al., 2004) oder das Gleiten auf der Wirtszelloberfläche (OPITZ und SOLDATI, 2002). 
Um genauer bestimmen zu können, welche Bestandteile von T. gondii die Inhibierung der Expression von PARP-1 induzierten, wurden auch ein PBS-lösliches Parasiten-Lysat und ein PBS-unlösliches T. gondii-Lysat mit Wirtszellen inkubiert. Dabei führte das PBS-unlösliche Parasiten-Lysat zu einer vergleichbaren Inhibierung des PARP-1-Proteinlevels wie lebende Parasiten. Es enthielt neben anderen Komponenten vor allem wasserunlösliche Membranbestandteile des Parasiten. Dies deutete auf die Beteiligung eines Membranmoleküls bei der PARP-1-Inhibierung hin und könnte - ein auf der Oberfläche exponiertes Membranmolekül vorausgesetzt auch erklären, dass tote Parasiten eine Inhibierung der Expression von PARP-1 verursachten.

Bei den verschiedenen Membranfraktionen handelte es sich einmal um eine Carbonatpuffer-Fraktion mit hohem pH-Wert, die lösliche und Membran-assoziierte Proteine enthielt, um eine Harnstoff-haltige Fraktion, die komplexere ProteinAggregate beinhaltete, eine Triton-haltige Fraktion, die hauptsächlich hydrophobe Proteine aufwies, sowie eine unlösliche Fraktion, die die restlichen Membranproteine aus den vorangegangenen Fraktionierungsschritten enthielt. Eine starke Inhibierung des PARP-1-Proteinlevels der Wirtszellen zeigte sich nach Inkubation mit der Fraktion, die hauptsächlich Membran-assoziierte Proteine des Parasiten beinhaltete. Eine Analyse der Fraktionen mittels SDS-PAGE und Silberfärbung zeigte in der PARP-1-hemmenden Fraktion eine deutliche Doppelbande bei ca. $30 \mathrm{kDa}$, die im PBS-löslichen T. gondii-Lysat nicht vorhanden war. SAG-1 (p30), ein 30 kDa großes Protein, ist das Hauptoberflächenprotein von T. gondii und stellt $5 \%$ des Gesamtproteingehaltes der Tachyzoiten von T. gondii dar (KASPER et al., 1983). Es besitzt einen Glycosyl-Phosphatidylinositol (GPI)-Anker, über den es in der Plasmamembran des Parasiten verankert ist (NAGEL und BOOTHROYD, 1989; TOMAVO et al., 1989). Infektionsversuche mit SAG1 Knockout Mutanten geben Hinweise, dass dieses Oberflächenmolekül für die Modulation der Immunantwort des Wirtes und für die Ausprägung der Virulenz mitverantwortlich ist (LEKUTIS et al., 2001) und nachweislich Einfluss auf Wirtszellen von T. gondii nimmt (SENG et al., 2002; KATO et al., 2005). So löst es sowohl eine IgA Antikörper Antwort aus (CHARDES et al., 1990) als auch die Produktion der Cytokine IFN-ץ und IL-2 (CHARDES et al., 1993). Auch ist von Trypanosoma cruzi und anderen einzelligen Parasiten bekannt, dass GPI-Anker bzw. GPI-Protein-Komplexe pro-inflammatorische Zytokinproduktionen durch Makrophagen auslösen (GAZZINELLI et al., 1997; AlmeIDA et al., 2000; ALMEIDA und 
GAZZINELLI, 2001). Um zu überprüfen, ob SAG-1 die PARP-1-Inhibierung in Wirtszellen auslöst, wurden RAW 264.7 Makrophagen mit SAG-1 defizienten Mutanten infiziert. Diese zeigten jedoch eine ähnlich starke Inhibierung des PARP-1Proteinlevels wie die entsprechenden parentalen SAG-1-positiven Parasiten und wie NTE Tachyzoiten. Aus diesen Ergebnissen ließ sich schließen, dass ein Membranassoziiertes T. gondii Protein für den Effekt auf PARP-1 verantwortlich war. Allerdings wurde SAG-1 als verursachendes Protein ausgeschlossen.

Auch die P1-Fraktion zeigte eine Inhibierung der Expression von PARP-1, allerdings könnte dies auf eine Kontaminierung dieser Fraktionen mit Proteinen aus der S1Fraktion zurück zu führen sein.

In weiteren Versuchen wäre zunächst eine Charakterisierung der Molekülgruppe, zu der das PARP-1 inhibierende Effektormolekül von T. gondii gehört, sinnvoll. Möglicherweise könnte es sich dabei auch um ein Lipoprotein oder Glycolipid handeln. Für Trypanosoma cruzi konnte nachgewiesen werden, dass Glycoinositolphospholipide immunregulatorische Aktivität besitzen (BRODSKYN et al., 2002). Um weitere Hinweise auf das Membranmolekül von T. gondii zu bekommen, welches PARP-1 inhibiert, könnte ein Verdau mit Proteasen oder eine Behandlung mit Lipasen der S1 Fraktion zu einer besseren Charakterisierung beitragen. Auch eine weitere Auftrennung der S1 Fraktion, z.B. mittels Chromatographie, wäre denkbar. Sobald eine Fraktion aus wenigen Banden einen Effekt zeigt, könnte eine MALDI-TOF Analyse durchgeführt und das entsprechende Protein näher bestimmt werden.

Außerdem besteht die Möglichkeit, dass es sich bei dem Effektormolekül von $T$. gondii selbst um eine Protease handelt. Bei $P$. falciparum wurden nach einer Genomanalyse mehr als 90 Gene gefunden, die Homologien zu bekannten Protease-Familien besitzen und auch bei T. gondii wird eine vergleichbare Anzahl an Proteasen vermutet. Die regulierte Proteolyse stellt einen integralen Teil der Biogenese sekretorischer Organellen bei T. gondii dar (JONGCO und KIM, 2007). Daher spielen Proteasen eine wichtige Rolle bei der Invasion von Wirtszellen durch T. gondii (CARRUTHERS, 1999; DowSE und SOLDATI, 2005). Sowohl in vitro (CONSEIL et al., 1999; QUE et al., 2002) als auch in vivo (BUITRAgo-REY et al., 2002) Experimente konnten zeigen, dass Proteaseinhibitoren das Penetrieren der Wirtszelle durch T. gondii verhindern. In T. gondii können bisher 4 Klassen an Proteasen nachgewiesen werden: Serinproteasen, Aspartatproteasen, 
Cysteinproteasen und Metalloproteasen (JONGCO und KIM, 2007). Aufgrund der Daten dieser Arbeit müsste es sich hierbei um eine Protease handeln, die auf der Parasitenoberfläche aktiv ist. Denn Experimente im Transwell-System zeigten, dass ein enger Kontakt zwischen Parasit und Wirtszelle für die Inhibierung der Expression von PARP-1 nötig war und die Behandlung von Parasiten mit Hitze zeigten, dass keine Invasion des Parasiten für die Inhibierung erforderlich war. Bisher ist bekannt, dass bis zu 3 Mikronemenproteinproteasen (MPP1-3) auf der Oberfläche von $T$. gondii aktiv sind. Allerdings gelang bisher keine eindeutige Identifizierung dieser MPPs (JONGCO und KIM, 2007). Jedoch zeigen Knockout Versuche von TgSUB1, einer Serin-Subtilase von T. gondii, zwar keine Beeinträchtigung des Invasionsverhaltens des Parasiten, wohl aber eine Inhibierung der Aktivität von MPP2 und 3. Diese sind für die Reifung von Adhäsinen bzw. für den regulierten Abbau von sekretorischen Komplexen verantwortlich (JONGCO und KIM, 2007). Neben TgSUB1 wären auch ROM4 und 5 Kandidaten als Effektormolekül der PARP1-Inhibierung, denn ROM4 und 5, Serin-Rhomboid-Proteasen, sind vermutlich für die MPP1 Aktivität verantwortlich und ebenfalls auf der Plasmamembran des Parasiten aktiv (JONGCO und KIM, 2007). Bisher sind keine Inhibitoren für diese beiden SerinProteasen bekannt und auch in dieser Arbeit nicht gezeigte Vorversuche mit verschiedenen Protease-Inhibitoren wie PMSF, Pepstatin, Leupeptin u.a. zeigten keine Auswirkung auf die Inhibierung der Expression von PARP-1 sowohl bei Infektion von RAW 264.7 Monocyten/Makrophagen mit T. gondii als auch bei Inkubation von T. gondii im zellfreien in vitro System. Zur weiteren Chrakterisierung des Effektormoleküls wäre jedoch eine Infektion von RAW 264.7 Monocyten/Makrophagen mit der TgSUB1 Knockout Mutante von T. gondii denkbar um den Effekt von TgSUB1 auf die Inhibierung der Expression von PARP-1 zu untersuchen.

\subsection{Auswirkungen der PARP-1 Überexpression in Wirtszellen} auf Parasit-Wirt Interaktionen

Sowohl PARP-1 als auch T. gondii haben Einfluss auf verschiedene zelluläre Abläufe, scheinen aber meist antagonistische Effekte zu verursachen. Während PARP-1 eine wichtige Rolle in der Apoptose spielt und nach Spaltung als wichtiger 
Apoptosemarker bekannt ist (DURIEZ und SHAH, 1997), moduliert T. gondii die Apoptose in Wirtszellen auf verschiedensten Wegen (LÜDER und GROSS, 2005; SCHAUMBURG et al., 2006). PARP-1 wird als Koaktivator von NF-KB regulierten Genen (z.B. TNF- $\alpha$, IL-6, IL-10, MIP-2, iNOS, etc.) beschrieben (HASSA et al., 2005), wo hingegen T. gondii die Expression NF-kB regulierter Gene inhibiert (DENKERS, 2003; DENKERS et al., 2004). Zu diesen gehören verschiedene pro-inflammatorische Moleküle, wie IL-12, TNF-a, IL-6 und iNOS. Auch bei anderen apikomplexen Parasiten wird PARP-1 in unterschiedlichen Zusammenhängen beschrieben. So wird bei der zerebralen Malaria unter anderem die PARP-1 Überaktivierung mit der Schwere des Verlaufs in Zusammenhang gebracht (CLARK et al., 2004), während bei T. gondii-Infektionen apoptotische und nicht-apoptotische Wirtszellen eine Abnahme des PARP-1-Proteinlevels zeigen (GOEBEL et al., 2001). Es stellte sich daher die Frage, welche Auswirkungen eine Überexpression von PARP-1 auf das Parasit-WirtVerhältnis haben würde. Aus diesem Grund wurden in der vorliegenden Arbeit PARP-1 überexprimierende RAW 264.7 Monocyten/Makrophagen generiert.

\subsubsection{Invasion und Replikation von T. gondii}

PARP-1 beeinflusst die Invasion und Vermehrung von verschiedenen pathogenen Organismen, wie Viren und Bakterien. Bei der Infektion mit HIV-1 zeigen verschiedene Klone der monocytischen Zellinie U937 eine unterschiedliche Anfälligkeit für HIV-1. Zellen mit einer hohen Anfälligkeit für HIV-1 Infektionen besitzen einen 4 - 7-fach reduzierten PARP-1 Gehalt. Daraus wurde geschlossen, dass die Herunterregulierung von PARP-1 eine wichtige Voraussetzung für die Infektion mit HIV-1 ist (TANAKA et al., 1995a). Für Chlamydiaceae, also intrazellulären Bakterien, scheint das Gegenteil der Fall zu sein. Sie zeigen in PARP-1/Fibroblasten eine 10-fach niedrigere Vermehrungsrate als in PARP-1 ${ }^{+/+}$Zellen und auch PARP-1 Inhibitoren führen zu verminderter Bakterienreplikation (YELAMOs et al., 2004). Welchen Einfluss PARP-1 auf Invasion und Replikation von Parasiten besitzt, ist bisher unbekannt. Zur Charakterisierung des Einflusses von PARP-1 auf die Parasit-Wirt Interaktionen und die funktionelle Bedeutung der PARP-1 Modulation durch den Parasiten wurden PARP-1 überexprimierende Makrophagen mit T. gondii Tachyzoiten infiziert und hinsichtlich des Invasions- und Replikationsverhaltens der Parasiten im Vergleich zu Wildtypzellen untersucht. Sowohl in einem quantitativen 
Wachstumstest mit ß-Galaktosidase-exprimierenden Parasiten, als auch bei Immunfluoreszenzfärbungen konnten keine Unterschiede bei Invasion oder Replikation von T. gondii zwischen PARP-1 überexprimierenden Makrophagen und deren Wildtypzellen beobachtet werden. Eine mögliche Ursache, warum die PARP-1Überexpression in den Mutanten keinen Effekt auf die Invasion und Replikation der Parasiten hatte, könnte in dem vergleichbar niedrigen Niveau der Proteinmengen von PARP-1 nach Infektion sowohl in Wildtypzellen und als auch in Mutanten gelegen haben. PARP-1 wurde schon wenige Minuten nach der Infektion mit T. gondii inhibiert und auch der zeitliche Ablauf der Infektion in Wildtypzellen und Mutanten war sowohl auf Protein- als auch auf Einzelzellebene über einen langen Zeitraum der Infektion vergleichbar erniedrigt. Dies bedeutete, dass T. gondii in der Lage war, die erhöhte PARP-1 Expression der Mutanten im Verhältnis stärker zu erniedrigen, nämlich auf ein vergleichbares Niveau wie in Wildtypzellen. Dennoch ist festzustelllen, dass die höheren Proteinmengen von PARP-1 in den Mutanten vor und 24 Stunden nach der Infektion keinen Einfluss auf Invasion und Replikation von T. gondii hatten.

\subsubsection{NF-KB regulierte Gene in der infizierten Wirtszelle}

Ergebnisse aus Versuchen mit einem murinen Asthma-Modell, das zur Untersuchung der PARP-1-Inhibierung und dessen Auswirkung auf Inflammation verwendet wurde, stellen eine Verminderung von Entzündungsmediatoren nach PARP-1-Inhibierung fest. So wird eine Unterdrückung der Produktion der pro-inflammatorischen Cytokine TNF- $\alpha$ und IL-12 nach PARP-1-Inhibierung mit PJ34 nachgewiesen (VIRAG et al., 2004), sowie von iNOS bei ischämischer Hirnverletzung (PARK et al., 2004). Eine Reduktion der Entzündungsmediatoren TNF- $\alpha$ und iNOS wird auch mittels Microarray Analyse von Gewebe aus PARP-1 $1^{-/-}$Mäusen bestätigt (HA et al., 2001). T. gondii könnte daher sowohl über die Inhibierung der Translokation von NF-kB in den Nukleus die Expression der pro-inflammatorischen Gene hemmen (DENKERS, 2003) als auch durch die Inhibierung der Expression von PARP-1. Tatsächlich ist PARP-1 als Koaktivator der NF-KB-regulierten Genexpression beschrieben worden (HASSA et al., 2005). Des Weiteren ist PARP-1 ein Koaktivator von Stat-1, einem weiteren, unter anderem pro-inflammatorischen Transkriptionsfaktor (HA et al., 2001), der auch 
bei der Infektion von T. gondii eine wichtige Rolle spielt (DENKERS und BUTCHER, 2005).

Es sollten daher verschiedene NF-kB-regulierte pro-inflammatorische Moleküle, für die eine Koaktivator-Funktion von PARP-1 beschrieben wurde (HASSA und HOTTIGER, 2002), hinsichtlich ihrer Expression in Wildtyp RAW 264.7 und PARP-1überexprimierenden Mutanten nach Infektion mit Toxoplasma untersucht werden. $\mathrm{Zu}$ den pro-inflammatorischen Molekülen, die durch PARP-1 als Koaktivator der NF-KBabhängige Transkription reguliert werden, gehören Cytokine (TNF- $\alpha$, IL-1ß, IL-6, IL-8,

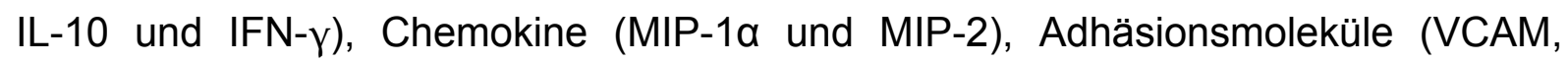
ICAM, P-Selektin, E-Selektin und CD-1 1a), sowie Enzyme (iNOS) (HASSA und HOtTIGER, 2002). Welche molekularen Mechanismen dabei zur Regulation der NFKB-regulierten Transkription durch PARP-1 führen, wird kontrovers diskutiert. Verschiedene Studien konnten zeigen, dass die Enzymaktivität von PARP-1 die NFKB-regulierte Transkription direkt beeinflusst. So wurde gezeigt, dass eine Poly(ADPRibosyl)ierung die DNA Bindeaktivität von NF-kB durch direkte Modifikation verändert (KAMEOKA et al., 2000). Außerdem scheint die DNA Bindeaktivität von NFKB-p50 NAD -abhängig zu sein und durch die Automodifikation von PARP-1 reversibel reguliert zu werden (CHANG und ALVAREZ-GonZALEZ, 2001). Die Automodifizierung von PARP-1 spielt auch eine wichtige Rolle in der NF-KBabhängigen Transkription und Genexpression in Gliazellen (NAKAJIMA et al., 2004). Andere Studien zeigen hingegen, dass weder die enzymatische Aktivität noch die durch PARP-1 veränderte DNA Bindeaktivität von NF-kB für die Transkriptionsregulation relevant sind (HASSA und HOTTIGER, 2002). Die Unterschiede in den Ergebnissen der Studien könnten auf die verwendeten, unterschiedlichen Systeme, unterschiedlichen Stimuli und unterschiedlichen Zelltypen zurückzuführen sein.

LPS-stimulierte Makrophagen zeigten eine stark erhöhte TNF- $\alpha$ Expression im Vergleich zu unstimulierten Kontrollen, allerdings führte die Überexpression von PARP-1 in LPS-stimulierten Klonen zu keiner stärkeren TNF- $\alpha$ Expression im Vergleich zu LPS-stimulierten Wildtypzellen (Abb. 26A). Dieses Ergebnis war insofern unerwartet, da $\mathrm{PARP}^{+/+}$und $\mathrm{PARP}^{-/-}$Mäuse extreme Unterschiede in der TNF-a Expression nach LPS-Stimulierung aufweisen (LIAUDET et al., 2002). Bemerkenswerterweise wurde die TNF- $\alpha$ Expression sowohl in LPS-stimulierten PARP-1 überexprimierenden Zellen als auch in LPS-stimulierten Wildtypzellen durch 
die Infektion mit T. gondii in ähnlichem Maße herunterreguliert (Abb. 26A). In Bezug auf die Wildtypzellen korrelierte dies mit anderen Studien, in denen ebenfalls eine Herunterregulation der LPS-stimulierten TNF-a Expression durch T. gondii zu beobachten ist (DENKERS, 2003). Dass auch die PARP-1 überexprimierenden Zellen eine vergleichbare Herrunterregulation der LPS-stimulierten TNF- $\alpha$ Expression zeigten, könnte auf die Notwendigkeit der Anwesenheit bzw. Abwesenheit von PARP-1, nicht aber auf die absolute Menge des Proteins zurückzuführen sein. Dies würde mit den starken Unterschieden in $\mathrm{PARP}^{+/+}$und in $\mathrm{PARP}^{-/-}$Mäusen bezüglich der TNF- $\alpha$ Expression nach LPS-Stimulierung (LIAUDET et al., 2002) korrelieren. Die hier vorliegenden Daten sprechen dafür, dass eine Überexpression von PARP-1 keinen Einfluss bei der LPS-stimulierten TNF- $\alpha$ Expression hatte.

Im Gegensatz dazu war die mRNA Expression des Chemokins Makrophage Inflammatory Protein (MIP)-2 in LPS-stimulierten PARP-1 überexprimierenden Makrophagen im Vergleich zu LPS-stimulierten Wildtypzellen erhöht (Abb. 26B). Auch in $\mathrm{PARP}^{+/+}$und in $\mathrm{PARP}^{-/-}$Mäusen werden extreme Unterschiede in der MIP-2 Expression nach LPS-Stimulierung beobachtet (LIAUDET et al., 2002). Außerdem zeigt sowohl die pharmakologische Inhibierung sowie die genetische Deletion von PARP-1 eine starke Unterdrückung der Expression der Chemokine MIP-1 $\alpha$ und MIP2 bei entzündlichen Erkrankungen (HASKO et al., 2002). Daher war auch eine mutmaßliche Zunahme der MIP-2 Expression nach LPS-Stimulierung in PARP-1 überexprimierenden Makrophagen im Vergleich zu Wildtypzellen möglich. Ausgehend von dem erhöhten PARP-1-Grundlevel in PARP-1 überexprimierenden Makrophagen war T. gondii in der Lage, die MIP-2 Expression um einen vergleichbaren Level wie in Wildtypzellen zu inhibieren. Dennoch zeigte dies, dass PARP-1 offensichtlich bei der MIP-2 Expression Regulatorfunktion hatte. Durch die Inhibierung der Expression von PARP-1 durch T. gondii könnte der MIP-2-Level unter einen Schwellenwert fallen, der die Entwicklung des Parasiten im Wirt begünstigte. Dies könnte ein erster Hinweis auf eine funktionelle Bedeutung der PARP-1-Inhibierung nach Infektion mit T. gondii sein.

Es ist denkbar, dass die Inhibierung der Expression von PARP-1 und die daraus resultierende MIP-2 Inhibierung ein bisher unbekannter Weg des Parasiten ist, in pro-inflammatorische Chemokin-vermittelte Abwehrmechanismen der Wirtszelle einzugreifen. Diese Hypothese wird von der Tatsache untermauert, dass die Chemokin-Suppression eine wichtige Rolle bei der anti-inflammatorischen Wirkung 
der PARP-1-Inhibierung spielt (HASKO et al., 2002). Durch die Inhibierung der Expression von PARP-1 könnte T. gondii die Produktion von pro-inflammatorischen Molekülen und die Infiltration von inflammatorischen Zellen vermindern. Ein ähnlicher Effekt konnte für die chronische Erkrankung Asthma nachgewiesen werden (VIRAG et al., 2004). Die Untersuchung von weiteren PARP-1- und NF-kB-regulierten Chemokinen, wie z.B. MIP-1a (HASSA und HOTTIGER, 2002), könnte darüber Aufschluss geben, ob es sich tatsächlich um eine bisher unbekannte Interaktion von T. gondii mit einem pro-inflammatorischen Chemokin-vermittelten Abwehrmechanismus der Wirtszelle handelt.

Neben Cytokinen wie TNF- $\alpha$ und Chemokinen wie MIP-2 und MIP-1 $\alpha$ werden auch Adhäsionsmoleküle wie das Intercellular adhesion molecule (ICAM)-1 durch PARP-1 und dessen Koaktivatorfunktion von NF-KB beeinflusst (HASSA und HOTTIGER, 2002). Dabei zeigt sich bei Mikroarrayanalysen von mit LPS stimulierten PARP ${ }^{+/+}$Gliazellen eine deutlich höhere Transkription von ICAM-1 im Vergleich zu PARP ${ }^{-/-}$Gliazellen (HA et al., 2002). Auch in Fibroblasten von PARP ${ }^{-/-}$Mäusen ist die Cytokin-stimulierte Expression von ICAM-1 deutlich reduziert im Vergleich zu Fibroblasten von PARP ${ }^{+/+}$ Mäusen. Außerdem führt eine pharmakologische Inhibierung der Expression von PARP-1 mit 3-Aminobenzidin zu einer Inhibierung der Expression von ICAM-1 (ZINGARELLI et al., 1998). Auch Wachstumsfaktoren wie einige Mitglieder der IGFBPFamilie zeigen deutliche Unterschiede in ihrer Expression in Wildtypzellen im Vergleich zu PARP ${ }^{-/-}$primären Fibroblasten. Während IGFBP-5 eine 4.5-fach niedrigere Expression in Wildtypzellen zeigt, ist die Expression von IGFBP-4 in Wildtypzellen um das 20 fache höher als in PARP $^{-/-}$Fibroblasten (SIMBULANRosentHAL et al., 2000). Aus diesem Grund wurde in dieser Arbeit auch die LPSstimulierte Expression von ICAM-1 und IGFBP-4 in PARP-1 überexprimierenden Monocyten/Makrophagen und deren Wildtypzellen mit und ohne Infektion mit $T$. gondii untersucht. Die Ergebnisse zeigten jedoch weder eine verstärkte Expression von ICAM-1 noch von IGFBP-4 nach Stimulierung mit LPS in Wildtypzellen und auch nicht in PARP-1 überexprimierenden Mutanten. Auch eine Infektion mit T. gondii führte zu keiner Veränderung der Expression von ICAM-1 und IGFBP-4 in Wildtypzellen oder Mutanten im Vergleich zu Kontrollzellen (Abb. 26C und D). Auch wenn diese Ergebnisse der Literatur offensichtlich widersprechen muss festgehalten werden, dass es bisher keine Vergleiche zwischen PARP Wildtypzellen und PARP überexprimierenden Mutanten hinsichtlich der Expression von ICAM-1 und IGFBP-4 
gibt. Stattdessen handelt es sich stets um den Vergleich zwischen PARP ${ }^{-/}$Zellen und PARP ${ }^{+/+}$Zellen (ZINGARELLI et al., 1998; HA et al., 2002) oder um Vergleiche zwischen Wildtypzellen und mit PARP-Inhibitoren behandelten Zellen (ZINGARELLI et al., 1998; SzABo et al., 2002; PICONI et al., 2004; ScotT et al., 2004; HADDAD et al., 2006). Es ist also durchaus denkbar, dass eine Überexpression von PARP-1 nicht notwendigerweise zu einer verstärkten ICAM-1 oder IGFBP-4 Expression führt. Eine weitere mögliche Erklärung für die unterschiedlichen Resultate könnte in den unterschiedlichen verwendeten Zelltypen liegen. Obwohl die hier vorliegenden Daten den Ergebnissen von Simbulan-Rosenthal und Kollegen widersprechen, korrelieren sie mit den Ergebnissen einer neueren Studie. So zeigt das mRNA-Profil von IGFBP4 in Skelettmuskelgewebe keine Veränderung durch LPS oder Sepsis (LANG CH et al., 2006).

Daten aus anderen Labors legen die Vermutung nahe, dass zwischen der hier beobachteten schnellen PARP-1-Inhibierung während der frühen Infektion mit $T$. gondii und der von anderen beobachteten Auswirkung der T. gondii-Infektion auf NFKB in Makrophagen ein Zusammenhang bestehen könnte. So kann 2 h p.i. keine nukleäre Lokalisierung von p65 oder c-Rel, Untereinheiten von NF-kB, in mit $T$. gondii infizierten Makrophagen beobachtet werden (SHAPIRA et al., 2002). Auch in peritonealen Makrophagen wird $2 \mathrm{~h}$ nach Infektion mit T. gondii keine Aktivierung von NF-kB gefunden (BUTCHER et al., 2001). Zudem kann keine Transkription von einigen NF-kB-regulierten Genen, wie IL-6, IL-8, IL-12, TNF- $\alpha$ und iNOS nachgewiesen werden. Die Daten der hier vorliegenden Arbeiten zeigten eine Inhibierung der Expression von PARP-1 sowohl in Wildtypzellen als auch in PARP-1 überexprimierenden Mutanten während der ersten Stunden der Infektion. Da der Parasit auch die erhöhten PARP-1 Level der Mutanten in vergleichbarer Weise über einen langen Zeitraum reduzieren konnte, war ein Effekt durch die Überexpression nur vor Infektion möglich. Dies ließ sich anhand der MIP-2 Expressionsprofile erkennen. Bei TNF- $\alpha$ hingegen schien, wie bereits erwähnt, nur die Anwesenheit von PARP-1 für die Expression ausschlaggebend zu sein, nicht aber die absolute Menge des Proteins in der Zelle, und damit hatte auch die Überexpression in Mutanten keinerlei Auswirkung auf die TNF- $\alpha$ Expression. Interessant wäre es nun, weitere NFkB-regulierte Gene, wie z.B. iNOS, IL-12 etc., in Bezug auf ihre Expression zu untersuchen. 


\subsubsection{Apoptose in infizierten Wirtszellen}

Die Apoptose stellt einen wichtigen Mechanismus in mehrzelligen Organismen während Embryogenese bzw. Homeostase dar, um funktionslose oder geschädigte Zellen des Organismus zu entfernen (HUPPERTZ et al., 1999). Dies geschieht in einer strikt regulierten Weise und verhindert entzündungsbedingte Schädigungen von umliegendem Gewebe. Auch bei Infektionen durch Pathogene spielt der programmierte Zelltod für den Wirt eine wichtige Rolle. Vom Immunsystem als infiziert erkannte Zellen können durch Apoptose eliminiert werden bevor sich die Infektion auf andere Zellen ausbreitet. Aus diesem Grund greifen viele intrazelluläre Pathogene in die Apoptoseregulation des Wirtes ein, entweder indem die Apoptose inhibiert oder induziert wird (SCHAUMBURG et al., 2006). Verschiedene Viren wie das Epstein-Barr-Virus (GREGORY et al., 1991), oder der Erreger des afrikanischen Schweinefiebers (REVILLA et al., 1997), Bakterien wie Coxiella burnetti (VOTH et al., 2007), Pseudomonas aeruginosa (ZHANG et al., 2004) oder Wolbachia (PANNEBAKKER et al., 2007) und protozoische Parasiten wie Leishmania donovani (MOORE und MATLASHEWSKI, 1994), Theileria parva (Heussler et al., 1999) und T. gondii (GoebeL et al., 1998; NASH et al., 1998; KELLER et al., 2006) inhibieren die Apoptose in Wirtszellen. Einige virale (TAKIZAWA et al., 1993), bakterielle (ZYCHLINSKY et al., 1992; CHEN und ZYCHLINSKY, 1994; MULLER et al., 1996; BELYI et al., 2006) und eukaryontische (KHAN et al., 1996; VAN ZANDBERGEN et al., 2007) Pathogene induzieren dagegen die Apoptose in bestimmten Wirtszellen. T. gondii hat sowohl Mechanismen entwickelt, um die Apoptose in Wirtszellen zu inhibieren (GOEBEL et al., 1998; NASH et al., 1998; Goebel et al., 2001; KelLeR et al., 2006), als auch in bestimmten Immunzellpopulationen zu induzieren (KHAN et al., 1996; LÜDER und Gross, 2005; SchaUmbURG et al., 2006). Dabei bildet sich ein empfindliches Gleichgewicht zwischen Replikation und Überleben von T. gondii und dem Überleben des Wirtes.

PARP-1 steht im Zusammenhang mit verschiedenen Formen des programmierten Zelltodes wie dem Apoptose-induzierenden Faktor (AIF)-abhängigen Zelltod (YU et al., 2002; Yu et al., 2003), einer verstärkten Sensibilität gegenüber Endonukleasen während der frühen Phase der Apoptose (Simbulan-RosentHAL et al., 1998) und einer Anfälligkeit für verschiedene Apoptose-Induktoren (TANAKA et al., 1995b; PACINI et al., 1999). Die Spaltung von PARP-1 durch die Caspase 3 stell einen Regulationsmechanismus im Ablauf der Apoptose dar und wird auch als zentraler 
Nachweisparameter für Apoptose verwendet (DuRIEZ und SHAH, 1997). Aus diesem Grund wird die Spaltung von PARP-1 durch die Caspase 3 als wichtige Größe für den Nachweis der Inhibierung der Apoptose nach Infektion mit Pathogenen verwendet (Goebel et al., 2001; ZHANG et al., 2004; KIM et al., 2007; VotH et al., 2007). Dabei zeigt sich in mit Coxiella burnetti (VоTH et al., 2007) bzw. T. gondii (GoEBEL et al., 2001; KIM et al., 2007) infizierten Wirtszellen eine reduzierte Spaltung von PARP-1 nach Apoptose-Induktion mit Staurosporin bzw. Actinomycin-D. Gleichzeitig ist die Actinomycin-induzierte Apoptose in Toxoplasma-infizierten Zellen deutlich gehemmt. Außerdem gibt es Hinweise, dass PARP-1 bei Überaktivierung ein Pro-Apoptose-Signal darstellen könnte. Bei übermäßiger Aktivierung von PARP-1 kann es zu einer kompletten Leerung der NAD ${ }^{+}$Speicher und damit zu einer starken Abnahme von ATP in der Zelle kommen, dies führt letztendlich zum Zelltod (ZHANG et al., 1994; HA und SNYDER, 1999; PIEPER et al., 1999; BoulU et al., 2001; YING et al., 2005). Obwohl die genauen Zusammenhänge noch nicht geklärt sind, scheinen bei dieser Art von Zelltod der Übergang zur Permeabilität der Mitochondrien (MPA), die Freisetzung von AIF (ALANO et al., 2004; YING et al., 2005) und die Inhibierung der Glycolyse aufgrund der Depletion von ATP (YING et al., 2005) eine Rolle zu spielen. Außerdem gibt es Vermutungen, dass diese Ereignisse in Zusammenhang mit der PARP Überaktivierung und NAD ${ }^{+}$Depletion auf mindestens zwei Wegen zum Zelltod führen (YING, 2008). Daher wird aufgrund des parasiten-induzierten PARP-1-Abbaus und der Inhibierung der Apoptose durch T. gondii auf einen möglicherweise antiapoptotischen Mechanismus geschlossen (GoEBEL et al., 2001). Ob die Inhibierung der Apoptose durch eine Infektion mit T. gondii dabei auf die Inhibierung der Expression von PARP-1 zurück zu führen ist, und ob eine Überexpression von PARP-1 diesen Effekt aufheben kann, sollte daher mit Hilfe der PARP-1 überexprimierenden RAW 264.7 Monocyten/Makrophagen geklärt werden. Die Daten der hier vorliegenden Arbeit zeigten jedoch deutlich, dass die Inhibierung der Expression von PARP-1 in infizierten Wirtszellen nicht den anti-apoptotischen Effekt durch T. gondii erklären konnte. Außerdem verhinderte eine Überexpression von PARP-1 in den Mutanten nicht die T. gondii-induzierte Inhibierung der Apoptose. Dass die Inhibierung der Expression von PARP-1 nicht primär mit apoptotischen Abläufen in Verbindung stehen dürfte, deuteten schon frühere Untersuchungen an, in denen gezeigt wurde, dass die PARP-1-Proteinlevel durch eine Infektion mit T. gondii sowohl in apoptotischen, als auch in nicht-apoptotischen Zellen stark reduziert sind 
(GoEBEL et al., 2001). Die hier dargestellten eigenen Ergebnisse bestätigten diesen Sachverhalt deutlich, da $4 \mathrm{~h}$ p.i. die PARP-1-Proteinlevel in Wildtypzellen stark erniedrigt waren (Abb. 3B), wohingegen T. gondii die Caspase 3/7 Aktivität zu diesem Zeitpunkt nicht beeinflusste (Abb. 27). Umgekehrt ließ die transiente Inhibierung der Expression von PARP-1 24 h p.i. stark nach, während die Caspase 3/7 Aktivität zu diesem Zeitpunkt eine starke Inhibierung durch T. gondii erfuhr. Untermauert werden diese Daten von der Tatsache, dass T. gondii die Apoptose in mit Actinomycin-D behandelten Wirtszellen durch die Inaktivierung der Caspase 3 und die Aktivierung von NF-kB inhibiert. Dabei wird auch die Inaktivierung von PARP-1 gezeigt (KIM et al., 2006). Außerdem inhibiert T. gondii die Caspase 3 in einem zellfreien in vitro System (KELLER et al., 2006).

Auch die Voraussetzungen seitens des Parasiten zeigten, dass die PARP-1Inhibierung nicht für die Blockade der Apoptose durch T. gondii verantwortlich war. So konnte in dieser Arbeit gezeigt werden, dass auch tote Parasiten PARP-1 inhibierten, was gegen einen aktiven Prozess sprach. Für die Inhibierung der Apoptose ist aber ein lebender Parasit unerlässlich (NASH et al., 1998; GoEBEL et al., 1999).

Allerdings bestand die Möglichkeit, dass die Inhibierung der Expression von PARP-1 durch T. gondii mit einem Caspase-unabhängigen Pfad des programmierten Zelltodes in Zusammenhang stand. Es ist bekannt, dass PARP-1 die Freisetzung des Apoptose-induzierenden Faktors (AIF) aus den Mitochondrien auslöst und so die Apoptose induziert (Yu et al., 2003; HONG et al., 2004; VAN WIJK und HAGEMAN, 2005; AgUILAR-QUESADA et al., 2007). Allerdings konnte bisher kein Anhaltspunkt gefunden werden, dass T. gondii in die Caspase-unabhängige Apoptose eingreift. Es werden ausschließlich Interaktionen von T. gondii mit dem Caspase-abhängigen extrinsischen (VUTOVA et al., 2007; HIPPE et al., 2008) und dem intrinsischen Signalweg der Wirtszellen (GoEBEL et al., 1998; GoEBEL et al., 2001; LÜDER und GROsS, 2005; KELLER et al., 2006; SchAUMBURG et al., 2006) nachgewiesen. Daher wäre eine Inhibierung der Expression von PARP-1 durch T. gondii in Verbindung mit der Blockierung eines Caspase-unabhängigen Pfades des programmierten Zelltodes, z.B. über einen AIF-vermittelten Weg, sehr unwahrscheinlich, muss aber in weiteren Versuchen abgeklärt werden.

Die PARP-1-Inhibierung durch $T$. gondii in infizierten Wirtszellen als antiapoptotischer Mechanismus (GOEBEL et al., 2001) konnte somit von uns widerlegt 
werden. Zusammenfassend kann damit festgehalten werden, dass ein Zusammenhang zwischen dem Caspase-vermittelten Weg der Apoptose und der PARP-1-Inhibierung durch T. gondii ausgeschlossen wurde. Die Möglichkeit einer Interaktion zwischen dem AIF-vermittelten Zelltod und der PARP-1-Inhibierung nach Infektion mit $T$. gondii konnte nicht ausgeschlossen werden, erscheint aber unwahrscheinlich. 


\section{Zusammenfassung}

Toxoplasma gondii ist ein weit verbreiteter und obligat intrazellulärer protozoischer Parasit, der unter anderem in Menschen meist asymptomatische, lebenslang persistierende Infektionen hervorruft. Er ist aber auch ein wichtiger opportunistischer Krankeitserreger des Menschen. T. gondii hat Mechanismen entwickelt, um innerhalb seines Wirtes langfristig zu persistieren, dabei spielt ein balanciertes Parasit-WirtVerhältnis eine wichtige Rolle. T. gondii verändert dazu verschiedene Aspekte in der Wirtszellphysiologie und verursacht neben der Modulation von WirtszellKompartimenten, der Interaktion mit Wirtszell-Signalwegen und der Apoptose auch die Inhibierung der Expression der Poly(ADP-Ribose) Polymerase (PARP)-1. PARP1 ist ein nukleäres Protein und spielt eine wichtige Rolle in verschiedenen zellulären Abläufen einschließlich DNA Reparatur, Apoptose, Nekrose und Regulation der Genexpression. Außerdem ist es an der Pathogenese von verschiedenen Krankheiten wie entzündlich-chronischen Erkrankungen, Ischämie und Malaria beteiligt. Ziel dieser Arbeit war es, den Effekt einer Infektion mit $T$. gondii auf PARP-1 eingehend zu charakterisieren, um neue Erkenntnisse über die Parasit-WirtInteraktionen während einer Toxoplasmose zu erlangen.

PARP-1-Proteinlevel wurden bereits innerhalb weniger Minuten nach Infektion von Mausmakrophagen mit $T$. gondii dosisabhängig inhibiert. Da diese Inhibierung in verschiedenen murinen und humanen Zelltypen beobachtet wurde, handelte es sich um ein generelles Phänomen einer $T$. gondii-Infektion. Die verminderten PARP-1 Proteinmengen führten zu einer signifikant verminderten ADP-Ribosylierung in infizierten Wirtszellen. Vergleichende Untersuchungen mit virulenten und avirulenten $T$. gondii Stämmen widerlegten die Theorie einer genotyp- oder virulenzabhängigen PARP-1-Inhibierung. Die Inhibierung erfolgte posttranskriptional und unabhängig von einer funktionsfähigen Translationsmaschinerie der Wirtszelle. Durch den Einsatz von Proteasominhibitoren wurde ein Toxoplasma-induzierter PARP-1-Abbau durch Wirtszellproteasomen weitgehend ausgeschlossen. Versuche mit unterschiedlich behandelten Parasiten zeigten, dass die PARP-1-Inhibierung unabhängig von Invasions- oder Replikationsfähigkeit von $T$. gondii stattfand, denn auch tote Parasiten waren zur PARP-1-Inhibierung in der Lage. Die Sekretion von Wirtszelleigenen Molekülen, die durch Infektion mit $T$. gondii induziert wurden, konnte als zugrunde liegender Mechanismus weitgehend ausgeschlossen werden. Dagegen 
war ein direkter Kontakt zwischen Parasit und Wirtszelle nötig, wie Experimente mit einem in vitro Transwell-System zeigten. Dabei schien ein bisher nicht näher identifiziertes Effektormolekül in der Parasitenmembran für die Herunterregulation von PARP-1 verantwortlich zu sein, wie Fraktionierungen von Parasitenextrakten nahelegten. Das Hauptoberflächenantigen von Toxoplasma, SAG-1, konnte jedoch als parasitäres Effektormolekül ausgeschlossen werden. Möglicherweise könnte es sich bei dem Effektormolekül um eine Protease von $T$. gondii handeln.

Um die funktionelle Bedeutung von PARP-1 und dessen Modulation durch Toxoplasma zu untersuchen, wurde PARP-1 in Monocyten/Makrophagen der Maus stabil überexprimiert (PARP-1 ${ }^{\text {hoch }}$ Mutanten). Bemerkenswerterweise inhibierte $T$. gondii nach Infektion die PARP-1-Proteinlevel in überexprimierenden Mutanten auf das gleiche Niveau wie in Wildtypzellen. Die zumindest teilweise erhöhten PARP-1Proteinmengen in PARP- $1^{\text {hoch }}$ Mutanten hatten keinen Einfluss auf Invasion und Replikation des Parasiten im Vergleich zu Wildtypzellen. Expressionsprofile von NFKB-regulierten Genen in PARP-1 überexprimierenden Mutanten und Wildtypzellen zeigten, dass PARP-1 an der parasiten-vermittelten Verminderung von MIP-2, nicht aber jener von TNF- $\alpha$ beteiligt zu sein schien. Die PARP-1-Inhibierung durch $T$. gondii könnte daher ein bisher unbekannter Mechanismus des Parasiten sein, in proinflammatorische Chemokin-vermittelte Abwehrmechanismen der Wirtszelle einzugreifen. Die zumindest zeitweise Überexpression von PARP-1 verhinderte jedoch nicht die $T$. gondii-abhängige Inhibierung der Staurosporin-induzierten Wirtszellapoptose, wobei ein Effekt auf Caspase-unabhängige Apoptosewege nicht ausgeschlossen werden konnte.

Durch diese Arbeit konnten neue Zusammenhänge zwischen $T$. gondii und der PARP-1-Inhibierung in Wirtszellen aufgezeigt werden, die zu einem besseren Verständnis der Parasit-Wirt-Interaktionen während einer Toxoplasmose beitragen. 


\section{Literatur}

Aguilar-Quesada, R, Munoz-Gamez, JA, Martin-Oliva, D, Peralta-Leal, A, QuilesPerez, R, Rodriguez-Vargas, JM, de Almodovar, MR, Conde, C, Ruiz-Extremera, A and Oliver, FJ (2007). Modulation of transcription by PARP-1: consequences in carcinogenesis and inflammation

Curr Med Chem. 14, 1179-87

Ahn, HJ, Song, KJ, Son, ES, Shin, JC and Nam, HW (2001). Protease activity and host cell binding of the 42-kDa rhoptry protein from Toxoplasma gondii after secretion Biochem Biophys Res Commun. 287, 630-5

Alano, CC, Ying, W and Swanson, RA (2004). Poly(ADP-ribose) polymerase-1mediated cell death in astrocytes requires NAD+ depletion and mitochondrial permeability transition

J Biol Chem. 279, 18895-902

Alexander, DL, Mital, J, Ward, GE, Bradley, P and Boothroyd, JC (2005).

Identification of the moving junction complex of Toxoplasma gondii: a collaboration between distinct secretory organelles

PLoS Pathog. 1, e17

Almeida, IC, Camargo, MM, Procopio, DO, Silva, LS, Mehlert, A, Travassos, LR, Gazzinelli, RT and Ferguson, MA (2000). Highly purified

glycosylphosphatidylinositols from Trypanosoma cruzi are potent proinflammatory agents

Embo J. 19, 1476-85

Almeida, IC and Gazzinelli, RT (2001). Proinflammatory activity of

glycosylphosphatidylinositol anchors derived from Trypanosoma cruzi: structural and functional analyses

J Leukoc Biol. 70, 467-77

Altmann, H (1983). [Poly-(ADP ribose) synthesis and regulation disorders in disease]

Wien Klin Wochenschr. 95, 861-4

Ame, JC, Spenlehauer, C and de Murcia, G (2004). The PARP superfamily Bioessays. 26, 882-93

Bakondi, E, Bai, P, Szabo, EE, Hunyadi, J, Gergely, P, Szabo, C and Virag, L (2002). Detection of poly(ADP-ribose) polymerase activation in oxidatively stressed cells and tissues using biotinylated NAD substrate $\mathrm{J}$ Histochem Cytochem. 50, 91-8

Beckers, CJ, Dubremetz, JF, Mercereau-Puijalon, O and Joiner, KA (1994). The Toxoplasma gondii rhoptry protein ROP 2 is inserted into the parasitophorous vacuole membrane, surrounding the intracellular parasite, and is exposed to the host cell cytoplasm

J Cell Biol. 127, 947-61 
Belloni, A, Villena, I, Gomez, JE, Pelloux, H, Bonhomme, A, Guenounou, M, Pinon, JM and Aubert, D (2003). Regulation of tumor necrosis factor alpha and its specific receptors during Toxoplasma gondii infection in human monocytic cells Parasitol Res. 89, 207-13

Belyi, Y, Niggeweg, R, Opitz, B, Vogelsgesang, M, Hippenstiel, S, Wilm, M and Aktories, K (2006). Legionella pneumophila glucosyltransferase inhibits host elongation factor $1 \mathrm{~A}$

Proc Natl Acad Sci U S A. 103, 16953-8

Berger, NA (1985). Poly(ADP-ribose) in the cellular response to DNA damage Radiat Res. 101, 4-15

Beyer, TV, Svezhova, NV, Radchenko, Al and Sidorenko, NV (2002).

Parasitophorous vacuole: morphofunctional diversity in different coccidian genera (a short insight into the problem)

Cell Biol Int. 26, 861-71

Blader, IJ, Manger, ID and Boothroyd, JC (2001). Microarray analysis reveals previously unknown changes in Toxoplasma gondii-infected human cells J Biol Chem. 276, 24223-31

Bohne, W, Heesemann, J and Gross, U (1994). Reduced replication of Toxoplasma gondii is necessary for induction of bradyzoite-specific antigens: a possible role for nitric oxide in triggering stage conversion Infect Immun. 62, 1761-7

Bohne, W, Holpert, M and Gross, U (1999). Stage differentiation of the protozoan parasite Toxoplasma gondii Immunobiology. 201, 248-54

Bonametti, AM, Passos, JN, Koga da Silva, EM and Macedo, ZS (1997). Probable transmission of acute toxoplasmosis through breast feeding J Trop Pediatr. 43, 116

Boulares, AH, Zoltoski, AJ, Sherif, ZA, Jolly, P, Massaro, D and Smulson, ME (2003). Gene knockout or pharmacological inhibition of poly(ADP-ribose) polymerase-1 prevents lung inflammation in a murine model of asthma Am J Respir Cell Mol Biol. 28, 322-9

Boulu, RG, Mesenge, C, Charriaut-Marlangue, C, Verrecchia, C and Plotkine, M (2001). [Neuronal death: potential role of the nuclear enzyme, poly (ADP-ribose) polymerase]

Bull Acad Natl Med. 185, 555-63; discussion 564-5

Brenier-Pinchart, MP, Villena, I, Mercier, C, Durand, F, Simon, J, CesbronDelauw, MF and Pelloux, H (2006). The Toxoplasma surface protein SAG1 triggers efficient in vitro secretion of chemokine ligand 2 (CCL2) from human fibroblasts Microbes Infect. 8, 254-61 
Brodskyn, C, Patricio, J, Oliveira, R, Lobo, L, Arnholdt, A, Mendonca-Previato, L, Barral, A and Barral-Netto, M (2002). Glycoinositolphospholipids from Trypanosoma cruzi interfere with macrophages and dendritic cell responses Infect Immun. 70, 3736-43

Buitrago-Rey, R, Olarte, J and Gomez-Marin, JE (2002). Evaluation of two inhibitors of invasion: LY311727 [3-(3-acetamide-1-benzyl-2-ethyl-indolyl-5oxy)propane phosphonic acid] and AEBSF [4-(2-aminoethyl)-benzenesulphonyl fluoride] in acute murine toxoplasmosis

J Antimicrob Chemother. 49, 871-4

Burkle, A, Diefenbach, J, Brabeck, C and Beneke, S (2005). Ageing and PARP Pharmacol Res. 52, 93-9

Butcher, BA, Kim, L, Johnson, PF and Denkers, EY (2001). Toxoplasma gondii tachyzoites inhibit proinflammatory cytokine induction in infected macrophages by preventing nuclear translocation of the transcription factor NF-kappa B J Immunol. 167, 2193-201

Buxton, D (1993). Toxoplasmosis: the first commercial vaccine Parasitol Today. 9, 335-7

Carruthers, VB and Sibley, LD (1997). Sequential protein secretion from three distinct organelles of Toxoplasma gondii accompanies invasion of human fibroblasts Eur J Cell Biol. 73, 114-23

Carruthers, VB (1999). Armed and dangerous: Toxoplasma gondii uses an arsenal of secretory proteins to infect host cells

Parasitol Int. 48, 1-10

Cepeda, V, Fuertes, MA, Castilla, J, Alonso, C, Quevedo, C, Soto, M and Perez, JM (2006). Poly(ADP-ribose) polymerase-1 (PARP-1) inhibitors in cancer chemotherapy

Recent Patents Anticancer Drug Discov. 1, 39-53

Chang, WJ and Alvarez-Gonzalez, R (2001). The sequence-specific DNA binding of NF-kappa $B$ is reversibly regulated by the automodification reaction of poly (ADPribose) polymerase 1

J Biol Chem. 276, 47664-70

Chardes, T, Bourguin, I, Mevelec, MN, Dubremetz, JF and Bout, D (1990).

Antibody responses to Toxoplasma gondii in sera, intestinal secretions, and milk from orally infected mice and characterization of target antigens

Infect Immun. 58, 1240-6

Chardes, T, Velge-Roussel, F, Mevelec, P, Mevelec, MN, Buzoni-Gatel, D and Bout, D (1993). Mucosal and systemic cellular immune responses induced by Toxoplasma gondii antigens in cyst orally infected mice Immunology. 78, 421-9

Chen, Y and Zychlinsky, A (1994). Apoptosis induced by bacterial pathogens 
Microb Pathog. 17, 203-12

Chiou, SH, Liu, JH, Chen, SS, Liu, WT, Lin, JC, Wong, WW, Tseng, WS, Chou, CK, Liu, CY, Ho, LL and Hsu, WM (2002). Apoptosis of human retina and retinal pigment cells induced by human cytomegalovirus infection Ophthalmic Res. 34, 77-82

Clark, IA and Cowden, WB (2003). The pathophysiology of falciparum malaria Pharmacol Ther. 99, 221-60

Clark, IA, Alleva, LM, Mills, AC and Cowden, WB (2004). Pathogenesis of malaria and clinically similar conditions

Clin Microbiol Rev. 17, 509-39, table of contents

Conseil, V, Soete, M and Dubremetz, JF (1999). Serine protease inhibitors block invasion of host cells by Toxoplasma gondii

Antimicrob Agents Chemother. 43, 1358-61

Cruz Cubas, AB, Gentilini, M and Monjour, L (1994). Cytokines and T-cell response in malaria

Biomed Pharmacother. 48, 27-33

Cuzzocrea, S (2005). Shock, inflammation and PARP

Pharmacol Res. 52, 72-82

Cuzzocrea, S and Wang, ZQ (2005). Role of poly(ADP-ribose) glycohydrolase (PARG) in shock, ischemia and reperfusion

Pharmacol Res. 52, 100-8

Decker, $\mathbf{P}$ and Muller, S (2002). Modulating poly (ADP-ribose) polymerase activity: potential for the prevention and therapy of pathogenic situations involving DNA damage and oxidative stress

Curr Pharm Biotechnol. 3, 275-83

Denkers, EY (2003). From cells to signaling cascades: manipulation of innate immunity by Toxoplasma gondii

FEMS Immunol Med Microbiol. 39, 193-203

Denkers, EY, Butcher, BA, Del Rio, L and Kim, L (2004). Manipulation of mitogenactivated protein kinase/nuclear factor-kappaB-signaling cascades during intracellular Toxoplasma gondii infection

Immunol Rev. 201, 191-205

Denkers, EY and Butcher, BA (2005). Sabotage and exploitation in macrophages parasitized by intracellular protozoans

Trends Parasitol. 21, 35-41

Denney, CF, Eckmann, L and Reed, SL (1999). Chemokine secretion of human cells in response to Toxoplasma gondii infection Infect Immun. 67, 1547-52 
Deszcz, L, Gaudernak, E, Kuechler, E and Seipelt, J (2005). Apoptotic events induced by human rhinovirus infection

J Gen Virol. 86, 1379-89

Diana, J, Vincent, C, Peyron, F, Picot, S, Schmitt, D and Persat, F (2005).

Toxoplasma gondii regulates recruitment and migration of human dendritic cells via different soluble secreted factors

Clin Exp Immunol. 141, 475-84

Ding, M, Kwok, LY, Schluter, D, Clayton, C and Soldati, D (2004). The antioxidant systems in Toxoplasma gondii and the role of cytosolic catalase in defence against oxidative injury

Mol Microbiol. 51, 47-61

Dobrowolski, JM and Sibley, LD (1996). Toxoplasma invasion of mammalian cells is powered by the actin cytoskeleton of the parasite

Cell. 84, 933-9

Dobrowolski, JM, Carruthers, VB and Sibley, LD (1997). Participation of myosin in gliding motility and host cell invasion by Toxoplasma gondii

Mol Microbiol. 26, 163-73

Dowse, TJ and Soldati, D (2005). Rhomboid-like proteins in Apicomplexa:

phylogeny and nomenclature

Trends Parasitol. 21, 254-8

Dubey, JP, Miller, NL and Frenkel, JK (1970). The Toxoplasma gondii oocyst from cat feces

J Exp Med. 132, 636-62

Dubey, JP (1991). Toxoplasmosis--an overview

Southeast Asian J Trop Med Public Health. 22 Suppl, 88-92

Dubey, JP and Rommel, M (1992). [Abortions caused by protozoa in agricultural animals]

Dtsch Tierarztl Wochenschr. 99, 355-62

Dubey, JP, Lindsay, DS and Speer, CA (1998). Structures of Toxoplasma gondii tachyzoites, bradyzoites, and sporozoites and biology and development of tissue cysts

Clin Microbiol Rev. 11, 267-99

Dubremetz, JF, Garcia-Reguet, N, Conseil, V and Fourmaux, MN (1998). Apical organelles and host-cell invasion by Apicomplexa

Int J Parasitol. 28, 1007-13

Duriez, PJ and Shah, GM (1997). Cleavage of poly(ADP-ribose) polymerase: a sensitive parameter to study cell death

Biochem Cell Biol. 75, 337-49 
Endo, T, Pelster, B and Piekarski, G (1981). Infection of murine peritoneal macrophages with Toxoplasma gondii exposed to ultraviolet light

Z Parasitenkd. 65, 121-9

Feldman, HA (1968). Toxoplasmosis

N Engl J Med. 279, 1370-5 contd

Ferguson, DJ, Hutchison, WM and Siim, JC (1975). The ultrastructural development of the macrogamete and formation of the oocyst wall of Toxoplasma gondii

Acta Pathol Microbiol Scand [B]. 83, 491-505

Ferguson, DJ, Birch-Andersen, A, Siim, JC and Hutchison, WM (1979). Ultrastructural studies on the sporulation of oocysts of Toxoplasma gondii. III. Formation of the sporozoites within the sporocysts Acta Pathol Microbiol Scand [B]. 87, 253-60

Fichera, ME and Roos, DS (1997). A plastid organelle as a drug target in apicomplexan parasites

Nature. 390, 407-9

Fischer, HG, Nitzgen, B, Reichmann, G and Hadding, U (1997). Cytokine responses induced by Toxoplasma gondii in astrocytes and microglial cells Eur J Immunol. 27, 1539-48

Forget, G, Gregory, DJ and Olivier, M (2005). Proteasome-mediated degradation of STAT1alpha following infection of macrophages with Leishmania donovani J Biol Chem. 280, 30542-9

Fox, BA, Gigley, JP and Bzik, DJ (2004). Toxoplasma gondii lacks the enzymes required for de novo arginine biosynthesis and arginine starvation triggers cyst formation Int J Parasitol. 34, 323-31

Frenkel, JK, Dubey, JP and Miller, NL (1970). Toxoplasma gondii in cats: fecal stages identified as coccidian oocysts

Science. 167, 893-6

Froelich, CJ, Hanna, WL, Poirier, GG, Duriez, PJ, D'Amours, D, Salvesen, GS, Alnemri, ES, Earnshaw, WC and Shah, GM (1996). Granzyme B/perforin-mediated apoptosis of Jurkat cells results in cleavage of poly(ADP-ribose) polymerase to the 89-kDa apoptotic fragment and less abundant 64-kDa fragment Biochem Biophys Res Commun. 227, 658-65

Gail, M, Gross, U and Bohne, W (2001). Transcriptional profile of Toxoplasma gondii-infected human fibroblasts as revealed by gene-array hybridization Mol Genet Genomics. 265, 905-12

Garcia, S, Bodano, A, Pablos, JL, Gomez-Reino, JJ and Conde, C (2008). Poly(ADP-ribose) polymerase inhibition reduces tumor necrosis factor-induced inflammatory response in rheumatoid synovial fibroblasts 
Ann Rheum Dis. 67, 631-7

Gazzinelli, RT, Camargo, MM, Almeida, IC, Morita, YS, Giraldo, M, AcostaSerrano, A, Hieny, S, Englund, PT, Ferguson, MA, Travassos, LR and Sher, A (1997). Identification and characterization of protozoan products that trigger the synthesis of IL-12 by inflammatory macrophages

Chem Immunol. 68, 136-52

Gobeil, S, Boucher, CC, Nadeau, D and Poirier, GG (2001). Characterization of the necrotic cleavage of poly(ADP-ribose) polymerase (PARP-1): implication of lysosomal proteases

Cell Death Differ. 8, 588-94

Goebel, S, Lüder, CG, Lugert, R, Bohne, W and Gross, U (1998). Toxoplasma gondii inhibits the in vitro induced apoptosis of HL-60 cells

Tokai J Exp Clin Med. 23, 351-6

Goebel, S, Lüder, CG and Gross, U (1999). Invasion by Toxoplasma gondii protects human-derived HL-60 cells from actinomycin D-induced apoptosis Med Microbiol Immunol. 187, 221-6

Goebel, S, Gross, U and Lüder, CG (2001). Inhibition of host cell apoptosis by Toxoplasma gondii is accompanied by reduced activation of the caspase cascade and alterations of poly(ADP-ribose) polymerase expression

J Cell Sci. 114, 3495-505

Gonzalez-Rey, E, Martinez-Romero, R, O'Valle, F, Aguilar-Quesada, R, Conde, C, Delgado, M and Oliver, FJ (2007). Therapeutic Effect of a Poly(ADP-Ribose) Polymerase-1 Inhibitor on Experimental Arthritis by Downregulating Inflammation and Th1 Response

PLOS ONE. 2, e1071

Gregory, CD, Dive, C, Henderson, S, Smith, CA, Williams, GT, Gordon, J and Rickinson, AB (1991). Activation of Epstein-Barr virus latent genes protects human $B$ cells from death by apoptosis

Nature. 349, 612-4

Grimwood, J and Smith, JE (1992). Toxoplasma gondii: the role of a 30-kDa surface protein in host cell invasion

Exp Parasitol. 74, 106-11

Gross, U, Muller, WA, Knapp, S and Heesemann, J (1991). Identification of a virulence-associated antigen of Toxoplasma gondii by use of a mouse monoclonal antibody

Infect Immun. 59, 4511-6

Ha, HC and Snyder, SH (1999). Poly(ADP-ribose) polymerase is a mediator of necrotic cell death by ATP depletion

Proc Natl Acad Sci U S A. 96, 13978-82 
Ha, HC, Juluri, K, Zhou, Y, Leung, S, Hermankova, M and Snyder, SH (2001). Poly(ADP-ribose) polymerase-1 is required for efficient HIV-1 integration Proc Natl Acad Sci U S A. 98, 3364-8

Ha, HC, Hester, LD and Snyder, SH (2002). Poly(ADP-ribose) polymerase-1 dependence of stress-induced transcription factors and associated gene expression in glia

Proc Natl Acad Sci U S A. 99, 3270-5

Haddad, M, Rhinn, H, Bloquel, C, Coqueran, B, Szabo, C, Plotkine, M, Scherman, D and Margaill, I (2006). Anti-inflammatory effects of PJ34, a poly(ADPribose) polymerase inhibitor, in transient focal cerebral ischemia in mice Br J Pharmacol. 149, 23-30

Hasko, G, Mabley, JG, Nemeth, ZH, Pacher, P, Deitch, EA and Szabo, C (2002). Poly(ADP-ribose) polymerase is a regulator of chemokine production: relevance for the pathogenesis of shock and inflammation Mol Med. 8, 283-9

Hassa, PO and Hottiger, MO (2002). The functional role of poly(ADPribose)polymerase 1 as novel coactivator of NF-kappaB in inflammatory disorders Cell Mol Life Sci. 59, 1534-53

Hassa, PO, Haenni, SS, Buerki, C, Meier, NI, Lane, WS, Owen, H, Gersbach, M, Imhof, R and Hottiger, MO (2005). Acetylation of poly(ADP-ribose) polymerase-1 by p300/CREB-binding protein regulates coactivation of NF-kappaB-dependent transcription J Biol Chem. 280, 40450-64

Hassa, PO, Haenni, SS, Elser, M and Hottiger, MO (2006). Nuclear ADPribosylation reactions in mammalian cells: where are we today and where are we going? Microbiol Mol Biol Rev. 70, 789-829

Herceg, Z and Wang, ZQ (2001). Functions of poly(ADP-ribose) polymerase (PARP) in DNA repair, genomic integrity and cell death Mutat Res. 477, 97-110

Heussler, VT, Machado, J, Jr., Fernandez, PC, Botteron, C, Chen, CG, Pearse, MJ and Dobbelaere, DA (1999). The intracellular parasite Theileria parva protects infected $T$ cells from apoptosis

Proc Natl Acad Sci U S A. 96, 7312-7

Heussler, VT, Kuenzi, P and Rottenberg, S (2001). Inhibition of apoptosis by intracellular protozoan parasites Int J Parasitol. 31, 1166-76

Hippe, D, Lytovchenko, O, Schmitz, I and Lüder, CG (2008). Fas/CD95-mediated apoptosis of type II cells is blocked by Toxoplasma gondii primarily via interference with the mitochondrial amplification loop Infect Immun. 
Hong, SJ, Dawson, TM and Dawson, VL (2004). Nuclear and mitochondrial conversations in cell death: PARP-1 and AIF signaling

Trends Pharmacol Sci. 25, 259-64

Horvath, EM and Szabo, C (2007). Poly(ADP-ribose) polymerase as a drug target for cardiovascular disease and cancer: an update

Drug News Perspect. 20, 171-81

Huppertz, B, Frank, HG and Kaufmann, P (1999). The apoptosis cascade-morphological and immunohistochemical methods for its visualization Anat Embryol (Berl). 200, 1-18

Jackson, MH and Hutchison, WM (1989). The prevalence and source of Toxoplasma infection in the environment

Adv Parasitol. 28, 55-105

Jacobs, L, Remington, JS and Melton, ML (1960). The resistance of the encysted form of Toxoplasma gondii

J Parasitol. 46, 11-21

Joiner, KA, Fuhrman, SA, Miettinen, HM, Kasper, LH and Mellman, I (1990).

Toxoplasma gondii: fusion competence of parasitophorous vacuoles in Fc receptortransfected fibroblasts

Science. 249, 641-6

Joiner, KA (1991). Rhoptry lipids and parasitophorous vacuole formation: a slippery issue

Parasitol Today. 7, 226-7

Jones, TC and Hirsch, JG (1972). The interaction between Toxoplasma gondii and mammalian cells. II. The absence of lysosomal fusion with phagocytic vacuoles containing living parasites

J Exp Med. 136, 1173-94

Kameoka, M, Ota, K, Tetsuka, T, Tanaka, Y, Itaya, A, Okamoto, T and Yoshihara, K (2000). Evidence for regulation of NF-kappaB by poly(ADP-ribose) polymerase Biochem J. 346 Pt 3, 641-9

Kasper, LH, Crabb, JH and Pfefferkorn, ER (1983). Purification of a major membrane protein of Toxoplasma gondii by immunoabsorption with a monoclonal antibody

J Immunol. 130, 2407-12

Kato, M, Claveria, FG, Maki, Y, Tanaka, T, Suzuki, N and Nagasawa, H (2005). Toxoplasma gondii antigens GRA1 (p24) and SAG1 (p30): a comparison of their stimulatory influence on T-cell activation and cytokine expression in in vitro cultures Pathobiology. 72, 160-4 
Kaufmann, SH (1989). Induction of endonucleolytic DNA cleavage in human acute myelogenous leukemia cells by etoposide, camptothecin, and other cytotoxic anticancer drugs: a cautionary note

Cancer Res. 49, 5870-8

Kaufmann, SH, Desnoyers, S, Ottaviano, Y, Davidson, NE and Poirier, GG (1993). Specific proteolytic cleavage of poly(ADP-ribose) polymerase: an early marker of chemotherapy-induced apoptosis

Cancer Res. 53, 3976-85

Kawana, K, Quayle, AJ, Ficarra, M, Ibana, JA, Shen, L, Kawana, Y, Yang, H, Marrero, L, Yavagal, S, Greene, SJ, Zhang, YX, Pyles, RB, Blumberg, RS and Schust, DJ (2007). CD1d degradation in Chlamydia trachomatis-infected epithelial cells is the result of both cellular and chlamydial proteasomal activity

J Biol Chem. 282, 7368-75

Keller, P, Schaumburg, F, Fischer, SF, Hacker, G, Gross, U and Lüder, CG (2006). Direct inhibition of cytochrome c-induced caspase activation in vitro by Toxoplasma gondii reveals novel mechanisms of interference with host cell apoptosis FEMS Microbiol Lett. 258, 312-9

Khan, IA, Matsuura, T and Kasper, LH (1996). Activation-mediated CD4+ T cell unresponsiveness during acute Toxoplasma gondii infection in mice Int Immunol. 8, 887-96

Kim, JY, Ahn, MH, Jun, HS, Jung, JW, Ryu, JS and Min, DY (2006). Toxoplasma gondii inhibits apoptosis in infected cells by caspase inactivation and NF-kappaB activation

Yonsei Med J. 47, 862-9

Kim, L and Denkers, EY (2006). Toxoplasma gondii triggers Gi-dependent PI 3kinase signaling required for inhibition of host cell apoptosis

J Cell Sci. 119, 2119-26

Kim, MY, Zhang, T and Kraus, WL (2005). Poly(ADP-ribosyl)ation by PARP-1:

'PAR-laying' NAD+ into a nuclear signal

Genes Dev. 19, 1951-67

Kim, SK, Fouts, AE and Boothroyd, JC (2007). Toxoplasma gondii dysregulates IFN-gamma-inducible gene expression in human fibroblasts: insights from a genomewide transcriptional profiling

J Immunol. 178, 5154-65

Kininis, M and Kraus, WL (2008). A global view of transcriptional regulation by nuclear receptors: gene expression, factor localization, and DNA sequence analysis Nucl Recept Signal. 6, e005

Knoll, LJ and Boothroyd, JC (1998). Molecular Biology's Lessons about Toxoplasma Development: Stage-specific Homologs

Parasitol Today. 14, 490-3 
Koskiniemi, M, Lappalainen, M and Hedman, K (1989). Toxoplasmosis needs evaluation. An overview and proposals

Am J Dis Child. 143, 724-8

Lai, XH and Sjostedt, A (2003). Delineation of the molecular mechanisms of Francisella tularensis-induced apoptosis in murine macrophages Infect Immun. 71, 4642-6

Lang, C, Algner, M, Beinert, N, Gross, U and Lüder, CG (2006). Diverse mechanisms employed by Toxoplasma gondii to inhibit IFN-gamma-induced major histocompatibility complex class II gene expression Microbes Infect. 8, 1994-2005

Lang, C, Gross, U and Lüder, CG (2007). Subversion of innate and adaptive immune responses by Toxoplasma Gondii

Parasitol Res. 100, 191-203

Lang, CH, Krawiec, BJ, Huber, D, McCoy, JM and Frost, RA (2006). Sepsis and inflammatory insults downregulate IGFBP-5, but not IGFBP-4, in skeletal muscle via a TNF-dependent mechanism

Am J Physiol Regul Integr Comp Physiol. 290, R963-72

Lebech, M, Joynson, DH, Seitz, HM, Thulliez, P, Gilbert, RE, Dutton, GN, Ovlisen, B and Petersen, E (1996). Classification system and case definitions of Toxoplasma gondii infection in immunocompetent pregnant women and their congenitally infected offspring. European Research Network on Congenital Toxoplasmosis

Eur J Clin Microbiol Infect Dis. 15, 799-805

Lecker, SH, Goldberg, AL and Mitch, WE (2006). Protein degradation by the ubiquitin-proteasome pathway in normal and disease states J Am Soc Nephrol. 17, 1807-19

Lekutis, C, Ferguson, DJ, Grigg, ME, Camps, M and Boothroyd, JC (2001). Surface antigens of Toxoplasma gondii: variations on a theme Int J Parasitol. 31, 1285-92

Liaudet, L, Pacher, P, Mabley, JG, Virag, L, Soriano, FG, Hasko, G and Szabo, C (2002). Activation of poly(ADP-Ribose) polymerase-1 is a central mechanism of lipopolysaccharide-induced acute lung inflammation Am J Respir Crit Care Med. 165, 372-7

Liaudet, L and Oddo, M (2003). Role of poly(adenosine diphosphate-ribose) polymerase 1 in septic peritonitis

Curr Opin Crit Care. 9, 152-8

Lin, C, Holland, RE, Jr., Donofrio, JC, McCoy, MH, Tudor, LR and Chambers, TM (2002). Caspase activation in equine influenza virus induced apoptotic cell death Vet Microbiol. 84, 357-65 
Lüder, CG, Lang, T, Beuerle, B and Gross, U (1998). Down-regulation of MHC class II molecules and inability to up-regulate class I molecules in murine macrophages after infection with Toxoplasma gondii

Clin Exp Immunol. 112, 308-16

Lüder, CG, Gross, U and Lopes, MF (2001a). Intracellular protozoan parasites and apoptosis: diverse strategies to modulate parasite-host interactions Trends Parasitol. 17, 480-6

Lüder, CG, Walter, W, Beuerle, B, Maeurer, MJ and Gross, U (2001b).

Toxoplasma gondii down-regulates MHC class II gene expression and antigen presentation by murine macrophages via interference with nuclear translocation of STAT1alpha

Eur J Immunol. 31, 1475-84

Lüder, CG, Algner, M, Lang, C, Bleicher, N and Gross, U (2003a). Reduced expression of the inducible nitric oxide synthase after infection with Toxoplasma gondii facilitates parasite replication in activated murine macrophages Int J Parasitol. 33, 833-44

Lüder, CG, Lang, C, Giraldo-Velasquez, M, Algner, M, Gerdes, J and Gross, U (2003b). Toxoplasma gondii inhibits MHC class II expression in neural antigenpresenting cells by down-regulating the class II transactivator CIITA

J Neuroimmunol. 134, 12-24

Lüder, CG and Gross, U (2005). Apoptosis and its modulation during infection with Toxoplasma gondii: molecular mechanisms and role in pathogenesis Curr Top Microbiol Immunol. 289, 219-37

Luft, BJ, Naot, Y, Araujo, FG, Stinson, EB and Remington, JS (1983). Primary and reactivated toxoplasma infection in patients with cardiac transplants. Clinical spectrum and problems in diagnosis in a defined population Ann Intern Med. 99, 27-31

Luft, BJ, Brooks, RG, Conley, FK, McCabe, RE and Remington, JS (1984). Toxoplasmic encephalitis in patients with acquired immune deficiency syndrome Jama. 252, 913-7

Luft, BJ and Remington, JS (1992). Toxoplasmic encephalitis in AIDS Clin Infect Dis. 15, 211-22

Marechal, E and Cesbron-Delauw, MF (2001). The apicoplast: a new member of the plastid family

Trends Plant Sci. 6, 200-5

Marinovich, M, Viviani, B, Corsini, E, Ghilardi, F and Galli, CL (1996). NF-kappaB activation by triphenyltin triggers apoptosis in $\mathrm{HL}-60$ cells

Exp Cell Res. 226, 98-104 
Markowitz, MM, Rozen, P, Pero, RW, Tobi, M and Miller, DG (1988). Hydrogen peroxide induced adenosine diphosphate ribosyl transferase (ADPRT) response in patients with inflammatory bowel disease

Gut. 29, 1680-6

Mattiussi, S, Tempera, I, Matusali, G, Mearini, G, Lenti, L, Fratarcangeli, S, Mosca, L, D'Erme, M and Mattia, E (2007). Inhibition of Poly(ADPribose)polymerase impairs Epstein Barr Virus lytic cycle progression Infect Agent Cancer. 2, 18

McFadden, DC, Seeber, F and Boothroyd, JC (1997). Use of Toxoplasma gondii expressing beta-galactosidase for colorimetric assessment of drug activity in vitro Antimicrob Agents Chemother. 41, 1849-53

Michel, R, Schupp, K, Raether, W and Bierther, FW (1980). Formation of a close junction during invasion of erythrocytes by Toxoplasma gondii in vitro Int J Parasitol. 10, 309-13

Mineo, JR and Kasper, LH (1994). Attachment of Toxoplasma gondii to host cells involves major surface protein, SAG-1 (P30)

Exp Parasitol. 79, 11-20

Mitchell, GH, Thomas, AW, Margos, G, Dluzewski, AR and Bannister, LH (2004). Apical membrane antigen 1 , a major malaria vaccine candidate, mediates the close attachment of invasive merozoites to host red blood cells Infect Immun. 72, 154-8

Molestina, RE, Payne, TM, Coppens, I and Sinai, AP (2003). Activation of NFkappaB by Toxoplasma gondii correlates with increased expression of antiapoptotic genes and localization of phosphorylated IkappaB to the parasitophorous vacuole membrane J Cell Sci. 116, 4359-71

Moore, KJ and Matlashewski, G (1994). Intracellular infection by Leishmania donovani inhibits macrophage apoptosis

J Immunol. 152, 2930-7

Mordue, DG, Desai, N, Dustin, M and Sibley, LD (1999). Invasion by Toxoplasma gondii establishes a moving junction that selectively excludes host cell plasma membrane proteins on the basis of their membrane anchoring J Exp Med. 190, 1783-92

Morisaki, JH, Heuser, JE and Sibley, LD (1995). Invasion of Toxoplasma gondii occurs by active penetration of the host cell

J Cell Sci. 108 ( Pt 6), 2457-64

Muller, A, Hacker, J and Brand, BC (1996). Evidence for apoptosis of human macrophage-like HL-60 cells by Legionella pneumophila infection Infect Immun. 64, 4900-6 
Muller, WE, Totsuka, A, Nusser, I, Obermeier, J, Rhode, HJ and Zahn, RK (1974). Poly(adenosine diphosphate-ribose) polymerase in quail oviduct. Changes during estrogen and progesterone induction

Nucleic Acids Res. 1, 1317-27

Mun, HS, Aosai, F, Norose, K, Chen, M, Piao, LX, Takeuchi, O, Akira, S, Ishikura, H and Yano, A (2003). TLR2 as an essential molecule for protective immunity against Toxoplasma gondii infection

Int Immunol. 15, 1081-7

Murray, HW, Nathan, CF and Cohn, ZA (1980). Macrophage oxygen-dependent antimicrobial activity. IV. Role of endogenous scavengers of oxygen intermediates J Exp Med. 152, 1610-24

Nagel, SD and Boothroyd, JC (1989). The major surface antigen, P30, of Toxoplasma gondii is anchored by a glycolipid

J Biol Chem. 264, 5569-74

Nakajima, H, Nagaso, H, Kakui, N, Ishikawa, M, Hiranuma, T and Hoshiko, S (2004). Critical role of the automodification of poly(ADP-ribose) polymerase-1 in nuclear factor-kappaB-dependent gene expression in primary cultured mouse glial cells

J Biol Chem. 279, 42774-86

Nash, PB, Purner, MB, Leon, RP, Clarke, P, Duke, RC and Curiel, TJ (1998).

Toxoplasma gondii-infected cells are resistant to multiple inducers of apoptosis J Immunol. 160, 1824-30

Nichols, BA, Chiappino, ML and O'Connor, GR (1983). Secretion from the rhoptries of Toxoplasma gondii during host-cell invasion

$\mathrm{J}$ Ultrastruct Res. 83, 85-98

Nirmala, J, DahI, S, Steffenson, BJ, Kannangara, CG, von Wettstein, D, Chen, X and Kleinhofs, A (2007). Proteolysis of the barley receptor-like protein kinase RPG1 by a proteasome pathway is correlated with Rpg1-mediated stem rust resistance Proc Natl Acad Sci U S A. 104, 10276-81

Obrosova, IG, Minchenko, AG, Frank, RN, Seigel, GM, Zsengeller, Z, Pacher, P, Stevens, MJ and Szabo, C (2004). Poly(ADP-ribose) polymerase inhibitors counteract diabetes- and hypoxia-induced retinal vascular endothelial growth factor overexpression

Int J Mol Med. 14, 55-64

Opitz, C and Soldati, D (2002). 'The glideosome': a dynamic complex powering gliding motion and host cell invasion by Toxoplasma gondii Mol Microbiol. 45, 597-604

Pacher, P and Szabo, C (2005). Role of poly(ADP-ribose) polymerase-1 activation in the pathogenesis of diabetic complications: endothelial dysfunction, as a common underlying theme

Antioxid Redox Signal. 7, 1568-80 
Pacini, A, Quattrone, A, Denegri, M, Fiorillo, C, Nediani, C, Ramon y Cajal, S and Nassi, P (1999). Transcriptional down-regulation of poly(ADP-ribose) polymerase gene expression by $\mathrm{E} 1 \mathrm{~A}$ binding to $\mathrm{pRb}$ proteins protects murine keratinocytes from radiation-induced apoptosis

J Biol Chem. 274, 35107-12

Pannebakker, BA, Loppin, B, Elemans, CP, Humblot, L and Vavre, F (2007). Parasitic inhibition of cell death facilitates symbiosis

Proc Natl Acad Sci U S A. 104, 213-5

Park, EM, Cho, S, Frys, K, Racchumi, G, Zhou, P, Anrather, J and ladecola, C (2004). Interaction between inducible nitric oxide synthase and poly(ADP-ribose) polymerase in focal ischemic brain injury

Stroke. 35, 2896-901

Parmley, SF, Gross, U, Sucharczuk, A, Windeck, T, Sgarlato, GD and

Remington, JS (1994). Two alleles of the gene encoding surface antigen P22 in 25 strains of Toxoplasma gondii

J Parasitol. 80, 293-301

Payne, TM, Molestina, RE and Sinai, AP (2003). Inhibition of caspase activation and a requirement for NF-kappaB function in the Toxoplasma gondii-mediated blockade of host apoptosis

J Cell Sci. 116, 4345-58

Piconi, L, Quagliaro, L, Da Ros, R, Assaloni, R, Giugliano, D, Esposito, K, Szabo, C and Ceriello, A (2004). Intermittent high glucose enhances ICAM-1, VCAM-1, E-selectin and interleukin-6 expression in human umbilical endothelial cells in culture: the role of poly(ADP-ribose) polymerase

J Thromb Haemost. 2, 1453-9

Pieper, AA, Verma, A, Zhang, J and Snyder, SH (1999). Poly (ADP-ribose) polymerase, nitric oxide and cell death

Trends Pharmacol Sci. 20, 171-81

Plummer, ER (2006). Inhibition of poly(ADP-ribose) polymerase in cancer Curr Opin Pharmacol. 6, 364-8

Przyborski, JM, Miller, SK, Pfahler, JM, Henrich, PP, Rohrbach, P, Crabb, BS and Lanzer, M (2005). Trafficking of STEVOR to the Maurer's clefts in Plasmodium falciparum-infected erythrocytes

Embo J. 24, 2306-17

Que, X, Ngo, H, Lawton, J, Gray, M, Liu, Q, Engel, J, Brinen, L, Ghosh, P, Joiner, KA and Reed, SL (2002). The cathepsin B of Toxoplasma gondii, toxopain-1, is critical for parasite invasion and rhoptry protein processing J Biol Chem. 277, 25791-7

Quinn, PJ and McCraw, BM (1972). Current status of toxoplasma and toxoplasmosis: a review 
Can Vet J. 13, 247-62

Raschke, WC, Baird, S, Ralph, P and Nakoinz, I (1978). Functional macrophage cell lines transformed by Abelson leukemia virus

Cell. 15, 261-7

Revilla, Y, Cebrian, A, Baixeras, E, Martinez, C, Vinuela, E and Salas, ML (1997). Inhibition of apoptosis by the African swine fever virus Bcl-2 homologue: role of the $\mathrm{BH} 1$ domain Virology. 228, 400-4

Riemann, HP, Meyer, ME, Theis, JH, Kelso, G and Behymer, DE (1975). Toxoplasmosis in an infant fed unpasteurized goat milk J Pediatr. 87, 573-6

Rozenfeld, C, Martinez, R, Figueiredo, RT, Bozza, MT, Lima, FR, Pires, AL, Silva, PM, Bonomo, A, Lannes-Vieira, J, De Souza, W and Moura-Neto, V (2003). Soluble factors released by Toxoplasma gondii-infected astrocytes down-modulate nitric oxide production by gamma interferon-activated microglia and prevent neuronal degeneration

Infect Immun. 71, 2047-57

Sacks, D and Sher, A (2002). Evasion of innate immunity by parasitic protozoa Nat Immunol. 3, 1041-7

Saeij, JP, Boyle, JP and Boothroyd, JC (2005a). Differences among the three major strains of Toxoplasma gondii and their specific interactions with the infected host

Trends Parasitol. 21, 476-81

Saeij, JP, Boyle, JP, Grigg, ME, Arrizabalaga, G and Boothroyd, JC (2005b). Bioluminescence imaging of Toxoplasma gondii infection in living mice reveals dramatic differences between strains

Infect Immun. 73, 695-702

Saeij, JP, Boyle, JP, Coller, S, Taylor, S, Sibley, LD, Brooke-Powell, ET, Ajioka, JW and Boothroyd, JC (2006). Polymorphic secreted kinases are key virulence factors in toxoplasmosis

Science. 314, 1780-3

Saeij, JP, Coller, S, Boyle, JP, Jerome, ME, White, MW and Boothroyd, JC (2007). Toxoplasma co-opts host gene expression by injection of a polymorphic kinase homologue

Nature. 445, 324-7

Schade, B and Fischer, HG (2001). Toxoplasma gondii induction of interleukin-12 is associated with acute virulence in mice and depends on the host genotype Vet Parasitol. 100, 63-74

Schaumburg, F, Hippe, D, Vutova, P and Lüder, CG (2006). Pro- and antiapoptotic activities of protozoan parasites 
Parasitology. 132 Suppl, S69-85

Schwab, JC, Beckers, CJ and Joiner, KA (1994). The parasitophorous vacuole membrane surrounding intracellular Toxoplasma gondii functions as a molecular sieve

Proc Natl Acad Sci U S A. 91, 509-13

Scott, GS, Kean, RB, Mikheeva, T, Fabis, MJ, Mabley, JG, Szabo, C and Hooper, DC (2004). The therapeutic effects of PJ34 [N-(6-oxo-5,6-dihydrophenanthridin-2-yl)$\mathrm{N}, \mathrm{N}$-dimethylacetamide. $\mathrm{HCl}$, a selective inhibitor of poly(ADP-ribose) polymerase, in experimental allergic encephalomyelitis are associated with immunomodulation J Pharmacol Exp Ther. 310, 1053-61

Seeber, F and Boothroyd, JC (1996). Escherichia coli beta-galactosidase as an in vitro and in vivo reporter enzyme and stable transfection marker in the intracellular protozoan parasite Toxoplasma gondii

Gene. 169, 39-45

Seeber, F (2003). Biosynthetic pathways of plastid-derived organelles as potential drug targets against parasitic apicomplexa

Curr Drug Targets Immune Endocr Metabol Disord. 3, 99-109

Sehgal, A, Bettiol, S, Pypaert, M, Wenk, MR, Kaasch, A, Blader, IJ, Joiner, KA and Coppens, I (2005). Peculiarities of host cholesterol transport to the unique intracellular vacuole containing Toxoplasma

Traffic. 6, 1125-41

Seng, S, Makala, LH, Maki, Y, Choi, Y, Yokoyama, M, Suzuki, N, Toyoda, Y and Nagasawa, $\mathbf{H}$ (2002). Unresponsiveness to surface antigen 1 modifies cytokine profiles in acute Toxoplasma gondii infection

Pathobiology. 70, 237-46

Shapira, S, Speirs, K, Gerstein, A, Caamano, J and Hunter, CA (2002). Suppression of NF-kappaB activation by infection with Toxoplasma gondii J Infect Dis. 185 Suppl 1, S66-72

Sheffield, HG and Melton, ML (1968). The fine structure and reproduction of Toxoplasma gondii

J Parasitol. 54, 209-26

Sibley, LD, Weidner, E and Krahenbuhl, JL (1985). Phagosome acidification blocked by intracellular Toxoplasma gondii

Nature. 315, 416-9

Sibley, LD, Krahenbuhl, JL, Adams, GM and Weidner, E (1986). Toxoplasma modifies macrophage phagosomes by secretion of a vesicular network rich in surface proteins

J Cell Biol. 103, 867-74 
Sibley, LD, Niesman, IR, Parmley, SF and Cesbron-Delauw, MF (1995). Regulated secretion of multi-lamellar vesicles leads to formation of a tubulo-vesicular network in host-cell vacuoles occupied by Toxoplasma gondii

J Cell Sci. 108 ( Pt 4), 1669-77

Sibley, LD, Mordue, DG, Su, C, Robben, PM and Howe, DK (2002). Genetic approaches to studying virulence and pathogenesis in Toxoplasma gondii Philos Trans R Soc Lond B Biol Sci. 357, 81-8

Simbulan-Rosenthal, CM, Rosenthal, DS, lyer, S, Boulares, AH and Smulson, ME (1998). Transient poly(ADP-ribosyl)ation of nuclear proteins and role of poly(ADP-ribose) polymerase in the early stages of apoptosis

J Biol Chem. 273, 13703-12

Simbulan-Rosenthal, CM, Ly, DH, Rosenthal, DS, Konopka, G, Luo, R, Wang, ZQ, Schultz, PG and Smulson, ME (2000). Misregulation of gene expression in primary fibroblasts lacking poly(ADP-ribose) polymerase

Proc Natl Acad Sci U S A. 97, 11274-9

Sims, JL, Berger, SJ and Berger, NA (1983). Poly(ADP-ribose) Polymerase inhibitors preserve nicotinamide adenine dinucleotide and adenosine 5'-triphosphate pools in DNA-damaged cells: mechanism of stimulation of unscheduled DNA synthesis

Biochemistry. 22, 5188-94

Sirard, JC, Vignal, C, Dessein, R and Chamaillard, M (2007). Nod-like receptors: cytosolic watchdogs for immunity against pathogens

PLoS Pathog. 3, e152

Smith, S (2001). The world according to PARP Trends Biochem Sci. 26, 174-9

Smulson, ME, Simbulan-Rosenthal, CM, Boulares, AH, Yakovlev, A, Stoica, B, lyer, S, Luo, R, Haddad, B, Wang, ZQ, Pang, T, Jung, M, Dritschilo, A and Rosenthal, DS (2000). Roles of poly(ADP-ribosyl)ation and PARP in apoptosis, DNA repair, genomic stability and functions of p53 and E2F-1

Adv Enzyme Regul. 40, 183-215

Soldati, D, Dubremetz, JF and Lebrun, M (2001). Microneme proteins: structural and functional requirements to promote adhesion and invasion by the apicomplexan parasite Toxoplasma gondii

Int J Parasitol. 31, 1293-302

Soriano, FG, Virag, L and Szabo, C (2001). Diabetic endothelial dysfunction: role of reactive oxygen and nitrogen species production and poly(ADP-ribose) polymerase activation

J Mol Med. 79, 437-48

Strober, W, Murray, PJ, Kitani, A and Watanabe, T (2006). Signalling pathways and molecular interactions of NOD1 and NOD2

Nat Rev Immunol. 6, 9-20 
Suss-Toby, E, Zimmerberg, J and Ward, GE (1996). Toxoplasma invasion: the parasitophorous vacuole is formed from host cell plasma membrane and pinches off via a fission pore

Proc Natl Acad Sci U S A. 93, 8413-8

Szabo, C, Zingarelli, B, O'Connor, M and Salzman, AL (1996). DNA strand breakage, activation of poly (ADP-ribose) synthetase, and cellular energy depletion are involved in the cytotoxicity of macrophages and smooth muscle cells exposed to peroxynitrite

Proc Natl Acad Sci U S A. 93, 1753-8

Szabo, C and Dawson, VL (1998). Role of poly(ADP-ribose) synthetase in inflammation and ischaemia-reperfusion

Trends Pharmacol Sci. 19, 287-98

Szabo, C (2005). Roles of poly(ADP-ribose) polymerase activation in the pathogenesis of diabetes mellitus and its complications

Pharmacol Res. 52, 60-71

Szabo, G, Bahrle, S, Stumpf, N, Sonnenberg, K, Szabo, EE, Pacher, P, Csont, T, Schulz, R, Dengler, TJ, Liaudet, L, Jagtap, PG, Southan, GJ, Vahl, CF, Hagl, S and Szabo, C (2002). Poly(ADP-Ribose) polymerase inhibition reduces reperfusion injury after heart transplantation

Circ Res. 90, 100-6

Takizawa, T, Matsukawa, S, Higuchi, Y, Nakamura, S, Nakanishi, Y and Fukuda, $\mathbf{R}$ (1993). Induction of programmed cell death (apoptosis) by influenza virus infection in tissue culture cells

J Gen Virol. 74 ( Pt 11), 2347-55

Tanaka, Y, Yoshihara, K, Kojima, K, Itaya, A, Kameoka, M, Ikuta, K and Kamiya, T (1995a). Poly(ADP-ribose) polymerase activity in various U937 cell subclones with different susceptibility to HIV-1 infection: its dramatic decrease following persistent virus infection

Biochem Biophys Res Commun. 213, 161-8

Tanaka, Y, Yoshihara, K, Tohno, Y, Kojima, K, Kameoka, M and Kamiya, T

(1995b). Inhibition and down-regulation of poly(ADP-ribose) polymerase results in a marked resistance of HL-60 cells to various apoptosis-inducers

Cell Mol Biol (Noisy-le-grand). 41, 771-81

Tenter, AM, Heckeroth, AR and Weiss, LM (2000). Toxoplasma gondii: from animals to humans

Int J Parasitol. 30, 1217-58

Tomavo, S, Schwarz, RT and Dubremetz, JF (1989). Evidence for glycosylphosphatidylinositol anchoring of Toxoplasma gondii major surface antigens Mol Cell Biol. 9, 4576-80 
van Wijk, SJ and Hageman, GJ (2005). Poly(ADP-ribose) polymerase-1 mediated caspase-independent cell death after ischemia/reperfusion

Free Radic Biol Med. 39, 81-90

van Zandbergen, G, Solbach, W and Laskay, T (2007). Apoptosis driven infection Autoimmunity. 40, 349-52

Virag, L, Bai, P, Bak, I, Pacher, P, Mabley, JG, Liaudet, L, Bakondi, E, Gergely, P, Kollai, M and Szabo, C (2004). Effects of poly(ADP-ribose) polymerase inhibition on inflammatory cell migration in a murine model of asthma Med Sci Monit. 10, BR77-83

Virag, L (2005a). Poly(ADP-ribosyl)ation in asthma and other lung diseases Pharmacol Res. 52, 83-92

Virag, $\mathbf{L}(2005 b)$. Structure and function of poly(ADP-ribose) polymerase-1: role in oxidative stress-related pathologies

Curr Vasc Pharmacol. 3, 209-14

Voth, DE, Howe, D and Heinzen, RA (2007). Coxiella burnetii inhibits apoptosis in human THP-1 cells and monkey primary alveolar macrophages

Infect Immun. 75, 4263-71

Vutova, P, Wirth, M, Hippe, D, Gross, U, Schulze-Osthoff, K, Schmitz, I and Lüder, CG (2007). Toxoplasma gondii inhibits Fas/CD95-triggered cell death by inducing aberrant processing and degradation of caspase 8

Cell Microbiol. 9, 1556-70

Wang, T, Zhang, $\mathbf{X}$ and $\mathbf{L i}$, JJ (2002). The role of NF-kappaB in the regulation of cell stress responses

Int Immunopharmacol. 2, 1509-20

Wei, S, Marches, F, Borvak, J, Zou, W, Channon, J, White, M, Radke, J, Cesbron-Delauw, MF and Curiel, TJ (2002). Toxoplasma gondii-infected human myeloid dendritic cells induce T-lymphocyte dysfunction and contact-dependent apoptosis Infect Immun. 70, 1750-60

Werk, R (1985). How does Toxoplasma gondii enter host cells? Rev Infect Dis. 7, 449-57

Yarovinsky, F, Zhang, D, Andersen, JF, Bannenberg, GL, Serhan, CN, Hayden, MS, Hieny, S, Sutterwala, FS, Flavell, RA, Ghosh, S and Sher, A (2005). TLR11 activation of dendritic cells by a protozoan profilin-like protein

Science. 308, 1626-9

Yarovinsky, F and Sher, A (2006). Toll-like receptor recognition of Toxoplasma gondii

Int J Parasitol. 36, 255-9 
Yelamos, J, Buendia, AJ, Ortega, N, Monreal, Y, Gallego, MC, Sanchez, J, Ramirez, P, Parrilla, P, Caro, MR, Aparicio, P and Salinas, J (2004). Genetic and pharmacological inhibition of poly(ADP-ribose) polymerase-1 interferes in the chlamydial life cycle

Biochem Biophys Res Commun. 324, 840-8

Ying, W, Alano, CC, Garnier, P and Swanson, RA (2005). NAD+ as a metabolic link between DNA damage and cell death

J Neurosci Res. 79, 216-23

Ying, $\mathbf{W}$ (2008). NAD+/NADH and NADP+/NADPH in cellular functions and cell death: regulation and biological consequences

Antioxid Redox Signal. 10, 179-206

Yu, SW, Wang, H, Poitras, MF, Coombs, C, Bowers, WJ, Federoff, HJ, Poirier, GG, Dawson, TM and Dawson, VL (2002). Mediation of poly(ADP-ribose) polymerase-1-dependent cell death by apoptosis-inducing factor Science. 297, 259-63

Yu, SW, Wang, H, Dawson, TM and Dawson, VL (2003). Poly(ADP-ribose) polymerase-1 and apoptosis inducing factor in neurotoxicity Neurobiol Dis. 14, 303-17

Zhang, J, Dawson, VL, Dawson, TM and Snyder, SH (1994). Nitric oxide activation of poly(ADP-ribose) synthetase in neurotoxicity

Science. 263, 687-9

Zhang, J, Li, H, Wang, J, Dong, Z, Mian, S and Yu, FS (2004). Role of EGFR transactivation in preventing apoptosis in Pseudomonas aeruginosa-infected human corneal epithelial cells

Invest Ophthalmol Vis Sci. 45, 2569-76

Zimmermann, S, Murray, PJ, Heeg, K and Dalpke, AH (2006). Induction of suppressor of cytokine signaling-1 by Toxoplasma gondii contributes to immune evasion in macrophages by blocking IFN-gamma signaling

$\mathrm{J}$ Immunol. 176, 1840-7

Zingarelli, B, Salzman, AL and Szabo, C (1998). Genetic disruption of poly (ADPribose) synthetase inhibits the expression of $P$-selectin and intercellular adhesion molecule-1 in myocardial ischemia/reperfusion injury

Circ Res. 83, 85-94

Zychlinsky, A, Prevost, MC and Sansonetti, PJ (1992). Shigella flexneri induces apoptosis in infected macrophages

Nature. 358, 167-9 


\section{Publikationen}

\section{Fachartikel}

A. Gais, N. Beinert, U. Gross and C.G.K. Lüder (2008). Transient inhibition of poly(ADP-ribose) polymerase expression and activity by Toxoplasma gondii is dispensable for parasite-mediated blockade of host cell apoptosis Microbes Infect., 10(4), 358-66

\section{Buchartikel}

D. Hippe, A. Gais, U. Groß and C.G.K. Lüder (2007). Modulation of caspase activation by Toxoplasma gondii. In: Rupp, S., Sohn, K. und Hauser, N. (Eds). Methods in Molecular Biology: Host-Pathogen Interactions.

Humana Press., Totowa, NJ, USA. In press

\section{Vorträge und Poster}

DGHM 2005, Göttingen (Poster):

"Toxoplasma gondii transiently inhibits Poly(ADP-ribose) polymerase protein expression of its host cells"

Statusworkshop Eukaryonten 2006, München (Vortrag):

"Inhibierung der Poly(ADP-Ribose) Polymerase durch Toxoplasma gondii"

$2^{\text {nd }}$ Short Course for Young Parasitologists 2006, Wien (Vortrag):

"Inhibition of the Poly(ADP-Ribose) Polymerase (PARP) expression after infection with Toxoplasma gondii” 
DGP 2006, Wien (Poster):

“Poly(ADP-Ribose) Polymerase (PARP) protein levels are strongly decreased after infection with Toxoplasma gondii”

COST 857 PhD Retreat, Brüssel 2006 (Vortrag):

"Characterization of Poly(ADP-ribose) polymerase inhibition in Toxoplasma gondii infected host cells" 


\section{Curriculum Vitae}

\section{Persönliche Angaben}

Name

Geburtsdatum

Geburtsort

Familienstand

Staatsangehörigkeit

\section{Studium / Ausbildung}

Mai 2004 - Mai 2007

Nov 2001 - Juni 2002

Okt 1997 - Okt 2001

$1989-1997$

\section{Praxiserfahrung}

Seit Aug 2008

Mai 2004 - Mai 2007

Sep 2002 - April 2004
Andrea Nadja Gais, geb. Stender 07.04.1978

Langen

Verheiratet

Deutsch

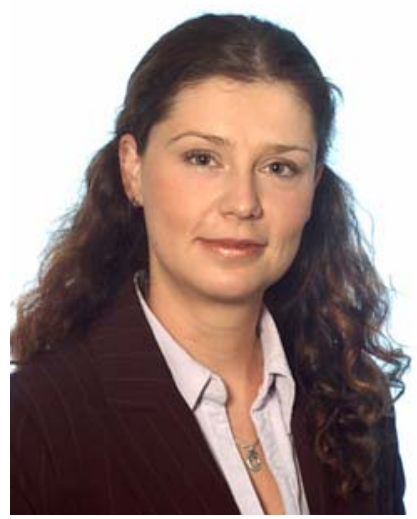

Praktische Arbeiten zu meiner Promotion: "Charakterisierung der Poly(ADP-ribose) Polymerase Expression in Toxoplasma gondii infizierten Wirtszellen" am Hygieneinstitut der Georg-August-Universität in Göttingen bei Prof. Dr. U. Groß (Note noch ausstehend; Rigorosum: Ende Oktober)

Externe Diplomarbeit: „In vitro Mutagenese, rekombinante Herstellung und funktionelle Analyse von Lektinen aus Sarcocystis muris" am Paul-Ehrlich-Institut, Langen, Abteilung Bakteriologie, Fachgebiet Parasitologie und Diagnostika bei Dr. T. Montag-Lessing (Note: 2,0)

Diplomstudiengang Biologie an der Johann-WolfgangGoethe Universität Frankfurt; Hauptfach Genetik, Nebenfächer Mikrobiologie und Biochemie (Note: 1,8)

Goethe Gymnasium, Neu-lsenburg, Abschluss Abitur (Note: 2,0)

Aufbau und Leitung eines Diagnostiklabors zur Mutationsanalyse am Nordwest-Krankenhaus in Frankfurt am Main bei Prof. Dr. E. Jäger in der Onkologie

Lehrtätigkeit und Forschungsassistenz während meiner Dissertation am Hygieneinstitut der Georg-AugustUniversität in Göttingen bei Prof. Dr. U. Gross

Wissenschaftliche Mitarbeiterin am Paul-Ehrlich-Institut, Langen, Abteilung Bakteriologie, Fachgebiet Parasitologie und Diagnostika bei Dr. Montag-Lessing 


\section{Familienphase}

Juni 2007 - Juli $2008 \quad$ Mutterschutz und Elternzeit, sowie schriftliche Ausarbeitung der Promotion

\section{Universitäre Tätigkeiten}

2006

2005 und 2006

Tutor auf Englisch für die Vorlesung: 'Viruses and Cancer' für Studenten des internationalen Master-Studiengangs „Molecular Biology" an der Georg-August-Universität in Göttingen während der Tätigkeit am Hygieneinstitut der Georg-August-Universität

Leitung eines Methodenkurses auf Englisch: 'SDS-PAGE and Western Blot' für Studenten des internationalen Master-Studiengangs „Molecular Biology“ an der GeorgAugust-Universität in Göttingen während der Tätigkeit am Hygieneinstitut der Georg-August-Universität

\section{Praktika}

Feb 2000 - März 2000

Praktikum am Paul-Ehrlich-Institut, Abteilung Bakteriologie, Fachgebiet Parasitologie und Diagnostika bei Dr. Montag-Lessing zur Erlernung grundlegender molekularbiologischer Arbeitstechniken

\section{Zusatzqualifikation}

Sprachen

Englisch:

gut und fließend

Latein: großes Latinum

Deutsch: Muttersprache

EDV-Kenntnisse

Windows XP:

ständig in Anwendung

Textverarbeitung MS Word: $\quad$ ständig in Anwendung

Textverarbeitung MS Powerpoint:ständig in Anwendung

Tabellenkalkulationen MS Excel: gut

Obertshausen, den 15.09.2008

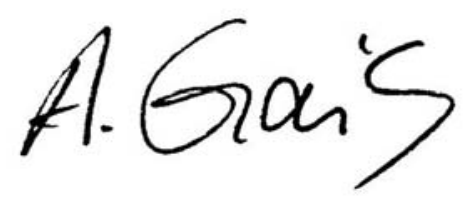

